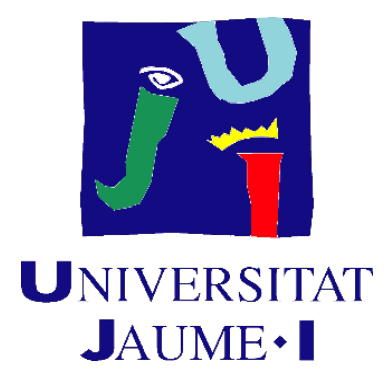

\title{
Applying Environmental Justice Approach to Sustainable Development Debate in South Korea
}

\author{
Eun Ah Hong
}

Supervisors:

Isabel Giménez García

Antonio Caballer Miedes

January 2021 



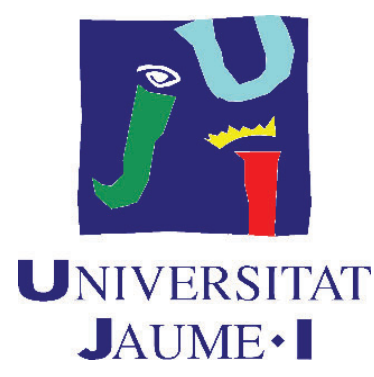

Doctoral Programme in International Studies in Peace, Conflict and Development

Universitat Jaume I Doctoral School

Applying Environmental Justice Approach to Sustainable

Development Debate in South Korea

Eun Ah Hong

Isabel Giménez García

Antonio Caballer Miedes

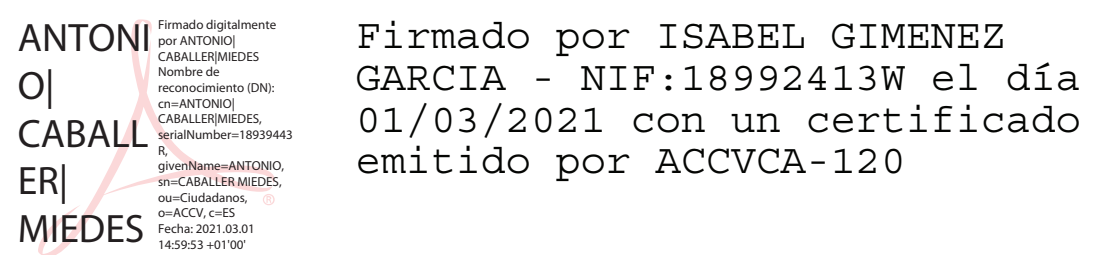

Castelló de la Plana, January 2021 



\begin{abstract}
The world has been burdened with numerous unprecedented environmental challenges since the emergence of industrial society. Concerns over the environmental issue have accelerated worldwide and sustainability has appeared as an essential approach to this problem in world politics. However, environmental conflicts have only intensified along with rapidly increasing environmental degradation, which has continued to increasingly impact marginalized groups of society. Therefore, this research has applied the environmental justice approach within a debate of sustainable development. By applying an environmental justice approach as an alternative tool to guide sustainability, this research discusses why sustainable development has not been able to meet its aims. More importantly, this research has also looked for how the environmental justice approach can pave the way towards a sustainable development which promotes sustainability and peace. Accordingly, the research examined the case study of the Miryang movement in South Korea where adoptance of sustainable development has been difficult. Even after sustainable development has been employed, the social-environmental conflicts in South Korea have worsened. In this regard, the Miryang environmental justice movement provides valuable insight on how environmental justice is connected to the sustainable development discussion.
\end{abstract}


All things, quite literally, are linked to all others. Accordingly, any striving for peace must take an account of this connectedness: of living things to soil and atmosphere, as well as to all other living things; of people to their natural environment, as well as their man- and woman- made social systems and each other; of the past to the future of this planet; and of risks to opportunities for everyone and everything

(Barash \& Weber, 2009: 418) 


\section{Acknowledgments}

I would like to thank the following people for taking this long journey with me. I owe a debt of gratitude to supervisors and tutor, Dr. Isabel Giménez García, Dr. Antonio Caballer Miedes, and Dr. Vicente José Benet Ferrando for their support and guidance. I am grateful to Dr. ByungDoo Choi for generously helping me to find different opportunities and advising me. Thanks to Dr. Andres Piqueras for broadening my interest and knowledge on the topic. A special thanks goes to the Miryang villagers for unwearying struggle. Their resistance is a great inspiration and valuable input for our society. Thanks to my parents and my brother for unconditional love and endless support. Without the strong root of family love and care, I could not be able to finish this long journey. I am grateful to Sibylle and Katie for investing their precious time to proofread my dissertation. Thanks to Marisol for boosting my spirit up with your beautiful wise soul. Thanks to Jean for supporting me and showing me your sisterhood, especially when I was going through a difficult time. Last but not least, thanks to my best friends Diego, Nicolas, Marco, and Balma for laughing with me and sharing beautiful time together. 


\section{TABLE OF CONTENTS}

\section{General Introduction}

Presentation of the Dissertation ................................................

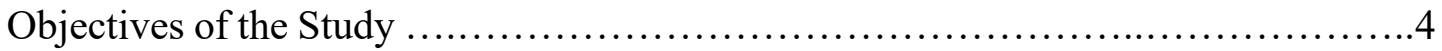

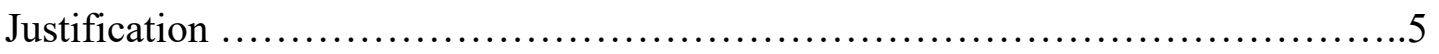

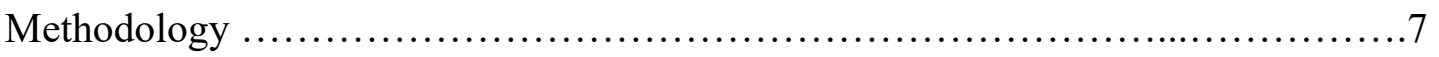

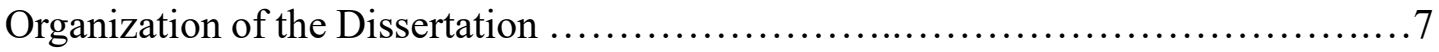

\section{PART I: Literature Review and Theoretical Framework}

Chapter One: The Emergence of Sustainable Development and its Critical Perspectives

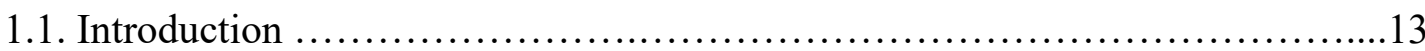

1.2. Theoretical Framing of the Root Causes of Environmental Crisis ................15

1.2.1. The Impacts of Capitalism: The Logic of Market Economic System ...........19

1.2.2. The New Era of Development: Development as Modernization ...............22

1.3. The Emergence of Sustainable Development ................................25

1.3.1. Pre-Sustainable Development Discussion: The 1972 Stockholm Conference. 27

1.3.2. The 1987 Brundtland Commission .....................................28

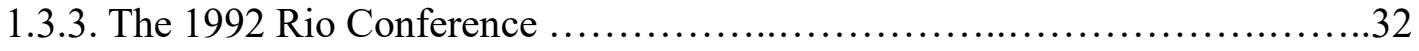

1.3.4. The UN Millennium Summit and the Millennium Development Goals ........35

1.3.5. The 2002 World Summit on Sustainable Development ......................38

1.3.6. Rio+20: The 2012 United Nations Conference on Sustainable Development

1.3.7. The New Context of the 2030 Sustainable Development Agenda and Paris Agreement 
1.4. Defining Mainstream Sustainable Development and its Characteristics .44

1.4.1. Sustainable Development based on Scientific Technology, Rationality .47

1.4.2. Sustainable Development: Sustainable Growth through Green-Neoliberalism

1.5. Critiques of Mainstream Sustainable Development Discourse .50

1.6. Conclusion .56

Chapter Two: Environmental Justice: Alternative Contribution to Sustainable Development

2.1. Introduction .59

2.2. Origins of Environmental Justice .62

2.2.1. Rise of Environmental Justice Movements as Environmental Racism \& Inequity

2.2.2. Consequences of the Environmental Justice Movement(s) .66

2.3. Defining Environmental Justice .70

2.3.1. Distributive Perspective in Environmental Justice . .71

2.3.2. Participatory and Procedure Perspective in Environmental Justice .73

2.3.3. Recognition Perspective in Environmental Justice . .75

2.3.4. Capabilities Perspective in Environmental Justice .78

2.4. Environmental Justice within the Debate of Sustainable Development .79

2.4.1. Environmental Crisis through the Environmental Justice Perspective .81

2.4.2. Bottom-Up Movements: Creating a Political Space .84

2.4.3. Environmental Justice: All for One and One for All .86

2.5. Conclusion .88

\section{Chapter Three: Environmental Sustainability and Peace}


3.1. Introduction .91

3.2. Defining Peace and Violence .............................................93

3.2.1. Negative and Positive Peace ............................................. 95

3.2.2. Direct, Structural and Cultural Violence .....................................96

3.2.3. Ecological Well-Being in Peace Studies ................................... 98

3.3. Transforming the Vicious Violence Cycle toward Peaceful Future ...............100

3.3.1. Understanding Interconnectedness within the System .......................102

3.3.2. Environmental Justice Perspective for Environmental Sustainability and Peace 105

3.4. Conclusion 109

PART II: Case Study - The Miryang Movement in South Korea

\section{Chapter Four: Situating South Korea in the Sustainable Development Debate}

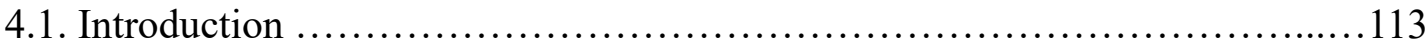

4.2. General Characteristics of Development Process in South Korea .................114

4.2.1. Characteristics of South Korean Development Model ......................115

4.2.2. General Energy Policy in South Korea .................................117

4.2.3. Producing 'Cheap' Labor ............................................121

4.2.4. Environmental Protection? Economic Growth! .........................123

4.3. Sustainable Development in South Korea ..................................... 126

4.3.1. First Encounter of Sustainable Development in South Korea ................127

4.3.2. The Birth of Green Growth and its Objectives ............................130

4.3.3. Korean-Sustainable Development Goals (K-SDGs) .......................134

4.4. Criticism of Sustainable Development Applied in South Korea .................136

4.4.1. Is Green Growth Sustainable Development? ..............................137 
4.4.2. Green Growth Energy Policy: Is it 'really' Green?

4.4.3. Renewable Energy as an Ultimate Solution?

4.4.4. Characteristics of Green Growth Policy 146

4.5. Conclusion 148

\section{Chapter Five: Transmission Towers and Lines Conflict in Miryang}

5.1. Introduction 151

5.2. General Overview of the Conflict in Miryang ..................................153

5.2.1. First Phase: January 2000 to December 2005 ............................ 155

5.2.2. Second Phase: December 2005 to November 2010 ...................................

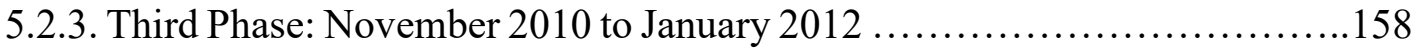

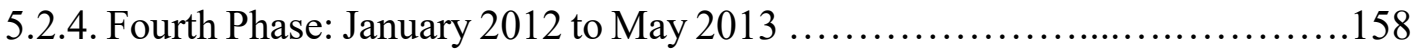

5.2.5. Fifth Phase: May 2013 to June 11, 2014 .................................159

5.2.6. Sixth Phase: June 2014 to December 2015 .................................160

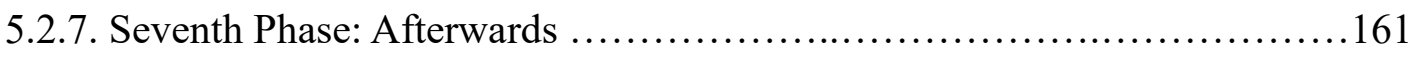

5.3. The Consequences of the Miryang Project ................................163

5.3.1. The Violation of Property Rights ....................................... 166

5.3.2. Destruction of Community ........................................ 170

5.3.3. Human Rights Violation ............................................. 171

5.3.4. The Violation of Health Rights ...................................... 173

5.4. Previous Studies on the Miryang Conflict and Suggesting Alternatives ...........175

5.5. Hegemonic Discourse of Energy Crisis ................................... 178

5.5.1. The Role of Korean Electronic Power Corporations (KEPCO) ...............181

5.5.2. The Role of Media ...................................................... 182

5.5.3. Silent Power of the Citizens ............................................ 186 
5.6. The Truth behind Energy Crisis: Economic Growth 188

5.6.1. The Purpose of the Miryang Project and the Hidden Dangers 192

5.6.2. Miryang Conflict within the Discussion of Sustainable Development 196

5.7. Conclusion 198

Chapter Six: Environmental Justice Movements in Miryang and their Contribution to Sustainable Development Discussion

6.1. Introduction .201

6.2. Applying Environmental Justice in South Korea 203

6.2.1. Academic Debate/ Previous Studies on Environmental (In)Justice in South Korea .204

6.2.2. Characteristics of Environmental Injustice in South Korea 208

6.3. Environmental Injustice of the Miryang Project 211

6.3.1. Distributive Injustice of the Miryang Project 211

6.3.2. Procedural and Participatory Injustice of the Miryang Project 217

6.3.3. Recognition Injustice of the Miryang Project 219

6.3.4. Capabilities Injustice of the Miryang Project .225

6.4. Outcome of the Miryang Movement .226

6.4.1. Previous Studies on the Miryang Movement ....

6.4.2. The Miryang Movement for Energy Transition 230

6.5. Miryang Environmental Justice Movement within the Sustainable Development .233

6.5.1. Miryang Movement from Environmental Justice Perspective .235

6.5.2. Environmental Justice Movement in Miryang: One for All and All for One .239

6.5.3. The Emergence of New Identity: Creating a Political Space .241 


\section{General Conclusion}

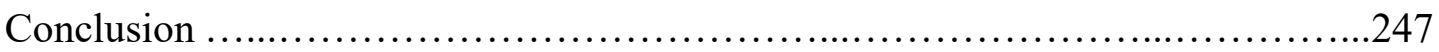

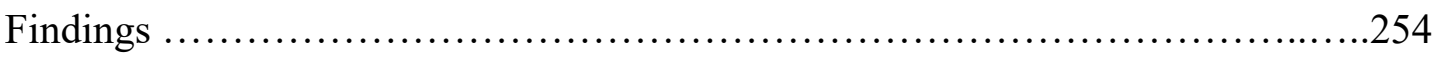

Future Research Area .....................................................255

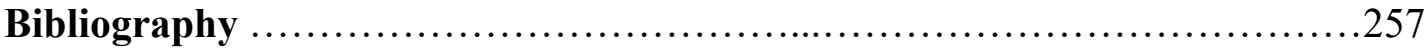

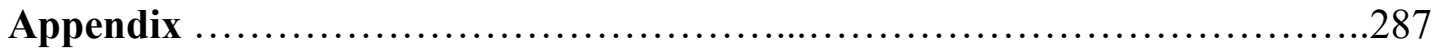




\section{LIST OF TABLES}

Table 1.1. Timeline of the Mainstream Discourse of Sustainable Development .......26

Table 4.2. Korea's Renewable Energy Supply ...............................142

Table 5.1. Added Territory Locations and Areas in Miryang ........................154

Table 5.2. How the transmission tower case was framed and frequency of the framing over environmental justice .............................................. 185

Table 5.3. Customer Statue by Contract Classification ...........................190

Table 5.4. Price of the Electricity Comparison ...................................191

Table 6.1. Sixteen Cities and Provinces on Self-Sufficiency in Electricity ...........213

Table 6.2. Percentage of Transmission Towers and Lines under the Ground ..........216 


\section{LIST OF FIGURES}

Figure 1.1. Mapping of Views on Sustainable Development .......................46

Figure 3.1. Galtung's Violence Triangle .....................................97

Figure 4.1. Location of Nuclear Plants in South Korea ........................ 120

Figure 4.2. Environmental Kuznets Curve ................................. 124

Figure 4.3. 2030 Energy Plan and Energy Mix ............................... 140

Figure 4.4. Raw Materials Used in Wind Turbines ................................... 144

Figure 5.1. The Location of Miryang and Overview of Miryang ....................152

Figure 5.2. Transmission Towers and Lines in Miryang .........................154

Figure 5.3. Electric Consumption per Person in South Korea ......................188

Figure 5.4. Residential Electricity Consumption .................................189 


\section{LIST OF ABBREVIATION}

ACCRC: Anti-Corruption and Civil Rights Commission

ADB: Asian Development Bank

CO2: Carbon dioxide

CSD: Commission on Sustainable Development

DSDPI: Declaration on Sustainable Development and the Plan of Implementation

EIA: environmental impact assessment

EKC: Environmental Kuznets Curve

EPA: Environmental Protection Agency

EU: European Union

GAO: General Accounting Office

GDP: Gross Domestic Product

GGGI: Global Green Growth Institute

GNP: Gross National Produc

IMF: International Monetary Fund

ITHRVMR: Investigation Team of Human Rights Violation over the Miryang

Transmission Tower

KEPCO: Korean Electric Power Corporation

K-SDGs: Korean-Sustainable Development Goals

MDGs: Millennium Development Goals

NACF: National Agricultural Cooperative Federation

NEJAC: National Environmental Justice Advisory Council

NGOs: non-governmental organizations

NIAMBY: Not In Anybody's Backyard 
NIMBY: Not In My Backyard

NOPE: Not On Planet Earth

OECD: Organization for Economic Cooperation and Development

OPEC: Organization of Petroleum Exporting Countries

PCBs: polychlorinated biphenyls

PTSD: post traumatic stress disorder

SDGs: Sustainable Development Goals

UAE: United Arab Emirates

UCC: United Church of Christ

UK: United Kingdom

UN: United Nation

UNCED: United Nations Conference on Environment and Development

UNCSD: United Nations Commission on Sustainable Development

UNDP: United Nations Development Programme

UNEP: United Nations Environmental Programme

UNESCAP: United Nations Economic and Social Commission for Asia and the Pacific

U.S: United States

USD: United States Dollar

WCED: World Commission on Environment and Development

WSSD: World Summit on Sustainable Development

WTO: World Trade Organization 



\section{GENERAL INTRODUCTION}

\section{Presentation of the Dissertation}

Due to the growing environmental and climate crisis since the emergence of industrial society, concerns over environmental sustainability are pushing sustainability to the forefront of policy agenda worldwide. Environmental sustainability and healthy nature are the most basic preconditions to live in peace. As Barash and Weber point out, "human happiness and human survival depend on the maintenance and proper functioning of natural systems" (209: 398). The discussion of sustainable development officially emerged more than 40 years ago at the 1987 World Commission on Environment and Development, and since then sustainability has become a "guiding principle" (Farley \& Smith, 2013: 2) for the world community, including South Korea. However, unfortunately, the result has been disappointing as humanity has been unremittingly challenged by the never before experienced ecological crisis, which has become the central source of social-environmental conflicts.

From a peace studies perspective, continuing the discussion of sustainable development is indispensable since sustainable development is "key to sustaining peace" (Martinez-Solimán, 2017). It is an irrefutable fact that the ecological crisis will eventually affect every living being on the earth. Thus, analyzing the mainstream sustainable development discussion from critical perspectives not only reveals why current sustainable development projects have not been able to meet their aims but also helps to seek to "chart the course" for building a sustainable future.

Accordingly, this dissertation, in the end, expects to find what are the possible alternative approaches to achieve the main purposes of sustainable development. For that, I 
examine the potential of applying the environmental justice perspective within the debate of sustainability since environmental justice can be a useful approach to guide action toward sustainability. In order to do so, the context in South Korea is specifically observed by analyzing a case of the Miryang conflict where people have created a space for resisting injustice and exploring ways of peaceful co-existence within healthy nature (sustainable nature).

As Robbins (2012) emphasizes, ecological issues are imperatively political issues. For that reason, nature cannot be seen outside of power, meaning that analyzing and solving the ecological crisis is closely related to political questions and concerns. Thus, in order to fulfill the main goals of sustainable development, it is compulsory to acknowledge the importance of questioning the hegemonic power which influences sustainable development discourse.

However, through the discourse of mainstream sustainable development, instead of questioning the power, the solutions provided to overcome the crisis and to reach sustainability are characterized as renewing the modernity (Lippert, 2004). Consequently, there have been numerous social-environmental conflicts since the discourse of sustainable development reproduces a timeworn system that is bound to subject marginal and powerless groups to the process of alienation and marginalization. On the other hand, those marginal groups whose livelihoods depend on the environment they live in, often become invisible because of their political marginality in the decision-making process (Robbins, 2012).

For reaching sustainability and a culture of sustainability beyond the hegemonic approach to sustainable development, it is recommended to "take into account all forms of knowledge, create an atmosphere for fundamentally open discourse, give the possibility to participate as individuals, but also enhance critical discussion within other groups" (Lippert, 
2004: 36). Given that, observing socio-environmental justice movements could make a positive contribution to fulfilling the very purpose of sustainable development and accomplishing a culture of peace, which is defined by the United Nations as a "set of values, attitudes, modes of behavior and ways of life that reject violence and prevent conflicts by tackling their root causes to solve problems through dialogue and negotiation among individuals groups and nations" (UN International Day of Peace, n.d).

Therefore, alternative concepts of sustainability and sustainable development must be newly constructed by including the values of the marginalized and powerless groups struggling within the existing power structures and creating the political space for them to be heard. Otherwise, conflicts cannot be transformed into a peaceful future. As Homer-Dixon (1994) points out, social conflict can be an opportunity for beneficiary changes. By examining socialenvironmental justice movements led by the powerless groups of the society, I observe how the destructive system relentlessly affects the planet where all the living beings, especially the marginalized, rely on for their surviving. Furthermore, the dissertation discusses the possible role of social-environmental justice movement that could shed light on the path toward sustainability and social justice by bringing the vital values of the deep interconnectedness of life and inner oneness.

By highlighting the voice of the marginalized, which has been frequently excluded in the mainstream sustainable development debate, it is possibly to demonstrate how their ways of living become a feasible alternative, if not a fundamental approach, to a sustainable lifestyle. However, at the same time, it is also critical to accept the "imperfect" aspects of the movement that could possibly bring refutable discussions. Accepting imperfection creates a possible space to debate and construct new paradigms as this approach helps us to reach the humane, "where 
positive and negative aspects, along with successes and errors, can coexist" (Muñoz, 2001: 15). Therefore, what must be highlighted through the struggles that demand for the well-being of the society is how they "act, create, engender, influence, carry out, work, operate, practice, proceed, and perform in a sense of positive, propositional transformation-of change towards-, of regulation of conflict" (Ibid.: 14-15).

Thus, the proposed dissertation examines the space that has been created by the villagers in Miryang and to investigate the voices of the Miryang villagers that have been excluded from the debate in order to explore their knowledge, which possibly could be an alternative approach to sustainability and a positive future.

\section{Objectives of the Study}

The general objective of this dissertation is to explore how an environmental justice approach, which imperatively involves the voice of the marginalized whose livelihood systems are endangered, could effectively pave the way for the environmental sustainability that certainly is related to issues of social justice and economic well-being within the context of South Korea.

The followings are specific objectives of this study:

1. Contextualizing sustainable development and the challenges of accomplishing its aims.

2. Explore how applying an environmental justice approach is able to challenge injustice and destructive aspects of the system that has been re-produced through the sustainable development discourse.

3. Investigate why it is important to continue the sustainability debate, especially within a peace studies perspective. 
4. Using the case study of Miryang justice movement in South Korea, discuss the lessons learnt as an input to the contemporary sustainable development debate, which can contribute towards building a culture of sustainability and peace.

\section{Justification}

The chosen research topic of sustainability is essential in the face of the ecological catastrophe (e.g., drought, wildfire, oil spill, nuclear disaster, etc.) that eventually causes relentless social-environmental conflicts, which have been researched and documented in various fields. There has been academic and practical research analyzing empirical cases of different socio-environmental conflicts, which are considered as an important topic to be discussed within a peace studies perspective. In fact, the issue of sustainability is a vitally important topic as it is a foremost precondition to live in peace.

However, there seems to be a considerable shortage of empirical research investigating ways to overcome the catastrophes that humanity is facing. To be more specific, there have been different studies showing the causes of the catastrophes along with various suggestions to reach sustainability. However, in the author's view, there hasn't been a fixed frame to see the whole picture (clear road map toward sustainability) putting all the scattered pieces together, especially from a peace studies perspective. Therefore, the dissertation introduces empirical research, which points out the core reasons of the current environmental crisis. In the process, the dissertation further reveals the community values, which could be helpful contributions to expand the discussion of sustainability. Meanwhile, it provides the practical approaches to better deal with the crisis thus walking on the road to peace. 
Furthermore, I have been directly and indirectly involved in this specific topic of sustainability as a responsible and committed citizen of South Korea and the world, but also as a peace researcher who cares about the well-being of living beings, especially the most marginalized and powerless groups. Thus, my personal experience in Miryang, where I participated in a sit-in protest, prompted me to pay more attention and observe the complexities of environmental conflicts and their consequences. Moreover, my personal interest in the specific conflict in Miryang is closely connected to my childhood experience with my grandparents who were both farmers. And, following the struggle in Miryang reminded me of my grandparents.

In retrospect, my grandparents had such a simple but thoughtful worldview that is deeply connected to land, nature, and community lifestyle. The way they treated each other and related to the world was very different from the city lifestyle that I experienced. It, in fact, took a long time for me to value and to respect the lifestyle my grandparents practiced and preached, as it was not easy for me to see the dark side of the modernity I was living in comfortably. Encountering the reality of Miryang was a moment of awakening that alerted me to face the real cost of comfortability that I did not even appreciate as it came 'naturally' and to realize my role within the destructive system as an energy consumer.

The way that the villagers in Miryang have struggled can be seen as an environmental justice movement that advocates for an inclusive, empathetic, humble, and respectful approach toward nature and society, which is lacking within the hegemonic approach to sustainable development. Accordingly, I believe that an environmental justice approach as shown by the case in Miryang can provide a realistic solution for the current crisis, which is a significant asset to be added in the peace research. 


\section{Methodology}

This dissertation is based on a qualitative research method that is suitable for "in-depth description" that provides "insights into the setting of a problem" (Omar, 2014). Since the dissertation aims to provide a better insight into the discussion of sustainable development from a critical perspective, applying a qualitative research method is useful as it helps explore the complex phenomenon within its context (Baxter \& Jack, 2008) by using discourse analysis, dialectical, and deconstruction methods.

Dialectical methods help to overcome "blockages to the flow of thought and movement of concepts" as "dialectical inquiry involves a process of critical reflection on its own (that is, someone's, some culture's, some class's, some gender's, some species's), perspective, and a willingness to allow that perspective to shift and be transformed" (Clark, 2008: 2, 3). Thus, going through dialectical analysis and questions, the social construction of reality is questioned by its contradiction. Following that, particular discourse, which is structured according to the patterns of how people take part in different domains of social life, is critically analyzed to explore "different ways of understanding aspects of the world", but also to deconstruct relations of powers and dominations, and hegemony (Jorgensen \& Phillips, 2002: 2).

Furthermore, a case study is applied mainly depended on secondary data sources, including books, academic journals, newspaper articles, institutional websites, and official documentation published by the different organizations.

\section{Organization of the Dissertation}

The doctoral dissertation consists of six main chapters in addition to the general introduction, which includes the presentation of the dissertation, the objectives of the study, the 
justification of choosing this specific topic of research, the methodology and the structure of the dissertation, and the general conclusions at the end of the dissertation that puts together the key findings, and future research. The first three chapters (Chapter One, Two, and Three) provide the theoretical ground and framework of the dissertation, which, in upcoming chapters (Chapter Four, Five, and Six), is applied to the case of South Korea, specifically through the case of Miryang movement.

Chapter One outlines the general overview of the historical and institutional development on the concept of sustainable development. In order to do so, the historical background of why the sustainable development discussion has emerged is analyzed before going through the historical progression of the mainstream sustainable development discourse, which ultimately is questioned from a critical perspective.

Chapter Two investigates applying an environmental justice perspective as an alternative contribution to reaching sustainable development. Since the term environmental justice is derived from the social-environmental movements, the chapter mainly shows how the environmental justice perspective is able to challenge the mainstream discourse of sustainable development based on practical approach and perspective gained through the movements.

Chapter Three justifies why the topic of sustainability, which in fact has not been examined enough within a peace studies perspective despite its urgent necessity and importance, is significant and essential within a peace studies perspective.

Chapter Four examines the chosen case study of the dissertation, South Korea. The chapter demonstrates the overall country's history, specifically paying attention to the 
economic development process and characteristics of the development process in the context of South Korea. Thus, the struggles and challenges of applying and practicing sustainable development in South Korea can be analytically examined.

Chapter Five focuses on the conflict in Miryang, which is an outcome of Korea's development process. The chapter presents a general overview of the conflict and its consequences. Furthermore, the chapter questions the necessity of the project that justified all kinds of violence that occurred through the conflict in Miryang, revealing the "true" picture of the development process of the country, and questioning the application of the current sustainable development discourse.

Finally, Chapter Six offers the fundamental knowledge and values provided throughout the environmental justice movement in Miryang. The movement in Miryang highlights the environmental injustice caused by the development process in South Korea that has adapted the idea of sustainability to the country's development process. Thus, the movement indicates how unsustainable the development process has been in South Korea, but the environmental justice movement in Miryang furthermore suggests an environmental justice approach that advocates a more inclusive form of sustainable development. Following that, the chapter concludes that the environmental justice movement approach contributes to the discussion of sustainability and peace, specifically in the context of South Korea. 
PART I

LITERATURE REVIEW AND THEORETICAL FRAMEWORK 


\section{CHAPTER ONE}

\section{The Emergence of Sustainable Development and its Critical Perspectives}

This is all wrong. I shouldn't be up here. I should be back in school on the other side of the ocean. Yet, you all come to us young people for hope. How dare you! You have stolen my dreams and my childhood with your empty words and yet I'm one of the lucky ones. People are suffering. People are dying. Entire ecosystems are collapsing. We are in the beginning of a mass extinction and all you can talk about is money and fairytales of eternal economic growth. How dare you!

(Parts of Greta Thunberg's Speech at the United Nations Climate Action Summit, 2019)

\subsection{Introduction}

Humanity has been facing a "war for survival" (Sancton, 1989) under the global environmental crisis. Historical events, such as heavy metal pollution in Rome and environmental degradation in the Babylonian Empire, reveal how humanity can cause severe environmental problems and how these issues can in turn affect humanity. However, the environmental issues that the world is currently experiencing are something completely different. Humanity has reached the greatest challenge due to unprecedented natural environmental degradation, resulting from the continuous violence/harm caused by the human race and the systems supported by human beings.

Since the earth has faced and grappled with ever-growing environmental and climate issues, sustainability issues have been pushed to the forefront of the policy agenda worldwide (Brand \& Thomas, 2005). For that, the issue of sustainable development has become one of the most important policies of the world led by the United Nations, especially since the 1987 Brundtland Commission. Since then, the amount of sustainable development related articles, books, and policy reports published well demonstrates the importance of the topic, which has 
been discussed in depth from multiple perspectives. Different sustainable development policies applied in each country and various sectors of world society further emphasizes the aspiration for a sustainable and peaceful future.

However, there have been numerous criticisms on sustainable development, from the definition being too ambiguous to the term being used to reproduce the modernization discourse. More importantly, the fact that environmental and climate catastrophes have been worsened and intensified requires the urgent necessity of questioning sustainable development from a critical standpoint. Countless dramatic events have been repetitively reported, including never-experienced super storms (for example: Category 5 Atlantic Hurricane, Hurricane Lorenzo in 2019), uncontrollable wildfires (for instance: bushfires in Australia from Sep.2019 to Jan.2020 that was caused by climate change that allowed the hottest and driest weather on record in Australia (Gramling, 2020), Amazon rainforest wildfires in 2019), and extreme temperatures (caused by heat and cold waves). As environmental degradation has different impacts on non-human and human beings, future generations and the current generation, and on the marginalized and those in power, the vulnerable communities suffer the most, thus constant social conflicts subsequently occur.

Since the UN sustainable development agenda has an excessive political and social influence, it often becomes the main target of criticism. It is indeed not easy to question this well-elaborated idea of sustainable development, which cares about the long-term benefit of the planet and humans who live on it. For that, it is needed to closely observe mainstream sustainable development discourse in detail, which would help to detect why achieving the aims of sustainable development has been challenging. In other words, it is imperative to observe the hegemonic discourse produced by the mainstream approach to sustainable 
development since, in my opinion, it is the main difficulty to accomplish its goals.

Therefore, in this chapter, I will in general question and examine the mainstream sustainable development discussion from a critical perspective. For that, the first section will review the root causes of environmental destruction. Exploring different approaches to identify the root causes of environmental destruction will help to view the mainstream sustainable development discussion from a critical perspective in the second section. The following section will scrutinize how sustainable development is defined from the mainstream approach to sustainable development, and its characteristics. Lastly, the main sustainable development that seems paradoxical will be questioned and criticized to find better alternatives.

\subsection{Theoretical Framing of the Root Causes of Environmental Crisis}

Environmental issues have become a worldwide crucial public concern, especially since the 1970s after the long economic boom of the 1950s and 1960s, at least in the Global North. For instance, The New York Times published environment-related articles about eleven times more from 150 in 1960 to 1,700 in 1970 (Sachs, 2010) as the U.S, the world's leading economy faced severe environmental crises during the 1960s. Major environmental crises included the "Los Angeles smog, the slow death of Lake Erie, oil spills and the planned flooding of the Grand Canyon" (Sachs, 2010: 25). The situation in Europe was not any better. For instance, England, where the Industrial Revolution started, faced severe environmental issues (for example, the great smog of London in 1952 that directly resulted in killing thousands of people) before the U.S. Therefore, environment-related laws/policies were established, but also social and environmental movements started in the 1960s, specifically in North America and Europe mainly led by the white-middle class (Elliott, 2006). 
There have been different hypotheses to explain the root causes of the environmental crisis, and one of the most frequently debated factors is population growth. For the NeoMalthusian scholars, rapid population growth was considered one of the main threats to the sustainability of the planet. Neo-Malthusian scholars have underlined their concerns of human survival through publications including The Population Bomb by Paul R. Ehrlich (1968), Limits to Growth by Clubs of Rome (1972), and A blueprint for survival by Edward Goldsmith (1972). In point of fact, in 1970, the world produced about 1,730 times more manufactured goods compared to 1800 as the population of the world dramatically increased from around 978 million in 1800 to 3,632 million in 1970 (Rostow, 1978: 47-48). As a result, strict restriction policies on population growth were proposed worldwide.

However, as Homer-Dixon (1994: 9) contends, environmental changes and population growth issues only become "most pernicious" under unequal resource distribution. In other words, what Homer-Dixon emphasizes is that issues of environmental changes and population growth cannot be analyzed in isolation from the political economy of resource distribution. In fact, some prominent intellectuals, such as Rachel Carlson (Silent Spring, 1963) and E. F. Schumacher (Small is Beautiful, 1973) also recognize the necessity of alternatives to the modern economic system that is madly obsessed with chrematistic growth, which encourages never-ending consumption, and inequality.

By experiencing unprecedented environmental concerns, some experts insist that the era of Anthropocene, or the age of man, has come. During the era of Anthropocene, which began (either) with the Industrial Revolution in the 19th century and/or with the nuclear bomb 
tests in the $1950 \mathrm{~s}^{1}$, carbon dioxide emission has remarkably accelerated, sea level has increased, the global mass extinction of species has begun, and land degradation and deforestation have happened (Carrington, 2016; Stromberg, 2013; Vaughan, 2016). The term of Anthropocene highlights the significant human impact planet's ecosystem.

Nonetheless, not everyone was alarmed by environmental/climate issues. For instance, Kenneth E.F, professor of environmental studies at the University of California Davis, considered the greenhouse effect as "the laugh of the century" (Sancton, 1989). Furthermore, economist Milton Friedman doubted the existence of an environmental crisis by giving an outrageous comment like, "horses produce more pollutants than cars" (Ravaioli \& Paul, 1995). In addition, some scientists doubt human-caused global warming and question the way the current science measures $\mathrm{CO}^{2}$ emission ${ }^{2}$. As a result, President Donald Trump ended up calling climate change "mythical", "nonexistence", or "an expensive hoax" even though he acknowledged the importance of the concept later (Cheung, 2020).

Despite the concerns from some skeptics, Will Steffen, the head of Australia National University's Climate Change Institute, reminds us that the important message is that humans (or the human lifestyle) are unquestionably affecting the environment of the planet (Stromberg, 2013). More explicitly, there is a continuous system of capitalism controlled by specific humans in power while the rest of humanity supports the "capitalist geoculture that reproduces extraordinary cheapening life and work" (Moore, 2019: 53). In fact, we are living in the "Age

\footnotetext{
${ }^{1}$ It varies from different scholars. For more information check "When did the Anthropocene begin? A mid-twentieth century boundary level is stratigraphically optimal" at: http://www.sciencedirect.com/science/article/pii/S1040618214009136 (Last access: January, 2017)

${ }^{2}$ Global Warming Petition Project: http://www.petitionproject.org/ (Last access: October, 2017)
} 
of Capital ${ }^{3}$ " that takes power over nature that has been used as a source for (re)production (Moore, 2019). In other words, the idea of human (white male) superiority over nature has not only been accepted but widely practiced.

The idea of separating human from nature can be traced back to the Judeo-Christian tradition (White, 1967). According to White (1967), the mentality and attitude of medieval people toward nature are established on Judeo-Christian theology that is exclusively anthropocentric, human-centered. Thus, dominating nature was fully justified by the Bible, which separates humans from the rest of beings/nature that were considered as soulless or irrational. These concepts from Judeo-Christianity have excessively influenced Industrialism by highlighting the superior mind of the man, especially the white-European man (ibid.). In the face of criticisms especially coming from Christians, the significant message of White's theory may be that without challenging the idea of human superiority environmental catastrophe cannot be avoided.

A similar worldview pervades in the Western-centered modernization process, which supports a "consumptive" economic model that must be stopped otherwise human history will inevitably end in "environmental catastrophe" (Peet \& Hartwick, 2009: 278). In other words,

\footnotetext{
3 Jason Moore has rejected the use of the term Anthropocene, and has introduced a new term, Capitalocene, as an alternative. According to Moore, most human beings have not been included as members of Humanity, especially "in the history of capitalism, there has been little room in the Anthropos for anyone not white, male, and bourgeois" (Moore, 2019: 50). Therefore, Moore argues to use the new term Capitalocene, the age of capital, which "rejects anthropocentric flattening - "We have met the enemy and he is us' (as in Walt Kelly's iconic 1970 Earth Day poster) - along with economic reductionism" (2019: 53).
} 
the humanity that supports the destructive system of capitalism cannot be free from the current catastrophe.

Given that, it is imperative to explore and scrutinize modern economic development to reveal the characteristics of the system that causes environmental destruction, and to understand the consequences of relentless environmental destruction.

\subsubsection{The Impacts of Capitalism: The Logic of Market Economic System}

The most influential power in modern society is "the dynamism of the economy" (Gare, 1995: 79). This powerful system has excessive influence, and no one can deny that currently the world is dominated by the capitalistic system. As the modern capitalistic economic system that excessively desires economic growth and accumulation emerged, the structure of the society changed by creating the labor market, which correspondingly indicates the emergence of the new form of society (Polanyi, 2001).

According to Hungarian-American economic anthropologist Karl Polanyi (2001), the economy was always embedded in society before the 19th century. However, the market economy for the first time has become a separated sphere as a self-regulating institution that

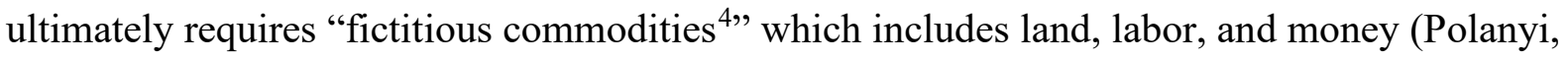
2001: xxv). Consequently, as Karl Marx describes the essence of capitalism, "for the first time, nature becomes purely an object for humankind, purely a matter of utility" (1974 in Gare, 1995: 79). But, as strong traditional social ties had dissolved, labor also became a commodity that can be bought and sold unlike in earlier economic-social organizations (Polanyi, 2001).

4 "For Polanyi the definition of commodity is something that has been produced for sale on a market." (Polanyi, 2001: xxv). 
The motive of action under the capitalistic system is based entirely on money transactions and natural resources are vitally controlled to retain the market economic system while the dehumanization process intensifies (Polanyi, 2001). Thus, traditional societies that emphasize the importance of social ties, which are maintained through the multiplication of giving and receiving (Godbout \& Cail, 1998) has been replaced by the culture of utilitarianism that represents the "hegemonic culture specific to capitalism" (Castro, 2004: 208).

However, neoliberal scholars, including Milton Friedman claim differently. From the neoliberal perspectives, the emergence of the capitalistic system means gaining personal freedom, an idea that neoliberalists honor. Therefore, neoliberal scholar Milton Friedman emphasizes the positive aspects of neoliberalism (1951:3):

The state would police the system, establish conditions favorable to competition and prevent monopoly, provide a stable monetary framework, and relieve acute misery and distress. The citizens would be protected against the state by the existence of a free private market; and against one another by the preservation of competition.

Friedman accepts the importance of engaging in public work while respecting the state law and order even though it is fundamental to secure the space of free competition and operating an effective price system despite some obstacles to overcome. To sum up, neoliberal scholars believe that neo-liberalism proposes a better future that is "capable of capturing the enthusiasm of men of good-will everywhere" (Friedman, 1951: 4).

Nevertheless, as some sociologists note, modern society has become a "consumer society" in which all things in society, including nature and human beings, are considered as consumer objects (Bauman, 2007). Subsequently, this powerful system even generated rational individuals called Homo Economicus (Castro, 2004). It seems that according to the logic of the 
market economic system, there is no natural limit and in many cases nature has been rendered completely invisible. For instance, the 1987 Nobel Prize winner for economics, Robert Solow stated, "The world can, in effect, get along without natural resources, so exhaustion is just an event, not a catastrophe" (Gare, 1995: 75).

In reality, capitalism ultimately destroys the very conditions needed in order to make steady profits. Because the modern capitalistic economic system requires maintaining economic growth and accumulation, natural exhaustion cannot be avoided. Hence, environmental degradation is an inevitable outcome for achieving continuous economic growth. In other words, reaching the biophysical limits of the planet has been expected since the industrial revolution (Bonaiuti, 2012) because the planet completely changed its character from "bare subsistence to affluence" (Mebratu, 1998: 495-496), which accelerates environmental exploitation. As society is subordinated to the logic of the market economy, the destruction of society was also anticipated (Polanyi, 2001).

Despite this cruel reality, the world productive system has been focused on continuous growth based on an unequal social system that thus inevitably causes social and environmental conflicts (Martínez-Alier, 2002). This is to say that it is obvious that systemic inequality causes various types of conflicts, social instability, and loss of well-being (Wilkinson \& Pickett, 2009).

For that reason, "the history of capital is the history of exploitation of production conditions" as Colombian anthropologist Arturo Escobar (1995: 200) explains. Accordingly, the modern economic system cannot sustain itself. However, the power of the market economy, which promised unlimited economic growth, expanded rapidly in the 20th century during the new era of development. 


\subsubsection{The New Era of Development: Development as Modernization}

The new era of development that initiated with the famous speech of President Truman, Truman's Inaugural Address, in 1949 had enormous impact and significance to world history (Truman, 1999: 591):

We must embark on a bold new program for making the benefits of our scientific advances and industrial progress available for the improvement and growth of underdeveloped areas. More than half the people of the world are living in conditions approaching misery. Their food is inadequate. They are victims of disease. Their economic life is primitive and stagnant. Their poverty is a handicap and a threat both to them and to more prosperous areas. Our aim should be to help the free peoples of the world, through their own efforts, to produce more food, more clothing, more materials for housing, and more mechanical power to lighten their burdens.

To simply put, escaping the undignified status of being "underdeveloped" became the prime attainment of development.

However, not only did Truman's speech mark the beginning of the era of development, but it also established the concept of underdevelopment. Following his speech, two billion people were framed as underdeveloped, meaning that "they ceased being what they were, in all their diversity, and were transmogrified into an inverted mirror of others' reality" (Esteva, 2010: 2).

In summary, what is emphasized in the speech is that 'underdeveloped' countries could successfully escape their misery by completing the development process, which became the universally desired goal. Based on scientific and technological knowledge, 'victims of underdeveloped' areas could help themselves by prioritizing economic growth. For that, 'underdeveloped' nations must imitate the model of the West, which requires entering "the modern age of capitalism and liberal democracy" (Elliott, 2006: 15). In other words, 
"development was seen in terms of modernization" and the modernization theory became the dominant theory of economic development from the late 1950s to 1970 s (ibid.).

A modernization that pursues the idea of progress promises an auspicious future with the reverence to science and technology, which secures endless economic growth (Sbert, 2010; Ullrich, 2010). The idea of modernity comes as the outcome of "a chain of processindustrialization, urbanization, rationalization, bureaucratization-associated with the ascendancy of capitalism" (Gomes, 2007: 42). More explicitly, the modernization process demonstrates as follows (Peet \& Hartwick, 2009: 122, author's emphasis):

In the economic sphere, modernization meant specialization of economic activities and occupational roles and the growth of markets; in terms of socio-spatial organization, modernization meant urbanization, mobility, flexibility, and the spread of education; in the political sphere, modernization meant the spread of democracy and the weakening of traditional elites; in the cultural sphere, modernization meant growing differentiation between the various cultural and value systems $[\ldots]$, secularization, and the emergence of a new intelligentsia.

Subsequently, the utmost objective of the modernization process during the era of the development was developing 'backward' or 'late-starter' countries from 'poverty' in order for them to self-sustain. For that, economic growth by capital investment was the easiest, if it is not the only approach to solving 'underdevelopment' by the West. Simply, the reason why a certain area was considered as 'backward' was because of lacking in factories that represent "the symbol of the new processes developed by science" (Alvares, 2010: 246).

Accordingly, through the process of development/modernization, the West, especially the U.S, attempts to replicate "the experience of the West" that specifically promotes the 'American way of life' (Peet \& Hartwick, 2009: 131, 222). Thus, development was seen as 
"the mental models of the West (rationalization), the institutions of the West (the market), the goals of the West (high mass consumption), and the culture of the West (the worship of commodities)" (ibid: 132). Consequently, the western discourse of development has spread rapidly to the rest of the world and the idea took over reality in the name of progress, specifically focused on chrematistic economic growth.

However, as Escobar points out, the development program generated the opposite from what it was promised: "massive underdevelopment and impoverishment, untold exploitation and oppression" (1995: 4). Empirical evidence, which was measured by Gross National Product (GNP), proves that the inequality within and between countries had worsened by the 1970s (Elliott, 2006). The situation in the 1980s was neither optimistic. It reveals how global inequality rapidly increased during the intense development era. Per capita, national incomes and investments declined while unemployment and underemployment increased in Latin America and Africa, for example (Hewitt, 2000).

Hence, in reality, the people who needed to be 'saved' by the 'development' process still struggle under the same problems of 'underdevelopment' while the development discourse colonized the reality. In the interim, environmental destruction intensified as the process of development encouraged dominating nature in order to transition from a traditional to modern society.

According to Parsons, in the words of Peet and Hartwick (2009), the main transition from traditional to modern societies is how to perceive nature, which was viewed as limited to manageable during the transition process (transition from 'wild' nature to 'manageable' environment). In other words, modernization, which emphasizes economization and 
industrialization, caused people to consider nature as consumer goods while dominating "the natural order" (Worster, 1993: 178).

Therefore, controlling natural resources has been critically vital during the industrialization process, especially with the issue of population growth that escalates the consumption of resources as neo-Malthusian concerns. In fact, massive consumption of resources, especially under the neoliberal globalization that expanded economic power, became a severe alarm even to the mainstream economists (Escobar, 2006; Du Pisani, 2006). Even though mainstream economists have enormous faith in new technology, which could be a solution for resource scarcity (Du Pisani, 2006) encountering environmental crises can be easily predictable in the modern world that worships the capitalistic market economic system.

\subsection{The Emergence of Sustainable Development}

Due to the continuous environmental problems/concerns caused by the capitalist market economic system, the discussion of sustainable development has emerged. Ecological crises and various forms of social crises have been extremely intensified during the era of development, which stimulated the expectations of unlimited economic growth. In fact, the capital-oriented modernized development system clearly showed its failure as it proves its unsustainable aspects:

The idea of development stands like a ruin in the intellectual landscape. Delusion and disappointment, failures and crimes, have been the steady companions of development and they tell a common story: it did not work. Moreover, the historical conditions which catapulted the idea into prominence have vanished: development has become outdated. But, above all, the hopes and desires which made the idea fly are now exhausted: development has grown obsolete.

(Sachs, 2010: xv) 
In relation to that, environmental concerns started to be discussed internationally. Hereafter, at the end of the 20th century, sustainable development became "one of the driving forces of world history" (Du Pisani, 2006: 83), especially after the 1987 Brundtland Commission generated by The World Commission on Environment and Development (Gladwin et al., 1995). Accordingly, the term sustainable development was successfully introduced to world politics and applied at the institutional level even though there have been constant struggles to achieve its goals. Thus, it is perhaps necessary to examine the main discussion and criticism highlighted through the mainstream sustainable development debate.

\section{Table 1.1. Timeline of the Mainstream Discourse of Sustainable Development}

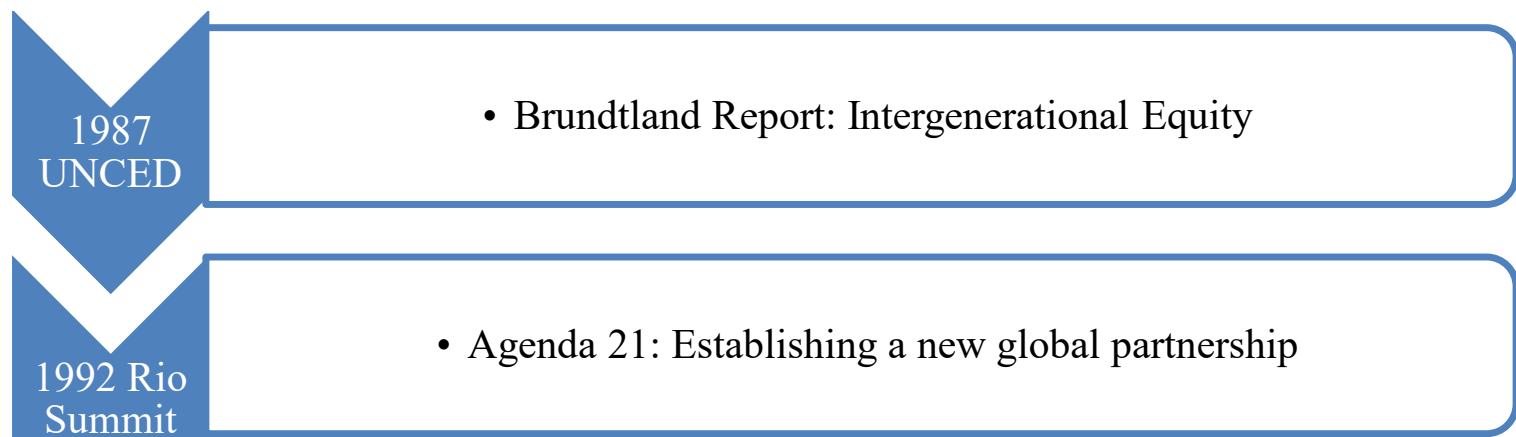

Summit
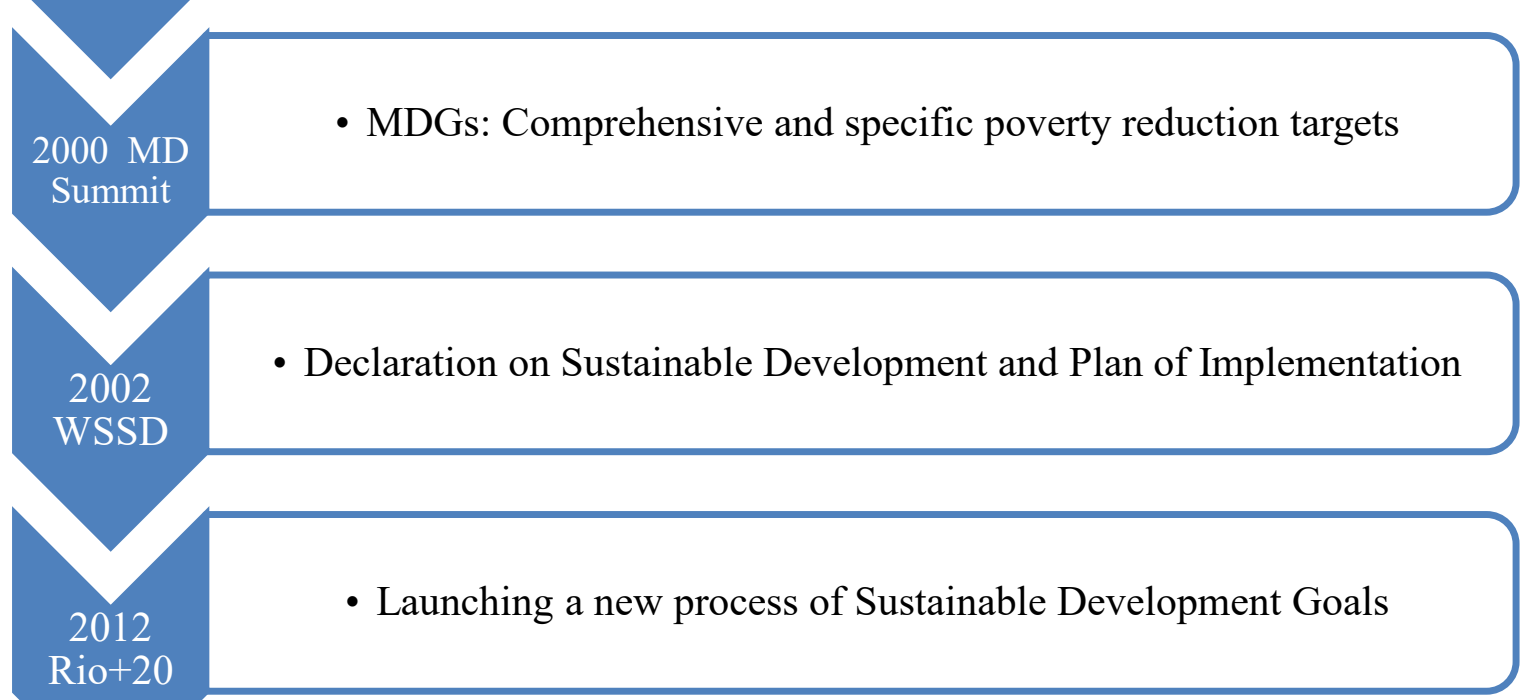


\subsubsection{Pre-Sustainable Development Discussion: The 1972 Stockholm Conference}

Following a series of environmental problems including acid rain, pollution in the Baltic, high levels of pesticides, and heavy metals in fish and birds, Sweden proposed that the UN hold a Conference on the Human Environment in Stockholm in 1972 (the Stockholm conference) (Sachs, 2010). At this point, several nations realized that environmental issues are not just a problem within a nation but are a global issue. Moreover, the idea of infinite growth/progress was questioned and critically examined through the Stockholm Conference that was mainly led by the Global North. As a consequence, 113 states agreed on the importance of environmental management and international cooperation for the matter of sustainability (Du Bose et al., 1995).

There was an agreed perception of understanding the global space as a system that requires the equilibrium of its components, including population, resources, and the environment, in order to maintain stability (Du Bose et al., 1995). Therefore, the 1973 oil crisis, for instance, alarmed people with possible resource shortages, which influenced strict restriction policies over population growth, especially in the 'Third World' countries. However, focusing too much attention on population growth in the Global South was problematic particularly when the issue of unequal distribution was not openly challenged. Furthermore, it was the Global North that primarily generated existing environmental problems.

For that, the objective of the Stockholm conference was not alluring for the countries in the Global South that were then focused on the industrialization process and economic progress. As a matter of fact, the Stockholm conference faced some criticisms:

The Stockholm conference was limited in its effectiveness because environmental protection 
and the need for development, especially in developing countries, were seen as competing needs and thus were dealt with in a separate, uncoordinated fashion. Birmie concluded that the conference was more concerned with identifying trade-offs between environment and development than with promoting harmonious linkages between the two. Even UN documents acknowledged after the Stockholm conference that little was accomplished to concretely integrate environmental concerns into development policies and plans. A more integrated perspective that incorporated both economic development and environmental sensitivities was clearly needed.

(Prizzia, 2007: 20)

Consequently, the Stockholm Conference was evaluated to improve how to 'manage' the natural resources 'efficiently' "as a part of development package" (Sachs, 2010: 27). Despite the critiques, however, the Stockholm conference, which concluded with valuable tenets, became the basis of the 1987 Brundtland Report, Our Common Future.

\subsubsection{The 1987 Brundtland Commission}

The Brundtland Commission (World Commission on Environment and Development, WCED) was proposed by then-Norwegian Prime Minister Gro Harlem Brundtland as a chairperson of WCED. The Brundtland Report successfully highlighted the significance of sustainable development, which was defined as "development that meets the needs of the present without compromising the ability of future generations to meet their own needs" (IISD, n.d.) through the report Our Common Future and it became a worldwide political catchphrase (Mebratu, 1998).

The report firmly established a space where environmental issues were on the global agenda in support of improving human well-being; "more equitable distribution of resource use benefits across and within societies; and development that ensures ecological integrity over intergenerational timescales" (Sneddon et al., 2006: 255-256). The report stresses the "needs 
of the present" especially the world's poor, and recognizes the necessity of "changing the quality of growth" (WCED, 1987: 43, 49). For that, the report underlines the necessity of "changes in attitudes, in social values, and in aspirations that the report urges will depend on vast campaigns of education, debate, and public participation” (WCED, 1987: xiv).

Meanwhile, human development that helps to eradicate poverty through well-managed nature is considered as a precondition to accomplish sustainable development (Elliott, 2006). And so, while the 1972 Stockholm Conference had focused on 'limited growth', the Brundtland Commission revived economic growth as a key to successful sustainable development:

Poverty was long regarded as unrelated to environmental degradation, which was attributed to the impact of industrial man; the world's poor entered the equation only as future claimants to an industrial lifestyle. But with spreading deforestation and desertification all over the world, the poor were quickly identified as agents of destruction and became the targets of campaigns to promote 'environmental consciousness.' Once blaming the victim had entered the professional consensus, the old recipe could also be offered for meeting the new disaster: since growth was supposed to remove poverty, the environment could only be protected through a new era of growth. As the Brundtland Report puts it: 'Poverty reduces people's capacity to use resources in a sustainable manner; it intensifies pressure on the environment. [...] A necessary but not sufficient condition for the elimination of absolute poverty is a relatively rapid rise in per capita incomes in the Third World.'

(Sachs, 2010: 27)

Ergo, "the marriage between the craving for development and concern for the environment" (Sachs, 2010: 26) had been finally declared by the Brundtland Commission. For that reason, both the global South and the North accepted the Brundtland Commission, earning it a reputation of being optimistic and successful.

However, the concept of sustainable development as defined by the commission caused great ambiguity. Thus, various alternative definitions of sustainable development were 
conceived. For instance, there were more than 80 different definitions and interpretations displayed through the WCED (Holmberg \& Sandbrook, 1992; Mebratu, 1998). Nevertheless, the 1987 Brundtland Commission definition remains the most used definition of sustainable development (Banerjee, 2003). Consequently, the variety of definitions and interpretations induced unnecessary but predictable turmoil:

Sustainability is "laden with so many definitions that it risks plunging into meaninglessness, at best, and becoming a catchphrase for demagogy, at worst. [It] is used to justify and legitimate a myriad of policies and practices ranging from communal agrarian utopianism to large-scale capital-intensive market development'

(Hopwood et al., 2005: 40)

Thus, Brenton concluded that "Mrs. Brundtland provided a slogan behind which first world politicians with green electorates to appease, and third world politicians with economic deprivation to tackle could unite. The formula was, of course, vague, but the details could be left for later" (1994: 129). As Richard Sandbrook explains, "push the environmental lobby of the North and development lobby in the South" were clear and straightforward until the term sustainable development emerged (Worster, 1993: 143). With its "blurring of distinction between the two" and its ambiguity, sustainability certainly stands on "shaky ground" based on "shallow thinking" (ibid.). Besides all the political discussion over sustainable development, in reality, "far less has been achieved that minimum for which a committed proponent of sustainable development might have hoped" (Lafferty \& Meadowcroft, 2000b: 440). Consequently, the Brundtland Report deserves to be called a "comfortable reformist" (Elliott, 2006: 36).

For the 'developing' countries, sustainable development was contemplated as an ideology that enforces strict conditions and rules on aid to 'developing' countries (Du Pisani, 
2006). Simply put, the global South lacked the technology that secures sustainable development or a new type of economic development supported by "alternative technology" (Mitcham, 1995: 318). There was not sufficient support of direct aid, technology transport, and debt relief (Sneddon et al., 2006). Additionally, during the 1980s, the countries in the Global South lost their economic sovereignty to a globalization process that increased the economic and political power of the U.S over the global economy (Duffield, 2001).

For instance, OPEC (Organization of Petroleum Exporting Countries), which was formed in the 1960s to manage the oil price, had an enormous influence on the world economy, especially the countries in the Global South. When the price of oil surged during the 1970 s, the world economy was dormant and the Western banks were left with enormous petroleum dollars. Consequently, during the 1970s, the money was used as loans to the global South, but these loans turned into debts in the 1980s that eventually constrained the Global South from being independent (Duffield, 2001). Furthermore, the influence of the UN to apply the "global agenda" was getting weaker while the World Trade Organization (WTO) expanded its power on global environmental governance by weakening local and national environmental regulation (Sneddon et al., 2006: 257). Thus, sustainable development could be regarded as a great tool to maintain the gap between the global South and the global North (Mitcham, 1995).

In addition, even though the WCED undoubtedly problematizes the issue of international consumption patterns (WCED, 1987: 95), it seems that the consumption patterns have not been challenged, especially in the industrialized countries. Accordingly, a study conducted by Lafferty and Meadowcroft (2000a) demonstrates how sustainable development policy/practice was applied unevenly within industrialized countries. The result of the study shows how industrialized countries cared less about the environmental concerns while 
emphasizing the economic sector, especially under the influence of sustainable development discussion (Lafferty \& Meadowcroft, 2000b). This is to say that sustainable development rather focuses on the interest of businesses and governments instead of challenging the ideology of economic growth or consumerism culture that causes environmental degradation and related conflicts (Hopwood et al., 2005; Elliott, 2006).

\subsubsection{The 1992 Rio Conference}

The next major milestone in the development of a mainstream understanding of sustainable development was the United Nations Conference on Environment and Development (UNCED) held in Rio de Janeiro in 1992. The conference is also known as the Rio Conference or the Earth Summit, and was attended by representatives of most governments along with 2,500 NGOs and 8,000 journalists (O'Riordan, 2000). It resulted in 172 countries signing the "sustainable development blueprint Agenda 21", which became the "guiding principle, a goal, and a standard that derives the actions of a wide variety of actors and organizations" (Farley \& Smith, 2013: 1-2).

Thus, despite reasonable confusions, critiques, and doubts, the concept of sustainability has become the universal policy objective of urban plans (Brand \& Thomas, 2005) since the 1992 UNCED. The main feature of Earth Summit was establishing a new global partnership, especially by including corporate businesses and environmental organizations as key groups to accomplish the goals of Agenda 21, which emphasizes practices of every level, from nations to local communities, and every part of the society.

In conclusion, the outcome of the Rio Summit includes (1) the Rio Declaration on Environment and Development, which includes 27 principles, (2) an 800-pages long Agenda 
21, (3) two binding conventions, which include the Biodiversity Convention and the Climate Change Convention, (4) a set of non-binding forestry principles, (5) agreements to develop subsequent legal instruments on the Convention to Combat Desertification, a Convention on Straddling Fish Stocks, and (6) on Land-Based Sources of Marine Pollution, and an agreement to create the Commission on Sustainable Development (as known as CSD or UNCSD) to monitor implementation of the Rio Agreements and Agenda 21 (Hens \& Nath, 2003).

In order to promote "a global plan of action for sustainable development" (Drexhage \& Murphy, 2010: 8), each UN member country was anticipated to examine the current environment and development condition within a nation (Mebratu, 1998). Moreover, the Rio Summit became a turning point for corporate business since environmental concerns were internalized as a central part of corporate governance, at least in the case of the global companies (Redclift, 2005). Since the world communities attended and actively engaged in the Rio Summit, the summit could be seen as a very successful meeting, especially from a political perspective (Drexhage \& Murphy, 2010).

However, the Rio Conference re-provoked a battle between the North and the South as Elliot (2006: 8) points out:

Whilst the primary output of the Rio Conference, the huge 'Agenda 21' document, carried much political authority and moral force (Mather and Chapman 1995) important tensions were evident through the proceedings at Rio such as between the environmental concerns of rich and poor countries, between those who wished to exploit resources and those who wished to conserve them, and between the development needs of current generations and those of the future.

The Global North condemned the Global South as the main actor of environmental crisis and climate change without tackling the root cause of global inequality and environmental 
degradation. Meanwhile, the North primarily focused on the conservation of nature and resources that ironically contradict the wish of the Global South.

On top of this tension, another issue that the Rio Summit faced was a shortage of funding. The Rio Summit failed to collect annual funding of US\$600 billion, which had been promised to be funded by the industrialized countries from 1993 to 2000 (O'Riordan, 2000; Hens \& Nath, 2003). The lack of commitment perhaps demonstrates that industrialized countries (also) had no enthusiasm to reach the goals of sustainable development unlike they contend. For instance, the world superpower, the U.S, proudly announced "The American way of life is not negotiable" (speech from George Bush in 1992). In fact, rather than implement "sustainability into business practice in the 1990s" (Redclift, 2005: 216), "the American way of life" was continued and advanced. Moreover, new ideas and terms, such as 'green capitalism' and 'green consumerism', had emerged.

Consequently, large corporations in the Global North have actually benefited from the higher environmental standards imposed by the U.S, because "good practice in environmental governance" could be a hard barricade to overcome for "Third World companies on global markets" (Redclift, 2005: 217). Thus, the Rio Summit placed too much emphasis on the environment or too superficially while applying too little effort on development aid and cooperation, at least from the perspective of the countries in the Global South.

Besides, as Wagaki Mwangi, a representative of the Nairobi-based International Youth Environment and Development organization, concludes the experience of UNCED, "Multinational corporations, the United States, Japan, the World Bank, the International Monetary Fund (IMF) have got away with what they always wanted, carving out a better and 
more comfortable future for themselves" (Doyle, 1998: 772). Timothy Doyle furthermore argues that "Agenda 21 has also been successful in selling a concept of sustainable development which continues to promote the Enlightenment goals of progress through economic growth and industrialization at all costs" (1998: 771). Hence, since the 1992 Rio Summit "the globalization of radical libertarian market systems" has advanced (Doyle, 1998: 771). Accordingly, liberal environmentalism became a significant influence on upcoming sustainable development debates.

\subsubsection{The UN Millennium Summit and the Millennium Development Goals}

The Millennium Summit was held in 2000 at UN Headquarters in New York, and 149 heads of state and government and high ranking officials from over 40 countries attended. In the summit, the world leaders committed to a "new global partnership to reduce extreme poverty, and set out a series of time-bound targets, with a deadline of 2015 " that have become the Millennium Development Goals (Conferences, Meetings and Events, n/d).

The 2000-2015 Millennium Development Goals (MDGs), which were declared in 2000 are (1) to eradicate extreme poverty and hunger, (2) to achieve universal primary education, (3) to promote gender equality, (4) to reduce child mortality, (5) to improve maternal health, (6) to combat HIV/Aids, malaria and other diseases, (7) to ensure environmental sustainability, and (8) to develop a global partnership for development.

One hundred and eighty-nine governments confirmed the shared goals of sustainable development by demanding better outcomes, especially for the world's 'poor' nations. The MDGs were examined as "unprecedented in the range of goals and targets chosen, in the recognition that most are interconnected, and in the public commitment from international 
agencies that they will be judged by whether these goals and targets are achieved" (Satterthwaite, 2003: 8 in Elliott, 2006: 39). Accordingly, the MDGs were considered as "the most broadly supported comprehensive and specific poverty reduction targets the world has ever established" (Sachs, 2005).

As a matter of fact, the result of the MDGs shows that at least 21 million extra lives were saved; there are positive changes, which include 111 million more people completed primary school and 471 million more people have been out of extreme poverty compared to the 1990s trends (McArthur \& Rasmussen, 2017). For that matter, the MDGs have been credited for global poverty and hunger reduction (Waage et al., 2010).

However, there is a different aspect of assessing the MDGs. In 2013 (2 years to complete the MDGs), about $15.5 \%$ of the world population still suffered from hunger as Fehling et al. (2013) reported. Moreover, the aim of reducing the child mortality rate was not met by 2015 among many other proposed goals (ibid.). In reality, as Pogge and Sengupta announced, "some 450 million people have died prematurely from poverty-related causes" that are "seven times more than were killed in World War II" (2016: 3). To sum up, as long as there are people who suffer from hunger and poverty, the MDGs cannot be considered to have been successful. In addition, as some development experts point out, reducing poverty might not be related to the planning of the MDGs, but it is perhaps because of rapid economic growth in China (Sandbu, 2015). Furthermore, as the development expert, Kenny, argues, "the poverty reduction was not improved dramatically as the income of hundreds of the million people only moved from "a few cents below $\$ 1.25$ to [a few cents] above." (ibid.).

In this sense, a question of why the MDGs could not eliminate poverty and hunger 
could be better posed. The case of poverty reduction highlights an inevitable debate on the MDGs. Do the MDGs make factual differences from what it really matters? Even if poverty reduction is achieved on a measuring process, if people still stay in extreme poverty, is it worth reaching the goal? Perhaps what must matter is more of the quality than the quantity. But yet, this does not mean to disvalue the importance and the necessity of measuring the process. Instead, the emphasis to make here is how to improve the quality of people's lives throughout the MDGs. As Reddy highlights, "It's not that we don't need better statistics [but the idea that] quantification automatically creates accountability is an error" (Sandbu, 2015).

Besides, the MDGs were seemingly designed to apply exclusively to the Global South while asking less responsibility for the Global North other than being donors. This is to say that the MDGs were mainly focused on eradicating the 'problems' that are concentrated specifically within the Global South instead of tackling the structural injustices within the current world economy and development system. On top of that, the Global South had almost no voice/input when the goals of the MDGs were arranged, but rather pushed by the world's big powers, including the U.S, Europe, Japan, the World Bank, the IMF, and the OECD (Organization for Economic Cooperation and Development) (Amin, 2006).

In consequence, the criticisms had risen especially from the South but also the authenticity and the intention of the MDGs were seriously questioned. The MDGs were considered as a discourse that continuously "legitimize the policies and practices implemented by dominant capital" since the goals are promoting the globalization that promotes intense privatization and maximized deregulation (Amin, 2006). Consequently, the MDGs were terminated with 'full of disappointment' despite contrasting arguments. 


\subsubsection{The 2002 World Summit on Sustainable Development}

To check and review the progress of sustainable development practices since the 1992 Rio Summit, there were various meetings organized, including the 1997 Earth Summit +5 in New York, the 2000 Millennium Summit, and the 2002 World Summit on Sustainable Development (WSSD) in Johannesburg.

The 2002 WSSD has been referred to as the "mega-summit"” (Elliott, 2006: 37) supported by tens of thousands of participants, including heads of 104 states and governments, national delegates and leaders from non-governmental organizations (NGOs), businesses and other major groups (SDGs Knowledge Platform, n/d). Therefore, the 2002 WSSD ended up with more groups and individuals attended than the previous conferences in both formal and informal meetings and social events. For instance, at the Civil Society Global People's Forum, there were about 40,000 people in attendance (Elliott, 2006). Moreover, more NGOs compared to the conferences beforehand, especially from the 'developing' world participated and emphasized issues of human rights, social justice, and business accountability (O'Riordan, 2000).

At the meeting of the 2002 WSSD, sustainable development focused on "complex interdependencies of environmental, social, and economic development" (Potter et al. in Elliott, 2006: 9; Drexhage \& Murphy, 2010), which need to be completed throughout the North-South partnership. In the end, the WSSD produced the Declaration on Sustainable Development and the Plan of Implementation (DSDPI), which includes principles of the MDGs and a recommitment to Agenda 21.

However, despite the successful environmental institution-building since the Rio 
Summit, the environmental problems have worsened (Hens \& Nath, 2003). Several reports produced before the 2002 WSSD hinted at disappointing outcomes. As an example, the reports from the 1997 UN General Assembly, and the 2002 UN Economic and Social Council concluded that the progress of reaching the goals of Agenda 21 had been too slow (Drexhage \& Murphy, 2010). The report of the Secretary-General of the UN, produced for the first Prepcom of the WSSD in New York, analyzed that the world had moved away from sustainable development since Rio (Hens \& Nath, 2003).

World politics led by the U.S primarily paid attention to world security issues especially in the aftermath of 9.11 in 2001. Moreover, liberal-environmentalism that promotes liberal economic order as a means to protect international environmental issues (Bernstein, 2002; Sneddon et al., 2006) was promoted by the Global North. In fact, the idea of liberal environmentalism was rooted in the 1992 Rio Summit, which fully embraced "the new economic orthodoxy" that supports an "open international economic system" (Bernstein, 2002: 4):

The main elements of the specific compromise institutionalized at Rio include state sovereignty over resources (and environment and development policies) within a particular state's borders on the political side, the promotion of global free trade and open markets on the economic side, and the polluter pays principle (and its implicit support of market instruments over strict regulatory mechanisms) and the precautionary principle on the management side. For example, according to Principle 12: "States should cooperate to promote a supportive and open international economic system that would lead to economic growth and sustainable development in all countries, to better address the problems of environmental degradation." The polluter pays principle refers to the idea that the polluting firm ought to shoulder the costs of pollution or environmental damage by including it in the price of a product. Ideally, price signals would reflect the real costs of pollution. This principle thus favors market mechanisms (such as tradable pollution permits or privatization of the commons) since they operate by institutionalizing schemes that incorporate environmental costs into prices. It also promotes an 
end to market-distorting subsidies and, generally, smooth operation of the market consistent with environmental protection.

Since the 1992 Rio summit, the Global North noticeably focused on development by “incorporating environmental assets into economic system” (Beder, 1994: 8).

In other words, liberal environmentalism became the essential foundation within the debate of sustainable development as it influenced the United Nations system in general and powerful international organizations, such as the World Bank and the World Trade Organization. The OECD greatly influenced the decision-making process of sustainable development policies by introducing alternative ideas, such as market-oriented and cost-efficiency agenda (Lee, 2011).

\subsubsection{Rio+20: The 2012 United Nations Conference on Sustainable Development}

Rio +20 that celebrated the mark of the 20th anniversary of the 1992 Rio Conference and 10th anniversary of 2002 WSSD in Johannesburg was hosted in Rio de Janeiro, Brazil in 2012. The main purpose of the conference was to make sustainable development a reality for people (UNDP, 2015) since the progress on achieving international goals of sustainable development had been slow, but also governments failed to implement the commitments of the Rio principles:

Since 2000 alone, forests equivalent in size to the landmass of Germany have been lost; $80 \%$ of the world's fish stocks have collapsed or are on the brink of collapse; and the Gobi desert is growing by roughly 10,000 square kilometers every year. The list of environmental pressures grows by the day, and there can be little doubt that the unsustainable use of natural resources will be the biggest challenge facing mankind in the 21 st century.

(Lucena \& Gummer, 2012)

Thus, the conference had three main objectives, namely "securing renewed political 
commitment to sustainable development, assessing the progress and implementation gaps in meeting already agreed commitment, and addressing new and emerging challenges" (Leggett $\&$ Carter, 2012: 3). In addition, the conference intended to re-asses international environmental agreements including the Kyoto protocol and MDGs (ibid.) while also launching a new process of Sustainable Development Goals (SDGs).

In order to 'save' the global environment, Rio +20 promoted two themes, the green economy and the institutional framework for sustainable development. Especially the green economy was proposed as a means of achieving sustainable development, but also as a means to eradicate poverty since it is characterized accordingly:

In a green economy, growth in income and employment should be driven by public and private investments that reduce carbon emissions and pollution, enhance energy and resource efficiency, and prevent the loss of biodiversity and ecosystem services. These investments need to be catalysed and supported by targeted public expenditure, policy reforms and regulation changes.

(UNEP, 2011: 16)

There are various definitions of green growth and different interpretations of its relation to sustainable development (Leggett \& Carter, 2012). However, the enormous influence of corporations caused harsh critiques. For instance, multinational corporate polluters, such as oil giant Shell, participated in the UN decision makings while an activist who exposed Brazil mining giant Vale in Mozambique, Jeremias Vunjanhe, was denied entry (FOE., 2012). As Lucia Ortiz, Economic Justice International Program Coordinator at Friends of the Earth International, highlights, "the more corporations influence governments and the UN, the less corporate crimes are exposed, and the less people's voices are taken into account at the UN" (ibid.). 
1.3.7. The New Context of the 2030 Sustainable Development Agenda and Paris Agreement Transforming our world: 2030 Agenda for Sustainable Development Goals (SDGs) was adopted in September 2015 by the UN General Assembly, and 193 member countries signed up for the agenda, which includes 17 goals (that are (1) No Poverty, (2) Zero Hunger, (3) Good Health and Well-Being, (4) Quality Education, (5) Gender Equality, (6) Clean Water and Sanitation, (7) Affordable and Clean Energy, (8) Decent Work and Economic Growth, (9) Industry, Innovation, and Infrastructure, (10) Reduced Inequalities, (11) Sustainable Cities and Communities, (12) Responsible Consumption and Production, (13) Climate Action, (14) Life Below Water, (15) Life on Land, (16) Peace, Justice and Strong Institutions, (17) Partnerships for the Goals ) and 169 targets. As the world is better connected than it was in 2000, the purpose of the newly proposed SDGs, a successor of MDGs, is to end all forms of violence whilst promoting peace and justice under the resolution of "the future we want".

The 2030 Agenda for SDGs clearly understands the necessity of shifting the world into "a sustainable and resilient path," thus, the world leaders agreed on promoting the SDGs based on the five aspects, including people, planet, prosperity, peace, and partnership (UN, 2015: 1). The SDGs indeed propose a "supremely ambitious and transformative vision" (ibid.: 7). The SDGs had been planned and negotiated among the UN members for three years even though it was criticized that the MDGs were continued while developing the SDGs (Ngwira, 2015). Thus compared to the MDGs, the SDGs are better prepared as the SDGs are considered more inclusive and detailed.

First, the SDGs are unvaryingly applied to all the countries so that all the countries both from the Global North and the Global South take action, but the SDGs also strongly ensure inclusiveness especially by emphasizing people's participation and social inclusion (Adhikari, 
2019). Furthermore, the SDGs focus beyond the hunger and poverty issues by including the concerns of justice and peace. Therefore, the SDGs propose to balance three dimensions (the economic, social, and environmental) of sustainable development (UN, 2015: 7). In conclusion, the SDGs pay more attention to quality rather than quantity, by promoting a culture of peace, non-violent global citizenship, and cultural diversity to sustainable development (Adhikari, 2019). In other words, it seems that the SDGs take a holistic approach to development.

While the SDGs outline a very ambitious vision, the member states are expected to implement the SDGs voluntarily (UN, 2015). However, there is no particular way of compelling the goals in each nation. It remains uncertain how to transform the existing economic-political system, which has a strong characteristic of being exclusive, toward a more inclusive version in the real economy and political scene.

The 2015 Paris Climate Change Conference (21st Conference) could be a good reference to observe how to apply and promote an inclusive economic system among other qualities within sustainable development. At the conference, world leaders agreed that all living beings on the planet are experiencing never-experienced climate and environmental catastrophe, and 196 countries, even including the U.S and China, signed up to reduce global greenhouse gas emissions. The participation of the U.S and China was considered a big success or even a miracle because UN climate negotiations usually failed because of the power dynamics between the U.S and China, which together represent almost 40 percent of global emissions. However, unfortunately, the U.S decided to withdraw from the Paris Agreement in 2017 due to its 'negative impacts' on the U.S economy according to President Trump.

A sustainable future is apparently impossible without a healthy Mother Nature. Simply 
put, with the ongoing climate crisis the future of human-beings is uncertain as it has been confirmed through the extinction of other living-being. Therefore, among different sectors within the sustainable development discussion, especially how to promote inclusive economic development that supposedly transforms the existing political-economic power is vital. Despite these very valid concerns, some argue that the world has been advancing for a better future, albeit slowly, and that forty years is a short period to make significant changes. However, a question that needs to be posed is what if there is not enough time for us to experiment more on a sustainable way of living as we face harsh environmental catastrophes more often each year.

\subsection{Defining Mainstream Sustainable Development and its Characteristics}

The history of mainstream sustainable development demonstrates how the term has been successfully adopted by world politics under the main principle of sustainable development, which is well-balancing on top of triangles that interconnect environmental, social, and economic concerns, and all three pillars must be integrated through the decision making process. However, its successful political consensus does not particularly indicate success in achieving its goals. In other words, it perhaps indicates that the discussion of sustainable development has not yet agreed on what sustainable development actually means.

As Lunghelle (2000) further explains, it can be tricky to define sustainable development as the term can be defined depending on different approaches and typologies developed. This means that defining sustainable development varies depending on what to emphasize. It can be defined based on "any action that considers social, economic, and/or environmental impacts - sometimes in combination and other times with simple and environmental dimensions incorporated into decision making" (Farley \& Smith, 2013: 3). As 
the term sustainable development involves two big notions of sustainability and development, sustainable development term could be interpreted in a wide spectrum from (very) weak to (very) strong sustainability, which shapes the way the economy and the environment are involved (Gibbs et al., 1998). Weak sustainability is concerned with maintaining the sum of human-made and total natural capital as each capital stock could be substitutable, whereas strong sustainability is concerned with maintaining the intact of capital stocks separately as these capitals (human-made and total natural capital) cannot perfectly substitute each other (Costanza \& Daly, 1992).

Accordingly, in order to apply different environmental policies to practice sustainable development, diverse groups, organizations, and individuals tried to capture the meaning of sustainable development from different approaches that lead to a wide variety of interpretations/versions.

The "mapping of views on sustainable development" (see Figure 1.1) presents an overview of the trends on the sustainable development debate (Hopwood et al., 2005: 41). The map includes two separate axes, including the socio-economic axis that covers "the level of importance given to human well-being and equality" and the environmental axis that covers "the priority of the environment from low environmental concern through technocentred to ecocentred" (ibid.). The map proposes three broad views on the sustainable development debate, which are status quo, reform, and transformation. Within the view of the status quo, it highlights the need for change but within the present structure. Thus, the supporters of the status quo see sustainable development as economic growth based on technology since market power is a driving force to reach sustainability. The reform approach recognizes problems thus supporting fundamental reform, but not fundamental changes of the system. The supporters of 
the reform approach also rely on the technology that benefits society and the economy by protecting the environment.

Figure 1.1. Mapping of Views on Sustainable Development

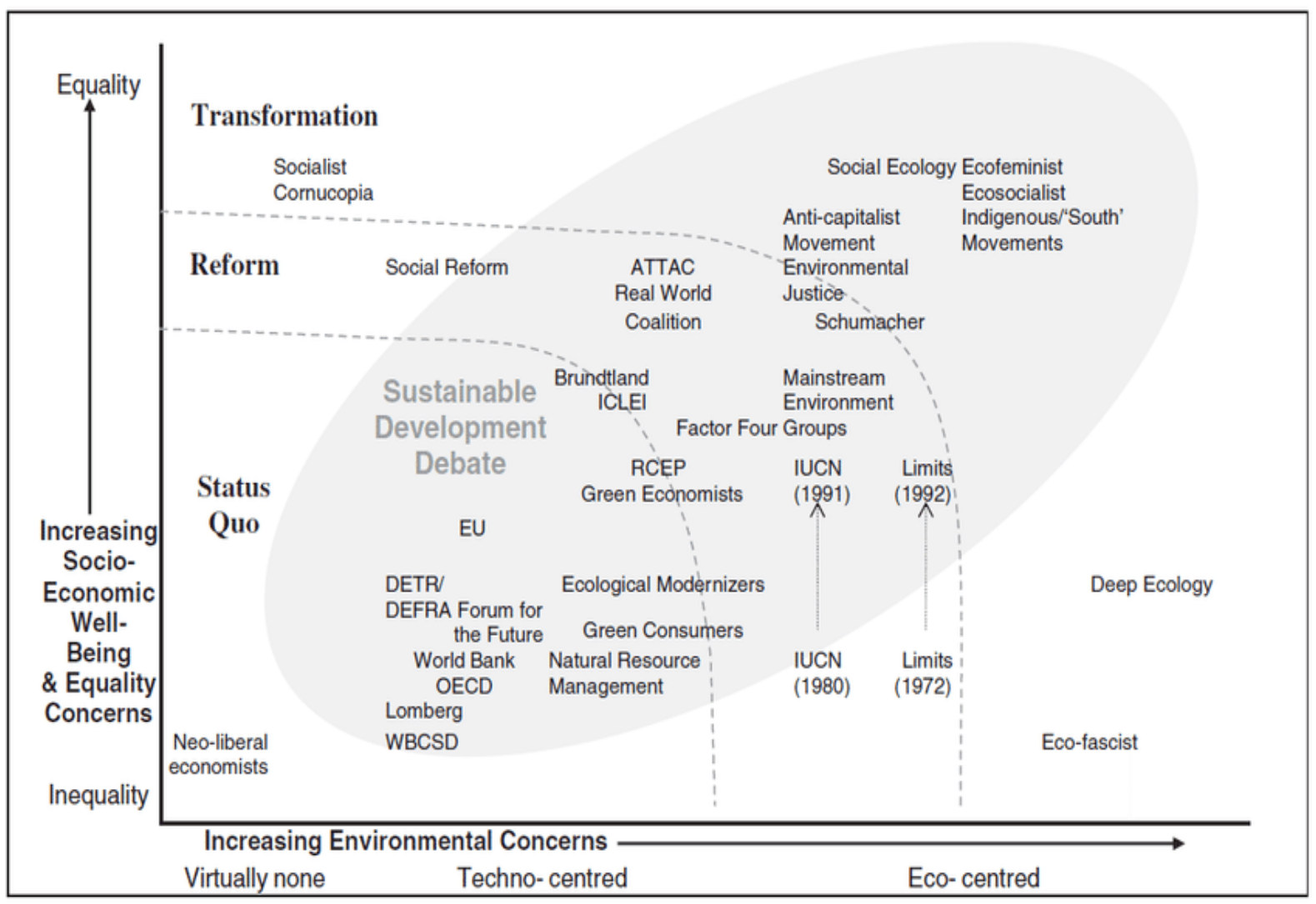

(Hopwood et al., 2005: 41)

The big difference between supporters of status quo and reform is that the status quo approach aims to reduce the role of governance and regulations (e.g., green growth), whereas a reform approach, recognizes the important role of government (e.g., ecological modernization). Unlike the first two, the transformation perspective highlights the necessity of radical transformation of the very economic and power structure of society that constantly causes social inequality and environmental degradation (e.g., eco-feminism) (Hopwood et al., 2005). 
Consequently, there are varied definitions of sustainable development, rather than having "a single unified philosophy of sustainable development" since "there is no sustainable development 'ism”' (Hopwood et al., 2005: 47).

Nonetheless, the mainstream sustainable development discussion, which has been socially and politically influenced by the presence of power, seems to be profoundly dominated by the status quo approach that promotes changes through managerial outlook rather than challenging the fundamental system (Hopwood et al., 2005). In other words, the mainstream discussion of sustainable development seems to follow weak sustainability while promoting an efficient strategy that essentially makes more profit based on rational-green technology and well-managed resources.

\subsubsection{Sustainable Development based on Scientific Technology, Rationality}

For the 1987 Brundtland Commission, the biggest concern was challenging the idea of limited growth, which was suggested by the 1972 Stockholm conference as a solution to the environmental crisis (Pearce \& Warford, 1993). As a traditional market economy demonstrates, classical economic growth contains self-destructive factors, which need to be surmounted. For this reason, scientific technology has been suggested as a perfect solution under the hegemonic discourse of sustainable development.

Since then, main discussion of sustainable development assured not only 'saving' the environment but also maintaining economic growth. For that, sustainable development was seen as a win-win strategy in which both environmental sustainability and economic development coexist. Sustainable development appeared as an answer to an alternative way of development. Doing so, after the 1992 Rio summit, the World Bank expresses the importance 
of advancing technology as it could help the periphery of the world by transferring knowledge, capital, and technology from 'developed' countries (1992).

It is to say that in the hegemonic discourse of sustainable development, scientific technology plays a key role in the link between development and the environment (Haque, 1991). One of the features of current sustainable development discourse is indeed “technological environmentalism" (Barry, 1999: 113), indicating faith in scientifictechnological knowledge to solve environmental problems. For that, then, scientific experts who produce "objective" knowledge take charge of decision making about environmental problems (Pepper, 1996).

Consequently, the discourse of sustainable development highlights (1) perceiving nature as "a set of issues identified through modern scientific inquiry" (2) assuming the human as "a rational being" and (3) depending on "an optimistic model of personal agency" that is simply being assumed “as 'responsible' citizens and consumers” (Macnaghten \& Urry, 1998: 217-218). In essence, each person is considered as a rational agent that could think and act 'ethically correct.' The contemporary sustainable development discourse continuously emphasizes the separation of human beings from nature, which can be transformed "rationally" based on scientific knowledge (Brand \& Thomas, 2005: 7-9).

\subsubsection{Sustainable Development: Sustainable Growth through Green-Neoliberalism}

Especially after the 1992 Rio summit, sustainable development visibly emphasizes the values of the neoliberal agenda that often includes "free trade, limited regulation, market mechanisms, economic growth, and conservative fiscal and monetary policies" (Castro, 2004: 197). According to the World Bank, the role of the free-market economy could be a solution to 
prevent environmental degradation because "liberalization trade fosters greater efficiency and higher productivity and may actually reduce pollution by encouraging growth of less-polluting industries and the adoption and diffusion of cleaner technologies" (World Bank, 1992: 67).

In other words, economic growth became a prerequisite to overcoming the ecological crisis, but also to approach sustainability within the hegemonic discourse of sustainable development. The logic behind this, directly supported by the United Nations, is as follows: world poverty is the main cause of environmental degradation, thus the best way of eradicating world poverty is through sustainable economic growth (Langhelle, 2000). Thus, the World Bank also supports the idea of sustainable development by insisting that "economic growth is an essential means for enabling development" (World Bank, 1992: 34).

As a result, the participation of large corporations, which promoted green consumerism, became more noticeable during the 1990s (Redclift, 2005). Corporations, aid agencies, and government departments finally engaged in these 'environmentally sound' practices (Macnaghten \& Urry, 1998). Following that, different capitalistic solutions to solve environmental issues have been provided, such as a carbon tax and carbon emission trading, in addition to introducing technological solutions to the countries in the Global South. Through the discourse of sustainable development, "environmentalists now share a common language and to some extent a common agenda with states and business" (Macnaghten \& Urry, 1998: 213).

Consequently, mainstream sustainable development has underlined the importance of embracing sustainable economic growth, which has been influenced by the neoliberal economic system. For that, the free market was expected to promote sustainable economic 
growth, thereby terminating poverty (and contribute to sustainable development).

However, the capitalistic solution demonstrates how nature becomes commodified under the logic of capitalistic sustainable development. For instance, a carbon tax is "the core policy for reducing and eventually eliminating the use of fossil fuels whose combustion is destabilizing and destroying our climate" (Carbon Tax Center, 2017). Furthermore, with the help of carbon emission trading, the countries can purchase the right to emit more carbon. Since the environmental crisis directly causes an economic crisis, the 'wise-use' of nature must be of necessity. Therefore, as the Greening of Industry conference demonstrates, the proposed strategy for sustainable development is focused on "scientific innovation, public service and turning the world populations into active consumers of its new products, and expanding global business into the less affluent segments of the world's population" (Rossi et al., 2000: 275).

\subsection{Critiques of the Mainstream Sustainable Development}

The current outcome noticeably demonstrates that modernity-based development has been prioritized over the environment in the discussion of sustainable development. In other words, throughout sustainable development, "plain old development" has been practiced (Castro, 2004: 197). Consequently, even though the UN constantly celebrates the success of sustainable development, environmental struggles have worsened as the environmental crisis has intensified. Perhaps, the current outcome confirms that sustainable development policies and practices have been anti-sustainable and anti-ecological/environmental as the history of mainstream sustainable development shows its self-contradictory relations.

The current policy of sustainable development has not led the world to the promised paradise, but to a devastating reality that invites constant inequality and injustice. For instance, 
OECD announces that the income inequalities in OECD countries have increased; the ratio between the richest $10 \%$ and the poorest $10 \%$ of the population escalated from $8: 1$ in the $1990 \mathrm{~s}$ to 9:1 in 2000 (2015). Since sustainable development discourse has merged into the norm of neoliberal environmental governance, obviously the consequences cannot be optimistic (Benton, 1994: 225):

Given the current institutional forms, power relations and economic norms which govern patterns of growth in the world systems, the proposal to target growth at meeting the needs of the poorest whilst preserving the environmental needs of future generations is simply not a feasible option. The prevailing institutional forms are such as to favour the subsumption of residual normative commitments to justice and environmental protection into an economist reading of sustainability as a project aimed at preserving the future resource base for future capital accumulation on a global scale

Besides, most conservative mainstream environmental economists do not even believe that the free market, which 'ultimately' promotes economic growth by demanding 'green' products, could protect the environment (Pearce \& Warford, 1993). Neoliberalism aims for laissez-faire policies that promote less government control, meaning limited regulations and tariffs. In other words, the utmost goal of the private sector is accumulating capital within the quick turnover, which is contrary to the purpose of the sustainable development (Foster, 2001) that actually highlights the value of peace and justice. Therefore, even though a 'greenized' neoliberal approach has been offered as a solution to approach sustainability, reaching the goals of sustainable development would be challenging under the philosophy of neoliberal environmentalism.

In the process of mainstream sustainable development, the capitalistic system has not been challenged. Instead, the system was rather backed up on the basis of scientific technology. 
However, scientific technology/rationality cannot be the ultimate solution. As Haque states, "technological interactions result in positive and/or negative effects on the environment and thus the environmental impact is synonymous with technological impacts" (1991: 152-3). Meanwhile, scientific technology can also be the source of environmental crises depending on how science and technology is applied. Thus, it is imperative to acknowledge that the environmental/climate crisis is closely related to social and political problems. Without challenging the modernity based social-economic-political system, there will be no sustainability even with the most advanced scientific technology.

It seems that sustainable development is rather searching for how to develop "an economy that the planet is capable of supporting indefinitely" (Hart, 1997: 67). In fact, what has been emphasized through the hegemonic discourse of sustainable development is the "dynamics of the capitalist modernity" that "ultimately" "improve environmental quality" (McCarthy, 2004: 328). This is to say that the mainstream sustainable development seems to aim at "increasing total 'pie' that is available and creating more opportunities for more nations to share in the unending resources through free trade, export stimulation and economic aid" rather than "redistributing wealth among nations" (Okereke, 2008: 181).

Consequently, since development officials created the discourse and practice of development to gain more power, the purpose of sustainable development does not seem to demonstrate distinctive outcomes: "The eco developmentalist vision expressed in mainstream versions of sustainable development reproduces central aspects of economism and developmentalism" (Escobar, 1996: 51-52). Thus, Maria Mies and Vandana Shiva suggest examining the sustainable development discourse as a third phase of colonization based on theoretical standpoints of colonialism and imperialism (1993: 264): 
In the early phases of colonization, the white man's burden consisted of the need to 'civilize' the non-white peoples of the world - this meant above all depriving them of their resources and rights. In the latter phase of colonization, the white man's burden consisted of the need to 'develop' the Third World, and this again involved depriving local communities of their resources and rights. We are now on the threshold of the third phase of colonization, in which the white man's burden is to protect the environment - and this too, involves taking control of rights and resources.

Sustainable development is rooted in a "colonizing discourse" as it duplicates a discourse of development (Banerjee, 2003: 6) that was one of the "founding ideals of Western modernity" (Omar, 2012: 43). Thus, the "philosophical tradition" of sustainable development discourse is rooted in "the Enlightenment" that promotes the goals of progress through economic growth and industrialization (Peet \& Hartwick, 2009: 26).

Unfortunately, "a story of violence and destruction" has been seemingly repeated in the discourse of sustainable development as the hegemonic discourse of sustainable development is reproducing modernity. In the modernization process, humans are in a higher position of a hierarchy, controlling and managing nature based on rationality and scientific technology (Lippert, 2004). Consequently, the sustainable development discourse has focused on how to improve the way we use nature efficiently and effectively. Therefore, by perpetuating the hierarchies of modernity, the hegemonic approach to sustainable development has worsened the problem that human and non-human beings are facing.

Furthermore, inequality and injustice issue highlighted through sustainable development has been intensified. The issue of fair distribution has been emphasized since the 1987 Brundtland Report. Inequality, which eventually causes injustice, was highlighted as a cause of environmental problems according to the report that concluded fair and just 
distribution of wealth was a key to reach the goals of sustainable development (Okereke, 2008). Therefore, through the 1992 Rio Conference and 2002 WSSD, distributive justice continuously became one of the most significant elements in the discussion of sustainable development discourse (ibid.). In other words, the equity issue has been pushed into the frontline of sustainable development discourse while highlighting a fair distribution in international regimes (Okereke, 2008).

However, by focusing solely on the distributive aspect within the sustainable development discourse, it easily overlooks the space that produces inequity and injustice. As mainstream sustainable development has been strongly influenced by neoliberal environmentalism that obliquely favors “dominant industrial interests" (Barry, 1999: 117), different minority sub-groups have not been recognized within the space of sustainable development. Therefore, even though a "great deal of the concern for distributional justice" has been constantly emphasized in international regimes, "it has largely co-opted for neoliberal ends, much to the disadvantage of the already marginalized sections of the global community" (Okereke, 2008: 4). As Okereke further addresses, a "neoliberal interpretation of justice" has nothing to say "about power, about the political-economic source of scarcity and about distributional politics" (2008: 176, 191). Accordingly, through the sustainable development discourse, which indeed emphasizes the importance and the necessity of equity, the world inequality ironically has worsened.

Thus, various scholars have criticized a conflicting relationship between neoliberal governance and the ideal of global environmental justice (Daly, 1996; Sachs, 1999; Redclift, 2000; Holland, 2000; Bernstein, 2001; Martinez-Alier, 2002 in Okereke, 2008). This is to say that the current sustainable development discourse inevitably causes inequality and injustice. 
The sustainable development discourse proves how the environmental crisis and its consequences have been interpreted from a privileged version of reality (Brand \& Thomas, 2005). In other words, the voice of the 'powerless' is accordingly unheard of.

As a matter of fact, during the course of the sustainable development discourse, "Western-style industrialization" has been considered as a prerequisite to reaching an "ecologically stable society" (Okerere, 2008: 180). However, different studies prove that the prosperity and the wealth enjoyed in the Global North is responsible for the environmental degradation and economic poverty in the Global South (Gokay, 2006; Okereke, 2006b in Okereke, 2008). As an example, the studies clearly demonstrate that the wealthy 'developed' countries, which compose a quarter of the world population, consume "70 percent of the world's energy, 85 percent of timber and 78 percent of metal" (Okereke, 2008: 180) while 'underdeveloped' countries that are abundant with natural resources have been endlessly exploited. It is obvious that footprints of 'developed' countries "have grown larger than their actual territories can sustain" (Wackernagel \& Silverstein, 2000: 393).

Accordingly, the sustainable development discourse could be seen as a "new power/knowledge formation" that advantages powerful nations and agencies while mobilizing "new knowledge about the performance of essential national economies and states that exert their authority to foster development at any cost (Luke, 1995: 27). Nevertheless, environmental issues have been considered as "depoliticized, managerialist discourse" (Hawkins, 1993: 23) even though ecological matters are inherently connected to politics (Robbins, 2012). Marxist geographer David Harvey (1993: 25) demonstrates this point:

All ecological projects (and arguments) are simultaneously political-economic projects (and arguments) and vice versa. Ecological arguments are never socially neutral any more than 
socio-political arguments are ecologically neutral. Looking more closely at the way ecology and politics interrelate then becomes imperative if we are to get a better handle on how to approach environmental/ecological questions.

The ecological system is rather "power-laden" than "politically inert" (Robbins, 2012: 13). This is to say that the structural changes must be necessary rather than "increasing the total 'pie' and creating more opportunities for more nations to share in the unending resources through free trade, export stimulation and economic aid" (Okereke, 2008: 181). Under the discourse of sustainable development, the idea of neoliberalism and technocrats was pushed forward and constantly highlighted as we currently live in a world that is controlled by the world economic power. Therefore, what we need is to find alternative approaches to reach sustainability through radical structural change that de-links from the logic of capitalism, which unremittingly produces injustice and inequality while obstructing environmental sustainability as nature is simply treated as a commodity.

\subsection{Conclusion}

The sustainable development discourse emerged several decades ago in response to the destructive aspects of the modernization process based on the capitalistic development system. This chapter reviewed the mainstream sustainable development discourse from critical perspectives, as humanity continues to face never before experienced ecological crises. The sustainable development discussion is indisputably significant as it is the first global political response to the environmental crisis. However, the discourse of sustainable development has been disappointing as it excessively focuses on maintaining economic power based on scientific technology instead of challenging the hegemonic power that generates continuous ecological catastrophe under injustice and inequality. In other words, the sustainable development discourse became a hegemonic discourse that seemingly reproduces the logic of 
modernity based on modern institutions like science, a capitalistic economic model, and government management that repeatedly cause inequality and injustice on top of the ecological crisis (Lippert, 2004). In other words, the construction of sustainable development is taking over power. Thus, in order to challenge the 'real' problems, subsequently this "modern hegemonic approach to sustainable development" must be challenged and the power is needed to be questioned rather than simply believing in "technology and rationalism" (Lippert, 2004: $34,38)$.

Accordingly, what must be transformed is the practice and structure of a market-based society that is inherently destructive to a sustainable system for the well-being of all living beings in nature. The purpose of sustainable development must be reconstructing the structure, fitting in "the logic of nature" instead of adopting the "logic of markets and capital accumulation" (Shiva, 1991). Hence, in this chapter, the logic, knowledge, and the reasons behind sustainable development were examined to see how the structural relations of domination and discrimination based on epistemic violence has justified and legitimized environmental destruction. The next chapter will consider how the concept of environmental justice may provide an alternative to the mainstream practice of sustainable development. 


\section{CHAPTER TWO}

\section{Environmental Justice: Alternative Contribution to Sustainable Development}

There are no small acts of compassion. Each one is a victory for peace and each brings us all closer to a better world.

Every moment has led to this moment. We are the ones we've waiting for. Together we can create a better world.

(Robert Alan Silverstein)

\subsection{Introduction}

In the previous chapter, the sustainable development discourse has been critically discussed and observed in light of its disappointing outcome. Even though the term sustainable development appeared after acknowledging the limits to growth (Pearce \& Warford, 1993), forthcoming conferences and agreements, especially after the 1972 Stockholm conference, have exclusively focused on how to overcome the idea of limits to growth by applying scientific knowledge and technology. For instance, the 1992 Rio Summit highly emphasized scientific knowledge and professional expertise for growing sustainably while effectively managing nature. Since then, the importance of scientific technology has continued as it has been considered a key solution to overcome the crisis.

Nevertheless, sustainable development has not been able to improve contemporary environmental problems. On the contrary, the situation has worsened as mainstream sustainable development (weak sustainability) has remained anthropocentric and has not challenged the underlying systems responsible for environmental destruction. Therefore, the fundamental question of what should be sustained and who benefits has emerged. At the moment it is seemingly the global market economy that sustains the position of the corporation in the course 
of sustainable development discussion. In the interim, the marginalized groups along with other living-beings become invisible, and nature has been treated as solely a resource for efficient development.

Thus, Peter Brand, a professor of urban and regional planning, insists that sustainable development is subsumed under the dominant economic paradigm (2005). The idea of sustainable development has expanded the influence throughout the globalization process, which helps to extend the power of neoliberal economics. Consequently, especially throughout the 1992 Rio Summit and the 2002 Johannesburg Summit, market-oriented policies, including free trade, deregulation, and privatization were overtly promoted. In other words, the mainstream idea of sustainable development became fully marketized instead of genuinely addressing the underlying cause of the environmental problems. Hence, the ecological crisis has worsened, and certain groups, especially those who depend profoundly on nature for their livelihoods, have been most affected by the crisis. In the end, the hegemonic approach to sustainability and sustainable development has seemingly worsened the situation although it promised to ease the conflictive issues and improve the situation based on the promise of technology and the modernized system.

As Agyeman and Evans (1995) emphasize, sustainability cannot be achieved through technical construction nor by expanding the neoliberal economy. What is actually required is changing the social structure to pursue a sustainable way of living that prevents inequality and injustice. For that matter, mainstream sustainable development has highlighted the need for justice, especially for intra- and intergenerational justice. However, the discussion has predominantly focused on distributive justice, which is one of the essential dimensions of environmental justice (Schlosberg, 2007), but not sufficient enough to transform an unjust 
social system that provides limited space to hear the voices of the most powerless and marginalized groups. As the present discussion of justice cannot even fully address the needs of the current generation, questions of how to deal with the future need to follow.

Consequently, the politically proposed and socially constructed hegemonic discourse of sustainable development must be challenged (deconstructed) and reconstructed by adopting a different approach to sustainability. This reconstruction needs to change the way we related to nature and each other. For that reason, I suggest applying environmental justice as an alternative approach to challenge the hegemonic approach to sustainable development, as environmental justice includes different voices, especially those of the powerless and marginalized (racial, class, ethnicity, and gender minorities).

In other words, this chapter scrutinizes how applying environmental justice contributes to challenging the current sustainable development discourse, and further explores alternative ways to approach sustainability and peace. Subsequently, the main question to query in this chapter is what aspects of environmental justice help to seek and challenge the root of inequality and injustice that unfortunately has been produced through the sustainable development discourse. The environmental justice approach is valuable since it is concentrated on the problems of the "real people in real places" through investigating empirical and practical contexts (Blowers, 2003: 71).

Due to that, through the chapter, the origin of the term environmental justice will be explored to understand the general idea of the history of environmental justice and the outcomes of the movement not only in the U.S where it was born but throughout the world. The struggles for environmental justice are indeed a universal issue (Schroeder et al., 2008). 
In the following section, the definition of environmental justice will be examined by analyzing the practices of the environmental justice movement. What does the environmental justice movement highlight and how has it been interpreted in practice? Accordingly, the last section discusses why it is helpful to apply the principles of environmental justice to the discourse of mainstream sustainable development.

\subsection{Origins of Environmental Justice}

The notion of environmental justice originated in the United States in the mid-1980s when the environmental justice movement was initiated. However, previously there had been consistent concerns and discussions about the issues of environmental justice without being explicitly labeled as environmental justice (Taylor, 2000).

Some scholars contend that the concept of environmental justice is derived from the civil rights movement (Bullard, 2000; Schlosberg, 2007). In fact, the South of the U.S where the environmental protests emerged due to racial inequality and injustice is the same region where the modern civil rights movement was born (Bullard, 1990). Faber and McCarthy argue that in addition to being inspired by the civil rights movement, the environmental justice movement in the U.S emerged out of "other popularly based political movements" including the occupational health, and safety movement, the indigenous land rights movement, the public health and safety movement, the solidarity movement, and the social/economic justice movement (2003: 45-46).To sum up, the environmental justice movement is often considered as an extension of the civil rights movement, especially at the beginning of the movement, but later expanded its influence by including a wider range of topics. 
In consequence, it is important to investigate the historical context of how the concept of environmental justice emerged and developed in order to better understand the leverage of environmental justice as applied to the discussion of mainstream sustainable development.

\subsubsection{Rise of Environmental Justice Movements as Environmental Racism \& Inequity}

The environmental justice movement began as minority populations in the U.S resisted against the toxic waste sites and hazard industries that are mostly located in the communities inhabited by minority populations (Bullard 1990; Agyeman et al., 2003). Despite constant demonstrations and struggles on related issues, the 1982 Warren County case marked a turning point in the U.S environmental movement. The Warren County case was the first major demonstration to connect the environmental issue to social justice (Rodeheaver, 1995).

The Warren County case is a legendary movement against environmental racism (Bullard 1990), which began in the poorest county with the highest percentage of African American population in North Carolina (Bullard \& Johnson, 2000). The Warren County protest was ignited by the decision to dump PCBs (polychlorinated biphenyls), and raised the idea of environmental racism, by demonstrating that environmental policies and practices affect people, groups, or communities differently based on color or race (Bullard \& Wright, 2003). As a matter of fact, at the beginning of the movement, the term environmental racism, and environmental equity was used overtly as the movement emphasized the equity issue among different races.

There had been constant struggles and protests prior to the Warren County case. In the early 1960s, Latino farmworkers led by Cesar Chevas in San Joaquin Valley, California fought for safer working places not polluted by harmful pesticides (Palmer, 2016). Martin Luther King 
Jr. supported garbage workers on strike (Memphis Sanitation Strike) for just wages and healthier working conditions (however, King was assassinated before he could complete an environmental and economic justice mission in 1968 in Memphis) (Bullard \& Johnson, 2000; Bullard \& Wright, 2003). In 1967, African American students protested to stop dumping garbage in their community in Houston, and in 1968, the residents of West Harlem in New York demonstrated to oppose sewage treatment plants in their community (Palmer, 2016).

At the same time, academic research on the subject of environmental equity and environmental racism started to emerge. William Burch (1971), for instance, searched for common ground on the peregrine falcon and the urban poor, and he revealed that the urban poor, predominantly non-white communities were disadvantaged by environmental harms. Freeman (1972) investigated how the wealth based on race and income is directly proportional to the danger of being exposed to environmental harm.

As mentioned above, the 1982 Warren County case marked a key milestone in the development of the environmental justice movement. After it provided a clear link between environmental and social justice issues, additional research confirmed how environmental problems disproportionately affect marginalized communities. The U.S General Accounting Office (GAO) initiated a report in 1983 about different hazard sites in region IV, comprising eight states in the South. The study showed that 75 percent of hazardous waste landfills in the south-eastern U.S are located in predominantly African American communities although they constitute only 20 percent of the region's population (GAO, 1983).

Additionally, in 1987, the United Church of Christ (UCC) Commission for Racial Justice published a report, Toxic Waste and Race in the United States, which explored the 
relationship between waste facility sites and demographic characteristics. The report concluded that 60 percent of African and Hispanic Americans live in the communities with uncontrolled toxic waste sites, meaning that race was a more potent variable to decide on locating these sites. Furthermore, the attorney Linda M. Bullard argued the illegality of a landfill project under the 1964 civil rights laws and filed the first lawsuit (Bean vs. Southwestern Waste Management, Inc.) to address environmental discrimination in Houston in 1979 (Bullard, 1994a). According to the research conducted by Robert Bullard on the spatial location of all the municipal landfills in Houston, the most garbage landfills and incinerators in Houston were located in mostly African American neighborhoods although African Americans are only a quarter of the city's population (Bullard \& Wright, 2003). The attorney, Linda M. Bullard, believed that the case of Houston (even though the attorney did not win the case, it highlighted the importance of establishing the legal premise.) is a classic case of institutional racism (Bullard, 1994a).

Mohai and Bryant (1992) correspondingly find that race is an even stronger variable to hazard facilities than income. The Federal Agency for Toxic Substances and Disease Registry investigated lead poisoning among children in urban areas in 1988, and the result showed that African American children are 2-3 times more likely to suffer than Euro American children under the same income (Bullard, 1993a). Accordingly, environmental racism is considered as "one form of environmental injustice and is reinforced by government, legal, economic, political, and military institutions" (Bullard \& Johnson, 2000: 559). In the U.S, racism has been a "conspicuous part of the American socio-political system, and, as a result, black people in particular, and ethnic and racial minority groups of color, find themselves at a disadvantage in contemporary society" (Jones, 1981: 47 in Bullard, 1993a). 
Given that, in the U.S, various studies and research have demonstrated that communities of minority races and ethnic groups have been systematically targeted for siting hazard facilities. For that, these community groups argue that they are victims of pollution by the government and the legal system (Lavelle \& Coyle, 1992). And this is why and how the U.S environmental justice movement initiated, as a response to environmental racism (Green Action, 2018).

\subsubsection{Consequences of the Environmental Justice Movement(s)}

The environmental justice movement emerged as the lives of many marginalized groups of the society were directly threatened, and the Warren County case played a significant role in popularizing the term environmental justice within the U.S. (Bullard \& Wright, 2003). As a consequence of the Warren County's case, more than 500 protestors were arrested, including the iconic leaders of the movement such as District of Columbia Delegate Walter Fauntroy, Reverend Benjamin F. Chavis, Jr., and Reverend Joseph Lowery (Bullard 1994a). Unfortunately, the movement failed to block the building of unwanted PCB landfills, which fifteen years later cost over 25 million dollars to clean up and detoxify (Bullard \& Wright, 2003). Nonetheless, constant struggles, like the Warrant County case, opened the door for changes, including the institutional changes as a response to the environmental justice movements.

The discussion of environmental justice 'finally' influenced the politics within the U.S. In 1992, under the Bush administration, the Office of Environmental Equity (later the Clinton administration changed the name to Office of Environmental Justice) was established and produced the government report Environmental Equity: Reducing Risks for All Communities, which reveals environmental hazards and social inequality. In 1993, the National 
Environmental Justice Advisory Council (NEJAC), a federal advisory committee to Environmental Protection Agency (EPA), was established on the purpose of providing advice and recommendations about environmental justice issues. In continuation, in 1994, President Clinton issued Executive Order 12898, "Federal Actions to Address Environmental Justice in Minority Populations and Low-Income Populations", which addresses the importance of environmental justice in minority populations and low-income populations so that minority communities are not disproportionately affected by environmental burdens. Furthermore, "Environmental Justice Strategy" was also implemented in 1995 for encouraging the public to engage meaningfully in planning and implementing projects. Subsequently, environmental justice became a "legally operational notion in the US" followed by sequential institutional developments (Beretta, 2012: 139).

In the meantime, the idea of environmental justice and grassroots activism traveled beyond the U.S. As a result, the First National People of Color Environmental Leadership Summit (the 1991 Leadership Summit) was held in Washington D.C in 1991. The summit was a great success as 300 community leaders, including delegates from all of the fifty U.S States, Puerto Rico, Chile, Mexico, and more, participated, and agreed on 17 principles of environmental justice ${ }^{5}$. The preamble states:

\footnotetext{
5 1) Environmental Justice affirms the sacredness of Mother Earth, ecological unity and the interdependence of all species, and the right to be free from ecological destruction. 2) Environmental Justice demands that public policy be based on mutual respect and justice for all peoples, free from any form of discrimination or bias. 3) Environmental Justice mandates the right to ethical, balanced and responsible uses of land and renewable resources in the interest of a sustainable planet for humans and other living things. 4) Environmental Justice calls for universal protection from nuclear testing, extraction, production and disposal of toxic/hazardous wastes and poisons and nuclear testing that threaten the fundamental right to clean air, land, water, and food. 5) Environmental Justice affirms the fundamental right to political, economic, cultural and environmental self-determination of all peoples. 6) Environmental Justice demands the cessation of the production of all toxins, hazardous wastes, and radioactive materials, and that all past and current producers be held strictly accountable to the people
} 
WE THE PEOPLE OF COLOR, gathered together at this multinational People of Color Environmental Leadership Summit, to begin to build a national and international movement of all peoples of color to fight the destruction and taking of our lands and communities, do hereby re-establish our spiritual interdependence to the sacredness of our Mother Earth; to respect and celebrate each of our cultures, languages and beliefs about the natural world and our roles in healing ourselves; to insure environmental justice; to promote economic alternatives which would contribute to the development of environmentally safe livelihoods; and, to secure our political, economic and cultural liberation that has been denied for over 500 years of colonization and oppression, resulting in the poisoning of our communities and land and the genocide of our peoples, do affirm and adopt these Principles of Environmental Justice

(Principles of Environmental Justice, 1991)

Consequently, after the 1991 leadership summit, the term environmental justice replaced the terms of environmental equity and environmental racism since the activists considered environmental justice as a more inclusive term (Bretta, 2012). Further to that, in

\begin{abstract}
for detoxification and the containment at the point of production. 7) Environmental Justice demands the right to participate as equal partners at every level of decision-making, including needs assessment, planning, implementation, enforcement and evaluation. 8) Environmental Justice affirms the right of all workers to a safe and healthy work environment without being forced to choose between an unsafe livelihood and unemployment. It also affirms the right of those who work at home to be free from environmental hazards. 9) Environmental Justice protects the right of victims of environmental injustice to receive full compensation and reparations for damages as well as quality health care. 10) Environmental Justice considers governmental acts of environmental injustice a violation of international law, the Universal Declaration On Human Rights, and the United Nations Convention on Genocide. 11) Environmental Justice must recognize a special legal and natural relationship of Native Peoples to the U.S. government through treaties, agreements, compacts, and covenants affirming sovereignty and self-determination. 12) Environmental Justice affirms the need for urban and rural ecological policies to clean up and rebuild our cities and rural areas in balance with nature, honoring the cultural integrity of all our communities, and providing fair access for all to the full range of resources. 13) Environmental Justice calls for the strict enforcement of principles of informed consent, and a halt to the testing of experimental reproductive and medical procedures and vaccinations on people of color. 14) Environmental Justice opposes the destructive operations of multinational corporations. 15) Environmental Justice opposes military occupation, repression and exploitation of lands, peoples and cultures, and other life forms. 16) Environmental Justice calls for the education of present and future generations which emphasizes social and environmental issues, based on our experience and an appreciation of our diverse cultural perspectives. 17) Environmental Justice requires that we, as individuals, make personal and consumer choices to consume as little of Mother Earth's resources and to produce as little waste as possible; and make the conscious decision to challenge and reprioritize our lifestyles to ensure the health of the natural world for present and future generations.
\end{abstract}


1992 the People of Color Environmental Groups Directory was published, and in 1994, environmental justice organizations were founded in the U.S, Puerto Rico, Mexico, and Canada (Bullard \& Johnson, 2000). In addition, the members who participated at the 1991 Leadership Summit resolved to play a leading role to the 1992 Rio Summit that influenced the environmental policies in different scales of governments, but also the environmental organization and mainstream institutions around the world (Walker \& Bulkeley, 2006; Choi, 2010).

The environmental justice movement has spread around the world ${ }^{6}$, supporting subjects ranging from anti-war to anti-nuclear, feminism, anti-globalization, urban pollution, immigrant rights, farmworker's rights, and inequality issues between the global North and South. Due to that, there have been many success stories of stopping projects and introducing alternatives through "a rural and urban global movement for environmental justice" (Martinez-Alier et al., 2016: 731). Accordingly, in 1997, the international conference on environmental justice was held in Austria (Low, 2000). In other words, the idea of environmental justice became a major part of the environmental discourse (Tylor, 2000).

For that matter, scientific research on environmental justice also rapidly grew, especially after the 1990s. There were different suggestions to improve methodological and analytical studies. Thus, for instance, there have been enormous academic debates about the relationship between race, ethnicity, and socioeconomic status, and environmental inequalities. However, Buckingham and Kulcur (2009) point out that within the environmental justice discussion gender issue has been neglected.

\footnotetext{
${ }^{6}$ see the map of environmental justice struggles around the world: https://www.ejatlas.org/
} 
Besides, various scientific methodologies were explored (for example: Brajer \& Hall, 1992; Napton \& Day, 1992; Hird, 1993; Perlin et al., 1995; Pollock \& Vittas, 1995; Yendle \& Burton, 1996; Boer et al., 1997; Chakraborty et al., 1999), which lead to more advanced methodologies (for example: Chakraborty \& Armstrong, 2001; Margai, 2001; Jerrett et al., 2001; Jacobson et al., 2005) and a widening of the objects of study based on high-quality empirical studies (for example: Pulido, 2000; Chakraborty \& Armstrong, 2001; Margai, 2001; Porter \& Tarrant, 2001; Jacobson et al., 2005; Mennis \& Jordan, 2005). Moreover, environmental justice started to be discussed in different fields of studies like philosophy, sociology, political studies, geography, environmental studies, urban development studies, environmental engineering, and so forth (Choi, 2010).

\subsection{Defining Environmental Justice}

In the earlier phase of the environmental justice movement, activists and academics put little effort into defining environmental justice, and most of the academic literature on environmental justice was mainly focused on distributive justice instead of attempting a more profound analysis of the definition of environmental justice. As a matter of fact, the environmental justice movement integrates broader notions of justice (beyond distributive justice) since it involves many different political, cultural, and economic environments (Agyeman et al., 2003). This is to say that defining environmental justice must be based on understanding a "broad, plural, and inclusive" environmental justice movement that indeed uses a wide range of conceptions of justice, which necessarily goes beyond distributive justice (Schlosberg, 2007: 5).

The discussion of justice theory, which is contested and multifaceted, has developed in numerous ways in the context of environmental justice. It is critical to scrutinize what 
environmental justice movements have essentially demonstrated since the movement is articulated to multiple approaches other than a single approach to defining the notion of environmental justice (Sikor, 2013). As Bryant emphasizes, the definition of environmental justice is broad by referring to different cultural norms, realizing people's highest potential, empowerment, and participation in democratic decision-making (1995). Taylor further highlights that the environmental justice movement integrates both social and ecological concerns while paying particular attention to questions of "distributive justice, community empowerment, and democratic accountability" (1993: 57).

Accordingly, there has been growing attention to the research of environmental justice under the abroad framework. Innumerable environmental justice movements confirm that there are clear connections between equity, recognition, participation, and capabilities. Thus, it is imperative to continuously use the "contested, complex discursive frame" to "defeat" environmental injustice (Holifield et al., 2010: 17). Following that, in this section, the concept of environmental justice that has been highlighted from various environmental justice movements is examined under the wide range of conceptions of justice, specifically focusing on distribution, recognition, participation/procedure, and capabilities (even though in the real movements all these different aspects occur at once and cannot be separated from each other).

\subsubsection{Distributive Perspective in Environmental Justice}

The classic justice literature in political theories has mainly focused on distributive justice and has been greatly influenced by the political philosopher John Rawls. For the last several decades, most of the political literature theories have defined justice as a fair distribution of social goods/bads and advantages/disadvantages. For that matter, the fundamental question within the theory of justice has been "how and, to what end, should a 
just society distribute the various benefits (resources, opportunities, and freedoms) it produces, and the burdens (costs, risks, and unfreedoms) required to maintain it?” (Brighouse, 2004: 2).

The environmental justice movement showcased how the livelihoods of the minority population were severely affected under the unequal system that disadvantages certain groups based on their race, wealth, and social status (Agyeman et al., 2003). Thus, issues of fair distribution have been predominantly highlighted within the literature of environmental justice movements as the minority communities are openly exposed to environmental hazards and risks inequitably. The most visible injustice of the environmental justice movement is in the realm of distributive justice (Bullard, 1990; Chavis, 1993), which is an important aspect to be observed and discussed within the society.

Hence, the environmental justice movement has focused mostly on "spatial distribution of environmental hazards, examining policy formulation" (Taylor, 2000: 508). Basically, environmental justice queries how to observe environmental problems related to the social justice aspect, thus, equity became a critical principle within the discussion of environmental justice. For that reason, academic researchers have further explored and examined the definition of environmental justice by emphasizing a distributive aspect, which requires "all things being equal, rich and poor, colored and white, educated and non-educated, be treated equally in the distributions of society's environmental benefits and burdens" (Shrader-Frechette, 2002: 24-25). In other words, environmental justice principally defined by distributional equity is essential.

However, most of the environmental justice movements use a wide range of conceptions of justice although often the discussion of environmental justice seems to solely 
focus on maldistribution. Accordingly, there have been various approaches to understanding the justice of environmental justice, which goes beyond the justice of fair distribution. In other words, what is necessary to query before everything, for instance, is the root causes of environmental degradation (Dobson, 1998), including systematic processes since the environmental policies and laws favor more of the wealthy white communities in comparison to minority communities that have less access to environmental goods, such as a park, green space, or clean water and air (Lavelle \& Coyle, 1992; Boyce et al., 1999). Fair distribution without considering other approaches does not necessarily mean that it is fair, and is certainly not the ultimate solution to reach environmental justice.

In essence, most of environmental justice movements do not only focus on the distributive issues, but further include "a more expansive, plural, and the pragmatic notion of justice" (Schlosberg, 2007: 45) since the environmental justice movements reflect "unequal power relations and concrete political context" (Sikor, 2013: 9). Consequently, it is imperative to explore environmental justice movements from multivalent perspectives to fully understand the justice of environmental justice.

\subsubsection{Participatory and Procedural Perspective in Environmental Justice}

Even though most discussion of environmental justice focuses on distributive justice, some studies also have focused on examining the importance of procedural and participatory justice. There was limited participation and representation of minorities, including people of color, low-income citizens, and women, in the decision-making process as they are institutionally excluded (Pulido, 1996). And, these mis/un/mal- recognized community members led most of the environmental justice movements. Subsequently, the 1991 First 
National People of Color Environmental Leadership Conference had well highlighted the participatory aspect of justice:

The right to participate as equal partners at every level of decision-making including needs assessment, planning, implementation, enforcement and evaluation', and 'the fundamental right to political, economic, cultural and environmental self-determination for all peoples.

For participating in the decision-making process, the democratic procedure process is a crucial condition (Young, 1990). Procedure justice highlights the importance of the fair and equitable institutional and political process that is also underlined through the environmental justice movements. Thus, Environmental justice defined by the U.S EPA emphasizes the procedural aspect of justice (U.S. EPA, 1998):

The fair treatment and meaningful involvement of all people regardless of race, color, national origin, or income, with respect to the development, implementation, and enforcement of environmental laws, regulations, and policies. EPA has this goal for all communities and persons across this nation. It will be achieved when everyone enjoys the same degree of protection from environmental and health hazards and equal access to the decision-making process to have a healthy environment in which to live, learn, and work.

According to the U.S EPA, there is a further explanation on what "meaningful involvement" precisely means, which is (1) people have an opportunity to participate in decisions about activities that may affect their environment and/or health; (2) the public's contribution can influence the regulatory agency's decision; (3) their concerns will be considered in the decision making process; and (4) the decision-makers seek out and facilitate the involvement of those potentially affected" (Laurent, 2011: 1847).

Consequently, to relieve distributional inequality, it is more than necessary to construct political and institutional procedures, which must include the participation of all the groups, 
especially the potentially affected group. This means that the procedural aspect of justice could be an effective tool to eliminate institutionalized domination and oppression. In fact, without the proper (e.g., democratic) procedure, there is no space to hear the voice of each individual and all of the communities effectively.

\subsubsection{Recognition Perspective in Environmental Justice}

In order to construct a broad and authentic public participatory procedure, recognizing different individuals and communities in the social realm is essential (Young, 1990). Even though some traditional justice theorists argue that respect and recognition are preconditions to the theory of procedural justice (Rawls, 1993), there have been numerous real cases that show how certain groups/individuals have been mis/un/mal-recognized within the systems of decision-making procedures.

The truth is that it is impossible to participate without being recognized, and it is impossible to be recognized in the distributional process without participating in the procedures. It actually signifies that observing the link between democratic participation and recognition is imperative, but also that recognition justice within the proper political procedure is closely related to relieving distributive inequity.

In essence, justice is a "trivalent package" that two issues of fair distribution and recognizing the differences must be actively interacting within political and social processes (Schlosberg, 2007: 29). To sum up, distributive justice is limited to recognizing institutional domination and oppression, thus it is not able to grasp the differences in the social realm. The lack of recognition causes a lack of rights, including participating in the decision-making process. 
Thus, mis/mal/un-recognition has been a critical topic highlighted through the different environmental movements both at the personal and community level (Schlosberg, 2007). Many environmental justice movements indeed show that the most powerless individuals and groups in society often experience misrecognition and disrespect, which lead to distributional inequity. For that reason, the focal point to be questioned here is how to distribute within the unjust system, which causes unjust distribution. Accordingly, what must be queried then is "how does the current maldistribution get produced?" other than "what is the best model for distribution?" (Young, 1990: 3).

As Young highlights, distributive injustice directly comes from "social structures, cultural beliefs, and institutional contexts" (1990: 22). Fraser (2001) further points out that for fair distribution, not only political-economic restructuring is necessary, but also cultural and symbolic changes are imperative. According to Fraser, mis/mal/un- recognition is a cultural form of injustice, which is rooted in patterns of representation, interpretation, and communication (2001). Thus, it is imperative to examine the political but also the socio-cultural realm of society to detect the maldistribution (Schlosberg, 2007: 14):

A lack of recognition in the social and political realms, demonstrated by various forms of insults, degradation, and devaluation at both the individual and cultural level, inflicts damage to oppressed individuals and communities in the political and cultural realms. This is an injustice not only because it constrains people and does them harm, but also because it is the foundation for distributive injustice.

In fact, one of the main struggles of the environmental justice movement is the issue of cultural meaning (Pulido, 1996), whereas identity is also a crucial factor that was seriously discussed through the environmental justice movement (Tesh \& William, 1996). 
To be more specific, justice does not only put importance on the issue of equity, but must include "a call for recognition and preservation of diverse cultures, identities, economies, and ways of knowing" (Schlosberg, 2007: 86). Otherwise, the local communities and local cultures cannot survive due to culture and social network breakdown (Schlosberg, 2007). In the mainstream society controlled by big capital, the environmental justice movement represents not just the simple relationship between individuals, but rather considers individuals alongside social groups and communities (Dobson, 1999).

Especially with the globalization process, cultural recognition became the central issue specifically within the indigenous activists. Through environmental justice struggles, community members and individuals often have demonstrated how their identities or culture are devalued. If the places where they make a living are environmentally disturbed and destroyed, these changes to their biophysical condition could change their "identity and personal integrity" as the communities often construct their identities "in place" (Peña, 1999: 6). Moreover, recent research clearly shows that environmental defenders experience physical violence, assassination, and criminalization, as especially indigenous people defending the environment have not been fully recognized nor legally protected (Scheidel et al., 2020).

Thus, for these (especially, indigenous) communities, the environmental justice movement is a battle to secure their homeland and cultural survival, which is directly connected to their actual survival (Peña, 1998; Johnson, 1993). Different cases explain how contaminating land means systematic genocide for the communities (Bretting \& Prindeville 1998). Consequently, recognition justice is a critical perspective to be observed within the environmental justice movements since without the proper recognition the lives of the individuals and communities are at risk. Therefore, besides fair distribution, the environmental 
justice movement must concentrate on "individual and community recognition; the point is to gain recognition for oneself, for one's own community, and for the movement as a whole" (Schlosberg, 2007: 64).

\subsubsection{Capabilities Perspective in Environmental Justice}

The capability approach, mainly discussed by Amartya Sen and Martha Nussbaum, is another perspective to develop a conception of justice apart from the standard distributive justice model. The capability approach puts importance on distributional theory, but the main focus is to examine how individuals and communities live fully by translating basic goods to achieve valuable functioning.

Functioning in this context means "various doings and beings: these could be activities (like eating or reading or seeing), or states of existence or being (being well-nourished, being free from disease)" (Sen, 1985: 197). Thus, functioning is a central idea in the capability approach as it emphasizes the qualities and capabilities people need in order to live a fully functioning life.

Accordingly, the capabilities approach is closely related to other perspectives of justice as it is, "a linked approach" that highlights how the lives of individuals function based on "a minimal distribution of goods, social and political recognition, political participation, and other capabilities" (Schlosberg, 2007: 33, 34). Thus, justice is to be able to live fully not only based on fair distribution, but also by including the aspect of recognition and participation.

Concerning that, Bryant's definition of environmental justice clearly shows the significance of including the capabilities element to define environmental justice as a place where "people can interact with confidence that the environment is safe, nurturing, and 
productive" (1995: 6). One of the main reasons why the environmental justice movements exist is to improve the living conditions of the minority groups, including, black communities and Native American communities since their living condition was threatened.

Thus, the most central part of the environmental justice movement is "building community and community capacity, and facilitating community empowerment" (Faber \& McCarthy, 2003: 58). For a healthy community to function, cultural preservation is essential since many indigenous cultures are directly connected to the land. Thus, land destruction causes not only recognition injustice by destroying the cultural practices but also impacts on community functioning by losing the culture of peacefully living in their communal place.

\subsection{Environmental Justice within the Debate of Sustainable Development}

The sustainable development discourse has principally appeared as a response to the environmental crisis, economic inequality, and social injustice. However, as sustainable development has not fulfilled its promises after several decades, it has faced severe criticisms. The mainstream approach to sustainable development has been simply repeating the modernity based development process by continuously producing inequality and injustice. Beyond doubt, the mainstream sustainable development discourse developed based on a weak sustainability/ narrow perspective, which is deeply rooted in a neoliberal economic system supported by scientific technologies. Simply put, in the discussion of the mainstream approach to sustainable development, it was believed that scientific technology could simply save humanity from the ecological crisis while providing an 'advanced' solution to sustainable economic growth.

Nonetheless, in reality, it clearly shows that mainstream sustainable development discussion structurally causes inequality and injustice due to the influence of the neoliberal 
systemic approach. In this matter, even though mainstream sustainable development discussions placed great importance on equity and justice (mainly concentrating on distributive justice) unfortunately, these values have been downplayed in the process of sustainable development (Walker \& Bulkeley, 2006). Without fundamental changes to the system, the current crisis of environmental degradation and human exploitation will unquestionably continue, which means that inequality and injustice issues, especially between the Global North and the Global South, human and non-human, the power and the powerless, and the current generation and future generation, will be most probably worsened.

Therefore, alternative approaches and concepts to sustainability and sustainable development must be discussed and developed. More specifically, to overcome the concerns of the current sustainable development discourse, "a postmodern concept of justice needs to be developed" that leads to the requirement of "a postmodern conception of sustainable development" (Lippert, 2004: 38). For that, applying environmental justice could be a great alternative to improve the practice of sustainable development, which has not been able to meet its enumerable aims.

Within the perspective of environmental justice, the issue of inequality and injustice must be observed from a multivalent perspective by including broader elements of justice as fair distribution can only occur under the fair and just social, economic, and institutional conditions (Schlosberg, 2007). In other words, in order to challenge the fundamental system that is ultimately unequal and unjust, investigating the reasons why and how inequality and injustice take place is essential. Therefore, focusing on distributive justice is compulsory but not sufficient (Shrader-Frechette, 2002) as the environmental justice movements certainly integrate different concerns such as fair distribution, recognition, participation, and capabilities. 
Consequently, an environmental justice perspective demonstrates its complicated relationship while understanding the numerous conceptions of justice that are inevitably integrated within the movement as Schlosberg points out (2007: 75):

The integration of notions of justice is evident throughout these cases. The environmental justice discourse, or frame, in these cases encompasses inequity, the lack of recognition, and exclusion from decision-making; but the discourse also includes an important reference to both individual and community capabilities, overall functioning, and the potential of individuals and communities to thrive.

In conclusion, various environmental justice movements demonstrate different perspectives of seeing environmental crisis, which is a distinctive view from the classical environmental movements, whereas providing a fundamental value that could be an alternative approach to the discussion of mainstream sustainable development by the space created from the people, especially the marginalized group.

\subsubsection{Environmental Crisis through the Environmental Justice Perspective}

The ideas of the various strands of the environmental justice movement are distinctive from the classic environmental movements that exclusively focus on the relationship between humans and nature, specifically on the issue of how humans exploit and harm nature. Therefore, the classic environmental activists, mostly white middle class, believed that a human-centered value is the main reason for environmental degradation, thus they are against an anthropocentric approach to nature (Shrader-Frechette, 2002).

For that, classical environmental movement activists particularly concentrated on wildlife preservation and nature conservation, while excluding social-environmental inequality issues since these are considered as 'too' political (Warrick, 2015). Accordingly, the social- 
political system that causes inequality and environmental degradation has not been examined within the classical environmental movement, and this is what the sustainable development discourse has lacked as the discourse put too much significance and confidence on scientific technology. This idea is essentially rooted in the "Euro-American conception of nature" or "Edenic thinking" that "separates humans from nature while constructing nature as in need of human control and domination" (Di Chiro, 1995: 302). However, the truth is that this dichotomous way of thinking is the root cause of the environmental crisis (Hwang, 2002).

On the contrary, the environmental justice approach, which presents "new critical engagements with relations between economy, environment and society" (Walker \& Bulkeley, 2006: 657), could bring more complex perspectives to discuss the matter of sustainable development. The environmental justice movement is deeply rooted in a wide perspective of justice that certainly points out the unjust system by including the voice of the marginalized of the society.

The environmental justice approach provides an alternative perspective to challenge the notion of the environment while examining different reasons of injustice from pluralistic perspectives. The different environmental justice movements mostly search for justice beyond inequality by bringing a multi-approach perspective, which further includes justice to nature. In this way, the environmental justice approach helps to redefine the relationship between humans and nature, but also to examine the environmental crisis from a different perspective.

Hence, even though the environmental justice movement could be considered as a sequence of the environmental movement, there are clear differences between the classic environmental movement and the environmental justice movement. The classic environmental 
movement has been practiced for several decades already, but the policymakers, the media, and (even) the environmentalists ignored the critical issues of environmental inequalities/injustice (Bullard, 1993a), whereas the environmental justice movement was built based on multivalent perspectives that do not only include environmental issues but matters of economic and social issues (Kwon, 2002).

Therefore, for the environmental justice activists, the environment is not something that needs to be preserved and protected by separating it from human beings, but it is more considered as a living space, "the place you work, the place you live, the place you play" (Di Chiro, 1995: 301). This is why the environmental justice movement activists consider themselves new civil rights or new social justice activists (Di Chiro, 1995) as the environmental justice movement challenges the unequal and unjust system. Consequently, it does not only confront the current reality but also helps to reimagine the future that people yearn for. Under the frame of environmental justice, what is more important is the unjust process of the causes rather than the outcome itself (Cho, 2013).

For that, the environmental justice movement concerns not only ecological issues but also social issues unlike the traditional movements, thus it correspondingly "pays attention to questions of distributive justice, community empowerment, and democratic accountability" (Taylor, 1993: 57). Given that, environmental justice shows how to change the perception of nature, but also the way to address/identify environmental crises. As Bryant (1995: 6 in Schlosberg, 2007: 50-51) further discusses, environmental justice indeed addresses the numerous issues that were demonstrated through the grassroots movements:

Environmental justice is served when people can realize their highest potential, without experiencing the 'ism.' Environmental justice is supported by decent paying and safe jobs; 
quality schools and recreation; decent housing and adequate health care; democratic decisionmaking and personal empowerment; and communities free of violence, drugs, and poverty. These are communities where both cultural and biological diversity are respected and highly revered and where distributed justice prevails.

Therefore, through the environmental justice perspective that inevitably includes the voice of the powerless, it can challenge the system that causes environmental conflicts and ecological crisis. As the marginalized of society raise their voice, there is a space created by their power struggle that could influence the discourse of sustainable development in a positive direction.

\subsubsection{Bottom-Up Movements: Creating a Political Space}

One of the most noticeable characteristics of the environmental justice movement is that the perspective of environmental justice inevitably includes the voice of the marginalized, which is an essential part to be considered in the discussion of sustainable development. Environmental justice movements (as grassroots movements ${ }^{7}$ ) have been focused on effectively demonstrating the messages of the people, especially the marginalized, while demanding a shared role in the decision-making process that ultimately affects the communities and livelihoods (Bullard, 1994b). Several examples of successful movements clearly show that "speaking for ourselves" has been a dominant discussion within the environmental justice movements even though it has been an important question to inquire about how to make a just decision for all.

The decision-making process that is based on "mutual respect and justice for all" was followingly emphasized through the 1991 First National People of Color Environmental Leadership Conference. In other words, the different branches of the environmental justice

\footnotetext{
7 According to EJ Atlas map, 3221 cases have been reported (current date, July, 31, 2020).
} 
movement outstandingly give emphasis to the recognition of individuals, but also the prominence of including the community level. However, there have been some cases of the locals playing NIMBY (Not In My Backyard) game, which brought doubts about involving the community members as to lead the decision-making process. Besides, there were also a few cases of accepting environmental hazards for the temporary economic benefit (Toda, 1996). In contrast, meanwhile, there are countless movements that effectively proved that "they are capable of leading, speaking, and doing for themselves and their communities" (Austin \& Schill, 1991: 74).

The central message coming from the environmental justice movements is rather how to challenge institutional domination and oppression by questioning "the foundation of the current environmental protection paradigm" (Bullard et al., 2007: 9) that excludes the voice of the marginalized. Thus, environmental justice activists focus on including the voices of the most marginalized in order to challenge the mainstream view on how to perceive the environmental crisis, which has been particularly understood from the point of the market economy. In other words, through the environmental justice movement, what was highlighted is "the self-respect and autonomy demanded by individuals and communities fighting for environmental justice include gaining recognition from others, and mutual respect for various communities, identities, and cultures" (Schlosberg, 2007: 64).

As Bullard emphasizes, "no community should be seen as compatible with pollution and poison" and communities are capable enough of sustaining the healthy community lifestyle as long as they recognize how to use the collective power (Milman, 2018). In this light, the environmental justice approach could be seen as a political opportunity since environmental justice potentially provides "a productive intellectual and policy space for multidimensional 
and multi-scalar exploration of its meanings, manifestations and implications" (Walker \& Bulkeley, 2006: 658). As political ecologist Paul Robbins also points out, how "new environmental regimes and conditions have created opportunities or imperatives for local groups to secure and represent themselves politically" (2012: 23). In other words, the environmental justice approach benefits to provide (or require to have) the political space that concerns the fundamental causes and dynamics of inequalities. Environmental justice is, therefore, "a vocabulary for political opportunity" (Agyeman \& Evans, 2004: 155).

\subsubsection{Environmental Justice: All for One and One for All}

The sustainable development discourse has highlighted the issue of justice by mainly focusing on distributive justice, which exclusively cares for the human condition. As such, sustainable development has been criticized for being an anthropocentric discourse. Through the traditional liberal justice view, which has a wide influence on the idea of justice in the mainstream sustainable development discussion, non-human beings in nature are often excluded from the discussion of justice. Rawls even contends that "they are outside the scope of the theory of the justice, and it does not seem possible to extend the contract doctrine" even though the liberalist understands that "it is wrong to be cruel to animals and the destruction of a whole species can be a great evil" (1971: 448).

To win the fight against the current crisis, having an insight into how environmental issues are interconnected to social, political, and economic issues, and more importantly, realizing the survival of every living being is essential to human survival. As a matter of fact, the seventeen principles of environmental justice agreed on at the 1991 First National People of Color Environmental Leadership Summit recognizes "cultural integrity with environmental sustainability and sustainability for humans along with other living beings" (Schlosberg, 2007: 
49). In this regard, the numerous environmental justice movements clearly demonstrate their recognition of a deeper connection to other living beings in nature, which must be included in the discourse of sustainable development. Throughout the mainstream sustainable development discussion, the importance of environmental sustainability has been emphasized since it is closely connected to the other two important factors of society and economy. Nevertheless, in different practices of sustainable development, the environment has been perceived as a means to achieve economic efficiency. This is why sustainable development faces the condemnations of being green-neoliberalism and repeating the destructive colonizing discourse.

In this light, the environmental justice perspective could be a beneficial input as the most environmental justice movements struggle against the colonialization of the capital that persistently requests the destruction of nature for surviving. Meanwhile, the environmental justice activists well understand the interconnectedness of human well-being within nature. In other words, most of the environmental justice activists clearly identify nature as part of life, and argue that nature cannot be separated from cultural histories and socially and ecologically destructive colonial and neocolonial experiences (Di Chiro, 1995). This means that "ideas of nature, for environmental justice groups, are therefore tied closely to ideas of community, history, ethnic identity, and cultural survival, which include relationships to the land that express the particular ways of life" (ibid.: 318).

According to Peña, the identity of individuals and the community are constructed based on the surrounding environment: "we construct our identities in place, whenever the biophysical conditions of a place are threatened, undermined, or radically transformed, we also see these changes as attacks on our identity and personal integrity" (1999: 6). The fact in this statement is that the only way to understand the essence of being is through other beings, thus 
the best possible way to achieve environmental justice is by embracing the importance of having a natural community and having a healthy mind (Hwang, 2002). For that matter, threats to the environment could be considered a systematic genocide, which endangers cultural practices (Krauss, 1994).

Consequently, most of the environmental justice movements indicate that the core of the movement is an interconnectedness with "other groups, other species, and the natural environment" (Di Chiro, 1995: 318), and this idea of interconnectedness is directly connected to the sovereignty and cultural surviving for the communities. To sum up, the fundamental idea of all for one and one for all that has been underlined by the worldwide environmental justice movements could contribute to developing an alternative conception of sustainable development.

\subsection{Conclusion}

Due to the contentious outcome of mainstream sustainable development, this chapter has applied an environmental justice perspective as an alternative perspective within the discussion of sustainability and sustainable development. Accordingly, the environmental justice movement that originally emerged from marginalized groups within the U.S eventually traveled worldwide to counter injustice and inequality with the peaceful existence of every being in nature.

As most environmental justice movements inevitably include the voices of community members who depend on nature to sustain their existence, the environmental justice approach demonstrates how to deal with the issue of environmental sustainability, which is interconnected and interdependent to social and economic sustainability. At the same time, 
environmental justice re-assures the simple truth that humans cannot exist alone in nature. Consequently, in order to overcome the environmental threats, the voice of the people must be heard to reshape the powerful discourse of sustainable development. In other words, including the perspective of environmental justice to the discussion of sustainable development could be a positive contribution toward walking on the peaceful road toward a sustainable future. Environmental justice opens different but essential perspectives to confront the unequal and unjust system of reality. 


\section{CHAPTER THREE}

\section{Environmental Sustainability and Peace}

The primary threat to nature and people today comes from centralizing and monopolizing power and control. Not until diversity is made the logic of production will there be a chance for sustainability, justice and peace. Cultivating and conserving diversity is no luxury in our times: it is a survival imperative.

(Vandana Shiva)

Sustainable development is the peace policy of the future

(Dr. Klaus Topfer)

\subsection{Introduction}

The well-being of humans is directly dependent on healthy nature. Environmental harmony is the basis of human well-being; thus, as long as there is an ecological crisis, environmental conflicts will be escalated as the marginalized struggle to exist peacefully within nature. Accordingly, there have been constant natural resource conflicts (for example, conflict mineral, including copper, cobalt, diamond, and more, in the Democratic Republic of Congo) that often cause warfare as "a handful of corporations and powerful countries seek to control the earth's resources and transform the planet into a supermarket in which everything is for sale" (Shiva, 2010).

To highlight again, healthy nature and environmental sustainability are the prerequisites to peace (Barash \& Webel, 2009). In that sense, as Shiva (2010) emphasizes, "sustainability is based on peace with the earth" and the war against the planet, which is the biggest war, must end. As such, the connection between peace and environmental sustainability has been made throughout the mainstream sustainable development discussion. 
However, the history of mainstream sustainable development verifies that the topics of healthy nature and environmental sustainability have been considered as a subsidiary matter within world politics since economic development while 'controlling' nature efficiently based on scientific technology has been the focal point. Thus, the situation of environmental sustainability has not improved through the course of mainstream sustainable development but rather worsened.

Besides, despite the importance of the topic, there seems to be a lack of literature linking the dots between peace and environmental sustainability as many authors, including John Barnett, point out. Thus, Barnett (2007) urgently highlights the necessity of including these two topics as environmental changes ultimately accelerate inequality, which is one of the main concerns in peace research.

Due to that, the main objective of this chapter is to observe how and why presenting the topic of environmental sustainability is necessary within a peace studies perspective by providing the theoretical framework of the dissertation. But, more importantly, the chapter explores how the environmental justice perspective could make a contribution toward peace and environmental sustainability by challenging the current violent system.

At first, concepts of peace and violence will be explored to comprehend better why and how the issue of environmental sustainability must be examined within peace studies. Throughout the section, the importance of including environmental sustainability within the topic of peace will be questioned and answered. Then, in the next section, how to transform the vicious violence toward a more peaceful future will be explored. Along the way, how humans are related to other beings within nature will be mainly examined. But also, the role of 
the environmental justice perspective that could be an efficient tool to enhance environmental sustainability and peace within peace studies will be scrutinized.

\subsection{Defining Peace and Violence}

As peace philosopher Francisco Muñoz highlights, peace is a condition that has been an integral part of humanity since time immemorial (2001) together with violence as these two are intimately linked to each other (Galtung, 1969). While the term and concept of peace has existed for millenia, there is a different meaning of peace for each epoch, culture, social status, and even each person: "Each ethnos-people, community, culture-has been mirrored, symbolically expressed, and reinforced by its own ethos-myth, law, goddess, ideal-of peace" (Illich, 1982: 53).

However, the traditional approach to peace research is mainly devoted to understanding "the causes of war by systematic analyses of the historical experiences of war" (Wallensteen, 2001: 6) as the field of peace studies originally derived from the field of international relations. According to Rapport (1992), conceptions of peace can be divided into (1) peace through strength, (2) balance of power, (3) collective security, (4) peace through law, (5) personal pacifism, and (6) revolutionary pacifism, which all are directly connected to the war system or direct violence.

Thus, the world community has searched for a possible "solution" to reach a peaceful condition, the absence of the war, especially after the World Wars. The main suggested solution is liberal peacebuilding based on democratization, international law, human rights, and the market economy (Tziarras, 2012). For that matter, various international organizations, including the United Nations, were established and different development projects (e.g., Point 
Four Program) were implemented in order to maintain world peace effectively. Hence, liberal peacebuilding has been promoted through international organizations and by increasing international interdependence through economic development.

Ivan Illich designates this kind of peace as the pax economica, which means a "balance among formally economic powers" (1982: 56). According to Illich (1982), the pax economica is the first monopolized meaning of peace that the world has agreed on. This means that "the pursuit of peace through development became the overarching unexaminable axiom" (Illich, 1982: 57). Therefore, anyone who goes against such an idea, economic growth as the means to reach peace, could be considered as an enemy of peace (Illich, 1982). However, liberal peacebuilding or the process of pax economica faces serious criticisms by hiding the destructive truth of development.

An absence of war is one of the necessary preconditions to reach peace, but not the only factor to consider. Subsequently, there are various factors that can interrupt the peaceful existence of all beings, and there are diverse aspects to be considered in order to define peace and violence. Accordingly, peace research has expanded to include different types of peace and violence related to social, cultural, and environmental issues, instead of solely focusing on the limited concept of peace and violence.

As Galtung highlights, violence is "any avoidable insult to basic human needs, and, more generally, to sentient life of any kind, defined as that which is capable of suffering pain and enjoy well-being" (2013: 35). In other words, peace does not only mean an absence of war but "it is a virtue, a state of mind, a disposition for benevolence, confidence, justice" as the philosopher Spinoza said. For that, in this section, the author explores how the definition of 
peace and violence has been discussed and developed, and observes how the topic of ecological well-being is deeply interconnected and interdependent with peace.

\subsubsection{Negative and Positive Peace}

The terms negative and positive peace were introduced by the prominent peace researcher, Johan Galtung, in the editorial to the founding article of the Journal of Peace in 1964. According to Galtung, negative peace is the "absence of violence, absence of war", while defining positive peace as referring to "the integration of human society" (1964: 2). More specifically, positive peace, which indeed is an ambiguous term, indicates "all other good things in the world community, particularly cooperation and integration between human groups" (Galtung, 1967: 12). Therefore, to simply put, positive peace puts more attention on the system of social justice and equality.

Positive peace intends to reach toward a more just and equal society even though Galtung does not specifically indicate the pathways to reach a just and equal society, which needs to be further discussed in peace studies. In comparison to negative peace, reaching positive peace is more complex and difficult, but then it is essential to challenge structural violence, which threatens positive peace along with negative peace. For example, social inequality can be the focal source of conflicts and even the outbreak of wars. In other words, despite the dichotomy between negative and positive peace, "positive peace provides the essential conditions of negative peace, because war, armed conflict and political violence result from the absence of positive peace" (Atack, 2009: 41).

As Galtung continuously highlights, "the most promising way to reduce the negative relations to the minimum is via an increase of positive relations" (1967: 14). However, even 
Galtung doubted that this could be realistic without complete disarmament (Grewal, 2003). For that matter, some scholars find the definition overly idealistic. However, despite all possible criticisms, Galtung established a theoretical tool that reveals "a connection between peace, conflict, and development research" by relating violence to the social structure due to its "social justice connotations" (Grewal, 2003: 3):

The definition of 'peace' becomes a major part of scientific strategy. It may depart from common usage by not being agreed to 'the most' (consensus not required), yet should not be entirely subjectivistic ('agreed to by many'). It should depict a state of affairs the realization of which is not utopian ("not impossible to obtain"), yet not on the immediate political agenda ("complex and difficult"). And it should immediately steer one's attention towards problems that are on the political, intellectual, and scientific agenda of today, and tomorrow.

(Galtung, 1969: 168)

\subsubsection{Direct, Structural and Cultural Violence}

According to Galtung, violence is "present when human beings are influenced so that their actual somatic and mental realizations are below their potential realization" (1969: 168), and Galtung furthermore points to six important dimensions of violence, which are: (1) between physical and psychological violence; (2) between the negative and positive approach to influence; (3) whether there is an object that is hurt; (4) whether or not there is a subject (person) who acts; (5) between violence that is intended or unintended; and (6) traditional distinction between two levels of violence, the manifest and the latent (ibid.: 169-172). By observing different dimensions, Galtung made the clear distinction between direct violence, which is characterized as easily seen because there is an "actor that commits the violence as personal or direct", and structural violence that is not straightforwardly shown as "it is essentially static, it is the tranquil waters" (Galtung, 1969: 170, 173). 
On top of the basis of this distinction, Galtung formed the typology of violence through the conflict triangle of direct, structural, and cultural violence (see Figure 3.1). Fundamentally, violence could start at any corner of the malicious violence triangle, which is direct, structural, and cultural violence since "violence breeds violence within and among actors, in space and over time" (Galtung, 2013: 35). In more detail, structural violence is built on an unequal and unjust structure that often takes a longer time to show the side effects since the causes are indirect (Bufacchi, 2005).

Figure 3.1. Galtung's Violence Triangle

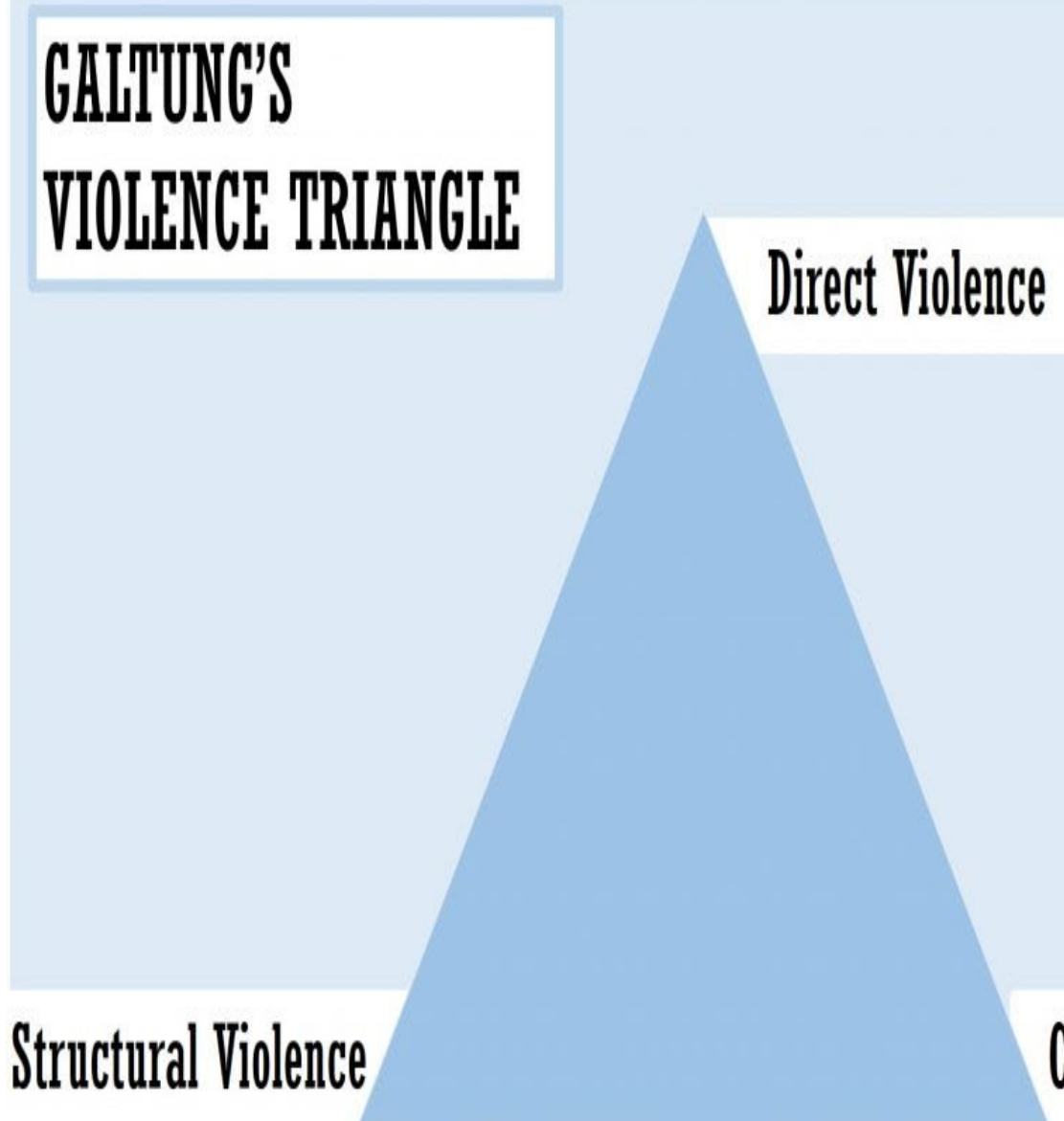

Cultural Violence

(Dutta, 2020) 
Consequently, through structural violence, people either die slowly out of deficiencies or permanently suffer from misery. Structural violence is often a direct outcome of a socioeconomic system that exploits human beings and non-human-beings by damaging the system of nature. Accordingly, under structural violence, the unequal and unjust system continues by exploiting the "underdogs" while benefiting "the top dogs" of the society (Galtung, 2013: 37).

Therefore, in order to eliminate direct (physical, event) and indirect (structural) violence (process) in the long term, it is critical to adopt non-violent means to promote a culture of peace. This means that a culture of peace is interconnected to negative peace defined as "the absence of organized collective violence" and positive peace defined as "sum total of other relatively consensual value in the world community of nations" (Galtung, 1967: 17). In conclusion, in comparison to positive and negative peace, achieving a culture of peace is a long process since cultural violence requires a long period of time to slowly transform the basic culture.

\subsubsection{Ecological Well-Being in Peace Studies}

As humanity has faced a worsening ecological crisis, which directly and indirectly influences the well-being of living beings that depend on nature for their existence, the matter of sustainability and environmental sustainability has become one of the most important topics that need to be investigated within peace research. In fact, the environmental crisis is a big threat to positive and negative peace as the ecological crisis is a cause of the violent circle and vice versa. Furthermore, Galtung also highlights the necessity of including natural violence within peace studies in order to answer questions "what is the cause of peace?" and "what is the effect of peace?" (Grewal, 2003: 5). 
The issue of justice and equality, including social justice, in general, is an essential topic in peace studies now more than ever since. As the constant ecological crisis threatens the wellbeing of all the living beings, the truth is that the powerless (e.g., non-human beings, the marginalized groups, future generations) are affected the most, which is a form of structural violence. This means that as long as there is systematic exclusion and inequality that determines the social condition of the marginalized, the structural violence that politically, economically, and socially excludes the powerless while causing the destruction of the environment will remain.

Thus, the ecological crisis that challenges the environmental sustainability, and directly threatens the well-being of all beings in nature must be critically engaged and addressed in peace studies. Ecological well-being is a prerequisite to a peaceful existence and an essential quality of maintaining a peaceful life:

'Ecological balance' is a frequently used term for environment system maintenance. If not satisfied there is ecological degradation, breakdown, imbalance. Ecobalance is to the environment what survival + wellness + freedom + identity are for human basic maintenance; if not satisfied the result is human degradation. The sum of all five, for all, might be one definition of 'peace'

(Galtung, 2013: 36)

In other words, the best way to prevent violence is through the positive peace approach (Grewal, 2003). Therefore, pax economica which fundamentally depends on economic power might help to reach negative peace by reducing the possibility of causing war, but it does not provide a clear path to reach positive peace as the current economic system causes extermination of natural resources. In addition, the economic system can cause direct violence as various resource wars (e.g., the Iraq War) have shown. 
This is why most of the environmental justice movements have requested for a peaceful future for all livingbeings within nature. In order to do that, the culture of peace that understands the necessity of healthy nature, and teaches how to respect Mother Nature must bloom. As Martínez Guzmán accentuates, peace research must ultimately promote "human relations based on justice and relations with nature based on sustainability" (2008: 25). For that matter, Martínez Guzmán further suggests including the issue of the "fragility of the world economic system" and the "vulnerability of the security system" within peace research (2008: 18). Consequently, the most realistic way to promote peace is reconstructing the ground rules based on our capabilities and competencies to live in peace (Martínez Guzmán, 2008).

\subsection{Transforming the Vicious Violence Cycle toward Peaceful Future}

Unfortunately, environmental conflicts have been rapidly increasing year after year as the environmental crisis intensifies. There has been constant direct violence against nature in daily life that is deeply connected to the systems of industrialization and commercialization (structural violence), which transforms nature to capital in order to achieve economic growth (Galtung, 2013). Due to the system, we have lost the connection to land and nature, and heavily relying on scientific rationality that justifies consumerism (cultural violence). Thus, environmental degradation/ecocide has become one of the biggest threats to world peace and justice.

In view of that, the discussion of sustainable development has emerged as a potential solution for environmental threat, but also to promote peace and justice: For example, in the 1992 Rio Declaration on Environment and Development Peace, development and environmental protection are considered interdependent and indivisible (Principle 25); SDG 16 
highlights the need to promote peaceful and inclusive societies, provide access to justice for all and build effective, accountable and inclusive institutions at all levels.

However, the sustainable development discourse has predominantly been focused on sustainable economic growth rather than environmental sustainability, thus ecocide has continued and catastrophe for living beings is to be expected. Meanwhile, through the practices of sustainable development, the issue of inequality and injustice (structural violence) has been constantly questioned as the powerless marginalized have been disadvantaged while the powerful overtly receives the benefit. In fact, the principal casualties of structural or "slow violence $^{8 "}$ are those vulnerable groups of people, also called "disposable people" by Kevin Bale (Nixon, 2011: 4).

There is no peaceful future without breaking the chain of the vicious cycle of violence, which causes infinite conflicts. Therefore, without a social system that is "layered, redundant, resilient, robust, and proactive", efforts to maintain a sustainable ecosystem will easily fail since a weak system is not able to efficiently share feedback in order to strengthen the system (Shifferd, 2011: 173 in Amster, 2014: 38). Moreover, without transforming environmental conflicts by peaceful means, there is no future where humans peacefully coexist with each other and with nature.

Consequently, what must be highlighted is that peace cannot be achieved without environmental security or a sustainable environment (Barnett, 2007), but neither the well-being

\footnotetext{
${ }^{8}$ It is a term created by an environmental literature scholar Rob Nixon through his book, Slow violence and the environmentalism of the poor. And, the term means "a violence that occurs gradually and out of sight, a violence of delayed destruction that is dispersed across time and space, an attritional violence that is typically not viewed as violence at all" (2011:2).
} 
of societies cannot be achieved without environmental sustainability (de Soysa, 2002). Following that, in order to create peace, it requires "creating whole culture" that provides (Shifferd, 2011: 110):

Attention to justice and fairness, to conflict resolution, to governance at all levels down to the very local, to the way in which our media need educating, to issues of ecological justice and human rights, to gross economic inequalities that distort the body politics, to the behavioral outcomes of religious belief, to the way in which we structure our families, to our educational system and so forth.

In order to shift the world toward a more peaceful and sustainable future, the critical question is how to break the vicious cycle of violence. In order to transform conflicts and to succeed in the peacebuilding process, which is "a complex task" and "an overwhelming challenge" (Lederach, 2005: 31), what is ultimately required is a "fundamental change in our way of thinking" (Lederach, 2003: 4). This means that normalized violence (for example, the economic system that requires environmental destruction and human exploitation) needs to be questioned first. Then, "the web of relationship" (Lederach, 2005: 78) that creates "social fabric, relationships, and relational spaces" (ibid.: 76) will be observed to understand the root of the violence and to move forward to a positive future. In this sense, conflicts, in general, can be seen as "life-giving opportunities for creating constructive change processes that reduce violence, increase justice in direct interaction and social structures, and respond to real-life problems in human relationships" (ibid.: 14).

\subsubsection{Understanding Interconnectedness within the System}

In order to successfully change the paradigm, it is critical to be cautious of being simplistic and superficial when observing and analyzing the complicated society since reality is complex. If we are not careful, our future will be the slave of the past and no change will be 
possible (Lederach, 2005: 39). Thus, acknowledging the complexity of the issue and understanding the different roles of the actors is crucial to see the picture outside of a hegemonic framework. Life is interdependent, and we live in a world where all beings influence each other. Therefore, to deal with the ecological crisis, the whole unequal violent system that is deeply interconnected with a violent culture must be challenged entirely.

For instance, even after applying sustainable development in world politics for more than 40 years, the ecological crisis has not been eased. Thus, humanity faces severe environmental threats under global warming. Climate change is not just an environmental threat, but it is a matter of surviving that is influenced by socio-economic issues. Hence, it is an indispensable process to observe the full picture of how everything is interconnected.

Various studies show that global warming is caused by the 'Northern' lifestyle that promotes excessive consumption. The truth is that twenty percent of the world population consumes eighty percent of natural resources (Norberg, 2003). And to maintain a luxurious lifestyle, a few economically advanced countries attain natural resources through the direct violence of war for nature. This means that it is impossible for the rest of the countries to reach the life standard that few rich countries practice. As Mahatma Gandhi said, the Earth provides enough to satisfy everyone's needs, but not everyone's greed. To meet this greedy expectation, we would need a few more earth.

In order to maintain the extreme wealth of a few countries, having a strong military force to enforce and maintain the structural violence (an unequal system controlled by imperial power), is thus of necessity. As State Department Policy Planning chief George Kennan confessed in 1948, "with $50 \%$ of the world's wealth and a position of power and security 
without historical parallel, the "real task" for the U.S was 'to maintain this position of disparity,' by force if necessary" (Chomsky, 2006: 91).

The U.S and the E.U are not free from the responsibility for many wars. In reverse, strong militarism is only possible based on wealth. For example, the U.S military budget in 2015 was 598.5 billion dollars, or 54 percent of all federal discretionary spending (NPP, n.d.). The U.S military budget (in 2015) was almost the same size as the next seven largest military budgets combined (ibid.). In other words, the U.S war industry has a strong power over society and politics.

The example of global warming clearly shows how all the different social, environmental, and economic issues are interconnected as one. There is no one who can completely understand what could happen as a result of global warming since the process is so complex that it is too overwhelming to understand all the changes at the current moment. In fact, often it is impossible to clearly see where we stand even if the current situation is harmful to the existence of the current living beings within nature or to the future generations.

It is indeed a challenging process since there is no decision that can rely on complete information as some uncertainty inevitably remains (Seidl, 2004). The existing social system clearly influences the decision-making process as every decision is influenced by earlier decisions and has an effect on later decisions (Seidl, 2004). Thus, there are fewer possibilities of including the voice of the marginalized groups as long as a certain social system that benefits certain specific groups exists.

Through the process of industrialization/modernization, influenced by Cartesian thought, human-beings have righteously objectified and dominated nature. In this modern 
society, the human species considered nature simply as a resource, whereby separating themselves from the natural world justified the whole cycle of violence. Furthermore, within the current system, 'rational' human beings replace the idea of God with the belief that scientific technology will solve all problems, thus believing that the rational mind can control the whole natural system.

In relation to that, it is perhaps appropriate to pose these two questions at this point: "what exists and how are we in relationship to it?" (Lederach, 2005: 111). John Lederach highlights the importance of observing the situation through the "web watching" that creates relational spaces and holds "the center of social change" while finding, understanding, and relating to the webs that exist (Lederach, 2005: 112). As this way of thinking focuses on the relational space of how everything interacts with each other, and through space, it requires shifting the perspective from measuring objects to mapping the relationships/patterns by thinking in terms of context and process (Capra, 1997).

Accordingly, in this way, the Cartesian way of thinking, which isolates humans from the rest of the worlds, is challenged; the "web of life" can help demonstrate how human beings are related to each other and to nature within the modern society that lacks the knowledge of interconnectedness. In relation to this, Martínez Guzmán suggests recognizing “other space in which humans and communities live, with their own narrative expressions and ways in which they nurture human and environmental relations" (2008: 38).

\subsubsection{Environmental Justice Perspective for Environmental Sustainability and Peace}

As a consequence, the purpose of peace research must be to create conditions for the culture of peace in which people "have the skills to resolve conflicts and struggle for just non- 
violently, live by international standards of human rights and equity appreciate cultural diversity, and respect the Earth and each other" (Hague Appeal for Peace Global Campaign for Peace Education, 1999 in Salomon, 2009: 107). In fact, culture plays a crucial role by justifying and legitimizing direct and structural violence as cultural violence makes people blind from seeing the violent act of fact (Galtung, 1990), thus reaching culture of peace is unquestionably the ultimate goal.

For that matter, what peace researchers must explore now is the knowledge of making peace(s) (Forastelli, 2013). Therefore, the pax economica mostly represented as the elite peace must be questioned and the history/story of people's peace that struggled to maintain their peace must be included (Illich, 1982). Many mainstream historians make history "appear as a tale of war" while the people's peace is "left in a zone of deep shadow" (Illich, 1982: 55, 56).

The mainstream history proves that it is extremely difficult to go against the hegemonic discourse given the power inequality. Nevertheless, another side of history reveals the resistance of the marginalized for their peaceful existence. Perhaps the best way to fight against injustice is by responding and acting directly. As Martínez Guzmán further (2008: 31) explains,

Our conception of human beings for making peace acknowledges that the creation of one's own personal identity always derives from an interaction with other identities or human groups. Every human being or every people of humankind is not an absolute identity enclosed within itself. The fear that can be produced by this interdependence to create our own identity can lead us to violent behaviours that are part of the human condition. Nevertheless, it can also lead us to organise our lives personally and politically starting from the awareness of our humility, earthliness and fragility, from which we can peacefully face the transformation of the conflicts that interdependence might generate. 
In relation to this, applying the concepts of the environmental justice movement within mainstream sustainable development is critical since the movement introduces new perspectives, which possibly challenge the existing system. The movement focuses on groupbased justice, which is directly connected to individual well-being. Besides, as the environmental justice movement focuses on people (mostly the marginalized groups) and communities that face environmental risks, nature is often revealed as an essential basis of the community. Various studies show that indigenous communities perceive the environmental crisis as a threat to themselves and their communities (Schlosberg, 2007). And, even if it is not the case at the beginning, on the process of the movements, activists often are aware of the spaces as where they live as a community member, thus express their relationship to the environment and among themselves.

Through the environmental threats and conflicts, the activists perceive the violent reality and critically reflect on the interconnected relationship of all things while questioning the current lifestyle that must be transformed toward a peaceful future. In other words, the activists challenge the neoliberal economic ecosystem even though the government often rejects the ideas of alternatives suggested by the activists. Consequently, the sustainable development discourse must be exposed and questioned enough for the system to open up and adopt a new philosophy that contains different ethics and values. In order to break the vicious cycle of violence, alternatives to the violent normality must be revealed and explored, and for that, as many different voices as possible need to be heard.

On that journey, we need to recognize the causes of isolation and exclusion that detach us from learning how to be integrated and how to dialogue with people, and the environmental justice perspective could be playing an important role by providing valuable lessons. The 
environmental justice perspective in a way shows us how important it is to learn how to peacefully exist within Mother Nature. It is perhaps the only way to save ourselves, but also to serve other lives of the life cycle. Without this essential work, no peace nor a (sustainable) future can be promised.

In fact, even though classical historians have been mainly interested in the history of war and the powerful, peace has been saved through the struggle of the powerless, including slaves, peasants, and social minorities and so forth. And, what these inspired movements have concluded is that "Peace is therefore not a natural condition of humans, it is something that people have to work at and achieve in order to minimize the amount of incompatibility. It does not exist in itself, it is attained" (Munene, 2009: 219).

Peace philosopher Francisco Muñoz further proposes the notion of imperfect peace that sees peace as a process, an unfinished road as "No podría serlo de otra manera, las realidades sociales y ambientales $<<$ evolucionan $>>$ continuamente, las formas conflictivas también” [In English: social and environmental realities are continually "evolving" as are the forms of conflicts] (2001: 17). As Gandhi famously announced, there is no road to peace, peace is the road. This could be interpreted that peace is the constant practice of the peaceful idea that we have learned day by day. In fact, "peaces are a constant incomplete process to build human relations through peaceful means (Martínez Guzmán, 2008: 36), and each of us has the ability to live in peace since peace simply begins with us as Thick Nhat Han (2008: 6) also highlights:

We all have a great desire to be able to live in peace and to have environmental sustainability. What most of us don't yet have are concrete ways of making our commitment to sustainable living a reality in our daily lives. We haven't organized ourselves. We can't only blame our governments and corporations for the chemicals that pollute our drinking water, for the violence 
in our neighborhoods, for the wars that destroy so many lives. It's time for each of us to wake up and take action in our own lives.

In order to change the world, it is important to remember to collect from the different communities their knowledge and skills of to live peacefully together among each other and within nature.

\subsection{Conclusion}

This chapter mainly observes how and why presenting the topic of environmental sustainability is compulsory within a peace studies perspective as healthy nature is the most basic requirement for well-being and peaceful existence. In other words, the chapter justifies why it is necessary to look for alternatives to the sustainable development discourse, and examines the possibilities of applying an environmental justice perspective.

By understanding different concepts and approaches to peace and violence, the necessity and importance of including the matter of environmental sustainability within a peace studies perspective has been explored. Furthermore, peace studies provides a critical perspective for transforming conflict by peaceful means in order to ultimately reach a culture of peace. In order to do so, Martínez Guzmán suggests including different pieces of knowledge to make peaces, and the environmental justice perspective, which includedes the marginalized voice, could be an efficient tool to enhance peace and justice. 


\section{PART II}

Case Study - The Miryang Movement in South Korea 


\section{CHAPTER FOUR}

\section{Situating South Korea in the Sustainable Development Debate}

\subsection{Introduction}

South Korea began the modern development process in 1962 with the Ulsan industrial complex, which was extolled by the media as "the symbol of prosperity" (Kim, 1994: 190). Since then, the industrialization process has intensified in South Korea especially during the $60 \mathrm{~s}$ to $80 \mathrm{~s}$. Therefore, South Korea had a late start in adopting the sustainable development paradigm, especially compared to the countries in the Global North. However, even then it seems that South Korea struggles to adopt the essential principles of sustainable development. Consequently, in this chapter, I will examine how South Korea has struggled to embrace the discussions and practices of sustainable development.

For that, in the first section, the general characteristics of the development process in South Korea will be observed. By briefly investigating the general development process and its characteristics in South Korea, how environmental problems have been treated will be observed. What has been required through the development process in South Korea seems hindering the idea of sustainable development to be adopted and practiced. Therefore, for the next section, how the sustainable development discourse has been adopted in South Korea will be analyzed, specifically by examining the Green Growth policy. In order to examine the paradox of the sustainable development discourse applied in South Korea, the energy policy of Green Growth will be precisely scrutinized. For the last section, the limits/challenge of applying the sustainable development discourse within South Korea will be investigated by exploring the political and economic influence on sustainable development policy. 
Understanding this context will be crucial to comprehend the process and consequences of the Miryang conflict explored in depth in Chapter Five.

\subsection{General Characteristics of Development Process in South Korea}

Korea was under brutal colonial rule by the Japanese from 1919-1945 and only five years after the end of WWII was torn apart by a dreadful civil war that led to the division of the country into North and South Korea. Following the merciless colonization and subsequent division of the Korean peninsula, South Korea experienced despairing economic threats, while the situation in North Korea was initially better off by taking advantage of the abundant natural resources and the remnant infrastructure that the Japanese colonizers constructed to efficiently control the Korean peninsula for resource extraction and exploitation. Accordingly, South Korea had to start all over from the ground, which was a difficult circumstance in general.

However, with the hope of "the new era of development" that supposedly brings prosperity and peace (Esteva, 2010: 2), South Korea had ambitiously initiated the development process. A successful development process was extremely essential since it is the ultimate way to protect the nation's security from the constant threat of North Korea but it was also believed to be the only way to overcome the misery of the devastated nation. Therefore, in South Korea, the development process was mainly led by the state authority that controlled and manipulated the market system.

Following that, there was absolute government support for South Korean industries, which on one hand was indeed advantageous for the industries to survive the harsh international competition (Duffield, 2014). And, it was believed to be the most effective way to support the economic development process in South Korea (Lee et al., 2014). As a result, South Korea 
achieved rapid economic growth and became one of the leading economies of the world (ranked as $12^{\text {th }}$ in 2020).

However, pursuing such economic development process eventually legitimized every injustice (e.g., dictatorship, social-oppression) that the government committed in the name of 'successful' economic development (Lee, 2016). In the interim, thus, Korean society put less importance on other important values (e.g., healthy environment, human rights), whereas the necessity of economic growth was excessively underlined. Furthermore, the culture/norm produced by the conventional development system makes unseen the dark side of the 'successes' of this system.

\subsubsection{Characteristics of South Korean Development Model}

The devastating civil war right after the painful colonization, in the end, caused unforgettable trauma for the whole nation. Therefore, to ensure rapid but successful economic growth, the state was granted vast authority to control the economy. Accompanying that, the state provided an attractive business environment for the investors while investing time and money for technology innovation. Furthermore, the state put extra attention to develop highly educated/skilled workers. More importantly, there was a widespread desire among the public for a successful and prosperous future.

Following that, South Korea has achieved remarkable economic growth in less than three decades that is called the miracle on the Han River. The success story of South Korea is noteworthy as it brought many positive changes to the country that rapidly transformed from an impoverished state to one of the strong economies of the world. 
However, due to the rapid economic growth, South Korea has developed a distinctive development model that causes social-environmental issues. The most unique feature of economic model in South Korea is high economic dependency on Chaebol that indicates a "large conglomerate formed by cross-worship and often under one family's control" (Business Dictionary, 2018). Bureaucratic capitalism that was the product of the corrupt relationship between the government and capital accumulation of the elite group has been strongly rooted in South Korea (Lee, 1990). Thus, South Korea shaped an abnormal economic model that highly depends on a few big companies (e.g., Samsung, Hyundai, LG, Posco, SK, and so on), whereas most elite groups of society took advantage of the unequal distribution of resources.

In fact, South Korea has been accumulated the nation's wealth by securing the maximum profit of these few major companies. Accordingly, Chaebol monopolizes the Korean economy, contributing about 90 percent of the nations' GNP, Gross National Product (Business Dictionary, 2018). Such a result is not conceivable without the unconditional support of the government that excessively focused on chrematistic growth (measuring GDP or GNP), rather than being concerned about the distribution of the wealth/benefits and burden for the people, especially for those who suffer the most.

For example, all the government-led projects, specifically constructing energy system, were legal based on the law of the Act on Special Cases Concerning Electric Source Development, which gave the state carte blanche to take private lands without the agreement of landowners (Lee et al., 2014). Such a law enacted in 1978, at the end of Park's dictatorship (1961-1979), was considered as an indispensable device for a development-oriented country, and it perfectly justified all sorts of violence carried out in the name of the nation with legal support. 
The state authority of South Korea exactly followed the hegemonic idea of development as Lewis's 1995 dictum shows; "first it should be noted that our subject matter is growth and not distribution" (Esteva 2010: 8). Doing so, the remarkable economic growth in South Korea has, in a big part, relied on the expense of the powerless, those who went through the painful marginalization process.

\subsubsection{General Energy Policy in South Korea}

A stable energy system is the basis for building an industrialized and modernized nation. Especially for a resource-poor country like South Korea that imports 97 percent of the required energy, which thus causes low energy self-efficiency (UNEP, 2009), supplying a stable energy system is critical for stable economic growth. Thus, in South Korea, constructing independent energy facilities has been an extremely important matter for the country to prevent energy shortages, particularly after experiencing a blackout ${ }^{9}$ in 1948 . Besides, the economy of South Korea depends highly on energy-intensive industries, such as petrochemical, shipbuilding, and automobile industries (Hermanns, 2015).

Thus, stabilizing the energy supply system has been one of the biggest challenges for South Korea to successfully achieve the intense modernization and industrialization process. As a result, the control and allocation of the power plants-were chosen strategically by the government, taking into consideration the industry, commerce, and households of each region, as well as the feasibility of transmission facilities, such as transmission lines and towers. Therefore, provinces like Gyeongsang (south-east part of South Korea) with a massive

9 On May 14, 1948, South Korea experienced a blackout after North Korea suspended the power supply to the South as sixty percent of the country's electricity power relied on the North (Jungang daily, 2001). 
industrial complex were considered to need more energy compared to other provinces (Lee et al., 2014).

For the successful development, the South Korean government implemented different energy resources, coal in the 1950s and oil from the 1960s, in order to overcome the energy poverty that hinders the national development process (Boo et al., 2013). The use of oil greatly benefitted Korea's economy even though two oil shocks in the 70s and the 80 s alarmed the issue of energy security (ibid.).

Given these uncertainties with oil, the use of nuclear energy has been raised as a possible alternative. Since the 1950s when the President of the U.S Eisenhower delivered the speech "atom for peace" to support "the peaceful use of nuclear energy," nuclear energy has been considered a "dream energy" with limitless availability" (Boo et al., 2013: 51, 52). For South Korea that had experienced severe energy poverty and energy threats, supporting nuclear energy was a great opportunity. For that matter, the introduction of nuclear energy technology became the main national policy from the president Seung-Man Rhee (the first, second, and third president from 1948-60) who invested to develop nuclear energy technology (Boo et al., 2013). Based on the ground established since then, accordingly, the era of nuclear energy officially started with the first nuclear plant in Gori (Gori Unit One) that was built in July 1978 (Boo et al., 2013).

Besides that, even after the oil price has been more secure since 2000, South Korea has been searching for alternative energy sources to reduce dependence on oil, which has to be imported and causes energy insecurity that ultimately has an impact on South Korea's economy. As the UNEP report (2009) points out, when oil prices went up to around 150 USD per barrel 
in 2008, South Korea had to spend one-third of the total revenue from exports. Thus, after the 2008 world financial crisis, South Korea's growth rate fell down to below four percent (ibid.). Added to that, since the 1990s, the worldwide concern for environmental degradation shifted the energy policy in South Korea toward cleaner energy sources that cause less environmental degradation, particularly reducing $\mathrm{CO}^{2}$ emissions while increasing energy efficiency (UNEP, 2009). In actuality, South Korea is the seventh-largest greenhouse gasses emitter and also ranked as the fifth-highest $\mathrm{CO}^{2}$ emitter per capita in 2017 (Union of Concerned Scientists, 2020). Moreover, the average temperature went up around 1.74 degrees from 1912 to 2008 while the sea level rose by $22 \mathrm{~cm}$ during the last 40 years (UNEP, 2009).

Thus, the government started focusing on high-efficiency energy resources like thermal and nuclear power energy (Lee et al., 2014). As a consequence, since the 1980s, dependency on nuclear energy has increased steadily as the technology of nuclear energy manufacturing has advanced in South Korea. Through these elaborate efforts, by 2012, South Korea celebrated owning the complete technology of producing nuclear energy, from designing to operating nuclear power plants (World Nuclear Association, 2019). There are currently (last checked in August, 2020) 24 nuclear energy reactors and four more reactors under construction (see Figure $\left.4.1^{10}\right)$.

${ }^{10}$ Currently (September, 2020), Wolseong power plant No. 1 was permanently shut down on 24 December, 2019. However, Shin Kori power plant No. 4 began commercial operation on 29 august, 2019. Thus, there are total 24 nuclear energy reactors, but 4 more reactors are under construction (different from the Map 4.1.) since the construction of Shin Kori power plant No. 4 has completed in 2019. 
In conclusion, for a resource-poor country like South Korea, it was believed that the most 'effective' and 'cheapest' way of securing energy was by promoting nuclear power energy even though there have been wide debates and concerns about using nuclear power energy.

Figure 4.1. Location of Nuclear Plants in South Korea

\section{Nuclear Power Plant Status}

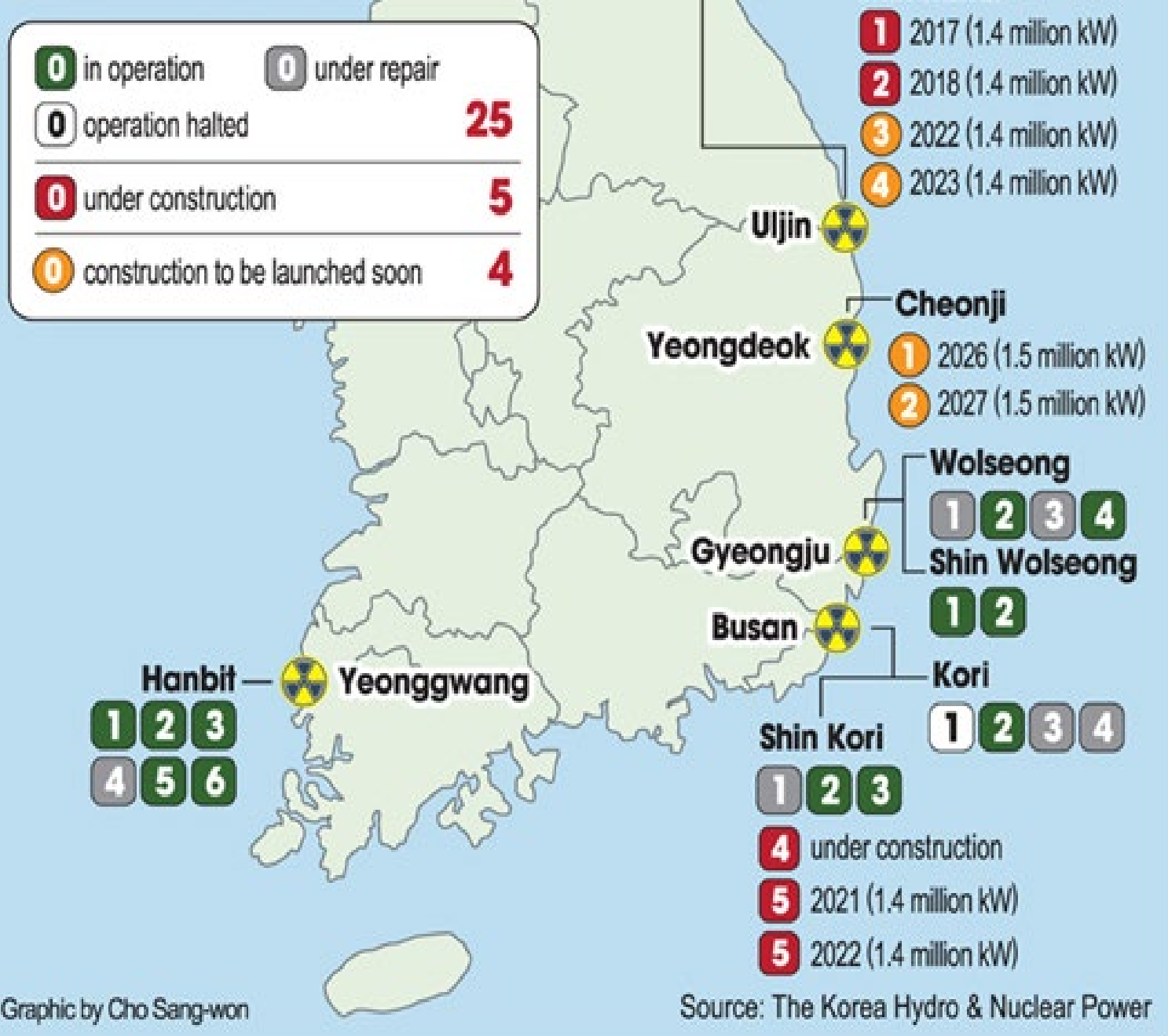

(Lee, 2017c) 


\subsubsection{Producing 'Cheap' Labor}

At the beginning of modernization and industrialization, South Korea lacked natural resources and basic infrastructure, including energy facilities. Thus, to be successfully developed, the government in a way provided 'cheap' labor for the industries that had to compete in a harsh environment. In the end, it was the minority groups of the society (e.g., young women, farmers, people with disabilities, the poor, etc.) that became the 'cheap' labor used for the industries to lead the successful development process. In other words, those people simply became a commodity working under extremely poor labor conditions (with a low wage for long hours), especially during the dictatorship era, for the nation to be effectively developed.

More specifically, to provide cheap labor for the industries, it was necessary to displace young farmers from rural areas, which was made possible by collapsing rural livelihoods. The statistics indeed illustrate how harsh the reality was for the farmers as a result of the government's “double grain price system” policy. Officially the policy was supposed to benefit all the citizens, including farmers; however, the reality was quite different. The objective of launching the 'double grain price system' was to protect the farmer's income by providing a stable price for the rice consumers as the government has the authority to set the price. Theoretically, throughout the double grain price system, the state buys rice directly from the farmers and sells it to the customers so that the price of the rice can be controlled and stabilized. This ensures that the price of rice does not get affected by the market, thereby protecting both farmers and rice consumers.

Nevertheless, because the policy set the price of rice excessively low, the income of farmers decreased while increasing the debt of each farmer (Kim \& Seo, 2015). Accordingly, each farmers' Gross National Product out of a total per capita steadily decreased from $74.3 \%$ 
in $1961,62.7 \%$ in 1970 to $55.8 \%$ in 1979 . On the other hand, the debt of each farm household increased from 29,500 won (about 30 USD) in 1971 to 170,600 won (about 170 USD) in 1976, and 808,400 won (about 800 USD) in the 1980s. This also affected grain self-sufficiency which decreased from 86.1 percent in 1970 to 79.1 percent in 1975 while food dependency increased from 15 percent in 1968 to 26 percent in 1978 (ibid.).

Consequently, even if the intention might be good, the policy became the main reason for the collapse of the rural economy (Jungang daily, 1987). Therefore, after the double grain price policy, unfortunately, the independence of the rural economy had completely shrunken. It is because the government could not possibly set up the high price of grains since the economic model that South Korea adopted during the 1960s and the 1970s was premised on 'cheap' labor. In other words, South Korea's remarkable economic growth has been built on the sacrifice of the rural economy and livelihoods. Followed by the collapse of the rural economy, a rapid population decline took place in rural areas even as the total population of South Korea increased from 32,241,000 in 1970 to $38,124,000$ in 1980 . This means that the rural population became increasingly aged. For instance, about 6.8 million moved to the city during the decade from 1965 to 1975 (Ah, 2007) while the population rate rapidly increased in big cities.

In such a process, those farmers from rural areas became one of the main sources of cheap labor that worked an average of 12 hours a day under extremely harsh working conditions that eventually threatened their health and well-being, all in the name of the country's economic development. In order for South Korea to join the league of 'developed' nations, exporting comparably cheaper industrial products was considered the most effective and realistic option for South Korea, especially during the 1960s and the 1970s. For that, 
providing 'cheap' labor was believed to be indispensable by the government of South Korea, even though the 'cheap' labor meant sacrificing someone's life and their right to be human.

\subsubsection{Environmental Protection? Economic Growth!}

While South Korea was exclusively obsessed with economic growth, environmental concerns were put to the side. Intensification of the country's industrialization inescapably accelerated ecological problems through the 1960s and 1970s when heavy chemical industries developed. However, these problems remained in silence while South Korea was proudly hailed the "Miracle of the Han River" or the "Four Asian Tigers". The country's GDP increased rapidly especially under the developmental dictatorship as economic growth was the utmost goal to be achieved. Therefore, despite the high cost to nature and the livelihoods of people, especially for the minority groups, the nation was seemingly satisfied with achieving a remarkable development process in such a short period of time.

During the developmental dictatorship, improving environmental conditions was suggested as the environmental situation had worsened through the economic development process. Thus, some remedies were proposed and applied to fix the issue but it was rather limited and superficial. For instance, the Environmental Pollution Prevention Act was enforced in 1963 , but the organization to execute the law was not established until 1967. This means that South Korea offered momentary and symbolic responses to issues of environmental degradation. As the government centralized power to promote the country's development, the issue of environmental degradation never became the main concern for society. There were only very 'minimum' attempts to prevent environmental degradation so that the country's economy could grow incessantly. 
Besides, there was a widespread faith that economic growth is the best tool to protect nature (Kim, 1994), which is coming from the belief that the main cause of environmental degradation is poverty. This assumption is keenly related to the idea of the Environmental Kuznets Curve (EKC) (see Figure 4.2) that outlines the close relationship between national income and environmental degradation: economic growth ultimately leads to environmental improvements (Grossman \& Krueger, 1991).

Figure 4.2. Environmental Kuznets Curve

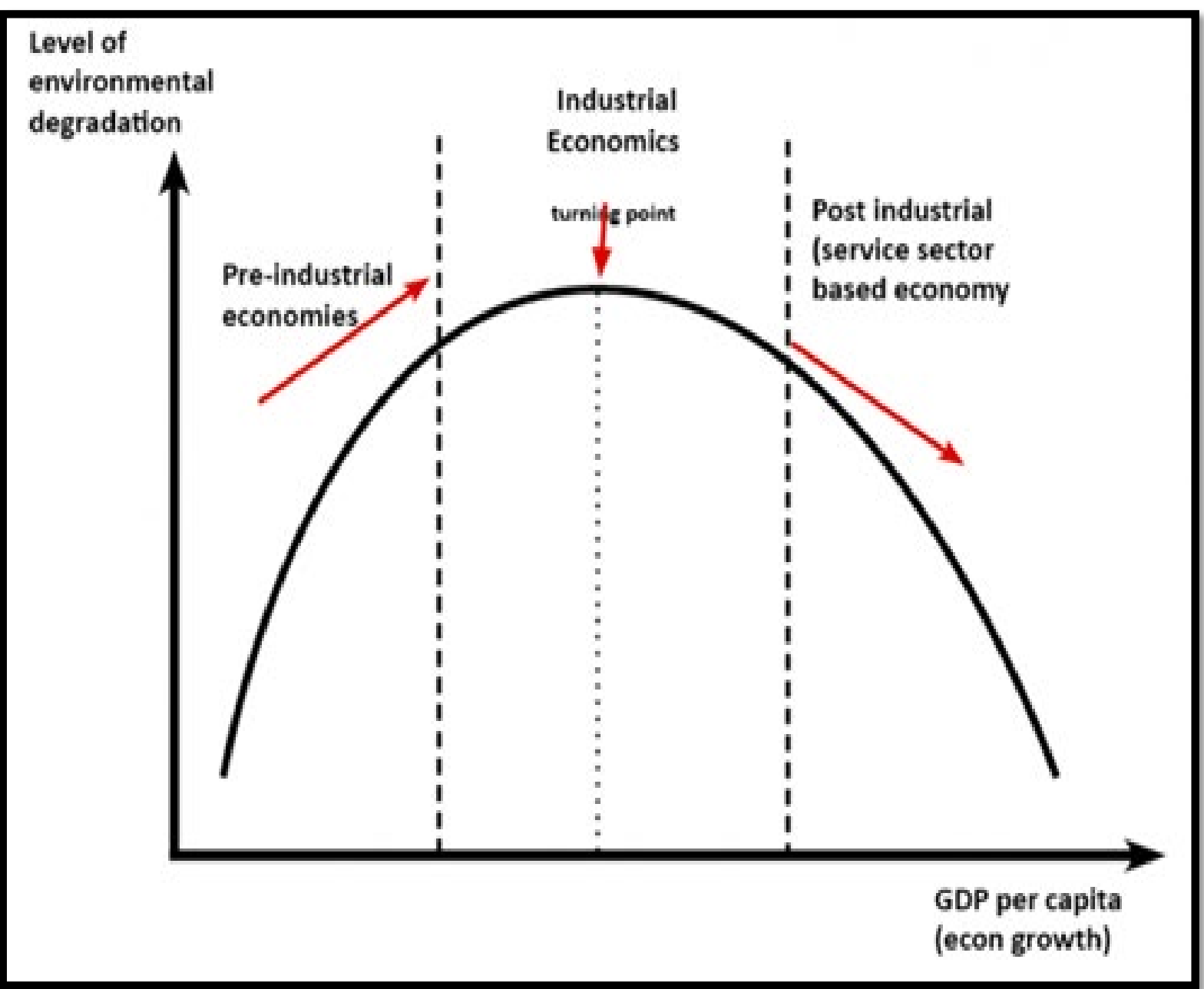

(Pettinger, 2017) 
Several countries, including South Korea, proved EKC accurate although the example countries, including South Korea, also demonstrated that it is accurate only up to a certain point. In the specific case of South Korea, the 1995 Environmental Statistics Yearbook (Ministry of the Environment Republic of Korea) reveals that the Gross National Product (see no. 2 of the statistics yearbook) increased about twice from 1989 to 1994. Meanwhile, it shows that air qualities in major cities (see no. 3 of the statistics yearbook), water qualities in major rivers (see no. 5 of the statistics yearbook), and water quality in major coastal areas (see no. 8 of the statistics yearbook) progressed even though some factors do not demonstrate the distinctive differences (Ministry of Environment Republic of Korea, 1995: 16-21, 23).

The idea of EKC seems to fit well in the real examples up to a certain point; however, the idea soon faced condemnation, specifically to its theoretical ground. First, there are many more factors to consider than what EKC focuses on. The classic version of EKC measured only limited types of pollutants. Furthermore, to prove EKC accurate, there must be an assumption that the classical way of economic growth is sustainable or environmental damage does not influence economic activity, otherwise, the hypothesis is proved counterproductive (Stern, 2004).

However, as the Club of Rome pointed out in 1972, the classical economic model will reach the limits of growth (Meadow et al., 1972). Besides, once South Korea reached a certain level of economic development at the beginning of the 1990s, it simply dumped all the industrial pollutants to other 'developing' countries (e.g., China). This 'strategy' was already widely practiced and still is practiced by 'developed' countries that export all the pollutant industries to 'developing' countries that cannot refuse the 'opportunities to grow'. More importantly, the world GDP has increased, but ironically, the world has been challenged by 
never before experienced environmental problems each year. Consequently, it shows that the close relationship between economic growth and environmental improvement cannot always be confirmed, unlike what the theory wants to prove.

To sum up, it is apparent that the current economic growth paradigm cannot be maintained nor sustained because it inevitably causes environmental exploitation since the environment is indispensable in the logic of classical economic growth. The current economic growth paradigm, in the end, does not solve the issue of environmental degradation, nor the issue of poverty, which was considered the main cause of environmental degradation. This is the case at least in South Korea where constant environmental issues (e.g., fine dust problem) have emerged after self-praised 'successful' economic development.

\subsection{Sustainable Development in South Korea}

During the developmental dictatorship in South Korea, environmental movements were considered an anti-governmental action (Kim, 1994). However, meanwhile, people were getting more aware of the importance of living in healthy nature. Thus, environmental concerns became a bigger issue for society and received more attention from the citizens since environmental issues were rapidly escalating and affecting the livelihoods of more and more people in South Korea.

Consequently, in the 1980s, there was the anti-pollution movement, and there were different civil organizations launched, including Research Institutes of Pollution, which was established in 1982. Furthermore, various environmental movements highlighted environmental pollution and its harm to humans as well as non-human beings. On top of that, 
since 1987, the political situation has changed completely from the developmental dictatorship to a democracy.

With the onset of democratic government, environmental movements escaped from the stigma of anti-society and anti-government, which in a way supported and promoted more active environmental movements (Kim, 1994). Such a change also led to institutional arrangements. For instance, a constitutional amendment in 1987 proposed including the environmental right (Article $35^{11}$ ), which indeed is rare to be contained within the Constitution. In addition, the ministry of environment was finally established in 1994, but also numerous environmental movement organizations were formed since then and actively engaged in various environmental conflicts. And then, finally, following world politics and international pressure, the issue of sustainable development became a political agenda in South Korea as well.

\subsubsection{First Encounter of Sustainable Development in South Korea}

It was the 1992 United Nations Conference on Environment and Development that finally influenced South Korea to pay attention to the debate on sustainable development. Agenda 21, which is considered a "sustainable development bible" (Doyle, 1998: 771), was applied in South Korea under the global governance that is supported by various institutional mechanisms to solve environmental problems more effectively (Drexhage \& Murphy, 2010; Redclift, 2005). Accordingly, South Korea seemed to eagerly adopt the idea of sustainable development. For that matter, the "National Declaration for Environmental Protection" was

\footnotetext{
11 Article 35 (1) All citizens shall have the right to a healthy and pleasant environment. The State and all citizens shall endeavor to protect the environment. (2) The substance of environmental rights shall be determined by Act. (3) The State shall endeavor to ensure comfortable housing for all citizens through housing development policies and the like.
} 
adopted in 1992. Meanwhile, the will of the government was also highlighted by raising the environmental department to the status of a ministry in 1994. Furthermore, more sustainable development-related acts/policies followed: local governments of the country applied Local Agenda 21 since 1995 to promote sustainability at the community level; the presidential committee on sustainable development was established under a presidential advisory body in 2000; the 'Framework Act on Sustainable Development' was enacted in 2007 (Kim et al., 2014).

Since the environmental movement became noticeably vitalized, the various campaigns started to influence government policies and corporate directions (Jin, 2007). Moreover, the debate over sustainable development has been initiated widely within academic circles. Correspondingly, there was a widespread belief and expectation of South Korea to be a successful sustainable development nation (ibid.), while experiencing comparably cleaner air and water, for instance, within the society especially after the 1990 s.

Nevertheless, the statistics prove that South Korea has not improved the country's sustainability effectively. For instance, the 2002 World Economic Forum reports an awful result of South Korea's sustainability that ranked 135 out of 142 countries on the Environmental Sustainability Index (ESI) although some scholars questioned the way the ESI was measured. Even though South Korea improved its ranking to 122 in the 2005 measure, it definitely indicates the unsustainability of the nation. According to Jin (2007), the outcome was shocking for South Koreans who perceived the reality 'differently', but yet, ironically, most people were not willing to change their pattern of consumption even after they understood that the overall environmental conditions had worsened (ibid.). 
The irony of the citizens indeed shows that the social response was limited due to immediate and superficial advantages of the consumption economy (Jin, 2007). Besides, in South Korea, some scholars and environmentalists who criticize the mass production economic system, which noticeably undermines environmental sustainability (thus, ultimately sustainable development), were seen as 'extremists' (ibid.). Therefore, at this point, what must be queried is if South Korea has actually been putting any meaningful and practical efforts to reach environmental sustainability.

South Korea and the corporations in South Korea, in actuality, had essentially no choice in whether to practice sustainable development or not since the liberal environmentalism was strongly influenced by world politics and economy since 1992. In other words, it is rather necessary to change corporate-related activities in South Korea since the nation's main economy is heavily dependent on export. It means that the corporations in South Korea finally have realized and accepted that environmental costs must be included in the production expense. Furthermore, as South Korea became a member of OECD in 1996, it put extra pressure on South Korea to follow the world's powerful discourse, sustainable development (Jeon, 2009). In sum, sustainable development turned into a core policy in South Korea due to the pressure of world politics.

The best way to accomplish "the principles of equity and living within ecological limits" is by redirecting social, political, and economic systems toward the sustainability that "integrated each other and the environment" (Prizzia, 2007: 21). However, instead of challenging the nation's structure, South Korea was continuously concerned over how to maintain (if not improve) economic benefits throughout the sustainable development process. Therefore, environmental sustainability was not significantly improved by implementing 
sustainable development policies and practices. In fact, the environmental threat has rather increased; therefore, social-environmental conflicts also have increased rapidly.

But yet, the Asian financial crisis, which happened in the 1990s made the situation even more difficult for South Korea to challenge the existing (injustice) structure. South Korea requested emergency rescue funds from the International Monetary Fund (IMF) in 1997 and then mainly had to focus on reviving the country's economy albeit South Korea was also pressured to adopt sustainability in its economic activities. Then, perhaps, such irony brought Green Growth to South Korea among many other Asian countries.

\subsubsection{The Birth of Green Growth and its Objectives}

The concept of Green Growth was made official at the fifth Ministerial Conference on Environment and Development in 2005 in Seoul, and 52 governments and different stakeholders decided to adopt 'the Seoul Initiative Network on Green Growth' (UNESCAP, n.d.). The concept was mainly promoted by the United Nations Economic and Social Commission for Asia and the Pacific (UNESCAP), the United Nations Environmental Programme (UNEP), and the Asian Development Bank (ADB) by emphasizing the necessity of a paradigm shift. Here, Green Growth (or Environmentally Sustainable Economic Growth) was recognized as a specialized policy in the region of the Asian Pacific (ibid.).

The concept of sustainable development, which highlights the balance among the three pillars of environment protection, economic prosperity, and social justice, was considered too abstract and ambiguous to be applied in the Asian Pacific region (Ahn, 2010) as sustainable development principally focuses on improving the environmental condition by imposing various regulations. However, there is a contradictory faith that economic growth is a 
prerequisite to environmental protection and social development possible for developing countries (UNESCAP, 2008).

This idea seems akin to the Environmental Kuznets Curve (EKC) although Green Growth does not support the conventional approach of EKC, "grow now and clean up later" (UNESCAP, 2006). In the logic of Green Growth, inequality and poverty cannot be solved without economic growth. Thus, enforcing regulations on economic activities will not lead to actual solutions, but worsen the environmental condition as it has been proven (UNESCAP, 2006). For instance, carbon dioxide gas emissions persistently increased even though a reduction of $\mathrm{CO}^{2}$ emissions had been promised through the 1992 Earth Summit in Rio de Janeiro, the 1997 Kyoto Protocol in Japan, and continued to the 2015 Paris Agreement.

As a consequence, Green Growth came out as a practical solution to both prevent environmental degradation (environmental protection) and boost the market economy (economic growth) (UNESCAP, 2008). And, for South Korea's desire for a pragmatic way to achieve sustainable development, Green Growth is an attractive option. Therefore, South Korea's 17th President Myung-Bak Lee (2008-2013) in a speech marking the 60th Independence Day, August 15, 2008, proposed Green Growth as the national vision. Then, 'the basic act on low carbon green growth' launched in 2008 (although the Framework Act on Sustainable Development had already been enacted in 2007) since Green Growth was considered as the most effective strategy to accomplish the goals of sustainable development in the long-run according to Presidential Council for Future and Vision announced (Kim et al., 2014). 
In the political onset, Green Growth became the major task to accomplish for the newly elected government. For that matter, the policy regime was greatly influenced. The government was eagerly involved in a debate on the climate crisis by applying specific policies, systems, and legal processes to fight the climate crisis while improving economic conditions (Yun \& Won, 2012). Accordingly, the Committee on Green Growth highlights (1) the promotion of eco-friendly new growth engines (2) the enhancement of people's quality of life by ensuring environmental sustainability, and (3) the contribution to international efforts to fight climate change. Consequently, Green Growth came as an "innovative development approach involving a fundamental shift in the country's growth paradigm, from quantitative growth to qualitative growth." (UNEP, 2009: 6)

However, in a conventional economic paradigm, environmental degradation is rather anticipated, and this is why sustainable development imposed strict regulations. In other words, it means that Green Growth must attempt to de-link the cycle of the modern economic paradigm, and eco-efficiency is considered a key answer for this fundamental paradigm shift (UNESCAP, 2009). Eco-efficiency means minimizing environmental degradation while maximizing economic benefits (UNESCAP, 2009) throughout effective policies, such as eco-tax reform, sustainable infrastructure, a greening of business, and sustainable consumption, based on technological innovations (UNESCAP, 2008: 8, 11). In this view, the core idea of Green Growth is similar to ecological modernization, which was introduced by German scholars in the late $1980 \mathrm{~s}^{12}$. Consequently, the government, in actuality, announced Green Growth as a

\footnotetext{
12 Ecological modernization, which originated in Western Europe in the 1980s (Orsato \& Clegg, 2005), provides a constructive/systematic approach to solve environmental problems grounded on scientific and technological knowledge (Mol \& Spaargaren, 1993). Thus, as Dryzek argues, there is no need to make tough choices between economic growth and environmental protection since ecological
} 
combination of sustainable development and ecological modernization (Green Growth Committee, 2009).

Ecological modernization promotes the belief of achieving both economic development and environmental protection (Mol et al., 2009). In fact, in ecological modernization, economic development improves environmental degradation although its success also depends on political modernization as a Dutch social scientist Gert Spaargaren highlights, "the central feature of the ecological modernization approach as a theory of political modernization is its focus on new forms of political intervention" (1997: 15). Despite all the criticisms, it is reasonable that ecological modernization was an attractive opportunity for the government since it underlines institutional reformation rather than radical changes, which would probably receive strong resistance from the existing power (Hermanns, 2015).

In this light, Green Growth shares several similarities with ecological modernization, both aim for economic growth that does not particularly cause environmental degradation, which could be mitigated by technological advances. However, as Hermanns demonstrates the major differences between ecological modernization and Green Growth, Green Growth indicates the "stronger focus on economic growth" instead of challenging "existing structures under ecological terms," whereas there is a lack of participation of the civil society in the process of decision making as it solely depends on economic and technocrat approaches (2015: 279).

modernization offers "a plausible strategy for transforming industrial society into a radically different and more environmentally defensible (but still capitalist) alternative" (1997: 143). 
This lack of participation of the civil society is demonstrated in the composition of the Green Growth Committee, which consisted of 18 professors (mostly majored in economics, business, and environmental engineering), five corporate-related people, three national project researchers, one lawyer, and a representative of a civic group that couldn't be regarded as a representative of whole civic groups in South Korea (Yun, 2009). As a consequence, the South Korean style of Green Growth could be seen as the "Green Revolution"” or "another version of industrial revolution" that was intensely led by the authoritative government (Hermanns, 2015: 280). For that matter, Green Growth faced several criticisms in both theoretical and practical levels, which will be examined in the following section (See. 4.4).

\subsubsection{Korean-Sustainable Development Goals (K-SDGs)}

Once the SDGs were established in 2015, the sustainable development committee in South Korea started to develop the SDGs within the South Korean context by including the diverse groups of the society and professions to discuss how to reach each goal (Sustainable Development Committee, 2019). Followed by that, the Korean-Sustainable Development Goals (K-SDGs) were established in 2018 (ibid.). Accordingly, K-SDGs exclude already existing targets and indicators from the original SDGs while adding new ones that fit into the context of South Korea.

There was a consideration of including one more goal, which would be Goal 18 founding peace in the Korean peninsula, as making peace is a critical factor to promise a sustainable future (Sustainable Development Committee, 2019). Furthermore, there were 122 
new targets and 214 indicators added (ibid.). For instance, targets $1.1^{13}$, target $2.2^{14}$, indicator 5.3.2 $2^{15}$ and indicator $8.7 .1^{16}$ are excluded for the respective reasons: the extreme poverty rate in South Korea is already very low, only 0.49 percent (1.1); South Korea is considered a highcalorie intake country (2.2); female genital mutilation/cutting has not been practiced in South Korea (5.3.2); and many other indicators are considered not suitable in the context of South Korea (e.g., 8.7.1 and more). On the other hand, there are new indicators included to improve the situation specifically in South Korea, including overcoming low-birth rates, inventing an alternative plastic material, extending sustainable development education, and so forth.

Consequently, due to the success of the K-SDGs, the sustainable development committee suggested enhancing the status of the committee. Additionally, the committee proposed to have a proper monitoring and evaluation process to regularly check on the progress, while promoting and sharing the visions of the K-SDGs in society by conducting the forum (Relay Forum) to continuously discuss the K-SDGs in-depth (Sustainable Development Committee, 2019).

By establishing the K-SDGs, the weakness of Green Growth, lacking social well-being, has been counted in. Furthermore, Green Growth Committee also has survived and has decided to exclusively focus on climate change, energy, and green industries (Sustainable Development

\footnotetext{
${ }^{13}$ By 2030, eradicate extreme poverty for all people everywhere, currently measured as people living on less than $\$ 1.25$ a day.

${ }^{14}$ By 2030, end all forms of malnutrition, including achieving, by 2025, the internationally agreed targets on stunting and wasting in children under 5 years of age, and address the nutritional needs of adolescent girls, pregnant and lactating women and older persons.

15 Proportion of girls and women aged 15-49 years who have undergone female genital mutilation/cutting, by age.

${ }^{16}$ Proportion and number of children aged 5-17 years engaged in child labour, by sex and age.
} 
Committee, 2019). At the same time, as the authentic idea of sustainable development has widely expanded (through the SDGs) under the vision of leaving no one behind based on 5P, which are People, Planet, Prosperity, Peace, and Partnership, the vision of K-SDGs also correspondingly points out the similar values (by highlighting justice and peace).

In summary, K-SDGs intend to promote a sustainable society that everyone, including future generations, could fully live a life that secures basic human rights within healthy nature along with sustainable economic development that enhances the quality of life (Sustainable Development Committee, 2019). K-SDGs truly contain significant values that the Korean society must embrace, but yet, the synchronization to the actual policies and practices to promote sustainable development is not clearly presented.

\subsection{Criticism of Sustainable Development Applied in South Korea}

There has been high pressure internationally for adopting sustainable development in South Korea, which also has been influenced negatively by environmental crises. For that, the related social-environmental conflicts have repeatedly occurred in South Korea. In other words, environmental conflicts became one of the top conflicts of South Korean society (Yun, 2011), and environmental related issues also have been treated more critically as environmental issues play a critical role to achieve social justice and a peaceful future. Thus, there have been different discussions to accomplish the objectives of sustainable development.

In the end, the Green Growth policy emerged as a "perfect solution" for South Korea. The Green Growth could be seen as the first official attempt (since it is a practical policy applied) to practice sustainable development since first, South Korea departed late in 
sustainable development history, and second, there were no practical policies led by the central government before Green Growth policy, which, unfortunately, faced various criticisms.

Those are including: (1) Could Green Growth be considered as sustainable development? (2) Is Green Growth 'really' green? (3) Is it enough to reach sustainable development based on the scientific technologies that help energy transition successfully from non-renewable to renewable energy without challenging the system? (4) Analyzing the characteristics of the Green Growth policy from the critical perspectives due to avoid repeating the same mistakes, but also to contribute the knowledge for succeeding the K-SDGs.

\subsubsection{Is Green Growth Sustainable Development?}

In a theoretical ground, some scholars argue that the concept of Green Growth must be considered as a distinctive concept from sustainable development since Green Growth exclusively highlights the relationship between securing economic growth and environmental sustainability, but disregards emphasizing on social justice, which must be included to balance with environmental sustainability and economic development (Yun, 2009; Ahn, 2010). Moreover, Ahn (2010) contends that the concept of Green Growth has been ambiguous and abstract, which creates unnecessary confusion and troubles. Accordingly, Green Growth in a narrower concept does not represent the three principles of sustainable development (Yun, 2009), whereas Green Growth can be regarded as a policy that reifies the concept of sustainable development into real actions (Lee, 2010).

In the end, it has been a polemic issue of using the concept of Green Growth to represent sustainable development in South Korea. However, despite all the valuable disputes, I believe 
sustainable development discussion, which contains a broad spectrum from weak to strong sustainability, can possibly include Gree Growth.

Sustainable development has occurred and has been discussed in world politics for more than 40 years. However, there is no consensus on what sustainable development is, and the fact is that there are more than 100 definitions of sustainable development. Thus, sustainable development has been overused, often with "misunderstood phrase" (Mawhinney, 2002: 5), and criticized as "“everything and nothing"” (Connelly, 2007: 260) seems only reasonable and accurate. On the contrary, since the term is ambiguous or (and) flexible, sustainable development could become the center of world politics. Especially after the 1987 WCED, sustainable development includes a "fuller version" that comprises social, environmental, and economic aspects, which could be beneficial as it allows embracing "a wider audience" at least from a political standpoint (Murray, 2001 in Mawhinney, 2002: 11).

According to Jacobs (1999), sustainable development is an "essentially contested concept" that nearly every group uses "the same language and endorsing the same nominal objective" (ibid.: 22). Jacobs goes on to argue that despite all the vagueness, sustainable development indeed has a unitary meaning based on core ideas; however, the 'real' challenge occurs when the concept of sustainable development needs to be defined. Therefore, as Jacobs points out, "disagreements over the 'meaning of sustainable development' are not semantic disputations but are the substantive political arguments with which the term is concerned" (1999: 26). For that, it is impossible to balance perfectly on three principles of sustainable development, including social, economic, and environment, but the triangle will most probably stay in a skewed position depending on the emphasis (Connelly, 2007). 
In the end, depending on how the power is shaped or used, defining sustainable development as being flexible can be astrength but, at the same time, a weakness. In other words, it is rather hegemonic power that has been exercised due to the claim of the definition of sustainable development.

In this light, Green Growth can be interpreted as an expression of sustainable development even though it lacks the emphasis on social justice. Besides that, the Green Growth Committee insists that the social aspect is a prerequisite to Green Growth policy even if it was not necessarily written down and emphasized. Thus, the ambiguity or flexibility of defining sustainable development provides a perfect justification for Green Growth Policy that has a subtle emphasis on a social justice aspect. Accordingly, Green Growth can be seen as one of the possible discourses derived from sustainable development.

\subsubsection{Green Growth Energy Policy: Is it 'really' Green?}

South Korea's economic model has been heavily reliant on the country's non-renewable energy resources, such as coal and oil, which might cause a high risk of locking the economy onto energy-intensive pathways, which eventually disables the long-run prosperity of the economy (Fouquet, 2016). Thus, Green Growth policy requires to successfully transform the energy policy by searching for possible alternatives, which must delink the conventional economic system.

To complete the objectives of Green Growth Policy, there are ten policy directions to follow, which include (1) reducing carbon emissions ${ }^{17}$, (2) decreasing energy dependence on oil and enhancing energy sufficiency, (3) supporting adaptation to climate change impacts, (4)

\footnotetext{
17 South Korea was predicted to cut down 130 million tons of carbon dioxide emission by 2020 (UNEP 2009:26)
} 
developing green technologies as future growth engines, (5) greening of industry, (6) developing cutting-edge industry, (7) set-up policy infrastructure for green growth, (8) green city and green transport, (9) green revolution in lifestyle, and (10) enhancing national status as a global leader in green growth (UNEP, 2009: 9).

Accordingly, the National Energy Committee (2008) in South Korea proposed a new energy plan for reducing non-renewable energy use, including oil and coal use (see Figure 4.3). Meanwhile, it includes increasing renewable energy and nuclear power energy use.

Figure 4.3. 2030 Energy Plan and Energy Mix

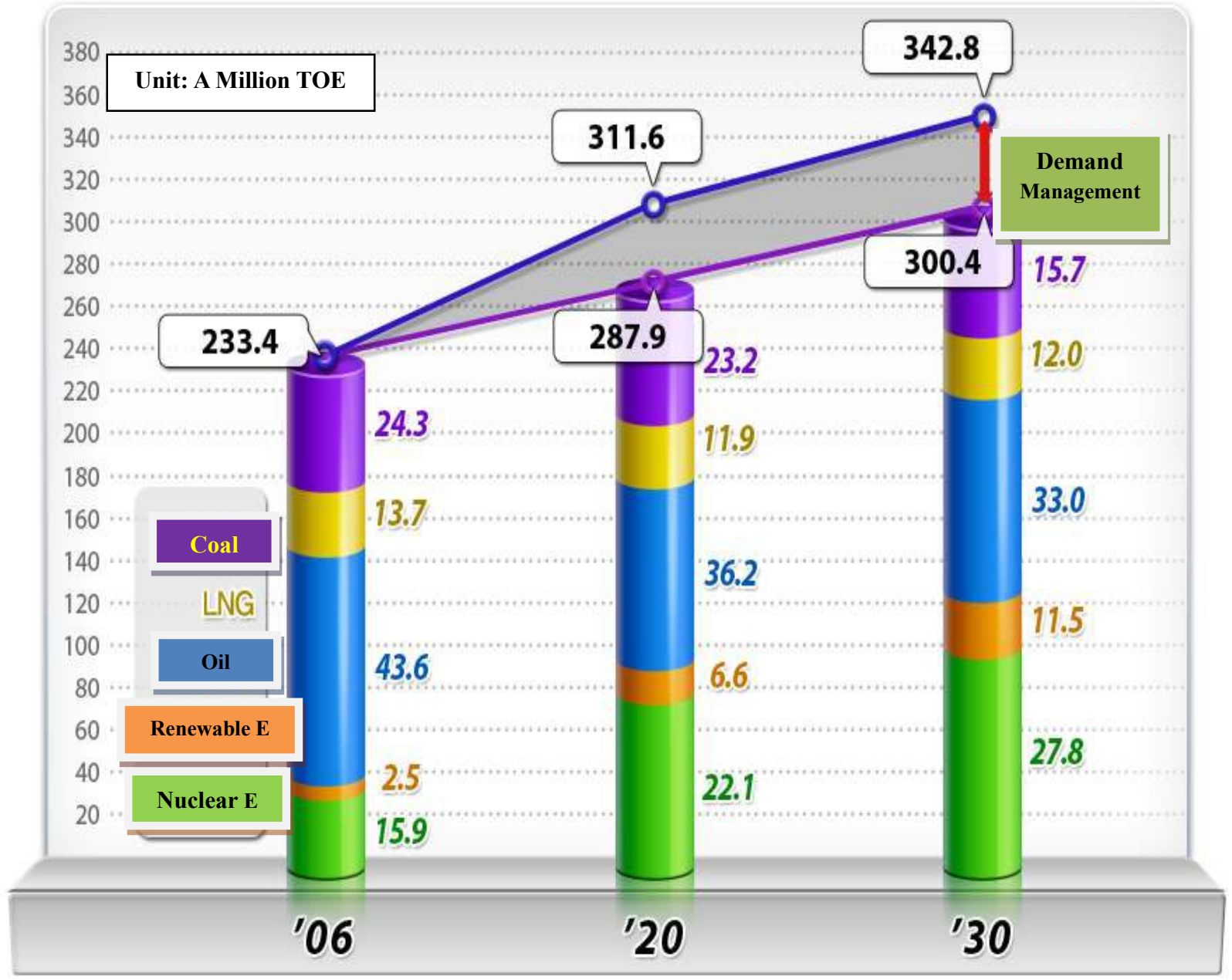

(National Energy Committee, 2008) 
Notwithstanding, since the total energy demand will increase by 2030 , there will be no significant changes in non-renewable energy resource consumption. In fact, in the case of oil consumption, the amount of oil out of total energy use changes from 101.8 in 2006 to 104.2 in 2020 to 99.1 in 2030 while the amount of coal use changes from 56.7 in 2006 to 66.8 in 2020 to 47.2 in 2030 (National Energy Committee, 2008). Consequently, the plan does not indicate the actual way to reduce carbon dioxide emissions by reducing non-renewable energy resources. To put it simply, it is completely against its objectives, specifically the first, second, and third policy of Green Growth.

Besides, to secure a stable energy supply system, Korea National Oil Corp., the staterun oil developer, had a plan to secure energy resources through overseas acquisitions. It means that oil and natural gas are planned to be secured up to 40 percent by 2030 from 3.2 percent in 2006 (National Energy Committee, 2008). This is absolutely contradictory to the Green Growth policy, in addition to the Paris Agreement, which promoted to replace the use of non-renewable energy resources.

What is more, including "waste-to-energy" (generating energy from waste) as renewable energy is also problematic since the project of waste to energy premises producing non-stop waste, which generate industrial waste gas. This is a paradox since promoting the "waste-to-energy" project possibly discourages reducing industrial waste gas that causes climate change. In addition, in the process of producing waste-to-energy, there is a possibility of releasing harmful pollutants into the air (Zafar, 2008).

Despite its appropriateness of using waste-to-energy, in 2015, 63.46 percent of waste to energy is included as a large share of renewable energy while about total 8.7 percent of 
photovoltaics $(6.38 \%)$, solar thermal $(0.2 \%)$, and wind energy $(2.1 \%)$ are involved (see Table 4.2). By 2035, the government plans to decrease waste-to-energy to 29.2 percent while increasing different energy sources, such as photovoltaics (14.1\%), wind power (18.2\%), and bioenergy (18\%) (Invest Korea, 2018). Furthermore, supporting nuclear energy as green energy is polemical.

Table 4.2. Korea's Renewable Energy Supply

(Unit: thousand toe)

\begin{tabular}{|c|c|c|c|c|c|c|}
\hline & 2010 & 2011 & 2012 & 2013 & 2014 & 2015 \\
\hline Total Supply & $6,856.30$ & $7,582.80$ & $8,850.70$ & $9,879.30$ & $11,537.3$ & $13,286.0$ \\
\hline Solar Thermal & 29.3 & 27.4 & 26.3 & 27.8 & 28.5 & 28 \\
\hline Photovoltaics & 166.2 & 197.2 & 237.5 & 344.5 & 547.4 & 849 \\
\hline Bioenergy & 754.6 & 963.4 & $1,334.70$ & $1,558.50$ & $2,822.00$ & $2,766.00$ \\
\hline Waste to Energy & $4,862.30$ & $5,121.50$ & $5,998.50$ & $6,502.40$ & $6,904.70$ & $8,436.00$ \\
\hline Hydraulic Power & 792.3 & 965.4 & 814.9 & 892.2 & 581.2 & 454 \\
\hline Wind Power & 175.6 & 185.5 & 192.7 & 242.4 & 241.8 & 283 \\
\hline Geothermal & 33.4 & 47.8 & 65.3 & 87 & 108.5 & 135 \\
\hline Hydrogen fuel cell & 42.3 & 63.3 & 82.5 & 122.4 & 199.4 & 230 \\
\hline Ocean Energy & 0.2 & 11.2 & 98.3 & 102.1 & 103.8 & 105 \\
\hline
\end{tabular}

(Statistics Korea, 2018) 


\subsubsection{Renewable Energy as an Ultimate Solution?}

It is critical to recognize that renewable energy technology is only a means to improve the environmental condition, but not an ultimate solution. Different renewable energy technologies that often generate environmental conflicts prove accordingly. The renewable energy projects cause ecological destruction, which inevitably affects the livelihoods of locals. Doing so, many people question if renewable energy is 'really' green and clean technology. To be true, implementing renewable energy infrastructure requires high ecological costs as well.

To construct a wind turbine, for instance, it needs various minerals, including "aluminum, boron, chromium, lead, limestone (for concrete), manganese, iron, nickel, cobalt, copper, molybdenum, rare earth (praseodymium, neodymium, terbium, and dysprosium) and zinc" (see Figure 4.4) that are imported mainly from "middle and low-income countries" (Kiezebrink et al., 2018: 6,7).

Consequently, local communities and environments within the countries where the ingredients are extracted are heavily impacted since the mining industries cannot be free from socio-environmental conflicts and human rights violation, including "forced displacement, child labor, land grabbing, destruction of ecosystems, depletion or pollution of water supplies, and air and soil pollution" (Kiezebrink et al., 2018: 10).

Added to this, wind turbines that consist of a high amount of iron and steel (an alloy of iron) demand the high cost of fossil fuels as producing steel necessarily requires coal-burning (Dunlap, 2018). Accordingly, even though wind energy itself might be considered a greenenergy, the production of wind turbines generates $\mathrm{CO}^{2}$ emissions. Thus, renewable energy is regarded as "fossil fuel+" that the renewable components (the + ) rely on fossil fuels (ibid.). 
Figure 4.4. Raw Materials Used in Wind Turbines

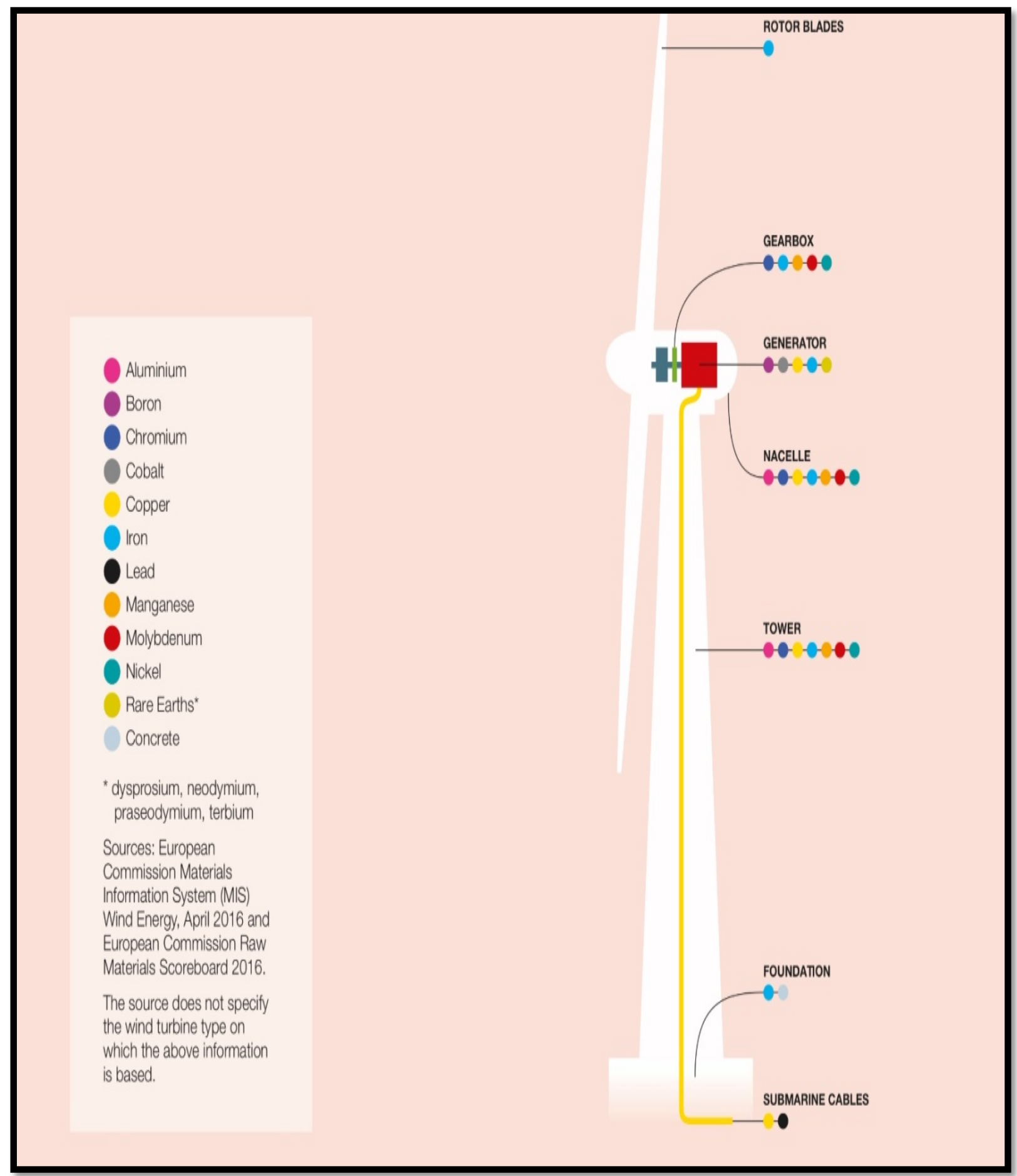

(Kiezebrink et al., 2018: 6) 
What's more, as wind energy projects in South Korea revealed, there is not a specific guideline to follow, which often allow the destruction of natural reserve areas (Sohn, 2015). Putting up wind turbines, clearing trees and animal habitats are logically required. Followed by that, the experts warn of the high possibility of landslides and destruction of the ecosystem that undoubtedly affect the livelihoods of the local villagers (Gwak, 2017; Lee, 2017b). Furthermore, as the case of wind parks in the Istmo, Peru has shown, operating wind turbines need oil as a lubricant to spin, which causes oil leaks that eventually goes into the ground, water well, and grass (Dunlap, 2017).

Even though it exceptionally examines the wind energy project, other renewable energy sources are not free from environmental conflicts as long as the industrial-scale renewable energy system applies. However, the current renewable energy system is the industrial-scale renewable energy system, representing the "renewal and expansion of the present political and capitalist order" (Dunlap, 2018). Meanwhile, considering renewable energy sources as clean energy, all the possible ecological costs have been ignored (ibid.).

In South Korea, the local governments promote various renewable energy projects while highlighting the economic benefit over environmental concerns (Lee, 2017b). It means that without the structural change, which worships the growth-oriented economy, so-called 'green-technology' clearly could be a source of conflicts as well.

In that sense, what South Korea needed is a long-term sustainable energy goal that possibly shifts the growth paradigm. Despite all, it implies that the policy noticeably draws more attention to maintaining economic growth while "Green" is simply a decoration. Consequently, Green Growth seems not so different from the narrative of classical economic 
growth. By far, there have been no genuine challenges of structural transformation from the existing system, more specifically to the energy policy.

\subsubsection{Characteristics of Green Growth Policy}

Is it appropriate to apply green growth, which has emerged for 'developing' nations, in the case of South Korea that ranks the $12^{\text {th }}$ largest economy and $7^{\text {th }}$ largest $\mathrm{CO}^{2}$ emitter (announced in the year 2020)? Accordingly, there are several pivotal points highlighted through the following questions: how much more does South Korea need to grow due to solving the poverty that threatens the healthy environmental condition?; "for whom do we need economic growth, who pays expenses for environmental protection, and who benefits out of it" (Yun, 2009: 233 the author's translation).

Even though Green Growth has emerged as a solution to the growth-obsessed economic model that must be challenged and transformed, Green Growth energy policy applied in South Korea, for example, revealed the true face of Green Growth Policy. It shows that Green Growth policy is excessively focused on 'reviving' the economy under the green growth paradigm that was a big part supported by nuclear energy instead of challenging the structural system by eventually transforming the energy system.

Consequently, Green Growth Policy applied in South Korea exposed the discourse produced from mainstream approach to sustainable development, which is criticized as repeating the modernization discourse that is heavily based on scientific technology while producing green-neoliberalism that constantly causes inequality and injustice. To sum up, the Green Growth policy demonstrates its anti-green facets by being obsessed with economic growth 'opportunities' that ultimately colonize nature (as being considered materials) and 
stimulate the dehumanization process.

The projects under the Green Growth policy indeed had heavily depended on civil engineering works, including the "Four Rivers Project ${ }^{18 "}$ that spent about 18 billion dollars. Besides, the government promoted green energy industries as a leading economy, especially including nuclear energy into green energy, which later became an important social debate. Besides, as various environmental conflicts are also caused by so-called renewable energy facilities, it demonstrates that technology cannot be an ultimate solution. In conclusion, Green Growth faces difficulties in challenging the system which constantly causes inequality and injustice since it has been immensely influenced by the current political and economic power.

In fact, after 'the 2008 financial crisis' that influenced Korea's economy, the government was pressured to find a new growth paradigm that also fits in the world trend, sustainable development. Besides, the main political slogan of president candidate Lee was reviving the economy, thus "economic President" became a peculiar brand to describe president candidate Myung-Bak Lee who at the end became the $17^{\text {th }}$ president of South Korea (Feb.2008Feb.2013). In actuality, President Lee was widely supported by the public for promising to revive the economy despite accusations of Lee's ethical lapses, which turned out to be corruption scandals. Accordingly, in order to respond to the expectations, President Lee proposed to increase seven percent of the economic growth rate based on the Green Growth policy.

Accordingly, the Green Growth policy could be seen as more of a political catchphrase

\footnotetext{
${ }^{18}$ However, the board of audit and inspection of Korea reaffirmed that the project was a total failure, thus there has been a constant discussion on removing the reservoirs.
} 
that represents the regime of President Lee. This means that the Green Growth policy became the symbol of the $17^{\text {th }}$ President of South Korea. For that reason, after President Lee ended his five years presidency term, Green Growth has been replaced with the birth of a new government led by the $18^{\text {th }}$ President, Geun-Hye Park (Feb. 2013-Mar. 2017) who introduced the new economic paradigm, "Creative Economy”.

After all, the only inheritance from the Green Growth policy is the Global Green Growth Institute (GGGI), which was established in 2010 and officially proved as an international organization in the 2012 Rio +20 Summit. Since the GGGI intends to influence the energy policy inside and outside of the country, different projects have been applied in various member countries. However, in general, the term Green Growth has almost been forgotten in Korean society and the influence of the GGGI in South Korea seems insignificant.

Green Growth has been faced by various criticisms as it can be considered to be 'simply' a political catchphrase in which blind citizens with an unrealistic dream, continuously grow without challenging the unjust and unequal system.

\subsection{Conclusion}

South Korea has developed in a particular way to survive through the harsh international competition to overcome the extreme poverty and misery caused by colonialization and the civil war. However, the price that the Korean society had to pay for the way South Korea has developed was too expensive even though the state authority, unfortunately, assumed such sacrifice is inevitable. In the given context, for a developing country like South Korea that was obsessed with chrematistic growth, implementing the idea of sustainable development was not a 'realistic' option to be considered. 
However, even after being a rich nation after the rapid economic growth, practicing sustainable development in South Korea has been extremely difficult as South Korea seems to have no desire for the ultimate systemic change that genuinely promotes sustainability and peace for the future. Thus, although the term sustainable development has been widely adopted in South Korea after the 1992 Rio Summit, the legal basis has been established after 2000 . Furthermore, the actual sustainable development policy represented through the Green Growth Policy only proved that it was simply a political catchphrase. Through the Green Growth policy, the modernization discourse seemingly reproduced while continuously causing inequality and injustice as various social and environmental conflicts demonstrate, including the conflict in Miryang (See. Chapter Five).

Thus, the sustainable development discussion in South Korea can be concluded as disappointing but even a failure. And yet, sustainable development indeed could be a significant opportunity to challenge the growth-oriented system. It consequently means that the success of sustainable development relies on how to shape and reshape the powerful hegemony that heavily influences the discourse of sustainable development in South Korea, which will discussed in Chapter Six. 


\section{CHAPTER FIVE}

\section{Transmission Towers and Lines Conflict in Miryang}

\subsection{Introduction}

Miryang, located in the southeast of South Korea (see Figure 5.1), is a small city that is composed of five dong (city precincts), two eup (large villages), and nine myeon (rural areas). Before the environmental conflict in Miryang started, Miryang was well known for a chimneyless city and food basket since the local economy relies upon the non-industrial economies, such as tourism and agriculture, particularly in outlying districts. In relation to that, ninety percent of the villagers are farmers, and the products like perilla leaves, jujube, strawberry, pepper, and persimmon are well-known special products of Miryang (Miryang Culture \& Tour, 2015). Additionally, the small city Miryang was famous for its beautiful nature consisting of lush mountains to the North and fresh rivers to the South. These features not only attract many tourists each year, but also many retirees who wish to spend the rest of their life in the beautiful countryside

However, once a beautiful scenic rural city, Miryang has earned a new reputation for the conflict created over the construction of the transmission towers, which is an essential part of South Korea's modernization process. In fact, the conflict in Miryang has accelerated as it involves a complicated web of participants, but also various factors influence each other. Thus, it is imperative to observe and analyze the conflict from the various perspectives so that the intact picture of the conflict in Miryang could be revealed. But, more importantly, by observing the conflict in Miryang it is possible to question critically how the conflict in Miryang could have been influenced by the discourse of sustainable development. Ultimately, the purpose of 
exploring the Miryang case is to prove the intensity in which South Korea has faced difficulties to embrace and process the idea of sustainable development but also examine the consequences of neglecting to practice the principles of sustainable development.

Figure 5.1. The Location of Miryang and Overview of Miryang
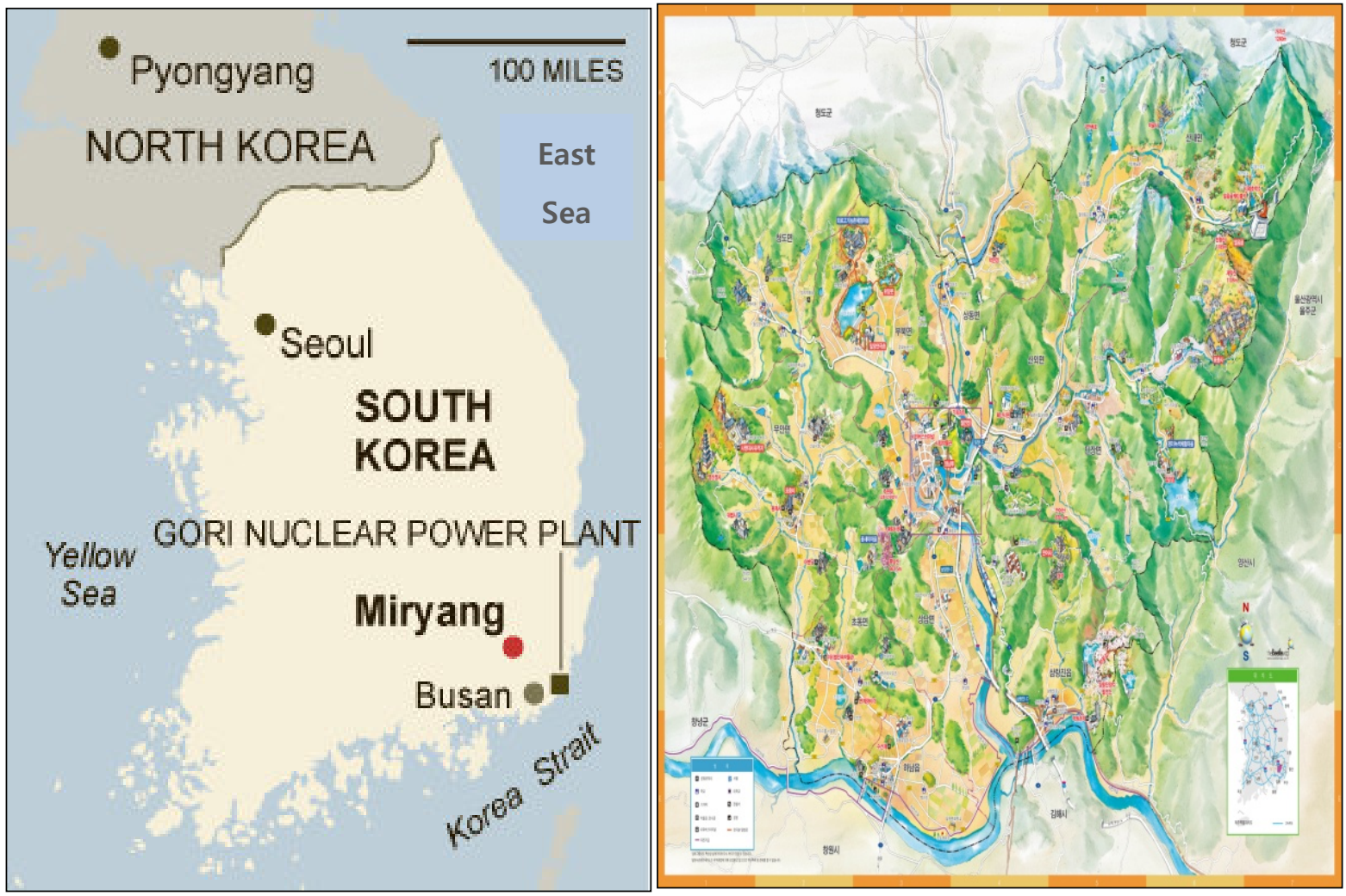

(Choe, 2013)

(Lee, 2017a)

Following that, in this chapter, the overall process of the Miryang conflict, which is divided into seven different phases, will be observed in order to have a clear view of how the conflict has developed. Then, the direct consequences of the Miryang conflict will be observed. Accordingly, in the next section, different factors of which directly and indirectly caused the conflict in Miryang must be investigated. For that, previous studies on the Miryang conflict will be first introduced. Then, the hegemonic discourse of the energy crisis, which is the official 
reason for applying the project in Miryang, will be critically observed. More specifically, this section will carefully examine how the hegemonic discourse of the energy crisis has become the "truth" that in fact has been questioned by the villagers in Miryang. Thus, the last section will follow the footprints of the villagers in Miryang who have challenged the hegemonic discourse by fundamentally examining the truth about the energy crisis but also the root cause of the conflict in Miryang.

\subsection{General Overview of the Conflict in Miryang}

The conflict in Miryang is directly caused by a national project, ' $765 \mathrm{kV}$ Extra-High Voltage Power Transmission Line Project' that was planned in order to send energy produced from Shin-Gori nuclear complexes to the Buk (North)-gyeongnam substation. The project consists of 162 transmission towers with a total length of $90.5 \mathrm{~km}$, which includes two different sections (Lee, 2013a). The project that goes through Miryang is in section two that is comprised of a total of 123 transmission towers, a total length of $69.976 \mathrm{~km}$ (ibid.) and, there are 69 transmission towers that go through Miryang (see Figure 5.2).

Consequently, the communities' livelihood system was severely threatened, especially in those five villages (see Table 5.1) most directly affected by the construction of the transmission towers and lines. Therefore, the struggle has continued for more than ten years and must be carefully analyzed to have a clear view of the conflict. For that, the summary of the Miryang conflict will be subsumed based on the local archives, which distinguished the struggle into six different phases (PNU Locality Achieves, 2015). However, since the conflict in Miryang has continued even after the local archives was published in 2015, a seventh stage will be further added by me. 
Figure 5.2. Transmission Towers and Lines in Miryang

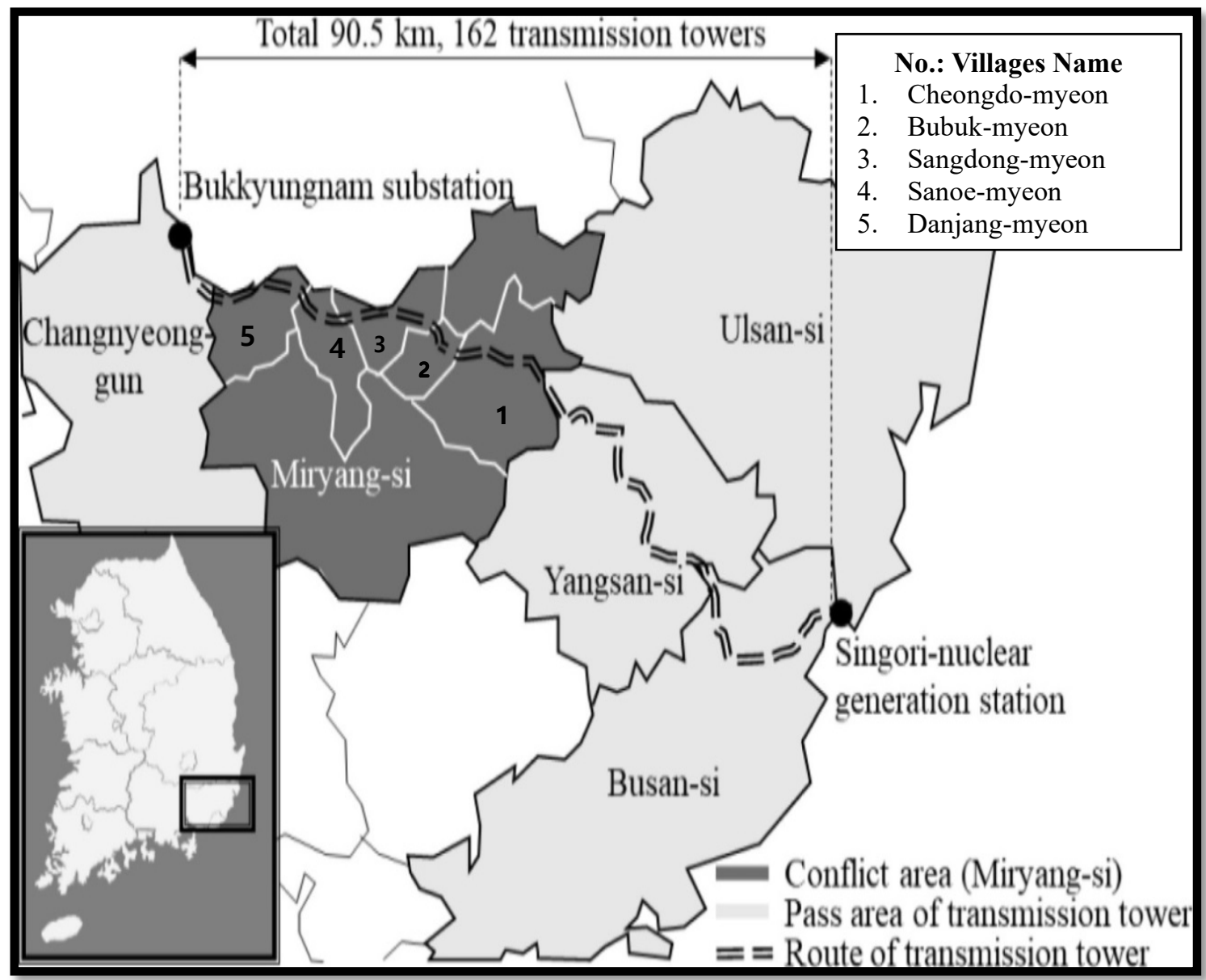

(Min et al., 2018)

Table 5.1 Added Territory Locations and Areas in Miryang

\begin{tabular}{|c|c|c|c|c|c|c|c|c|}
\hline & \multicolumn{2}{|c|}{ Added Territory } & \multirow{2}{*}{ Number } & \multicolumn{5}{c|}{ Location } \\
\cline { 2 - 5 } \cline { 5 - 8 } & Plot & Area (m2) & & $\begin{array}{c}\text { Danjang- } \\
\text { myeon }\end{array}$ & $\begin{array}{c}\text { Sanoe- } \\
\text { myeon }\end{array}$ & $\begin{array}{c}\text { Sangdong- } \\
\text { myeon }\end{array}$ & $\begin{array}{c}\text { Bubuk- } \\
\text { myeon }\end{array}$ & $\begin{array}{c}\text { Cheongdo- } \\
\text { myeon }\end{array}$ \\
\hline $\begin{array}{c}\text { Transmission } \\
\text { Tower }\end{array}$ & 90 & $\begin{array}{c}30,005 \\
(155 \mathrm{ppl})\end{array}$ & 69 & 20 & 7 & 17 & 7 & 18 \\
\hline Length line & 622 & $\begin{array}{c}1,406,942 \\
(579 \mathrm{ppl})\end{array}$ & $\begin{array}{c}39,157 \\
\mathrm{~km}\end{array}$ & 11,055 & 4,549 & 10,108 & 3,419 & 10,026 \\
\hline
\end{tabular}

(Eom, 2012: 68) 


\subsubsection{First Phase: January 2000 to December 2005}

The project in Miryang was mentioned for the first time in 2000 as a part of "the fifth long-term demand-supply program" (PNU Locality Achieves, 2015) that also includes the $765 \mathrm{kV}$ Extra-High Voltage Power Transmission Line Project. The purpose of the project was to send energy produced from newly constructing Shin-Gori nuclear power plants to the northern Gyeongnam province in order to prevent energy shortage as energy demand apparently will be increased in long-term use (Lee, 2007).

Due to preceding the government project, it requires carrying the environmental impact assessments that are defined as "the process of identifying, predicting, evaluating and mitigating the biophysical, social, and other relevant effects of development proposals prior to major decisions being taken and commitments made" (IAIA, 1999) and holding a public presentation to give adequate information about the government project.

However, most of the villagers had not received proper information about the project until 2005, despite the government planning of the project since 2000. Even though the presentation about the project was held for the residents in Miryang in 2005 as the law requires (Kim, 2014b), only 0.6 percent of the whole population $(136 / 21,069$ people) of five directly affected villages participated in the presentation (PNU Locality Archives, 2015). In short, KEPCO only invited a few villagers whose livelihoods were barely affected by the project and the leaders of the villages by providing compensation money, gifts, and meals. For that matter, the secret process of the project that inevitably excludes the participation of the villagers became a crucial cause for what would soon become a long struggle (ibid.).

In addition, the presentation itself did not adequately provide all the necessary 
information, including the purpose of the project, the possible threats on health and private property, the possible changes in the villager's life, and the justification of why the project must locate in Miryang (ITHRVMR, 2013). Instead, KEPCO constantly provided false information while avoiding informing key points of concerns over the project, such as safety issues related to the hazards of electromagnetic waves. Therefore, for instance, regarding the issue related to an electromagnetic wave, KEPCO emphasized the safety of the project by arguing that the electromagnetic wave of $765 \mathrm{kV}$ is equivalent to the use of a hairdryer (ITHRVMR, 2013). Consequently, the few villagers who participated in the public presentation did not fully grasp the clear idea about the project while KEPCO strongly emphasized preceding the national project.

After the public presentation, some villagers read the environmental impact assessment (EIA) and then delivered general feedback about the project in 2006. It is indeed a perfect chance to hear the locals so that the project could be less conflicted by including the voice of the locals. However, unfortunately, KEPCO barely included the request and opinions of the villagers, which is a contrast to the purpose of EIA. Moreover, KEPCO rejected the villagers' request for holding a public hearing. In other words, it demonstrates a strong will of KEPCO to enforce the project's completion regardless of opposition, and finding an agreement was not in their interest. The whole process presented as a formal act done for the show.

Moreover, as the report concludes, the procedure process that KEPCO conducted is completely against the Article 2 of constitution No. 10 ("Guarantee the dignity of man and basic human right"), and declaration on the rights of peasants and other people working in the rural area that was determined at the UN General Assembly (Article 2 Rights of Peasants 4: Peasants have the right to participate in the policy design, decision making, implementation, 
and monitoring of any project, program or policy affecting their land and territories) in 2012. Accordingly, as KEPCO never engaged in clear communication, the conflict has initiated and further intensified.

\subsubsection{Second Phase: December 2005 to November 2010}

In the second phase, the struggle was initiated as the villagers had discovered the project in Miryang. Afterward, the villagers voluntarily organized a committee to manifest their opposition to the project, but also forged links with different cities where the project is applied. Moreover, during the second phase, there was full support from the city government. For instance, the city council organized a committee, and continuously strengthened oppositional movement through various campaigns, asking for support from nation-wide environmental organizations such as Green Party and Green Korea United (Eom, 2012).

However, the project was 'legally' launched in 2008. Thus, the struggle of the committee strengthened against the central and provincial governments. As a result, in November 2009, the Anti-Corruption and Civil Rights Commission (ACCRC) mediated a dispute addressing the situation; however, the villagers were not fully convinced by suggestions made by the ACCRC (Eom, 2012). In fact, the report was not able to represent the position of the villagers sufficiently, but it rather justified the objectives of the project. Thus, the project continued only a month later of an arbitration procedure made by ACCRC (ibid.).

To make the situation worse, the mayor of Miryang, who supported and represented the villagers, backtracked the stance. Besides that, the mayor approved the project in October 2010 and also nullified the legal struggles against the government authority. The mayor proclaimed that it was an inevitable decision since the central government authority legally pressured the 
Miryang city council and the mayor. For instance, the Mayor was charged with dereliction of duty. Consequently, from this point, the villagers were more isolated both socially and politically.

\subsubsection{Third Phase: November 2010 to January 2012}

In order to continue the project, the government authority modified the compensation system although most of the villagers did not consider compensation as a possible option or an alternative for the solution. Nevertheless, the violation of property rights had 'legally' happened through the unjust compensation system. The whole process of the compensation policy indeed was inadequate.

Thus, despite the difficult situation, the villagers continuously struggled on the field even though the construction repeatedly went on. In fact, according to the villagers, the third phase is possibly highlighted as the most isolated period in which the physical violation toward the villagers was intensified. Accordingly, the elderly villager's human rights have been violated in different forms through the conflict.

\subsubsection{Fourth Phase: January 2012 to May 2013}

Because of KEPCO's forcible way of rushing through the construction, Mr. Chi-Woo Lee committed suicide in November 2011, on KEPCO's ninth attempt of construction (ITHRVMR, 2013). Before the tragic death of Mr. Lee, the villagers were left to struggle in complete solitude. Specifically after the retreat of the Miryang council and government in October 2010. In fact, the last words of Mr. Lee: “The only way to stop this project will be my death today" (Eom, 2012: 55), show the isolation and despair the villagers must have felt when the general public turned their back on them. 
However, Mr. Lee's death was not entirely in vain. It brought various changes within the movement and society. This was the movement when the larger public had learned about the conflict in Miryang, and was also made aware of the seriousness of the situation. Additionally, the villagers requested help from the civil groups in Miryang, and the countermeasures committee to oppose $765 \mathrm{kV}$ transmission towers in Miryang was organized in 2012. In other words, the tragic death of Mr. Chi-Woo Lee ignited a flame that caught the public attention and created a shift in public opinion.

As a matter of fact, after the incident of Mr. Lee, the media, especially liberal and local newspapers, mentioned the conflict more often than ever (Lee \& Yun, 2013). And then as a way of exposing the incident, the media framed the conflict under the environmental justice discourse, rather than focused on the villager's illegality and the inevitability of the project as conservative newspapers do (ibid.). Subsequently, the struggle in Miryang became a nationwide concern. For that, various individuals, civil organizations, and even politicians visited Miryang to support the villagers' manifestation. For instance, candlelight rallies started in Miryang every Wednesday, and a "Hope Bus" was organized and hundreds of citizens voluntarily participated. The wide support of the citizens helped the villagers to protest constantly, but furthermore to suspend the construction twice.

\subsubsection{Fifth Phase: May 2013 to June 11, 2014}

According to PNU locality archives, this is the most intense phase since the government authority put the highest pressure in order to finish the project in Miryang. Despite the possible alternatives to solve the conflict, the government preferred to overuse governmental authority to finish the project. In fact, the government authority let 3,000 police 
officers "protect" the construction sites for 10 months against the elderly villagers who were simply attempting to protect their homes.

At this moment, "only" four sites (No. 101, 115, 127, 129), which were occupied by the villagers, were left to be "unavailable" to end the project. For that matter, the government authority basically declared war in order to chase the elderly villagers and the citizen supporters out of the sites.

In the process, state violence reached the climax. As an unfortunate result, in December 2013 there was another tragedy: the death of Mr. Han-Suk Yu happened. But, meanwhile, there was a strong co-resistance between the activists and citizens. Accordingly, the "Hope Bus" brought people from all over the country to support the villagers in Miryang. However, on the day of June 11th, 2014, the abuse of the government authority reached its peak, thus everyone who struggled and resisted, including the elderly villagers, activists, and nuns, was violently and inhumanly removed from the remaining four sites

\subsubsection{Sixth Phase: June 2014 to December 2015}

In spite of endless struggles, all the sixty-nine $765 \mathrm{kV}$ transmission towers were finished in September 2014. Throughout the process, the villagers not only suffered from physical violation, but also from mental and emotional abuse. For that, most of the villagers needed medical treatments and psychiatric services. Experiencing such state violence is obviously traumatic.

Add to this, the villagers had to suffer by the government authority that threatened the villagers by using the legal procedure to "punish" the "illegal" actions of the citizens. However, the worst of all is experiencing community destruction. In order to finish the project 
'successfully', the government authority consistently used an old tactic to destroy the village community by bribing certain villagers who held the most power in the community to turn their back from resisting together.

At the end of the project, the government authority announced that all the conflicts in Miryang were resolved and the project was successfully finished. However, the villagers in Miryang have continued to struggle in many ways. For instance, by trying to stop the transmission test held in December 2014. Furthermore, the Miryang Committee has organized different activities, including the $10^{\text {th }}$ commemoration event on "Struggle against the Miryang Transmission Tower Project," and publishing a book (published December 17, 2015) about the Miryang struggle.

\subsubsection{Seventh Phase: Afterwards}

After the commercial operation in June 2015, as the project was completed, the government authority announced the end of the conflict in Miryang. However, it was not the end for the villagers who have been continuously suffering, especially by the lawsuits among the villagers. It reveals the cruel reality of how this strong community bond, which has been an essential part of the villagers' identity, has rapidly broken.

Therefore, the Miryang Committee has been prepared for the judicial action for the villagers, whereas the villagers have requested the government for a long-term energy policy. In relation to that, the villagers have demanded the nuclear phase-out, discontinuation of using nuclear power for energy production since the conflict in Miryang is directly related to the nuclear energy policy, precisely constructing Shin-Gori nuclear plant No.5 and 6. As Miryang villagers give emphasis to, what has happened in Miryang should not be repeated anywhere. 
In consequence, a new government that was elected in May 2017 introduced a new policy of nuclear power phase-out, which will occur over a period of the next forty years. However, in the reality occupied by the neoliberal economic power, the new policy introduced has received constant counter-proposals from the main opposition party and nuclear powerrelated science professors and scholars.

For instance, a group of 410 university professors and scholars publicly criticized the nuclear phase-out policy while arguing, "Immediately halt the push to extinguish the nuclear energy industry that provides cheap electricity to the general public" (World Nuclear Association 2019). In addition, the main opposition party, Liberty Korea Party (renamed People Power Party since Sep. 2020), insists to abandon the nuclear phase-out policy to reduce fine dust, which is one of the biggest social issues in South Korea, but also to maintain the stable energy policy (Liberty Korea Party, 2019).

Nevertheless, the nineteenth president Jae-In Moon announced: “exit the era of nuclear energy" at the closing ceremony ${ }^{19}$ of Gori reactor unit one in June 2017. Furthermore, in order to reach a social consensus on the construction of Shin-Gori reactors units five and six, the KHNP (Korea Hydro and Nuclear Power) board made a decision to suspend the construction for three months of public debate and government decision in June 2017.

Subsequently, 59.9 percent of the committee members who participated in the public debate in October vote in favor of resuming the construction of the two units. However, the committee voted to reduce using nuclear power energy (53.2\%) while 35.5 percent voted in favor of the status quo, and 9.7 percent supported the expansion of nuclear energy (Kim et al.

19 See video on https://www.youtube.com/watch?v=3JUSf5285O4 [In Korean] 
2017). At the same time, the committee suggested to enhance the safety standards for nuclear power generation, but also to increase the share of renewable energy resources (ibid.).

Even though most people put the important value on holding a public debate to transform the conflicting social issue, there was obviously a limit on the public debate: it was short time limits (the discussion has lasted for only three months), but also there was no space for the villagers to speak up on the public decision process where their (direct) future was chosen. As a result, not just the villagers of the Miryang have lost their right to live peacefully within nature, but also the future generation, all other living beings who could not have their voice and nature, have lost their opportunity to express their rights and needs.

As a result of the public decision, the movement in Miryang has been definitely weakened. Therefore, unfortunately, but understandably, some villagers had stopped the resistance. Nonetheless, there are still some villagers who continue to fight relentlessly against the project and are struggling for justice. There is indeed a realistic concern for how much longer they could resist, but the message is very clear for them. As to properly conclude the Miryang movement, the Miryang Committee has been requested for the official apology of the government, the appropriate punishment for those who are responsible for the violence that the villagers had to experience, and, as importantly, the sustainable energy transition, which would help the sustainable development process $\left(Q^{20} 4\right)$.

\subsection{The Consequences of the Miryang Project}

${ }^{20}$ I had a short conversation with the representative committee to confirm the existing position of the Miryang committee. (Script attached in Appendix I, and in the text citation referred to as Q \#) 
Due to the completed government project in Miryang, all sorts of violence have been justified. In fact, throughout the long struggle in Miryang, the villagers have experienced the biggest war in their life, as an elderly woman expressed in an interview conducted by Miryang Statement Project (2014). There has been constant violence and injustice caused by government authority/power.

I also had chances to participate in the protest with the villagers in Miryang. Based on the two short visits, I could roughly sketch the reality of the villagers. On the first visit, I participated in a sit-in demonstration with Miryang villagers in the mountain where the construction of the transmission towers began. The villagers started the day by waking up at four in the morning so that they could arrive at the demonstration site before KEPCO workers and the police. The first thing they did was binding their neck with chains to excavating equipment in order to hold off the construction. This was also a way to prepare themselves for any possible tensions created by KEPCO workers. Because the villagers realized they are not strong enough to resist, they always put a chain around their neck; so in the case of disruption of their acts, they can hang themselves. This situation dramatically shows how desperate they are to protect their lands, but furthermore how important the lands mean to them.

There were many KEPCO workers surrounding the villagers. Although there was some physical space, I felt emotionally suffocated by the enclosure. The tensions were high; KEPCO workers were constantly taking pictures of the villagers; so wearing a mask and a hat was of necessity to protect their identity. There were various sites of resistance where villagers organized sit-in protests. Since there were limited villagers compared to the number of KEPCO workers and police, villagers in one site had to detour through the steep mountain passes to come to the aid when tension arose in another site (it happened twice on my first day there). 
An elderly woman in her seventies (with a chain on her neck) told that the situation gets much worse when there are no supporters from different regions there and only the villagers are around. There are constant threats and provocations from the police as well as insults and curses to make the villagers react emotionally. According to the elderly woman, there were no ways for them to prove the violence that KEPCO workers perpetrated because none of the villagers had electronic devices to take pictures or record video/audio. She thanked the activists for sitting there with them, being ready to record any possible violent incident, and listening to her.

The villagers had various awful experiences to share other than being dispossessed of their lands, community, and life. For instance, most of them were sued by KEPCO, and elderly people in their 70 s and 80 s were mocked and disgraced by young workers who treated the villagers like $\operatorname{dog} \mathrm{s}^{21}$. Once, an old lady showed me a piece of paper full of curse-words, in order for her to learn how to swear. She gave me a hollow smile after calling herself a foulmouthed grandma. That was, however, her way of showing the anger toward the government authority abusing their citizens.

In the book Living Miryang (Miryang Statement Project, 2014), villagers' resentment and rage toward the government, KEPCO and the police authority were presented through various interviews:

Damn it! Since the Japanese colonization, the country hasn't done anything for us. We endured such a hard time under the damn Japanese. The Korean War also made us suffer greatly. [...] Later, two brats, the U.S and North Korea went completely insane. [...] I was

${ }^{21}$ According to the villagers, since they are old, meaning that they cannot walk fast and at times they had to crawl in the mountains, then the laborers were making sounds to the villagers as if they were calling dogs. 
born in the year 1928 and now it is 2014. Until today, there hasn't been a single moment that I felt this country as my country.

Kim, Mal He (39, author's translation)

[E]very morning when I see the police line, I cannot believe it. I wonder if it is real because there are so many of them. They really look like a swarm of ants. There are only a few villagers. [...] Even if we try our best to scatter the police, we are too slow. We get stopped so easily and usually police just throw us out. When they grab us, first they twist our wrist, and then do whatever. I feel like an idiot. And I cannot believe what is happening. I don't understand why police officers do such a thing.

Gu, Mi Hyun (225, author's translation)

My heart is breaking when I see elderly people demonstrating in such cold weather. It is extremely cold at seven in the morning. I'm always thinking about how I can make the elders stay in the warm house and how I can stop the construction. But I can't find it anyway. Once an old lady told me that it would be better if the government/KEPCO just shot us instead of killing us slowly and painfully like this. It was very shocking but there was nothing I could do to make her feel better. It was sad.

Kim, Young Ja (237, author's translation)

On the second visit to Miryang, I had a chance to learn how the villagers' lives were violated by participating in the Investigation Team of Human Right Violation over the Miryang Transmission Tower (ITHRVMR) meeting. ITHRVMR reports clearly show how the villagers in Miryang have been exploited through the conflict. ITHRVMR summarized the report well with one sentence: "the country robbed the villagers' life and future" (2013: 95, author's translation).

\subsubsection{The Violation of Property Rights}

The inadequate compensation policy and the outdated law, which support the government project and unjust policy, were definitely one of the main factors in this conflict. 
Furthermore, the main reason besides these two issues was a lack of understanding of the value and meanings the villagers placed on the land.

Since only limited individuals were able to receive a small amount of compensation, most of the villagers have suffered from the nosedive of the land value. Apparently, there is no way for the farmers to begin the agricultural activities of the year without money, which needs to be borrowed from the National Agricultural Cooperative Federation (NACF). Nonetheless, all the values of the land became nothing after the project was initiated, thus the NACF did not permit loan money to those farmers who lost all the values of their property.

In addition to many of the villagers losing possible income by restricting agricultural activities, there were also damages to private businesses (e.g., restaurants) near transmission towers and lines. Furthermore, the value of future development was lost, as the current property value was depleted by the risks of electromagnetic waves.

Besides, most of the villagers are elderly farmers depending on their life heavily to the land, which is the matter of surviving for the villagers. In other words, the land is the only means to survive for elderly farmers. The land could be seen as a pension for those farmers. The villagers usually practice agricultural activities until they cannot anymore, and this is when they sell the land to maintain the rest of their life. However, after the project was launched, the entire sale of property stopped in Miryang.

Another issue is that there is no appropriate compensation for the farmers who rent the land for agricultural activities. Since the compensation goes to the landowners, those farmers who need to rent the land simply lose all their means to survive. The compensation specifically indicates the land, but not agricultural products that often have as important values as the land 
itself. Since the compensation policy is awfully exclusive, there is no preparation for the direct hazards on the agricultural products caused by transmission towers.

There is no doubt that the government and KEPCO never engaged in any conversation to hear the villagers. The following letter written by Mr. Yang to a judge highlights critical issues the government and KEPCO overlooked:

\section{Dear Judge!}

I am a farmer who has been growing chestnut trees for 30 years in Sayeon-Li, Danjang-Myeon in Miryang. Because I was born into a poor family with ten siblings, I was not able to attend an elementary school. However, I lived my life diligently without harming anybody. Even though my wife and I did not have a single penny when we got married, we survived by working on someone else's farmland. We really worked hard motivated by our dreams to have our own farmland in the future. Since then we tried our best to save money; for instance, having porridge for every dinner, only eating potatoes that we planted in abandoned lands, and searching for edible plants in the mountain. After saving a bit of money, we finally bought the land we dreamed about. It was indeed not the best land to farm since it was an inclined mountain. That was 30 years ago. It was a tough time until we finally had the land, so we really worked hard every day and every night. Can you imagine how happy we were to finally have our land? Although the work was hard, we never felt tired. It was pure joy. We hoed up the soil, picked up stones with our hands, cut all the scrubs with saw and sickle, and then we finally planted chestnut trees. This is how we made the chestnut tree farm (near No.97 transmission tower). Currently, we earn about 7 to 8 million won (approximately $7,000-8,000$ USD) per year. Since we have no other income farming is the only way we earn a living each year. It might be a small amount of money, but we have been living happily.

Dear Judge!

I am 72 years old now. I still have the energy to do farm work in order to survive. Actually, three years ago, I had a chance to sell this land for 150 million won (approximately 150,000 dollars) but I postponed selling my land. It was just because I really wanted to continue farm work even if it is really hard work. Then if I have no more energy to farm, I am planning to sell this land. With this money, my wife and I can live off it, and we can go to the hospital if we get sick. But, KEPCO wants to build transmission lines over my lands. In that case, I cannot farm anymore because I 
cannot do crop dusting on my chestnut trees anymore. I already tried to sell my land but nobody is interested in buying it. What can I do? I really do not know how to live in the future. I cannot think of any ways to survive in the future. Recently, KEPCO called me. They told me to take compensation money, 1,540,000 won (approximately 1,540 USD).... At that moment, I shouted at them "I do not need 1,540,000 won. I would not accept the money, so feed us until my wife and I die. We will starve if we don't have these lands". I wasn't afraid of being penniless when I was young but I feel hopeless to think about living in the future without any money, especially now that I am weak. I am very scared. Often, I feel nervous whenever I hear the helicopter around our mountain. I am worried that KEPCO started to build the transmission towers. We have cultivated this land our whole life. This land is our body and our sons and daughters. I would feel painful and empty even if someone pays me the proper price but KEPCO is trying to steal my land after giving me $1,540,000$ won. If the land is taken like this, we have no other options but of dying out of anger and rage.

Dear Judge! I do not know how to write so my neighbor is writing for me. I do not know the law, nor how to sue. How can I survive when I did not learn enough so I do not know much? Dear judge, please save us. I am not trying to be greedy. All I want is to farm on my land until I die. If it is not possible, if the transmission towers and lines must be on my land ...

Please help us to survive. I am not asking for a fancy life but simply asking not to starve. I do not know much about the role of the government since I did not have enough education, but I am guessing this is the minimum responsibility of the country?

Yang, Sang Yong

(ITHRVMR, 2013: 36-38, author's translation)

Most villagers in Miryang are farmers and Mr. Yang's story is nothing extraordinary, meaning that the majority of villagers share similar stories. Therefore, the government/KEPCO proposed 'a special compensation to solve Miryang conflict' (e.g., invest money in constructing solar power station valley) in April 2013. However, the proposal not only includes unrealistic promises but also the proposal embraces the 'wrong' attitude that money solves the entire problem, especially when the compensation money causes community destruction. The conflict in Miryang cannot be simply solved by providing more compensation money. 
For the villagers in Miryang, the land means the life that they live now and the life that they will continue, even after their death. Life cannot be easily replaced with monetary compensation. As Mr. Yang said in the letter, the land is their body, their sons, and daughters. If the plan from the government/KEPCO was inevitable as they argued, it had to be performed in a better way, since the lives of entire villages were violated apart from the villager's property rights.

\subsubsection{Destruction of Community}

After the long conflict in Miryang, the community lifestyle has been completely destroyed as friendly neighbors and even family members became enemies to each other. Thus, there hasn't been any conversation; there was no need to communicate about community activities as the community connections have demolished. Subsequently, several villagers both those who supported and those against the project expressed that community destruction has been the most painful experience out of all the horrors they had to go through.

And, according to ITHRVMR (2013), KEPCO has a huge responsibility behind community destruction. The strategy carried out by KEPCO to make that happen was: (1) to contact villagers individually, especially their representatives, rather than contacting them as a group, in order to bribe them so that they signed the authorization of the project, (2) to spread rumors like "you are the only one who disagrees on the project", (3) to create conflict between villagers by convincing them the other received more money.

Furthermore, the same strategy had applied among villages in Miryang. KEPCO selectively approached the villages, which are less affected by the project, thus the conflict among villages only intensified. Nevertheless, KEPCO preferred to use power and money to 
convince people instead of having a conversation to gather different opinions and the end result was a shattered community.

\subsubsection{Human Rights Violation}

Accordingly, the elderly villagers' human rights have been violated in different forms through the conflict. In fact, most KEPCO workers committed verbal insults and physical violations including sexual assaults and harassment towards the elderly villagers through the project. However, meanwhile, the government authority overused the power to violate the human rights of the elderly villagers, especially by using the police force. KEPCO is a public enterprise and should value the interest of the public, while the duty of the police is protecting citizens safely. However, in Miryang, all types of violations from KEPCO workers have been tolerated and consented to by the police authority.

When the project was started, as there was no consideration or 'real' conversation with the villagers from the beginning, the workers only concentrated on initiating the project. In other words, to initiate the project, the workers intentionally abused the villagers verbally and physically. KEPCO workers constantly used swearing and threatening words toward the elderly villagers who were holding trees as a way to protest. According to the reports, young workers were consistently calling elderly females 'bitch' (confessed by Jeong/ Sohn/ Seok, 72, 78, 86 years old). Also, when a villager fell down on the stacks of wood, the workers mocked them by saying that they deserve to be burned (confessed by Song, 78 years old). Furthermore, whenever the villagers crawled to reach another tree to hug, the workers insulted them by making the sound of dogs (confessed by Gwak, 65 years old). (ITHRVMR, 2013: 53). There were no forms of respect. Thus, even when the villagers were injured and carried away by ambulance, the workers brought them into contempt. No villagers received a sincere apology 
from the workers but mocked. KEPCO workers only behaved in an ethical way during the visit of a commission of human rights.

Besides, many elderly women protestors were openly exposed by sexual insults and harassment. In fact, there were two sexual violence cases committed by KEPCO workers. The first case is violating a female Buddhist monk in November 2011 and the second one is violating a female member of Miryang city council in August 2012. However, KEPCO not only denied sexual violation happened in spite of all the evidence, but also ignored their own responsibility of supervising and managing the whole project safely.

In a way, KEPCO encouraged all kinds of violations by intentionally turning a blind eye. However, the government authority also cannot avoid the responsibility as police on the sites did nothing for ten minutes while the workers were sexually violating the female monk, then the workers were not charged for not having 'enough evidence' although there was enough evidence to prove the crime occurred. Hence, the perpetrators could dare to come to the Buddhist temple with a hunting dog and sickle to threaten the monk who fainted and needed psychotherapy in the following months.

The situation had been worsened while the elderly villagers were pushed to the limit. In actuality, compared to fully equipped and young KEPCO workers, the elderly villagers were too fragile to protect themselves from constant violations. At the same time, the workers had become even more audacious by violating the villagers in the worst ways, including arresting a villager before the police arrive at the site, dragging elderly females out with force, and physically threatening the villagers who were protesting under the excavators by starting up the machine (ITHRVMR, 2013). 
To make the situation worse, KEPCO hired 50 subcontract workers from January 2012. In fact, subcontract workers (Yong-Yeok in Korean) are described in a negative term in Korean society since they have been playing villains who often 'legally' use force to deprive someone's property or means to survive. Often, these workers overuse power, which is illegal. The illegal power use happened in Miryang as well, and by using the outer force (Yong-Yeok) the intensity of violation had only increased.

Thus, a villager confessed through the interview that struggle against the national project has been a war-like situation since a man of power, specifically meaning the police and KEPCO workers, oppress the powerless, the elderly villagers (Miryang Statement Project, 2014). As a result, the tragic accident, the death of 74 years old Chi-Woo Lee happened.

According to the villagers, from the first day (January 16, 2012, the day of Mr. ChiWoo Lee's death) the physical and verbal violations were too harsh for the villagers who were lonely after fighting several years isolated. Meanwhile, the government authority/police had been ignoring all the violence happening in the daily lives of the villagers. In other words, the police authority was not involved to mediate the conflict, but rather simply guarding the project of KEPCO all the way through, whereas the safety of the villagers was put aside.

Nevertheless, both KEPCO and the police continued abusing their power over the villagers even after the tragedy of Mr. Lee's death. In fact, the violence became more intense once KEPCO gained support from the police authority. As a result, for ten days, from May 2029,2013 , a total of 20 villagers whose average age is 70.8 years old were injured. (ITHRVMR, 2013).

\subsubsection{The Violation of Health Rights}


Most of the villagers have suffered psychological and emotional trauma besides the physical violation. Due to this, the investigation on the mental health of the villagers was conducted on June 8,2013. According to the report, 25 percent of the total villagers (79 people) attended the research that was conducted by ten doctors, three pharmacists, three activists, and three students who were in the field of public health. The general characteristics of the attendee are 70.9 percent of women (29.1 percent of men) whose average age is 70.4 years old.

The research shows how the villagers understand the conflict, which is: (1) the lack of information from the beginning of the project, (2) the villagers are the marginalized of the society, (3) thus, the government and KEPCO could completely disregard the villagers, (4) there has been the violation of property rights, and it will be worsened in the future, (5) it is depressing not to protect the land, (6) it is uncomfortable having a bad relationship with the villagers who support the project, (7) meanwhile, it is sad to witness and experience community destruction, (8) they are nervous that the project will be complete, (9) it is exhausting fighting against the project, (10) they are afraid of the strangers, and (11) but also they are afraid of the government authority (ITHRVMR, 2013).

In detail, the research indicates that 59.9 percent of the villagers had been threatened through hostile behavior by KEPCO workers, and 44.3 percent experienced insulting remarks while 34.2 percent had been sued (ITHRVMR, 2013). And, 15.2 percent of the villagers even had experienced not only physical violations but also injured by the deadly weapon used by the workers (ibid.). As a result, 40.5 percent of the villagers suffered from depression which is higher than the general public, whereas 48.1 percent had to deal with higher anxiety than the general public, and 41.8 percent experienced extreme fear that is higher than the general public (ITHRVMR, 2013). 
In conclusion, many of the villagers greatly suffered from depression, higher anxiety, and extreme fear. Thus, 31.7 percent answered having a thought or feeling about wanting to die while more than 50 percent of the people feel depressed, worrisome, exhausted, and sensitive in daily life (ITHRVMR, 2013). Furthermore, there was 69.6 percent of the villagers who have symptoms of having high-risk post traumatic stress disorder (PTSD) (ibid.).

\subsection{Previous Studies on the Miryang Conflict and Suggesting Alternatives}

As the conflict in Miryang has lasted for more than a decade, there have been different researchers and scholars dedicated to finding the core reasons for the conflict in Miryang along with the alternative solutions. Among various factors that caused the conflict in Miryang, the very first factor to observe is a lack of communication. Since there was no effective communication channel opened, most of the villagers were not able to receive any information about the project, but also there were no attempts to engage in a sincere dialogue with the villagers on the process of the conflict in Miryang.

Accordingly, Professor Heung-Soon Kim observed the Miryang conflict in terms of lessons of Chang-Tzu. These lessons highlight the importance of communication-based on principles including: "acknowledging the other, respecting it, abandoning prejudice, acknowledging relativity, emptying oneself, filling creative alternatives in the empty one, and

mediating the situation" (2014a: 1). It is a critical point to be made since there has been no sincere conversation, which must contain "dialogue, the exchange of understandings and meanings in the endeavor to construct between information" (hooks, 2010: 44). According to hooks, the conversation must be inclusive to encourage and nourish individual voices as "it strives to develop a community vision" (ibid.). 
On the other hand, some scholars paid attention to the legal process behind the conflict since the existing legal system supported and justified all the violence in Miryang, which became the root cause of the conflict. Following that, Moon-Young Woo and Jeong-Gyu Gang (2013) criticize the existing law, 'the Act on Special Cases Concerning Electric Source Development', as the main reason for intensifying the conflict. Therefore, they argue to strengthen the compensation system as a means to minimize the level of conflict.

Sung-Bae Cho (2012) points out the necessity of reforming the existing law of 'the Act on Special Cases Concerning Electric Source Development' that inevitably caused the conflict. Dong-Wook Pyo (2015) correspondingly supports the idea of reforming the power transmission related law since the project in Miryang was inevitable. Additionally, Sang-Gun Ha (2014) suggests strengthening legal and institutional strategy as an alternative since the violation of private property rights, uncertainty on maleficent caused by high voltage transmission lines, unilateral project plan, and lack of justification of the project are seen as the reasons of the Miryang conflict.

The Miryang project is a government-led project characterized as a top-down approach, which has been typical through the developmental process in South Korea. Consequently, this domineering attitude of the government could be seen as a reason why it has been difficult to transform the Miryang conflict peacefully. In relation to that, Sang-Soo Lee (2013c) observes how the government misused their authority to complete the project. According to Lee (2013c), the government connived with KEPCO violating the basic human rights of the villagers in Miryang. Thus, perhaps the key to understanding the conflict in Miryang is challenging the government system, which is criticized as top-down and bureaucratic authoritarianism. 
Accordingly, a survey conducted by Sim et al. (2014) demonstrates the main reason for the conflict is the untrustworthy government and the way Korean Electronic Power Corporation (KEPCO) carries out the project, thus the research proposes to reach a consent made by the villagers in Miryang. As a matter of fact, the government and KEPCO highlighted the importance of following the legal procedure, which was exceptionally applied for the case of Miryang. However, the procedure process has been seemingly used by the government to justify the violent process of the project according to Woo-Chang Kim (2016).

Apart from these, Hwa-Yeon Lee and Soon-Jin Yun (2013) conducted research to investigate the role of the media that failed to frame the Miryang conflict under the environmental justice frame. The media indeed has a huge responsibility for intensifying the conflict in Miryang. Most media outlets intentionally ignored the tragedy that is happening in Miryang while framing the conflict in Miryang under NIMBY. Thus, most of the citizens in South Korea had missed an opportunity to learn about the conflict in Miryang even though an unjust situation (e.g., the way police were treating the villagers and dealing with the situation) made the villagers more furious than ever.

Thus, to simply put it, the villagers in Miryang were completely excluded while all kinds of violence were legally applied to stop their resistance. Basically, the government destroyed the present and the future of the villager's lives in Miryang under the excuse of public interest, and the struggle has obviously intensified. However, the reason why all kinds of violence have been legally justified was to maintain the current energy system, which is closely related to an economic system. Therefore, besides critically analyzing the current legal system, investigating the unjust and unequal energy system is also essential. 
As a matter of fact, Lee et al. (2014) explored the state-led energy system, which inevitably causes social/environmental conflicts, throughout scale politics. Consequently, the researchers propose to change the unequal and unjust energy system to the "soft energy system" (Lee et al., 2014). Soon-Cheol An (2014) also agrees on the necessity of paradigm changes on environmental/social issues although An further recommends adopting a practical alternative approach to the conflict through the "perspective of environmental compassion" (2014: 56) in order to actualize the procedure justice. An contends that a healthy environment and development could co-exist together based on "environmental compassion" that promotes "benefit-sharing, risk communication, and consensus-building" (2014: 47-48).

All of the research conducted well explains the reasons why the conflict has begun and has intensified in Miryang along with the possible alternative solutions. Nonetheless, I believe that it is necessary to put all these pieces of the puzzle together to better and deeper understand the course of the conflict in Miryang, but, more importantly, to search for the alternatives not to repeat the Miryang conflict anywhere else. For that matter, in the following section, the core reason of the conflict in Miryang, the energy crisis, will be discussed by examining how the reality (the proposed energy policy) could be conceptualized depending on the government authority exercising their power (hegemonic discourse of energy crisis), which justifies the project that inevitably causes all the violence while being fully supported by the citizens in Korea.

\subsection{Hegemonic Discourse of Energy Crisis}

The conflict began after the Korean government and KEPCO planned to construct electronic transmission towers and lines that carry $765 \mathrm{kV}$ through the villages and nearby mountains within Miryang. The main reason for the $765 \mathrm{kV}$ project in Miryang was planned to 
secure future energy demand, as it was planned to expand generating units as a prediction of power demand increases 4.3 percent each year (Ministry of Trade, Industry, and Energy, 2000). Consequently, the energy crisis discourse had successfully convinced the whole nation that the necessity of constructing transmission towers and lines in Miryang was going to be carried out despite opposition from the villagers against the decision made by KEPCO. In other words, as the "interest of powerful actors and agents" is projected and enforced onto society as "normalcy" (Robbins, 2012: 219), the energy crisis became the hegemonic discourse.

The hegemonic power of governmental energy policy and system gains support from their citizens, through the practice of "silent power" 22 " (Tetsuya, 2013), consenting to the ideology of the ruling class. In other words, the non-elite population must be convinced by the hegemonic discourse so that the elite group maintains the power over the public:

[T] he State is 'hegemony protected by the armor of coercion' (1975, Q6 888$)$, and at the same time, the State is the entire complex of practical and theoretical activities with which the ruling class not only justifies and maintains its dominance, but manages to win the active consent of those over whom it rules (Gramsci 1975, Q15§10). In addition, civil society represents a complex network of so-called private apparatuses in which one exercises ethico-political leadership or hegemony and through which is produced active consent. It is clear that Gramsci intended to be critical of, and then supersede, the old theory of States in which the State is defined as a simple instrument or apparatus of domination and oppression.

(Gramsci, 1975 cited in Matsuda \& Ohara, 2008: 52)

The idea of hegemony is created by the ruling class through two different methods: in the "civil society", through "private organisms - schools, churches, clubs, journals, and parties that

${ }^{22}$ The term used by Tetsuya Takahashi in one of his books, System Fukushima Okinawa of Sacrifice (2013), to show how (choosing) to be silent can be beneficial to the citizens by ignoring minority groups' voices. 
contribute in molecular fashion to the formation of social, and political consciousness"; and in the "political society", through "public institutions-the government, courts, police, and army which exercise direct dominion" (Bate, 1975: 353).

As a result of the energy crisis, either it is the truth or not, the critical point to be made is how the insertion of a hegemonic idea as the norm to the public resulted in the isolation of certain groups of individuals:

[T] he key to success are ideological and economic: to achieve cultural hegemony, the leaders of a historical block must develop a worldview that appeals to a wide range of other groups within the society, and they must be able to claim with at least some plausibility that their particular interests are those of society at large. This claim may require selective accommodation to the desires of subordinate groups. The emerging hegemonic culture is not merely an ideological mystification but serves the interests of ruling groups at the expense of subordinate ones.

(Lears, 1985: 571)

Under the discourse of the energy crisis, the destruction of the farmers' lives - by destroying their land and therefore their community - inevitably followed, since the hegemonic worldview clashed with the desires of this particular subordinate group. Although the supposed energy crisis may affect an entire community, it is those farmers so far away who are "least able to bear the associated costs in terms of disrupted livelihoods" (Bryant, 1998: 6-8).

After some actors became delegitimized under the hegemonic discourse taking the form of absolute truth, it is not an easy process to 'deconstruct' or 'reframe' the reality. Thus, it is important to ask (1) how this "truth" was reified into reality (through different actors and historical events) and (2) what was left outside (or overlooked) in the enframed reality. In order to challenge the hegemonic power that heavily influenced the conflict in Miryang, it is 
important to understand how its discourse is constructed and functions through the contributions of different actors.

\subsubsection{The Role of Korean Electronic Power Corporations (KEPCO)}

A state-run service, KEPCO argued for the absolute necessity of the project in Miryang, under the threat of a national power shortage, especially after the blackout of September 2011. In 2007, the Ministry of Commerce, Industry and Energy, and Gyeongsandnam-do stated clearly that the purpose of the '765kV Shin Gori-Buk Gyengnam' was to secure the electricity to the North part of Gyeongsang-do and, in the long term, to establish a nation-wide energy transportation system by connecting Shin-Gori power plant energy to a nation-wide power system (Eom, 2012: 66).

The discourse presented the nation as going through a severe energy shortage, which could affect the entire country's economy. For example, in September 2013 the vice president of KEPCO announced to the public "it will be more difficult (to meet power demand) next summer than it was this last summer. It will also be harder this winter" (Cho \& Chung, 2013). With statements like these, the issue of the energy crisis, thus the economic crisis, was being constantly repeated so the problem could be clinically treated through the various social campaigns organized by the government/KEPCO, legitimizing their intentions. There would be no alternative to Miryang in the face of a national catastrophe.

KEPCO had a clear role and was in a position to "define the boundaries of commonsense 'reality' by ignoring views outside those boundaries" (Lears, 1985: 572). This means that the hegemonic discourse of the energy crisis/energy shortage became a 'social truth' to South Korean society but also the dominant ideology. 
As a result, the voice of the villagers in Miryang was rarely heard by the larger public. Therefore, reasonable alternatives proposed by the villagers to the government and KEPCO were rejected and ignored on the ground of excessive costs (Choe, 2013). With this discourse, KEPCO silenced the Miryang residents' voices and ensured the execution of their project, sustaining not only the distribution of electrical power but also the power of their corporate take on the state.

\subsubsection{The Role of Media}

Foucault indeed shows how strategically constructing 'reality' or 'truth' works:

No knowledge is formed without a system of communication, registration, accumulation, and displacement that is in itself a form of power, linked in its existence and its functioning to other forms of power. No power, on the other hand, is exercised without the extraction, appropriation, distribution, or restraint of knowledge. At this level, there is not knowledge [connaissance] on one side and society on the other, or science and the state, but the basic forms of "power knowledge" ["pouvoir-savoir"].

(Foucalt et al., 1997: 17)

And, in this sense, the media has a significant impact on the perception of citizens who learned about problems through their outlets (Anderson, 1997 cited in Lee \& Yun, 2013). The media can selectively choose certain aspects of the story and strategically frame the reality of society by underlining the information selectively (Lee \& Yun, 2013). This means that what the public understands is the frame of 'reality' given by the media in the exercise of their "powerknowledge" (Foucault et al., 1997).

According to George Lakoff, no one can avoid the 'framing' process (Lakoff, 2010: 72), and "all of our knowledge makes use of frames." No word makes sense alone without 
situating it in a context; this is framing. All communication and thinking involve framing (2010: 71):

The facts must make sense in terms of their system of frames, or they will be ignored. The facts, to be communicated, must be framed properly. Furthermore, to understand something complex, a person must have a system of frames in place that can make sense of the facts. [...] Such frame systems have to be built up over a period of time.

(Lakoff, 2010: 73)

Therefore, making sense in the system of framing is directly related to power, and this sense can be "defined as a social relation between groups or institutions, involving the control by a (more) powerful group or institution (and its members) of the actions and the minds of (the members) a less powerful group" (Dijk, 1995: 10). In other words, "controlling the means of mass communication is one of the crucial conditions of social power in contemporary information societies" (ibid.). Media is the door to inform the "social truths" based on the values of "objectivity", "balance" and "public interest" (Hobbs, 2008: 11).

The best way of making sense of people's minds is to continuously produce knowledge and build up frames (Lakoff, 2010). In the end, it does not matter if anyone is telling a fact or not because the fact only has sense as long as it makes sense to the existing systems of frames (ibid.). This might be a crucial reason why the voices of Miryang locals were not heard by the larger public; either mass media did not mention the villager's situation often enough or the situation of the villagers was framed in an unfavorable way for the villagers (e.g., describing their claim simply as not-in-my-backyard, NIMBY). The role of (mainstream) mass media is critical since it can easily activate what is relevant in the minds of the public. 
So how did the media frame the Miryang case? And what was the impact it had? How did it influence the Miryang case? Lee and Yun (2013) conducted research during the period between 2006 and 2012 analyzing seven daily newspapers (five major national daily newspapers, including three 'conservative,' two 'liberal', and two regional daily newspapers). The research includes the number of reports, their frequency, the article's allocation side, its length, and the news source. Surprisingly, the research on how the media framed the conflict changed considerably after the shock of Mr. Chi-Woo Lee's death in 2012.

Lee and Yun (2013) concluded how the media reports framed the conflict in Miryang until Mr. Lee's death; they had been framed either as environmental justice discourse or outside of such discourse. The focus under environmental justice includes the concerns of the environment; safety issues; alternative ways of carrying out the project; the possibility of changing energy policy; an unequal energy system; and the violence of the project. Meanwhile, other frames focused on: villagers' illegality; conflict composition between KEPCO and villagers; emphasizing the negative actions of the villagers; and the inevitability of the project (Lee \& Yun, 2013).

The conservative national daily newspapers (Donga (D), Joseon (Jo), and Jungang (J)) barely used the frame of environmental justice, whereas 'liberal' national daily newspapers (Gyeonghyang $(\mathrm{G})$ and Hangyere $(\mathrm{H})$ ) and regional newspapers (Gyeongnamdomin (Gy) and Busan (B)) focused more on framing the environmental justice (Table 5.2) (Lee \& Yun, 2013: 62). However, the death of Mr. Lee opened up a new phase of the conflict: the transmission tower case finally grasped the public attention. Meanwhile, a Miryang committee was formed, based on many groups/individuals' support, making Miryang a nationwide struggle. This atmosphere changed the media's attitude toward the conflict (Table 5.2) and how often the 
conflict was mentioned, especially in 'liberal' newspapers.

Table 5.2. How the transmission tower case was framed and frequency of the framing over environmental justice

\begin{tabular}{|c|c|c|c|c|c|c|c|c|c|}
\hline Newspaper & & D & Jo & $\mathbf{J}$ & G & $\mathbf{H}$ & Gy & B & Total \\
\hline \multirow{3}{*}{ No. of report } & B.I & 4 & 0 & 2 & 4 & 2 & 34 & 17 & 63 \\
\hline & A.I & 1 & 2 & 0 & 9 & 24 & 119 & 54 & 209 \\
\hline & Total & 5 & 2 & 2 & 13 & 26 & 153 & 71 & 272 \\
\hline \multirow{3}{*}{$\begin{array}{l}\text { No. of } \\
\text { framing }\end{array}$} & B.I & 12 & 0 & 5 & 10 & 5 & 88 & 42 & 162 \\
\hline & A.I & 1 & 3 & 0 & 24 & 71 & 264 & 125 & 488 \\
\hline & Total & 13 & 3 & 5 & 34 & 76 & 352 & 167 & 650 \\
\hline \multirow{3}{*}{$\begin{array}{c}\text { Environmental } \\
\text { Justice Frame } \\
\text { (Ratio \%) }\end{array}$} & B.I & $\begin{array}{c}4 \\
(36.0)\end{array}$ & $\begin{array}{c}0 \\
(0.0)\end{array}$ & $\begin{array}{c}3 \\
(60.0)\end{array}$ & $\begin{array}{c}7 \\
(70.0)\end{array}$ & $\begin{array}{c}3 \\
(60.0)\end{array}$ & $\begin{array}{c}58 \\
(65.9)\end{array}$ & $\begin{array}{c}23 \\
(54.8)\end{array}$ & $\begin{array}{c}98 \\
(60.5)\end{array}$ \\
\hline & A.I & $\begin{array}{c}0 \\
(0.0)\end{array}$ & $\begin{array}{c}0 \\
(0.0)\end{array}$ & $\begin{array}{c}0 \\
(0.0)\end{array}$ & $\begin{array}{c}19 \\
(79.2)\end{array}$ & $\begin{array}{c}54 \\
(76.1)\end{array}$ & $\begin{array}{c}177 \\
(67.0)\end{array}$ & $\begin{array}{c}81 \\
(64.8)\end{array}$ & $\begin{array}{c}331 \\
(67.8)\end{array}$ \\
\hline & Total & $\begin{array}{c}4 \\
(30.8)\end{array}$ & $\begin{array}{c}0 \\
(0.0)\end{array}$ & $\begin{array}{c}3 \\
(60.0)\end{array}$ & $\begin{array}{c}26 \\
(76.5)\end{array}$ & $\begin{array}{c}57 \\
(75.0)\end{array}$ & $\begin{array}{c}235 \\
(66.8)\end{array}$ & $\begin{array}{c}104 \\
(62.3)\end{array}$ & $\begin{array}{l}429 \\
(66)\end{array}$ \\
\hline
\end{tabular}

** B.I (Before Incident of Mr. Lee in 2012), A. I (After Incident of Mr. Lee in 2012)

** Analysis Period: March 27, 2006, to October 10, 2010

(Lee \& Yun, 2013: 63)

Conservative newspapers had much higher subscription rates $(\mathrm{J} 14.1 \%, \mathrm{Ju} 9.0 \%, \mathrm{D}$ 7.4\%) compared to liberal newspapers (H 2.3\% G 2.3) (2012 standard). For instance, the most subscribed newspaper $\mathrm{J}$ (Joseon) only reported the conflict twice, but in both times the focus was on the rising tensions in the conflict by emphasizing the violent actions of villagers (Lee 
\& Yun, 2013: 66). Also, the villager's perspectives were not sufficiently described through the media (especially conservatives). Although concerns over the conflict in Miryang increased, they were not enough to stop the construction. Moreover, the villagers in Miryang continued to be exposed by all sorts of violence.

\subsubsection{Silent Power of the Citizens}

In the end, the power exists based on the public. No power will function without people. However, based on the unjust and unequal system, unfortunately, the message of the villager's perspective of the conflict was barely delivered to the larger public. Often the villagers were described as battling for more compensation money despite the country's urgent situation. Also, the villagers were described as a group that is controlled by 'outside forces ${ }^{23}$, after the struggle was intensified.

Nonetheless, there were different opinions and ideas which came up within the public as the conflict in Miryang was intensified. As Gramsci indicates, hegemony is not about brainwashing the masses, but it is to "make some forms of experience readily available to consciousness while ignoring or suppressing others" (Lears, 1985: 577). As a matter of fact, the research conducted (September 2013) by the Seoul Federation of Environmental Movement shows a surprising result: 66.1 percent understand and support the struggles of the villagers in Miryang whereas 17.6 percent disagrees with the struggle; 49.3 percent believed the conflict occurred due to the system that requires the sacrifice while 31.2 percent believed opposite; 34.7 percent considered the conflict as NIMBY whereas 47.3 percent disagreed; on the suggestions

${ }^{23}$ Outside forces usually mean some forces that try to subvert a nation's stability, and often it is synonym of 'Pro-North Korea forces' (Political Propaganda). Meanwhile, by implying such a frame, the conflict becomes only a community problem although it must be concerned at the national level. 
of alternative possibility, 63.4 percent took the suggestion as a good plan whilst 21.6 percent disagreed; last, 53.9 percent answered "No" for putting transmission tower near the house while 19.1 percent supported the idea. Consequently, the public started feeling an overall discontent regarding the project in Miryang, demonstrating an awareness of the difficult situation that the villagers were going through (KFEM, 2013).

In retrospect, when I learned about the conflict in Miryang, I felt an awful sense of responsibility and shame, since I realized the suffering in Miryang was directly connected to me as a daily energy-consumer in the city, considering that the transmission towers are necessary to send energy to the big cities. Once I realized the true costs associated with the electricity I consumed in my daily life, I could finally see the system of inequality that required someone else's sacrifice along with the destruction of nature.

Curiously, the public started demonstrating similar reactions to the government's project. As seen in the research, many people started disagreeing with the project; demonstrating that most understood the painful situation Miryang residents underwent. This demonstrates the overall public understanding of the injustice and inequality of the project. But what made the public so hesitant to act? A powerful analysis suggests that "the problem is not necessarily what people don't know (the facts). Rather, the problem may be what they do know (underlying assumptions)" (Reinsborough \& Canning, 2010:10). Under the "narrative filters", which are rooted in the dominant culture's control mythologies, it is challenging to let people hear the "social changing messages" because of the existing stories of the world (ibid.).

Therefore, even if the public disagrees with the way the government deals with the Miryang conflict, it is challenging to readdress the reality due to the existing 'fact' of the energy 
crisis, which justifies the violence of the state under the current norm of the system. And this is why the villagers eventually began to question the nation's energy system as the conflict continued.

\subsection{The Truth behind Energy Crisis: Economic Growth}

The Miryang conflict inevitably shows how marginalized people and communities have been aggrieved as a consequence of being exploited, excluded, discriminated against, displaced, and dispossessed based on the energy policy, which is closely related to the economic model of South Korea. To sum up, the threat of the energy crisis directly means the possible threat of an economic crisis. Therefore, maintaining a stable energy system has been considered extremely important to South Korea which depends on high electricity consumption.

Figure 5.3. Electric Consumption per Person in South Korea

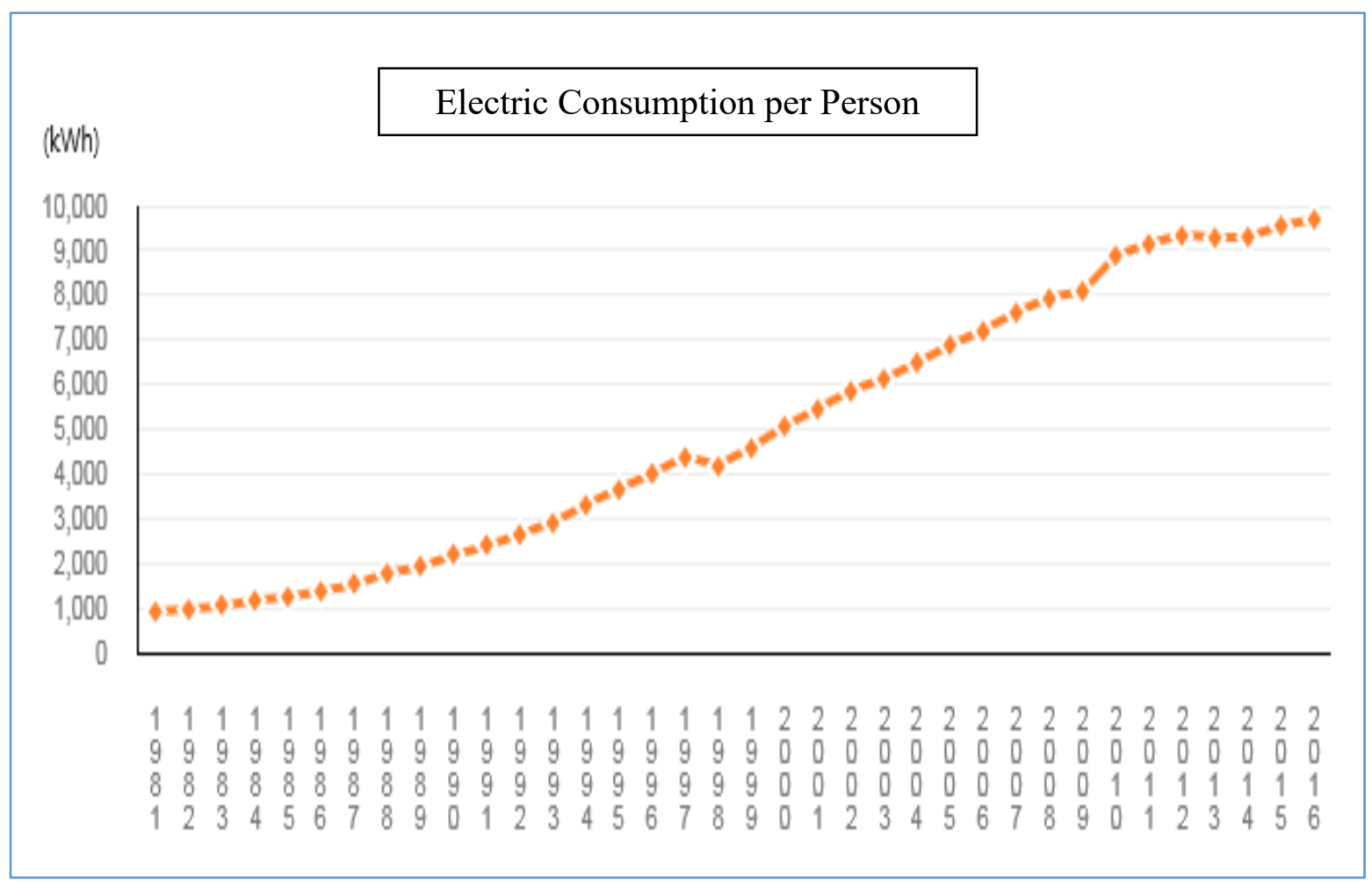

(National Key Indicator, 2018) 
South Korea is a high energy-consuming nation on electricity consumption even among other OECD countries. For instance, the World Factbook in $2016^{24}$ indicates that South Korea ranks as the $9^{\text {th }}$ most energy-consuming nation. This is comparably a high ranking since South Korea uses more electricity energies compared to the countries like the U.K and France which have bigger economies than South Korea (Ji \& Jang, 2013). Besides, electric consumption per person has steadily increased in South Korea (National Key Indicator, 2018) (see Figure 5.3) whereas residential electricity use in South Korea, which is composed of only about 12-13 percent of the total electricity consumption of the country, is lower than the OECD average (see Figure 5.4).

\section{Figure 5.4. Residential Electricity Consumption}

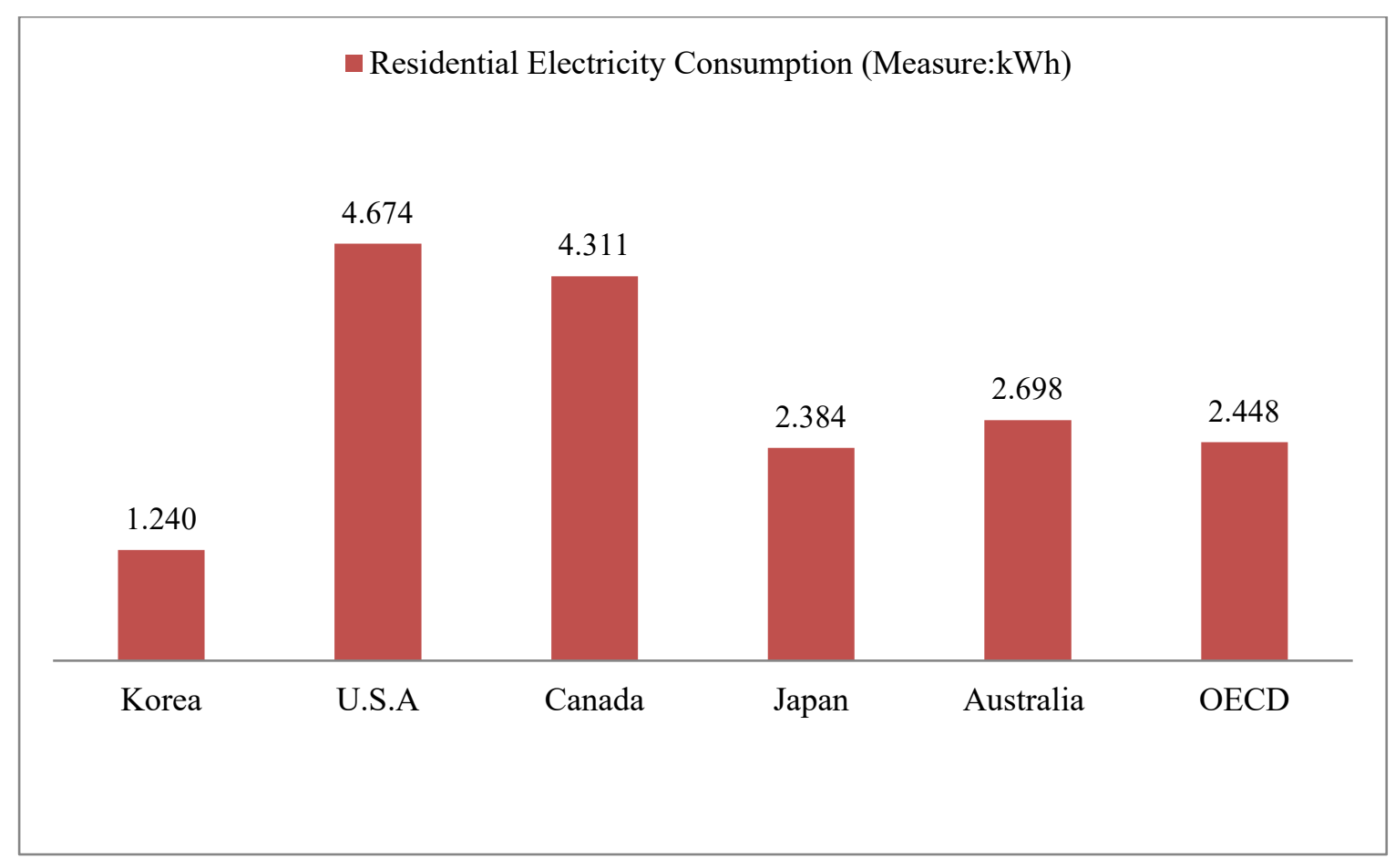

(Ji \& Jang, 2013)

${ }^{24}$ See the link: https://www.cia.gov/library/publications/the-world-factbook/geos/ks.html 
As the CEO Report demonstrates, in 2010, the total electricity consumption in South Korea was 9,851 kWh (per person), which composes 1,240 kWh of residential electricity (Ji \& Jang, 2013: 2). But yet, industries consume more than half of the country's total electricity. According to KEPCO (2018), residential electricity consumption in 2015 was only 13.6 percent while industrial electricity consumption was 56.6 percent and general electricity consumption including business and public use was 21.4 percent (see Table 5.3). Therefore, for instance, monthly energy consumption (e.g., December in 2012) of three major factories of Samsung Electronics, LG Display, and SK Hynix is more than the monthly residential energy consumption of two megacities of Daegu (2,465 million) and Busan $(3,524$ million) (KEPCOa, n.d.).

Table 5.3. Customer Statue by Contract Classification

\begin{tabular}{|c|c|c|c|}
\hline Classification & $\begin{array}{c}\text { Number of Customers } \\
\text { (Thousand Household) }\end{array}$ & $\begin{array}{c}\text { Power Sold } \\
\text { (Million kWh) }\end{array}$ & $\begin{array}{c}\text { Percentage } \\
\text { (\%) }\end{array}$ \\
\hline Residential & 14,419 & 65,619 & 13.6 \\
\hline Public Service & 3,017 & 103,679 & 21.4 \\
\hline Educational & 20 & 7,691 & 1.6 \\
\hline Industrial & 397 & 273,548 & 56.6 \\
\hline Agricultural & 1,638 & 15,702 & 3.2 \\
\hline Street Lighting & 1,673 & 3,341 & 0.7 \\
\hline Total & $\mathbf{2 2 , 0 3 0}$ & $\mathbf{4 8 3 , 6 5 5}$ & $\mathbf{1 0 0}$ \\
\hline
\end{tabular}

(KEPCO-a, n.d.) 
As a matter of fact, the industries in South Korea consume electricity double the OECD average, and the country's industrial energy consumption is ranked as fourth among the OECD countries (Ji \& Jang, 2013). The outcome is certainly connected to the 'cheap' electricity fee (Table 5.4), which obviously has advantaged in chaebol to benefit the maximum profit.

Table 5.4. Price of the Electricity Comparison

(Measured in 2014)

\begin{tabular}{|c|c|c|c|c|c|c|c|c|}
\hline & S. Korea & Japan & U.S.A & France & U.K & Taiwan & Malaysia & Philippines \\
\hline Currency/kWh & $\begin{array}{c}111.28 \\
\mathrm{KRW}\end{array}$ & $20.98 ¥$ & $10.45 \varnothing$ & $0.1128 €$ & $\begin{array}{c}11.565 \\
\text { penny }\end{array}$ & $\begin{array}{c}3.0705 \mathrm{NT} \\
\$\end{array}$ & $\begin{array}{c}0.3779 \mathrm{MY} \\
\mathrm{R}\end{array}$ & $\begin{array}{c}7.4443 \\
\text { Peso }\end{array}$ \\
\hline $\begin{array}{c}\text { Price in Korean } \\
\text { Currency/kWh } \\
\begin{array}{c}\text { Energy charge } \\
\text { level in \%) }\end{array}\end{array}$ & $\begin{array}{c}111.28 \\
(100)\end{array}$ & $\begin{array}{c}209.00 \\
(188)\end{array}$ & $\begin{array}{c}110.05 \\
(99)\end{array}$ & $\begin{array}{c}157.79 \\
(142)\end{array}$ & $\begin{array}{c}200.62 \\
(180)\end{array}$ & $\begin{array}{c}106.64 \\
(96)\end{array}$ & $\begin{array}{c}121.62 \\
(109)\end{array}$ & $\begin{array}{c}176.58 \\
(159)\end{array}$ \\
\hline
\end{tabular}

(KEPCO-b, n.d.)

The explanation for the cheap electricity fee could be (1) the government's strict control on electricity fee, (2) high dependency on nuclear energy, and (3) insufficient environmental cost applied in the electricity fee (Ji \& Jang, 2013). Besides, for industrial electricity users, especially for big companies, the government provides a discounted price, albeit the electricity price is already relatively cheap. For instance, KEPCO charged South Korea's top 20 big companies, including Samsung, Posco, and Hyundai Steel Co., Ltc., below the production cost, and for three years from 2012 to 2014, the total discount that these companies were allocated was 3.7191 trillion won (Han, 2016).

Consequently, by providing 'cheap' energy, industries/companies secured maximum profit. However, providing 'cheap' electricity, which is mainly based on nuclear energy, does 
not help to build a stable energy system or to avoid possible energy shortages. The policy rather encourages companies to exploit the energy system, thus the lives of the marginalized have been exploited while discouraging companies to invest in self-generation electricity/renewable energy generated electricity. The obsession with economic growth and the logic of the capital is clearly seen as the core reasons of the conflict in Miryang.

\subsubsection{The Purpose of the Miryang Project and the Hidden Dangers}

The project in Miryang is directly related to the new construction of a nuclear power plant, and ultimately to the state-led energy policy (Lee et al., 2014). According to KEPCO, constructing $765 \mathrm{kV}$ lines was more than necessary in order to transmit massive energy produced from the Gori nuclear power complex. In fact, there were six Gori nuclear power plant reactors (Gori 1,2,3,4, and Shin-Gori 1,2) when the Miryang project had initiated, and Shin-Gori 3 and 4 were planned to be constructed in an effort to prevent the energy shortage. Accordingly, KEPCO insisted that three presented $345 \mathrm{kV}$ lines are not sufficient enough to send all the energy out when Shin-Gori No. 3 and 4 (since there will be a total of eight nuclear power plant reactors) start producing energy. Additionally, the government expected to build two more nuclear energy reactors, Shin-Gori 5 and 6 . Thus, it seems that there would not be many possible options to take for Miryang in the face of a possible national catastrophic energy crisis. Nevertheless, the struggle in Miryang has continued as the villagers queried about the necessity of constructing $765 \mathrm{kV}$ lines and towers, but also came up with possible alternatives.

Because of the end of the design life of Gori nuclear reactor No. 1 (June 19, 2017), there were six nuclear reactors (Gori 2,3,4, and Shin-Gori 1,2,3) operating and three $345 \mathrm{kV}$ lines must be enough to carry all the energy produced. Besides, Shin-Gori nuclear reactor No. 4, which was planned to generate energy from September 2018, could not start generating 
energy up until September 2019 since it faced the serious scandals of using defective materials (Kim, 2017b). Meanwhile, Shin-Gori nuclear reactors 5 and 6 are currently in the construction process., They are planned to be completed in March 2022 (no. 5) and March 2023 (no. 6). In addition, Gori nuclear reactors 2, 3, and 4 are about to reach the end of design life. Consequently, it shows that constructing transmission lines and towers in Miryang was not that extremely urgent despite what KEPCO insisted. Regardless of the validity, urgency does not justify all the violence applied in Miryang.

At first, KEPCO's main reason for the Miryang project was to transmit energy after constructing Shin-Gori nuclear reactors 3 and 4, but the reality is that the transmission towers and lines in Miryang are only needed after Shin-Gori nuclear reactor 5 and 6 have finished. It means that KEPCO had enough time to plan the project in a better term by examining various alternatives, convincing and listening to the villagers, thus minimizing all the possible conflicts. However, in reality, the villagers have not only experienced all sorts of 'justified' violence but KEPCO has also rejected the alternative solutions that the villagers suggested due to high economic expense. In other words, there was no compromise from the KEPCO as it constantly represents the benefits of the capital, and asking for endless sacrifice of the marginalized.

On top of this, the statement that the vice-president of KEPCO released at a press conference in May 2013 made the villagers reasonably doubt the purpose of the project. The statement strongly showed that the Miryang project is nothing to do with the energy crisis as the government insists: "Shin-Gori reactor No. 3 is the same model as the one that we agreed to construct in the United Arab Emirates (UAE), and one of the conditions of the contract is to confirm its safety before 2015 . Otherwise, we have to pay the penalty. Thus, the conflict in 
Miryang must be stopped now so that the construction could be completed in time" (Lee, 2013b).

Even though KEPCO simply denied the statement and continuously stressed the danger of the energy crisis, it is only reasonable to query the correlation between the Miryang project and one of the 17th President Lee's 'accomplishments', winning a deal to build atomic power plants in the UAE. Since then, the technology of nuclear power plants became a future economy that will benefit South Korea, which is a polemic issue as the nuclear phase-out has been the leading energy policy of world politics. Even if the purpose of the Miryang project is nothing to do with economic benefit (e.g., as the UAE case shows), there must be different alternatives to replace the current energy system if it is searching for a solution exclusively for the energy crisis as the government/KEPCO insists. Thus, more importantly, it is imperative to question a fundamental economic system that heavily depends on 'cheap' electronic energy in order to maximize the benefit of the capital.

The Miryang villagers have realized that as long as there is a plan for constructing more nuclear reactors as followed by the state-led energy policy, there will be constant cases like Miryang. Therefore, the Miryang movement in the short-term aimed to cancel the plan of constructing Shin-Gori nuclear reactors number 5 and 6, whereas in the long-term it has been focused on nuclear-phase out that ultimately requires the energy transition. Unlike $\mathrm{KEPCO} /$ government, the villagers believe that nuclear energy is enormously expensive and dangerous since their lives are under threat as their livelihoods are simply wasted to fulfill the desire of the capital. 
In South Korea, there have been intense discussions and concerns about increasing nuclear power energy, especially by going through conflicts like Miryang. But also by experiencing "unexpected" earthquakes inside and outside of Korea, the citizens critically questioned over the safety of using nuclear power energy. For example, the 2011 Fukushima Daiichi nuclear disaster in Japan proved the possible danger of using nuclear energy. In addition, South Korea is no longer considered an 'earthquake-safe' zone since major tremors had occurred two years in a row, 2016 in Gyeongju (magnitude 5.8) and 2017 in Pohang (magnitude 5.4) where more than half of the country's power plants are concentrated (see Map 5.2). For that matter, the government suggested advancing seismic design criteria from magnitude 6.5 to 7.0 , which is still lower criteria than the Japanese power plants seismic guideline, magnitude 7.9. Thus, many citizens have been nonstop concerned about the possible nuclear disasters in Korea.

Regarding this, the critical point to be paid attention to is that South Korea has the world's highest density of nuclear power plants. All four sites are a nuclear power complex where more than six nuclear power reactors are concentrated (see Map 5.2). For instance, in the southeast of South Korea where Gori and Wolseong power plants are located, there are more than 4.2 million residents living within $30 \mathrm{~km}$ of the nuclear power complex. Even though the experts (or "nuclear mafia" 25 ") are convinced of the security and safety of nuclear power technology, if there is an accident, it is clear that no experts can be responsible for the chaotic disaster and its aftermath.

25 Since there are enormous money involved within the nuclear energy related technology and companies, they have huge influence on the decision-making, thus often they are called as nuclear mafia in South Korea 
Accordingly, discussion on the issue of nuclear phase-out has been intensely discussed although nuclear energy has been treated as one of the 'realistic' alternative energy sources to fulfill the goals of sustainable development. For that matter, there have been varied scientists/scholars/experts who discuss ${ }^{26}$ the safety issue of using nuclear power energy and the necessity of using nuclear power, but their argument is basically focused on how nuclear power energy could reduce $\mathrm{CO}^{2}$ emission while 'effectively' maintaining the current economy. Thus, despite endless questions and doubts over the positive use of nuclear power energy, nuclear energy has been considered the most realistic, safe, clean, and cheap energy to solve the catastrophe of the nation and even the globe, according to some.

The issue of nuclear energy is an ongoing debate that everyone has an opinion about but meanwhile, no one really knows the 'answer' for it. It is indeed a crucial topic to discuss, however, the safety issue of nuclear energy is not the main focus of this dissertation. Instead, the dissertation questions and analyzes how one's life could be in terror under the governmentled energy policy that in the end focuses on securing the maximum economic advantages despite constantly producing injustice and inequality.

\subsubsection{Miryang Conflict within the Discussion of Sustainable Development}

Even though the idea of sustainable development was introduced since the 1992 Rio Summit and the term has been widely used in South Korea, unfortunately, there have not been any noticeable changes so far. Instead, South Korea has seemingly struggled to adopt the principle ideas of sustainable development. Thus, South Korea also has faced worsened (and/or new) social-environmental conflicts in each year since the sustainable development practiced

\footnotetext{
${ }^{26}$ See, for instance, this video "Debate: Does the world need nuclear energy?" https://www.youtube.com/watch?v=UK8ccWSZkic
} 
in South Korea seems exceptionally focused on economic growth based on scientific technology but without challenging the system that produces inequality and injustice.

It is true that the Miryang project is directly connected to the nation's energy policy planned in 2000. However, the Miryang conflict is related to the nuclear energy policy, which has been widely supported throughout the Green Growth energy policy. In this regard, the conflict in Miryang clearly reveals and proves how difficult it was to adopt and practice the essential ideas of sustainable development in South Korea.

In South Korea, there had not been any visible sustainable development policies until the emergence of the Green Growth policy. Despite the aforementioned disputes and critiques, Green Growth could be considered as one of the most visible sustainable development policies applied in South Korea. Green Growth promises the bright future that sustains healthy nature, but also secures economic growth, ultimately for the sake of (at least) the citizens in South Korea even though the outcome has been desperately disappointing. Green Growth, in the end, could not accomplish its objectives to reach sustainable development.

The conflict in Miryang has shown how the lives of the villagers in Miryang have been further exploited due to the unsustainable aspect of Green Growth policy that highly emphasizes the technological renovation to maintain economic growth rather than challenging the system that causes injustice and inequality. Therefore, meanwhile, the voice of the villagers in Miryang was barely heard by the larger public that was convinced by the hegemonic discourse of the energy crisis.

Consequently, the Green Growth policy that supposedly helps to enhance the quality of people's life has shattered the livelihoods of the villagers while securing and maintaining 
the economic benefit. What is worse, by going through Green Growth policy, direct and structural violence even looked right, or at least not wrong, as nuclear energy has been considered as the basis to succeed Green Growth.

For that, observing the Miryang movement is crucial since the Miryang struggle that has lasted for more than a decade gives us a chance to reflect on how to apply and practice sustainable development that actually sustains the lives of living beings within healthy nature other than solely sustaining economic development.

\subsection{Conclusion}

In this chapter, the conflict in Miryang has been observed drawing upon the existing literature. Through the chapter, the process and the consequences of the conflict in Miryang have been examined in order to help the readers to see the clear picture of the conflict. The chapter shows how the state-led project in Miryang has caused endless violence. But also, it demonstrates how the Miryang conflict is directly connected to South Korea's developmental process that is enormously influenced by political-economic power. More importantly, by exploring the Miryang case, the question of how to embrace and practice sustainable development has emerged as economic-political power continuously has influenced the conflict in Miryang under the sustainable development discussion.

Accordingly, the Miryang conflict gives us an opportunity to think about the following questions; if green/renewable energy (nuclear energy in this specific case of Miryang) continuously requires sacrificing livelihoods of the villagers, could it be the future energy to succeed green growth/ sustainable development as some politicians and scientific experts argue? 
The same question indeed goes for all other mega energy policies, including wind energy, solar energy, and so forth since these energy sources also cause social-environmental conflicts.

Consequently, by analyzing the conflict in Miryang, the chapter shows how important it is to include the voice of the marginalized that have been affected the most due to successful sustainable development in South Korea. Otherwise, sustainable development will inevitably fail to reach its goals by continuously causing environmental-social conflicts as it produces injustice and inequality as proven by the Miryang conflict. Thus, the next chapter will focus on how the Miryang movement has challenged the hegemonic power and its significance. 


\section{CHAPTER SIX}

\section{Environmental Justice Movements in Miryang and their Contribution to Sustainable Development Discussion}

\subsection{Introduction}

Sustainable development discourse has faced different criticisms as it is exclusively representing the interest of the capital while excluding the voices of the people, especially the marginalized of society, whereas environmental degradation has been intensified. Therefore, environmental justice that inevitably includes the voice of the marginalized has been suggested to be included within the discussion of sustainable development. As the recent Sustainable Development Goals (SDGs) emphasized, "leaving no one behind" is one of the pillars, which is a big improvement over the MDGs (Economic and Social Council, 2018: 11). This value is critical and central to any discussion on sustainability since the voice of the vulnerable groups within the society could be easily neglected especially under the powerful hegemony that unfortunately has also influenced the sustainable development discourse.

South Korea demonstrates how the interests of the capital economy have been the main force of the nation even during the sustainable development discussion, which, therefore, explains the failure of achieving sustainability of the nation while worsening the socialenvironmental conflicts, including the Miryang case. The Miryang conflict ultimately demonstrates that the sustainable development discussion must be examined within a systematic perception that could fundamentally question and challenge the current economic system rather than discussion in the sense of technological renovation. Otherwise, the ongoing 
conflict in Miryang, for instance, will probably be continued, but more importantly, similar conflicts will most likely continue to occur.

In other words, the Miryang case proves very unsustainable aspects of the development process in South Korea, the country that recently initiated 2030 K-SDGs. The villagers in Miryang have experienced all sorts of 'justified' violence (even throughout the sustainable development practices, Green Growth policy) as they continue to struggle to peacefully exist within nature. This means that the concerns of the villagers in Miryang have not been seriously considered in the discussion of sustainable development. Since the discussion of sustainable development has been skewed over the economic development that is based on neoliberal capitalism, the unjust and unsustainable system, which apparently caused the conflicts like the one in Miryang, would expect to continue even throughout the discussion of K-SDGs.

Hence, it is crucial to inquire how to accomplish objectives of sustainable development while "leaving no one behind". Searching for the possible answers/alternatives, the Miryang movement will be examined from the environmental justice perspective to point out environmental injustice aspects of the project, but more importantly to highlight the essential values that could be practical contributions to the sustainable development discussion which must be inclusive so that no one will be left behind.

For this, in the first section, how environmental justice theory has been applied and practiced in the context of South Korea will be observed. Since the situation in South Korea is distinctive from the U.S, where the term environmental justice has originated, there have been adequate efforts to distinguish the characteristics of environmental (in)justice in South Korea, which helps to highlight the environmental injustice case in Miryang. For the next section, the 
outcome of the Miryang movement will be presented. In fact, the Miryang movement that brought meaningful discussions and changes within Korean society have been examined from different studies and perspectives.

However, the movement in Miryang has not been further discussed to improve sustainable development practice. As the Miryang movement has strong characteristics of the environmental justice movement, meaning that the voice of the voiceless is included, it could be a practical contribution to the sustainable development discourse in the context of South Korea. For that, in the last section, I will pay attention to the political space created by the villagers as the movement contains the simple but treasured messages that often have been ignored by the hegemonic power of capital, which profoundly influences the discourse of sustainable development.

\subsection{Applying Environmental Justice in South Korea}

Excessive obsession with economic development caused numerous socialenvironmental conflicts in South Korea. Concerning that, different grassroots movements, supported by environmental movement activists, occurred. When the dictatorship had collapsed in 1987, the environmental concerns in South Korea have become more of a public discussion. Furthermore, the environmental movement has been advanced but also more influential.

Following that, in the late 1990s, environmental justice, the term first emerged in the U.S in the $1980 \mathrm{~s}$, has been introduced as an alternative approach to examine environmental issues in South Korea (Park, 2006). Then, in 1998, the new environmental organization, entitled 'environmental justice' that adopted new ideas and activism was initiated by academics 
and activists (ibid.). Environmental justice approach uses a wide perspective that not only pays attention on environmental issue, but matter of social justice.

However, since applying environmental justice in South Korea must be different from the U.S where the concept of environmental justice has originated, different academics studied to understand the characteristics of environmental injustice/inequality produced under the features of South Korean society, but also to identify which groups of society are most disadvantaged in the case of South Korea. Thus, this section will examine how the concept of environmental justice has been discussed, and what are the characteristics of environmental (in)justice in South Korea.

\subsubsection{Academic Debate/ Previous Studies on Environmental (In)justice in South Korea}

When the new concept of environmental justice has been introduced to South Korea, many scholars focused on discussing the concept and the definition of environmental justice (for instance see: Go, 1997; Kwon, 1997; 2001; Kim, 2004; Park, 2004; Jeong, 1997; Han, 1999; 2002, Hwang, 2002 in Park, 2006: 77). As a result, the discussion of environmental justice, at first, mainly stayed within the environmental groups and academic researchers instead of spreading out widely in society (Park, 2006).

The scholars believed that environmental justice discussion could effectively deal with both the social and environmental problems since environmental justice discussion opens up different perspectives due to observing environmental injustice. This is despite the fact that the characteristics of environmental injustice in South Korea are different from the ones in the U.S. Therefore, various scholars investigated to analyze environmental injustice within the South Korean context (for example see: Kwon, 2002; Park, 2000; Seo, 2000; Oh, 2005; Yun, 2003; 
2004; 2006; Yun \& Jang, 2005; Lee, 2000; Jeon, 2000; Ju, 2003; Choi \& Ryu, 2005; Han, 2000; 2005).

The root of environmental injustice in the U.S is based on racism and classism. Additionally, the environmental injustice(s) in the U.S are mostly focused on the maldistribution of environmental hazards that are produced from post-industrialization. Contrarily, environmental injustice(s) in South Korea is caused by the process of economic development and industrialization (Cho, 2013). Therefore, the cause of environmental injustice in South Korea is related to being excluded from fair distribution on economic benefits, whereas the environmental injustice in the U.S focuses more on the distribution of environmental hazards. In other words, the questions of environmental (in)justice in South Korea are probably caused when the government is applying the development policy. Thus, the victims of environmental injustice in South Korea are mostly the marginalized of the society who are often systematically excluded from the process of development and decision making since the economic benefit was highly valued (Cho, 2013).

Accordingly, various authors have observed and analyzed different case studies under the environmental justice frame. For instance, Sang-Heon Lee explores the case of the Wicheon Industrial Complex in Daegu and proposes environmentally just solutions (2000). Meanwhile, Jae-Gyung Jeon (2000) investigates how the case of the Saemangeum Project produced environmental injustice that affected nature and the marginalized. Furthermore, Hae-Su Kwon (2002) evaluates the environmental justice movement in South Korea through the Greenbelt Preservation movements and National Trust Movements by pointing out the environmental injustice for future generations. In addition, Soon-Jin Yun (2006) analyzes the case of how a low and medium level radioactive waste disposal site was selected unjustly. 
These databases of environmental conflicts under the environmental justice frame have been an important asset since the discussion of environmental justice directly comes from the actual movement(s), and the discussion must go beyond the theoretical debate. As Hae-Soo Kwon (1997) points out, it is important to observe varied environmental conflict cases under the environmental justice frame in an effort to provide a method to complete actual environmental justice throughout its related policy. In other words, environmental justice discussion in South Korea must be expanded by observing and analyzing more of empirical research since the discussion of environmental justice research has been heavily focused on the discourse itself as In-Hee Yi (2008) explains.

As a result, there was a suggestion of revising and reforming the legal and policy system by including the concept of environmental justice. It is critical to engage with institutional changes because environmental injustice is caused by an unequal political and economic system. In South Korea, environmental justice was barely discussed within the environmental policy field because of excessive influence from the political authorities (example: through tax policy) (Kwon, 2000). However, in actuality, varied scholars argue that it is more than necessarily providing (economic and political) institutional strategies to ease down the environmental injustice(s).

As a matter of fact, in 1999, the Korean Environmental Policy Law tried to include the principles of environmental justice, which emphasize the equality of distributing benefits and the danger of environmental policy, and the process ( $\mathrm{Gu}, 2012)$. However, the environmental justice law and related policy failed to be enacted. There were opposing groups who were against revising the environmental policy law. For instance, a jurist Sang-Don Lee criticized revision of the environmental policy and law because (1) the law could possibly drag the 
economy down, (2) the law seems based on Marx-Leninism, which is a taboo in South Korea, and (3) the law would do nothing with the equity issue (Han, 1999). The arguments of Lee reflect the 'reality' of Korean mainstream society that is obsessed with the economic growth paradigm and the worldview of the elite group who definitely ignores how this unequal system constantly violates nature and the lives of the marginalized.

However, meanwhile, it is also important to understand that the legal operation of environmental justice cannot be the end of the goal, and the solution for all. Even though the U.S is the most advanced country that recognized the importance of environmental justice and improved environmental protection, as Bullard et al. explored, "millions of Americans continue to live, work, play and go to school in unsafe and unhealthy physical environments" (2007: 9). In fact, the U.S EPA has not always recognized how "government and industries (whether intended or unintended) have adverse impacts on poor people and people of color" (ibid.).

There have been critical approaches to discuss environmental justice in the context of South Korea (e.g., Lee, 1997; Cho, 2000; Choi, 1998a; 1998b; 2001; 2005). Nevertheless, the discussion of environmental justice has been limited since it has been based on the mainstream environmental justice that is mainly focused and based on equality and distributive justice (Park, 2006). In other words, it lacks to achieve "progressive practical environmental justice" (Lee, 1997).

As Byung-Doo Choi further explores liberal environmentalism that focuses on equality issues in terms of environmental justice (2005), what is necessary is that environmental justice must be explored by different theoretical backgrounds other than liberal justice (1998a, 1998b, 
2001, and 2010). Thus, Choi suggests transforming liberalism to critical pluralism in order to understand the environmental problem accurately, but also to conceptualize a proper theory of environmental justice (2005).

In the end, in the context of South Korea, the necessity of practical environmental justice is critical since the academic discussion of environmental justice is not specific enough while the current modern system continuously creates unlimited environmental threats. This is to say that environmental justice discussion should not only rely on the justice theory since the environmental issues are the real problems that must be solved. Instead, environmental justice needs to be practically understood, which means how environmental injustice is related to the unequal social system specifically from a perspective of South Korea (Cho, 2000, 2013).

\subsubsection{Characteristics of Environmental Injustice in South Korea}

As South Korea has been obsessed with quantitative growth, the escalating environmental/social conflicts through "the state vs. civic groups, government vs. residences, central government vs. local government, development vs. protection, and economy vs. environment" have only increased (Cho, 2013: 98, author's translation). However, most of the development projects, which have ignored the voice of the marginalized, have been justified by emphasizing the public interest. Thus, Cho, Myung-Rae (2013) considers South Korea as a "developing state" even though the nation is probably best defined as a developed country due to comparably high GDPs.

South Korea has been concentrated on 'spatial development' that promotes the economy by developing the space (Cho, 2013). For that reason, South Korea has been exclusively focused on the projects of constructions, such as building industrial factories, 
households, highways, energy-power plants, followed by the government-led development policy. Therefore, environmental injustice in South Korea could be divided into six different areas which are, (1) developing the regional resources, (2) developing the large-scale substructure facilities, (3) sprawl development, (4) development on city environment, (5) industrial development, and (6) construction of environmental hazard facilities (Cho, 2013).

First, developing the regional resources, such as the Saemangeum land reclamation project and Dong-gang Dam Construction, cause destruction on the local ecosystem in order to maximize the benefits of the current generation while depriving the local livelihoods. The second type is developing the large-scale substructure facilities (e.g., Kyung-Bu high-speed railway, construction on a new town, and power production facilities) that ultimately destroy the national ecological system, but also the local community. Sprawl development is also a great cause of environmental injustice by damaging the green belt and agricultural land. Due to the unplanned development, residential environmental degradation also occurs, thus especially the smallholder farmers affect the most. Next, development of the city environment, including residential redevelopment, river restoration, or development of traffic equipment, further leads to violating residential rights and right to live, especially the poor, by degenerating the downtown environment and its ecosystem. Another type to observe is industrial development, which evokes the loss of local residential life, but also causes pollution, for instance, the drinking water resources, thus spreading related disease. Last, constructing the environmental hazard facilities, such as the construction of landfills and incineration facilities produces environmental injustice by damaging local living conditions and the environment.

To sum up, the environmental (in)justice in South Korea is heavily influenced by political powers, which have a close relation to economic elite groups. As it has been 
scrutinized, the developmental process in South Korea has exclusively been led by the government, thus, the unequal development process has implied a designated region, such as the south-east region where most of the industrial complex is located. For that matter, the importance of environmental justice was barely recognized within the environmental policies and law, whereas the sacrifice of the marginalized continued. This is to say that many applied policies were anti-environmental and anti-democratic while not recognizing the minority groups, including the poor, elderly, women, children, farmers, and so forth.

Consequently, since the developmental process of South Korea has unequally proceeded, the gap of regional inequality is wide. This ultimately causes conflict not only among social groups but also among different generations (Kwon, 2002). Thus, there have been different resistances against the state-led development projects although the grassroots movements often have been treated as NIMBY (Not In My Backyard).

However, most of the grassroots movements lack the discussion within the environmental justice frame as the famous grassroots movement, the 'Cheong-Gye San Movement against the Transmission Tower' shows. The movement was considered a successful environmental movement by emphasizing the importance of a healthy environment but also the safety and peaceful existence of living beings (Jin, 2003). As the committee further insisted, the problem was solved with detouring transmission towers and proper compensation (Eom, 2012). However, from the environmental justice perspective, such outcomes cannot be considered successful. As Eom highlights, environmental justice requires accomplishing the value of NIAMBY (Not In Anybody's Backyard) (2012), which indeed could be extended to the idea of NOPE (Not On Planet Earth). The fact is environmental justice must care for all of the citizens, future generations, and even whole ecospecies for the long term. 
In conclusion, the environmental justice frame provides a different perspective to observe the environmental conflict in South Korea, however, the discussion of environmental justice needs to be developed and advanced further in order to achieve practical environmental justice by challenging the social-political system that constantly threatens the healthy environment as the Miryang case demonstrates.

\subsection{Environmental Injustice of the Miryang Project}

The Miryang conflict clearly shows different aspects of environmental injustice, which could be divided into distribution, participation/procedure, recognition, and capabilities aspects that are interplaying among each other. The Miryang project is indeed typical in the context of the South Korean development process that prefers economic benefits. In other words, the Miryang conflict is nothing new in South Korea's developmental history even though the resistance of the Miryang villagers is exceptional. This is why the movement in Miryang is significant to observe.

Before observing and examining the importance of the movement in Miryang however, it is imperative to observe the injustice aspects of the Miryang project, which became the main motive of the movement. Consequently, analyzing the injustice aspects of the Miryang project, the Korean version of environmental injustice could be examined in a way that is distinctive from the U.S version, but more importantly it could contribute to reaching practical environmental justice that could eventually help to reach just and sustainable development in the context of South Korea.

\subsubsection{Distributive Injustice of the Miryang Project}


As South Korea has obsessed with quantitative economic growth, the country developed an abnormal model that does not distribute advantages and disadvantages equally. Consequently, the minorities of society mostly receive environmental bads in order to secure the benefits for some other groups, mostly the elite groups, of the society. In South Korea's development process, rural areas have been predominantly selected to complete the process of "successful" development by locating harmful facilities, as revealed by the Miryang project.

The rural areas in Miryang were the peaceful traditional farm villages mostly composed of the elderly population. Demographic data shows that the elderly population (people aged more than 65) in Miryang is about 25 percent $(27,157 / 107,159$ people) in 2017 (Miryang City, n.d.), which is higher compared to the average of the elderly population in South Korea, which is 14.3 percent in 2018 (Lee \& Lee, 2018: 3).

According to KEPCO, the Miryang project is mandatory to prevent the possible energy crisis, which eventually threatens the economic system. On the other hand, from the beginning of the movement, the villagers constantly claim to oppose the project since most of the villagers in Miryang live off farming activities. It was the struggle to protect the villagers' right to live a healthy life, which would be an instinctual response for anyone even though the struggle has been treated as NIMBY that eventually restrains the development process of South Korea. Therefore, the villagers continued to struggle to cancel the project of building transmission towers and lines from the villages in Miryang.

Additionally, it shows that the Miryang project has nothing to do with the issue of the energy crisis since it was for benefitting the big companies by producing cheap electricity. But also the project was treated as a means to promote the new economy by exporting nuclear 
energy technology. As a result of the $765 \mathrm{kV}$ transmission lines and tower project, the livelihoods of the villagers in Miryang have been completely violated. Thus, the villagers in Miryang have brought up the topic of inequity and injustice issues.

Table 6.1. Sixteen Cities and Provinces on Self-Sufficiency in Electricity

(Measure: TWh, \%)

\begin{tabular}{|c|c|c|c|c|c|}
\hline Division & Consumption & $\begin{array}{c}\text { Self } \\
\text { Sufficiency }\end{array}$ & Division & Consumption & $\begin{array}{c}\text { Self } \\
\text { Sufficiency }\end{array}$ \\
\hline $\begin{array}{c}\text { Gyeonggi } \\
\text { Province }\end{array}$ & 100 & 28.5 & $\begin{array}{c}\text { Jeonbuk } \\
\text { Province }\end{array}$ & 21 & 36.2 \\
\hline $\begin{array}{c}\text { Seoul } \\
\text { (Capital) }\end{array}$ & 47 & 4.2 & $\begin{array}{c}\text { Chungbuk } \\
\text { Province }\end{array}$ & 21 & 5.9 \\
\hline $\begin{array}{c}\text { Gyeongbuk } \\
\text { Province }\end{array}$ & 45 & 156.7 & Busan City & 21 & 172.7 \\
\hline $\begin{array}{c}\text { Chungnam } \\
\text { Province }\end{array}$ & 44 & 266.9 & $\begin{array}{c}\text { Gangwon } \\
\text { Province }\end{array}$ & 16 & 72.8 \\
\hline $\begin{array}{c}\text { Gyeongnam } \\
\text { Province }\end{array}$ & 33 & 49.8 & $\begin{array}{c}\text { Daejeon } \\
\text { City }\end{array}$ & 9 & 2.6 \\
\hline $\begin{array}{c}\text { Ul-San City } \\
\text { Daegu City }\end{array}$ & 226.0 & $\begin{array}{c}\text { Gwangju } \\
\text { City }\end{array}$ & 8 & 1.7 \\
\hline $\begin{array}{c}\text { Jeonnam } \\
\text { Province }\end{array}$ & 28 & 337.2 & $\begin{array}{c}\text { Jeju City } \\
\text { (Island) }\end{array}$ & 4 & 79.7 \\
\hline \begin{tabular}{c} 
Incheon City \\
\hline
\end{tabular} & 23 & 226.3 & & 9.8 \\
\hline
\end{tabular}

* Self Sufficiency $=$ Electricity Output - Electricity Consumption

* Miryang is a small city located in Gyeongnam province

(Kim, 2013: 5)

In South Korea, most of the electronic power production facilities are located in the countryside to supply 'cheap' energy for the big cities to consume. The capital area among big cities is heavily dependent on other regions in order to sustain the 'luxurious' city lifestyle 
(Table 6.1.). In other words, for the convenience of the citizens of big cities and big companies, the detriment in the rural areas is followed by establishing harmful facilities there, as the Miryang project proved.

As table 6.1 demonstrates, most of the provinces, including Gyeongnam province where Miryang is located, produce more electricity output than what they consume, whereas most major cities, especially the capital area, produce less than what they need. Since the Miryang project is closely related to the energy policy, most villagers apparently queried why KEPCO does not plan to construct nuclear reactors in Seoul if it is as crucial as KEPCO argues. Through this valid point, Miryang villagers highlight the unequal and unjust system that supports the maldistribution of environmental bads.

However, the Miryang villagers further point out the equal distribution of benefits other than distributing harmful facilities. For instance, since the situation is supposed to be urgent as KEPCO argues, the Miryang villagers proposed different alternatives, which could satisfy both parties of KEPCO and the villagers while succeeding in the government project to benefit the public.

Accordingly, the proposed suggestions were either making a detour to be away from the villages or burying partial transmission towers and lines under the ground as these towers and lines are too closely passing the villages at only 200 to 300 meters away. Some transmission towers and lines actually have been built upright in the middle of fertile rice fields, behind the villager's houses and schools, and next to the burial sites where the villager's ancestors are buried. The main reason to construct $765 \mathrm{kV}$ transmission towers and lines is for the necessity of constructing more nuclear reactors, Shin-Gori 5 and 6 that is expected to be 
ready in 2022 and 2023 according to the then-president of KEPCO Hwan-Ik Cho. Thus, when the villagers suggested an alternative solution up until 2013, there was supposed to be no technical problem of transmitting the energy with the $345 \mathrm{kV}$ transmission towers and lines as KEPCO also agrees.

However, all suggested alternatives were turned down due to the high costs and technological deficiency. And, the decisions made by KEPCO seem unjust and unfair. For instance, the technology of superconducting wires was commercialized in November 2019 by KEPCO-LS wire (Sohn, 2019). Furthermore, there is a case in Bundang ${ }^{27}$ where all the $345 \mathrm{kV}$ transmission towers and lines are buried, whereas 69 extra high voltage power transmission towers $^{28}$ are put up in the villages of Miryang.

Accordingly, the villagers in Miryang obviously find the reality unfair, which has also been highlighted in the case of telephone poles. KEPCO reports from 2019 shows that in Seoul, one of the cities that has the lowest self-sufficiency rate on electricity, 89.6 percent of the transmission towers and lines are under the ground while the rate of burying transmission towers and lines under the ground in Gyeongnam province is only 3 percent (see Table 6.2) (Kim, 2019). In the end, the provinces that produce the most electricity have a low percentage

\footnotetext{
${ }^{27}$ One of the most populated areas in South Korea is Bundang, a district within Seongnam city located in Gyeongnam province that has 28.5 percent energy self-efficiency.

28 Even though the transmission towers in Miryang are $765 \mathrm{kV}$, the villagers in Miryang proved that it is sufficient to transmit all the produced energy with $345 \mathrm{kV}$ transmission towers and lines, which KEPCO also agreed at first (see more details: https://www.nocutnews.co.kr/news/1122160). Furthermore, building $765 \mathrm{kV}$ transmission towers and lines that are not urgently necessary at the current situation, thus, is closely connected to the exporting the $765 \mathrm{kV}$ energy model to UAE, the outstanding achievement of the $17^{\text {th }}$ President Lee, M.B.
} 
of burying transmission towers and lines under the ground, except Incheon and Busan. This distributive injustice is clearly showcased in the Miryang project.

Table 6.2. Percentage of Transmission Towers and Lines Under the Ground

\begin{tabular}{|c|c|c|c|c|c|c|c|}
\hline Places & $\begin{array}{c}2014 \\
(\mathrm{~A})\end{array}$ & 2015 & 2016 & 2017 & 2018 & $\begin{array}{c}8.2019 \\
(\mathrm{~B})\end{array}$ & $\begin{array}{c}\text { Increase } \\
(\mathrm{B}-\mathrm{A})\end{array}$ \\
\hline Seoul & 88.6 & 89.4 & 89.4 & 89.5 & 89.6 & 89.6 & 1.0 \\
\hline Incheon & 62.8 & 66.7 & 69.2 & 69.6 & 71.6 & 71.9 & 9.1 \\
\hline Busan & 45.0 & 44.8 & 45.0 & 45.8 & 45.4 & 46.2 & 1.2 \\
\hline Gwanju & 38.1 & 38.1 & 38.1 & 38.1 & 41.1 & 41.1 & 3.0 \\
\hline Jeju & 35.9 & 35.9 & 35.9 & 35.9 & 35.3 & 35.3 & -0.6 \\
\hline Daejeon & 28.6 & 28.8 & 27.8 & 27.8 & 28.3 & 28.3 & -0.3 \\
\hline Daegu & 30.2 & 30.1 & 26.3 & 28.6 & 26.7 & 27.8 & -2.4 \\
\hline Sejong & 9.3 & 9.5 & 9.0 & 18.0 & 17.9 & 17.9 & 8.6 \\
\hline Gyeonggi & 12.9 & 12.8 & 12.9 & 14.9 & 15.5 & 17.4 & 4.5 \\
\hline Jeonbuk & 5.9 & 5.9 & 5.9 & 6.8 & 7.1 & 7.0 & 1.1 \\
\hline Ulsan & 4.0 & 4.2 & 4.1 & 4.5 & 5.8 & 6.4 & 2.4 \\
\hline Jeonnam & 4.3 & 4.8 & 4.8 & 4.8 & 4.9 & 4.9 & 0.6 \\
\hline Gyeongnam & 2.7 & 2.7 & 2.8 & 2.8 & 2.8 & 3.0 & 0.3 \\
\hline Chungbuk & 2.5 & 2.5 & 2.5 & 2.5 & 2.5 & 2.5 & - \\
\hline Chungnam & 1.2 & 1.2 & 1.3 & 1.3 & 1.3 & 1.3 & 0.1 \\
\hline Gyeongbuk & 0.9 & 0.9 & 1.1 & 1.2 & 1.2 & 1.2 & 0.3 \\
\hline Gangwon & 0.9 & 0.9 & 0.9 & 1.1 & 1.1 & 1.1 & 0.2 \\
\hline Total & 11.1 & 11.3 & 11.3 & 11.9 & 12.0 & 12.4 & 1.3 \\
\hline
\end{tabular}


(Go, 2019)

\subsubsection{Procedural and Participatory Injustice of the Miryang Project}

Through the Miryang project, there is clearly distributive injustice such as placing harmful facilities (transmission towers and lines) in the region. Therefore, the villagers in Miryang contend to withdraw the harmful facilities while requesting to equally distribute benefits. However, in order to accomplish distributional justice, there must be a proper procedure of justice to ensure the participation of all parties involved in the process. In other words, in the process of the Miryang project, there was no appropriate procedure to secure the right to participate from the moment when the plan had applied to Miryang. When the project was selected to be applied in 2001, none of the villagers in Miryang were aware of the project.

In South Korea, the energy policy has been entirely controlled by the state authority since stable energy is a key to "successful" economic development. Therefore, KEPCO was capable of controlling enormous power that legally justified all the violence committed. For that, the villagers had to go through the solitude of the resistance, and ceaseless violence that was justified by the government authority. This is to say that through the Miryang project, there was no space to hear the voice of each individual and community of Miryang, and this is one of the main reasons why the conflict in Miryang has intensified.

Nonetheless, KEPCO believed that there was enough cooperation and consent of the villagers. KEPCO indeed contends that they managed and transformed the conflict well by achieving procedure justice (Kim, 2016). Besides, according to the sustainability management report (KEPCO, 2014), KEPCO further highlighted the key to solve the Miryang conflict was an authentic conversation with the villagers. On the contrary, the chairperson of the 
countermeasures committee to oppose $765-\mathrm{kV}$ transmission towers in Miryang pointed out in 2015 at a press conference that the main reason why the Miryang villagers struggle for such a long time is directly connected to the way KEPCO was being exclusive on the process of the project (Kim, 2016).

It is true that the Electric Source Development Promotion Act, a modified version of the Act on Special Cases Concerning Electric Source Development, adds an extra article: hearing an opinion of the inhabitants. Therefore, there was an organized meeting of KEPCO to present the project in Miryang, but also to hear the opinions of the villagers. However, in reality, only very few people who were in favor of KEPCO and the project participated while most of the villagers who were directly affected by the project were intentionally excluded from the process.

Just because KEPCO simply followed the law, it does not mean the Miryang project has accomplished the procedure justice. In other words, the existing procedure process did not encourage the 'Model Plan for Public Participation,' established by the National Environmental Justice Advisory Council in 1992, which includes: "active community participation, institutionalize public participation, recognize community knowledge, and utilize crosscultural formats and exchanges to enable the participation of as much diversity as exists in a community" (Schlosberg, 2007: 67).

For that matter, every alternative suggestion from the villagers was turned down, which means that KEPCO did not put any effort to actually hear the opinions of the villagers to include them in the project. Instead, KEPCO constantly highlighted how the project has followed the legal process, which helped KEPCO to justify the project. The law not only 
enables KEPCO to ignore the opinion of the residents but also allows them to ignore local autonomous entities' fair right of examining and checking the project (Eom, 2012 in Kim, 2016). Meanwhile, KEPCO legally oppressed all the opposing parties by using strategies of suing, individual compensation, threatening, in order to increase the consensus. In the end, the project can be finished as it was planned.

Accordingly, the law gives enough justification for the government/KEPCO to righteously steal the lands of the villagers despite their struggle. Thus, even though KEPCO insists the project was followed by a just and legal process (that justified the unjust procedure), the Miryang project clearly shows an aspect of procedural injustice. The Miryang case indicates that South Korea needs to form a better procedure process that assures meaningful participation because without achieving procedural justice, it will be difficult to reach fair distribution.

\subsubsection{Recognition Injustice of the Miryang Project}

In order to fulfill the democratic participatory procedure, recognizing varied individuals and communities is of necessity. In South Korea, it has been normalized to put the government project from a top-down approach. Therefore, as the Miryang project demonstrates, it has been normalized to exclude certain individuals and communities, especially the minority groups of the society. In the context of South Korea, economic growth has been such a powerful ideology that it is prioritized over many other important values. Due to that, the discussion of distribution has been often postponed, and the martyrdom of the social minorities was treated as something inevitable and necessary for the successful development. In other words, in the decision-making process, it was common not to recognize the minority groups, thus it is only obvious to cause inequitable distribution on environmental benefits and bads. 
Environmental justice generally emphasizes social, cultural, and ecological misrecognition and community devastation since the mainstream culture easily ignores the marginalized populations, traditions, and cultures (Schlosberg, 2007). In regard to this, through the process of the Miryang project, there was no consideration of comprehending the cultural background. For instance, KEPCO's strategy of solving the conflict through monetary compensation by overusing authority made the situation worse by destroying the community culture in Miryang villages. In other words, the solutions (i.e., selective monetary compensation) provided by KEPCO became another main source of the Miryang conflict.

However, KEPCO insists and considers the reality differently by arguing that the villagers were included in the process since KEPCO enthusiastically tried to manage the situation to reach the consensus while providing 'fair' compensation that followed the law. For that, the media harshly criticized the villagers under the frame of NIMBY by describing them as someone who wants more compensation money. But yet, what KEPCO does not realize is that they misrecognized the cultural practices of the villagers related to the lands. In fact, throughout the environmental justice movement, misrecognition of culture and identity issues have been treated as a key component both at the personal and community levels (Schlosberg, 2007).

Therefore, it is important to understand the connections the villagers of Miryang have to their lands and community. In that sense, the book, Living Miryang (Miryang Statement Project, 2014), may be helpful to understand the values on which villagers lived. Different interviews of the villagers are introduced in the book, demonstrating what it is like to live in Miryang. The book gives a very clear picture of the value and the meaning of land and community for each villager through their different experiences. 
They believe that the land is the living foundation that provides life for all villagers: their farming work provides a connection to the land that goes beyond feeding their families; they perceive the land as a fundamental part of their community as it is the type of work in the land that defines one's membership to the community and how each member is connected to one another and where they find themselves together. In Miryang the land does not simply mean a property that can be financially estimated. Below is an excerpt of Living Miryang (ibid.) highlighting the importance of land and community for the villagers:

There is no way we are giving out this land to KEPCO. No way. Compensation? Even if they give us billions of dollars, they are not able to buy us; farmers. [...] I have grandchildren, and the land is for them. In fact, this is not only for my grandchildren, but for the future generations of Korea in general. And, I cannot pass down the spoiled land. So, even if what is required is sacrificing my life, I make sure that they don't steal this land. I can't give it away.

Interview on Sara Lee (P. 74 author's translation)

For me, the neighbors are the best. I couldn't forget when I had a car accident. There is a newly married woman with a limp, so all the neighbors helped her. And, I can never forget the moment of seeing her coming to my house to help me despite her difficulty because I could not move a step from the house after the car accident.

Interview on Young Ja Kim (P. 172 author's translation)

Miryang villages are typical farm villages where most of the villagers share the strong bond of community value, 'Ul-Ryeok'. This was the central value of the community in Miryang, which has been practiced for several generations. Therefore, there is no clear distinction between someone else's work and mine; it was, indeed, a communal task of everyone. In other words, living in the village is like living together as a big family helping each other. 
Traditionally, most of the people in the Korean peninsula used to live in clan villages, and it is still commonly practiced, especially in Gyeongsang province since the region was not heavily affected by the Civil War (1950-1953) as compared to other regions in Korea. Therefore, it is common to share the same family name since most of them are basically relatives. For instance, many villages in Miryang are clan villages, thus most of the villagers share the same last name. Danjang village located in Danjang-myeon (see map 5.2) is a wellknown clan village for Yeoyang Jin clan and Miryang Park, and in Sanoe-myeon (see map 5.2) there are clan villages for Miryang Park clan and Miryang Son clan (Kim \& Yun, 2018). Accordingly, these traditional villages, including Miryang often tend to practice community cultural activities. For instance, on Daeboreum, the first full-moon day (the $15^{\text {th }}$ day of the first month of the lunar calendar), it is widely spread out to do different activities to strengthen the sense of community, including the village memorial service for the well-being of the village, playing $y u t^{29}$ altogether, and sheaf burning for chasing all the bad lucks/energy while inviting all the good lucks/energy of the year.

However, through the conflict in Miryang, the village scene has completely changed. Due to the government energy project, steel towers have been built upright in the middle of fertile rice fields, behind the villager's houses and schools, and next to the burial sites where the villager's ancestors are buried. These abrupt changes in Miryang have deeply influenced the locals' lifestyle and community and cultural practices. Ordinary routines such as preparing seeds, cultivating crops, harvesting, drying crops on the road, and preparing farm work for the

29 Traditional board game played in Korea.

See more information: http://en.trykorea.com/article/about-korea/8/74/ 
coming year, but also the related cultural activities could no longer be practiced after the transmission tower project initiated in Miryang.

The land means the start and the end for the villagers. It is the space where the villagers were born and also where they will be buried, as their ancestors were. This is also why taking care of ancestor's graveyards are crucial. Additionally, in Korean culture that has been influenced by Confucius, the well-being of the ancestors is directly connected to their offspring, and such tradition is still playing a critical role especially for elderly generations. Accordingly, the Miryang villagers also demonstrate their concern about how the project would influence their ancestor's graveyard, thus the well-being of their ancestors and their descendants.

For instance, a villager, Mal He Kim, expressed anxiety as the calmness of her ancestors' graveyards had been disturbed, which is essential for the ancestors to rest in peace (Living Miryang, 2014). In fact, Mal-He Kim suffered from having nightmares of her ancestors asking for help from being drowned (ibid.). There are some other villagers also expressing the importance of protecting the burial sites, which is the life duty as a villager, Hee-Kyeong explains (Living Miryang, 2014: 88 author's translation);

It cannot be real that there will be a steel tower where my ancestors are laid. My father-in-law gave me a mission, which is protecting our mountain where all our ancestors are buried. Otherwise, my father-in-law will refuse to see me. You might say that spirits do not exist, but I believe that you can't say that spirits don't exist.

It seems a great shame not to protect the lands passed by the ancestors and it demonstrates the strong connection that they feel toward the ancestors and the lands. According to the villagers, the villages and nearby mountains where the ancestors' burials are not simply a property, but something that has been bestowed upon them by their ancestors. 
Thus, protecting their hometown, Gohyang ${ }^{30}$, is a lifelong duty. As Ok-Hee Kim further describes, the reason why their village (Yong-Heo village) does not agree on the project is to not humiliate their ancestors who had protected the village and community for them. In Korea they say that if you misbehave your parents get humiliated. For Ok-Hee Kim, allowing the project by giving up the land means disrespecting and mocking the ancestors (Living Miryang, 2014).

However, the Korean Electronic Power Cooperation (KEPCO) wanted to carry out its project by giving the citizens financial compensation for the right to build on their land, while the sum offered did not match the market price; yet money cannot fully compensate the value of the land for its residents anyways. As a matter of fact, the KEPCO's repeated attempts to resolve the conflict with monetary compensation caused more tension to the situation. The government and KEPCO paid no attention to the values the villagers placed on the land or the strength of the community who lives there. Rather, the value of the land taken into consideration was narrowed down to a simple monetary number.

For the villagers, land and community are the same: the destruction of one means the loss of the other. Therefore, the villagers themselves are the rice fields, the mountains, and the streams. However, KEPCO has been ignorant about the cultural practice of the villages

\footnotetext{
${ }^{30}$ For Korean, gohyang means more than the place where you were born, but it means a mother that you can always go back to for resting. Especially after Korean War and industrialization, many people had to leave their gohyang, so many Koreans feel great fondness and nostalgia for the word, gohyang. Moreover, there are many literatures and songs about gohyang and it often is described as a place with beautiful nature, contrary to industrialized cities where one cannot feel the mother's warmth, for instance.
} 
(injustice on recognition) and its significance on the process of decision-making (Procedure justice) obviously has caused injustice.

\subsubsection{Capabilities Injustice of the Miryang Project}

The capabilities approach points out the importance of living a fully functioning life for both individuals and communities. Within the environmental justice movement, environmental justice aspects are interconnected. Therefore, only focusing on fair distribution would be superficial without considering the capabilities approach, which challenges the simple way of dividing environmental goods and bads equally. Adopting the capability approach also means to care about issues of recognition and procedure perspective.

Through the Miryang project, capability justice has not been considered as the project hinders individual and community fully functioning. Community functioning includes "the basics of health, safety, and well-being, along with equality, recognition, and participation" (Schlosberg, 2007: 71). As a result of the project, the villagers in Miryang could not live fully functioning life as the community has destructed, but also they are fully exposed by the possible danger of high electromagnetic waves from $765 \mathrm{kV}$ lines.

Even though KEPCO denies the possibility of causing cancer because of the highvoltage power transmission due to lack of 'scientific' evidence, there is a whole village in Dang-Jin (located in Chung-Nam province) suffering under cancer after the $765 \mathrm{kV}$ transmission towers and line put up in their village. Furthermore, the issue of electromagnetic waves might be also influenced by agricultural activities although KEPCO denies such possibilities. 
However, the villagers in Dang-Jin prove that their agricultural activities are affected as bees are disappearing and different animals fail to bear babies. Apart from this, there will be a problem with the noise of transmitting energies. According to people in Dang-Jin, they suffer every night under the sound of the transmitting energies. They say it sounds like a crying ghost. Therefore, as one grandmother demonstrates, none of her children want to come to their hometown. This means even after KEPCO highlights the security of the transmission tower and lines, people, in general, do not feel safe about it. Besides, there is a report that shows differently from what KEPCO argued.

Moreover, the community destruction has worsened, and it seems impossible to go back to the old community lifestyle. Most of them are family members and lifetime neighbors. However, because of the way KEPCO dealt with the villagers, the community lifestyle has been completely destroyed. In fact, destroying the community was one of the stressful factors for the villagers, feeling betrayed. As it has been examined, the community culture in Miryang has been the central force to carry the individuals' livelihoods. However, by destroying the community culture, the villagers cannot function as they are supposed to function.

\subsection{Outcome of the Miryang Movement}

Since South Korea has developed an abnormal economic model that requires the sacrifice of lives, especially minority groups of the society, along with environmental destruction for the benefits of the powerful groups, there have been constant socialenvironmental conflicts. However, many conflicts that have occurred in South Korea have been "easily solved" with monetary compensation as the economic growth has been considered of the utmost importance to the nation. This means that the Miryang conflict is one of many conflicts that happened in South Korea due to its economic model, but yet the movement in 
Miryang, or the way they have resisted, is a rare case observed in South Korea, which must put more attention on.

At the start of the project in Miryang, there was no considerable emphasis on protecting the livelihoods of the farmers, but instead, the government expected the sacrifice of the villagers for the country to economically grow stronger. In fact, such sacrifice has even been expected in modern South Korea. Thus, especially for elderly generations, such as the villagers in Miryang, who experienced severe national crises, such as Japanese colonization, the Korean War, and military dictatorships, state violence and abuse were often normalized.

Accordingly, the Miryang movement is an extraordinary case that is worthy of note, especially for the following reasons: (1) the movement has been mainly led by the elderly farmers, average age from 60 to 80 years old; (2) Miryang is one of the most conservative areas in South Korea, thus the elderly villagers in Miryang being against the national project were unthought-of; and (3) in these traditional villages of Miryang, the movement has continued for more than a decade; even after the unfavorable outcome, which is the completion of the transmission tower project. In consequence, the movement in Miryang has remarkable impacts on South Korean society as it brings valuable discussions, specifically on the energy policy.

\subsubsection{Previous Studies on the Miryang Movement}

Due to the significant importance of the Mioryang movement, the Miryang case has been researched and investigated by different scholars and activists. At the beginning of the conflict in Miryang, the research related to the case of Miryang was mainly focused on questioning the roots of the conflict in Miryang, which was examined in a previous chapter (Chapter 5). However, as the resistance led by the elderly villagers has been prolonged, many 
researchers and activists paid attention to the space created by the villagers. Therefore, there have been efforts to analyze and interpret the movement by pointing out the significant values and messages of the villagers with questions such as: why have the villagers struggled for such a long time?; what are the villagers fight for?; how has the space been created?; what are the characteristics of the movement?; and what are the messages of the villagers through the long resistance? It is extremely significant to notice that the elderly villagers in Miryang have created a space to be heard.

For that, some scholars (e.g., Eom, 2012; Lee et al., 2014) observed the space created by the villagers from a perspective of scale politics, a multi-scalar perspective. The researchers concentrated on how this space has transformed from space of dependence to space of engagement since "the scale jumping" has been mainly led by the villagers (Lee et al., 2014: 274). Through the scale jumping, the conflict has transformed from regional scale to national and international scale as the villagers learned about the root cause of Miryang conflict that is closely connected to the nation's nuclear energy policy. In fact, the process of "re-scaling toward anti-nuclear movement" initiated from the tragic death of Mr. Chi-Woo Lee that eventually created the space of resistance, which has challenged the 'truth' or the 'reality' (energy crisis) of society. In the space created by Mr. Lee, the resistance has been continued by people who are ready to act by calling themselves a second or third Chi-Woo Lee (Eom, 2012: 85, 86). Therefore, through the movement in Miryang, the value, the "ethics of the others" (Eom, 2012: 51), has been observed, which indeed is a basis of establishing environmental justice in a practical term.

Since the main discourse of the society could easily exclude the marginalized, elderly villagers in Miryang, collecting the voice of the villagers is significant. Accordingly, Young 
Kim and Moon-Won Seol studied the biographies of women participants who experienced state violence in a specific context of ideological conflict that traumatized the participants during their lifetime. The article further reveals that throughout the participation of the socialenvironmental movement, the participants legitimize the family history and heal their traumabased on the solidarity and support they experience (Kim \& Seol, 2015). The research indeed shows the experiences of different individuals who overcome their trauma, which was caused by state violence, by participating in the movements to lead a more just and peaceful society for all.

The experiences of individuals are, however, often excluded from the 'official' version of the history despite its importance and significance. Thus, Young-Hee Kim emphasizes the necessity to hear those unheard voices through biography documents (2017a). For that, Kim (2017a) analyzed the interviews of the villagers to understand how community members (especially females) remember the movement and what narratives were represented, which are resistance and solidarity. It is indeed noteworthy to focus on how the most marginalized of the society: elderly farmers, became the protagonists of the movement. As Jae-Won Mun (2016) further examines, the Miryang villagers, especially the Miryang grandmothers, who constantly practice "local subjectivation" have created a space of solidarity while imagining a new ground of self-generation.

Since the Miryang movement has been led by the elderly community members, especially the female members, the Miryang movement has been investigated from the gender perspective. As Young Kim, (2015) examines, the female community members eventually took charge of leading the movement, and 'Miryang Grannies' became the symbol of the movement in Miryang. In other words, Kim (2015) examines the space where the leaders of struggle 
changed from male to female-oriented. According to Kim (2015), the male leaders who led the beginning of the movement were more concentrated on economic compensation, whereas the female leaders focused on protecting nature, which provides them and their future generations a secure, healthy life and community. Furthermore, Kim (2015) noticed that the long resistance based on local women's leadership helped to build nation-wide solidarity.

In conclusion, various scholars have examined the movement in Miryang from different perspectives while highlighting notable characteristics of the movement. The movement was mainly led by the elderly villagers, but also the space created by the villagers highlights numerous values, which obviously go beyond environmental issues. In fact, the Miryang movement contains strong characteristics of the environmental justice movement. The Miryang movement not only concentrates on either environmental well-being or social justice but the movement also highlights the importance of both by emphasizing valuable lessons to the society to be more just and peaceful.

\subsubsection{The Miryang Movement for Energy Transition}

As the Miryang transmission tower project destroyed the livelihoods of the villagers in Miryang (see. 6.3) due to the unjust energy policy, the topic of the energy transition has been constantly highlighted. Since the project in Miryang is directly connected to the nuclear energy policy, the villagers have demanded to not only stop the construction of Shin-Gori reactors 5 and 6, but also close down old nuclear reactors (Gori no. 2, 3, 4) for the safety matter (Q3). As a matter of fact, the Miryang movement has expanded by including the anti-nuclear energy movement. At last, all these desirable wishes only could be reality-based on successful energy transition. Therefore, the villagers have demanded to revise the unjust energy policy and energy 
laws to reduce dependency on nuclear resources while promoting a non-destructive and nonviolent energy system (Q3).

Consequently, the national energy principles recognized the necessity and importance of energy transition, which is indeed one of the SDGs (SDG 7) that is an essential basis to reach other goals of sustainable development. For that matter, the government has planned to reduce nuclear and carbon energy dependency while increasing renewable energy resources. In detail, K-SDG 7 (affordable and clean energy) provides an alternative plan of increment to produce clean energy, specifically solar photovoltaic power (57 percent) and wind power (28 percent) by 2030 mainly to prevent a climate crisis.

However, unfortunately, there have not been substantial changes followed to prevent KEPCO to repeat the kind of conflict raised in Miryang anywhere else (Q5), including the issue of producing "clean" energy (since it also causes environmental conflicts), but also to fulfill the SDGs successfully. In summary, so far the energy transition process seems very disappointing.

The energy transition has been confronted by numerous difficulties as the construction of Shin-Gori nuclear reactors no. 5 and 6 were decided to be continued due to the public decision. In addition, the plan for constructing Shin-Hanul reactors no. 3 and 4 that must be canceled according to the government energy transition plan was reconsidered on the "Energy transition (specifically on the nuclear energy section) follow up and complementary measures" on, June 21, 2018 (Lee, 2018). In this way, eventually, the carbon energy dependency will be increased during the current government (Lee, 2018), therefore, reducing $\mathrm{CO}^{2}$ emission cannot be fulfilled. Failure of the energy transition, in the end, means the failure of reaching 
sustainable development goals. Meanwhile, not only the villagers in Miryang will suffer, but also there will be second and third cases of the same conflict that has taken place in Miryang.

When the villagers and the committee of Miryang brought up the topic of the energy transition, it was suggested for a more just society. Therefore, the villagers expected to receive a sincere apology and real systematic changes in the energy transition. Due to that, the government/KEPCO is supposed to understand what had happened through what process, and who are the persons in charge that must be responsible for all the violent processes and results; if then, the powerful authorities could provide proper action and policy (Q3). However, in reality, what the villagers have experienced is superficial changes, including revising transmission tower and compensation law, which are not what the villagers yearned for as a countermeasures committee Gye-Sam Lee states.

Nonetheless, such change, which is disappointing and dissatisfying for the villagers, must be considered as a significant step ahead. It may look a small insignificant step but constant challenge/struggle to reshape the powerful hegemony is the ultimate way for the great future change. In fact, the Miryang movement is also grounded upon the countless efforts of people who protested/dissented. In this sense, the movement in Miryang opened a door for change as it made the public recognize the unjust and unfair state-centered energy supply that legally justifies all the state-led violence and undemocratic processes, which has been invisible for a long time in South Korea. In other words, the movement has underlined why it is necessary to change the energy system, which ultimately confronts the current economic system that also influences the discourse of sustainable development.

The Movement in Miryang could add the crucial input for succeeding in the goals of 
sustainable development by questioning not only how to do the successful energy transition, but more importantly what it means to do the successful transition. It is obvious that without fundamental changes in the system, social-environmental conflicts continue. However, within the mainstream sustainable development discussion, the successful energy transition often simply indicates promoting renewable energy technology. For that, there are experts/scholars who question if renewable energy projects are sustainable (See 4.3.2). This technology might help to reduce $\mathrm{CO}^{2}$ emission, however, there are numerous social-environmental conflicts out of so-called clean energy resources since environmental destruction continues while violating the livelihoods of the indigenous population whose life depends on nature.

\subsection{Miryang Environmental Justice Movement within the Sustainable Development}

In the case of South Korea, the outcome of sustainable development practices has been so far disappointing as described in the previous chapter. Sustainable development practices in South Korea have focused on reviving the economy while intensifying the ecological crisis. Particularly the Green Growth policy that is based on technology, rationality, and efficient management, proved that without questioning the present power, objectives of sustainable development cannot be completed despite different attempts. In conclusion, South Korea has been involved in adopting sustainable development discourse at a superficial level by simply reproducing the discourse of modernity. Thus, repeating social-environmental conflicts like in Miryang undoubtedly has continued.

As various researchers and activists have examined the Miryang case from different perspectives, the researchers are inquiring not only about the reasons why and for what the villagers have resisted, but also its significance of the struggles. In simple words, the main reason to resist is to peacefully coexist within the community and nature that is closely 
correlated to the objective of sustainable development, "making a better world for people and our planet". However, there is not enough research exploring how the environmental justice approach could be an effective contribution to reach sustainable development, especially in the case of South Korea.

Consequently, in this sense, examining the case of the Miryang movement that contains strong characteristics of the environmental justice movement could be a great potential to improve the objective of sustainable development. In other words, the villagers in Miryang possibly provide specific actions guiding the discussion of sustainable development to a positive direction as a hegemonic approach to sustainable development easily excludes the voice of the marginalized by repeating the development process as a modernization discourse.

Hence, applying the environmental justice approach that inevitably includes the marginalized of the society whose livelihoods are closely dependent on nature could be helpful as the most environmental justice movement groups understand that healthy nature as a basis for a peaceful existence. For that matter, most of the environmental justice movements, including the Miryang environmental justice movement, predominantly consider a matter of living healthy, safe, and respecting the rights of all beings as they comprehend that we are part of nature.

The Miryang movement has clearly shown that South Korean society is far from being "truly" sustainable in the process of sustainable development. Furthermore, the movement has presented significant values of what it means to be sustainably developed. Thus, in order to successfully fulfill the Korean Sustainable Development Goals (K-SDGs: Korean version of 
$\mathrm{SDGs}^{31}$ ) in the near future, embracing the values highlighted from the Miryang movement could be a beneficiary contribution.

To summarize, the environmental justice movement in Miryang that provides significant values will be examined so that the critical dialogue could be included to promote sustainability, which eventually contributes to fulfilling the objectives of sustainable development, particularly in the case of South Korea.

\subsubsection{Miryang Movement from Environmental Justice Perspective}

In South Korea, environmental justice discourse has been mainly focused on a theoretical level. For that, the concept of environmental justice faces different criticisms. Various scholars proposed to overcome its limitation by applying different theoretical backgrounds and methods. However, as many scholars in general highlight, the necessity of establishing practical environmental justice discourse is inevitable since the environmental justice perspective comes from the real movements of the people. Therefore, it could be seen as having a strong ability to solve the real problems of society. In relation to that, the movement in Miryang is a significant and critical event to be observed from the environmental justice perspective since it contains the strong characteristics of the environmental justice movement.

The environmental justice movement has appeared as environmental issues threaten minority populations throughout the developmental process. Thus, one of the main

\footnotetext{
31 As a matter of fact, there are varied goals that are far from being reached if it is specifically applied to the case of Miryang, such as SDG 8 Decent work and economic growth (specifically 8.1 Economic growth for everyone's happiness), SDG 10 Reduce inequalities (specifically 10.2 Expanding inclusion of social-economic-political capacity for all), SGD 11 Sustainable cities and communities, and SDG 16 Peace, justice and strong institutions. However, in general, the goals stay as words rather than existing in actions of daily life.
} 
characteristics of the environmental justice movement is that it is a bottom-up movement, mostly led by minority groups of society. To sum up, the environmental justice movement is concerned about how people, especially the most vulnerable groups, are influenced by environmental threats rather than focusing only on environmental protection/problem. Thus, the environmental justice movement is seen as an extension of the social justice movement discussion that specifically addresses how environmental issues affect the minority population of the society. In other words, through the environmental justice movement, there could be a high possibility of creating a space to hear the voice of the marginalized that possibly challenge mainstream power. Doing so, the environmental justice movement clearly demonstrates how human beings are interconnected not only with each other but also with nature.

Additionally, as most of the environmental justice movements recognize the interrelation among environmental, social, and political issues, the environmental justice discussion brings a multi-approach perspective while dealing with environmental conflicts under socio-political-environmental realities. Thus, it ultimately could detect the root causes of the environmental crisis. This is undoubtedly distinctive from typical environmental movements that often separate environmental issues from political and social issues. Therefore, environmental justice movements often provide a broad definition of environmental justice, which goes beyond the distribution of environmental goods and bads while including different conceptions of recognition, participation/procedure, and capabilities for both individuals and communities (Schlosberg, 2007).

In this regard, the conflict/movement in Miryang demonstrates distinctive highpoints that could be read from environmental (in)justice perspectives, including various discussions of justice perceptions (see 6.3) that provides multidimensional perspectives. 
At first, the villagers led a social-environmental movement in their favor as the livelihoods of the villagers were directly threatened by the development plan. However, after the tragic incident of Mr. Lee's death in 2012, a wider range of the movement began (Eom, 2012; Lee et al., 2014) due to the various changes within the movement especially by creating the space of solidarity and resistance.

As the French philosopher, Alain Badiou writes, "The truth comes about only by forcing the real and by displacing the empty place, so as to make the impossible possible. 'Every truth is post-eventual'" (cited in Park, 2011: 62). Thus, in the created space, the 'truth' and the 'reality' has been questioned even though the government and KEPCO intentionally ignored the space created by devaluing the importance and the meaning of the incident. However, Mr. Lee certainly opened the door to the new reality (Eom, 2012); otherwise, the conflict in Miryang would not be able to become a nationwide issue. At last, the villagers along with the larger public began to query questions including the reason for building $765 \mathrm{kV}$ transmission towers and lines.

Since the villagers have realized the issue in Miryang was directly related to the new construction of nuclear power plants as a part of the nation's energy policy the villagers put excessive efforts to stop expanding dependency on nuclear energy. Thus, later the movement in Miryang has expanded to the anti-nuclear movement while highlighting human values and social solidarity (Kim, 2017a). The Miryang movement indeed played a significant role in putting importance on energy democracy (Q6). Subsequently, the Miryang movement led by the elderly farmers succeeded to create the space of resistance under the environmental justice frame by requesting for a post-nuclear society (Eom, 2012). 
Besides, the villagers in Miryang expanded the solidarity beyond the Miryang case by connecting other parts of social-environmental conflicts in South Korea. The villagers have realized that all the social-environmental issues are interconnected and these are problematic for all of the society (Living Miryang, 2014). In the process, the movement has become bigger and wider while emphasizing not only the personal benefits and rights but also the public interests and welfare. Followed by that, the villagers and the committee requested for the fundamental change of the system.

Before the Miryang movement, not much attention was paid to how electricity is produced, which inevitably requires sacrificing the lives of the marginalized throughout violence (Q6). However, through the Miryang movement, the cruel reality of how the violent system sustains in order to produce one of the most essential public goods, electricity, for the convenience of the public has been revealed. Meanwhile, due to the long resistance, many citizens in South Korea have awakened to see the vicious reality and realized what is owed to the Miryang villagers (Q7).

In conclusion, the movement has succeeded to form a strong connection with different social movements, including the anti-nuclear movement, which indeed became one of the most important topics discussed in South Korea. In response to this, the politics answered the villagers who requested to withdraw the construction plan of Shin-Gori reactor 5 and 6 even though, unfortunately, in October 2017, the public decided to continue with the construction of Shin-Gori reactor. 5 and 6. Due to the unfortunate decision, the situation in Miryang has worsened as the movement has weakened. However, there are still some villagers along with the committee who struggle to resist to spread the valuable messages for South Korean society to take in due to reach a sustainable and peaceful future. 


\subsubsection{Environmental Justice Movement in Miryang: One for All and All for One}

The current ecological-climate crisis is directly connected to the discourse of modernity, and the neoliberal economic model (Lippert, 2004). Thus, without striving to deconstruct the main issues of the problem, it is doomed to replicate ecological crisis and social-environmental conflicts. What is critical is that as long as the conventional system that requires the sacrifice of the people (especially from the most marginalized and from nature) continues to exist, then technological renovation (e.g., transforming energy resources to clean energy) cannot be enough to reach peace and sustainability. Therefore, perhaps what is needed is constructing different conceptions of sustainable development, which contains expanded notions of justice that go beyond the distributional concept of justice that has been emphasized through mainstream sustainable development (Lippert, 2004).

In fact, the Miryang case proves that sustainable development discourse in South Korea has been superficial and exclusive by emphasizing the economic sector that constantly requires the sacrifice of people and nature. This means that the sustainable development discussion in South Korea has been perhaps on the wrong track while failing its utter importance of being inclusive as to promote peace and justice at a practical level. In this regard, the messages from the environmental justice movement in Miryang could be valuable to reconstruct different conceptions of justice and sustainable development as the essential principles of sustainable development must be re-comprehended.

Through the movement in Miryang in general, the villagers highlighted living peacefully together within nature, and the truth is that when nature cannot thrive, peaceful existence is not possible, as the Miryang case has demonstrated. Within the Miryang movement, the villagers have pointed out how everything is interconnected and interdependent. This is 
why the villagers concentrated on the importance of their benefits and harms, but furthermore focused on the well-being of the society in general.

For that matter, the villagers in Miryang have underlined different topics, which include state violence; a state-led energy policy that contains the danger of nuclear energy use; the necessity of alternative energy and successful energy transition; and living a healthy and peaceful life by sharing valuable discussions to be included in the country's sustainable process and discussion. In other words, the movement opened a space to share essential values ignored within the sustainable development discussion, such as the sense of community, which has expanded widely as the villagers testified through their interviews in the book Living Miryang (2014):

The transmission tower issue is not the only matter of the energy policy. It actually is a part of all the social problems. [...] Recently, I have met many groups of people who are struggling like us, such as workers of Ssangyong motors, and so on. Of course, I already knew about all these issues but back then, I did not want to think about it [...] in the end, a similar thing happened in Miryang and I also became one of the victims by the governmental authority power. [...] We have visited all these conflict areas, from Hanjin heavy industry \& construction holdings, etc., workers of Ssangyong motors in Pyeongtaek and so on, in order to move forward together. It gave me the hope that we will be able to move forward if we all walk together by holding hands. There are countless people who are suffering like us so we must help each other. We must stand up for each other.

Mi-Hyun Gu (158-160, author's translation)

This is not only our struggle. The public supports us. The way to live together is to stop nuclear energy. Stopping the transmission tower is the only answer for our hometown. Also, stopping nuclear energy is the best way for the future of the nation. [...] My son once told me, "Mom, you will never stop fighting even if the current issue in Miryang is done". Yes, indeed I will not be able to forget the reality; there are so many people who are suffering out there. These moments will stay in my mind forever. Even after our struggle is ended, I want to continue 
fighting by supporting other people who are continuously struggling. It might be a small effort, but this is a secret power of how we resist, with many small actions of the people.

$$
\text { Young-Ja Kim (179, author's translation) }
$$

The Miryang movement emphasizes how their lives are deeply involved in the wellbeing of nature, but also clearly shows what it means to live as community members (see more details in 6.3.3) and as a member of society. Consequently, through the movement, strong space for solidarity has developed, which is the basis of the idea, all for one and one for all. Due to reaching sustainable development that promotes justice and peace, the narrow concept of sustainable development that has been used and practiced through the mainstream sustainable development must be over. And, for reaching a 'real' sustainable way of living, understanding how everything is interconnected is of necessity, which the Miryang movement clearly highlights.

\subsubsection{The Emergence of New Identity: Creating a Political Space}

In the case of Miryang, the well-being of the villagers has not been considered while going through sustainable development practices since the economic section was exclusively underlined (as it was shown in Green Growth policy). Furthermore, even with the K-SDGs that highlight the significance of the citizen's wide participation, there are seemingly no specific tools or ways to guarantee the participation of the marginalized of society. For instance, the villagers in Miryang have been completely excluded from the public debate to decide for the

continuation of constructing nuclear reactors Shin-Gori 5 and 6. Therefore, it seems fair to criticize the discussion of sustainable development for remaining shallow and superficial. Throughout the mainstream discourse of sustainable development that replicates the 
modernization process, there seems no space to include different forms of knowledge towards diverse individuals and groups that are affected by socio-environmental conflicts.

Accordingly, for developing a profound discussion within sustainable development, it is imperative to create a channel to include the voice of the marginalized because counting in different types of local knowledge of living peacefully together could be beneficial to enrich the sustainable development discussion.

In the case of the Miryang movement, the villagers started to form new types of resistance with a sense of agency. Therefore, instead of continuing to be marginalized, the villagers took a step out to represent themselves under a new form of political action while questioning the reasons and power dynamics behind the project in Miryang. For that, the Miryang movement led by the elderly villagers earned the reputation for being a "symbol of resistance" (Kim, 2017a). In fact, through such a long and painful struggle, "new kinds of people" have emerged "with their own emerging self-definitions, understandings of the world" (Robbins, 2012: 217). In other words, within the Miryang justice movement, counting in the voice of the villagers and self-empowerment has become a central part.

However, despite the constant struggle, the Miryang transmission tower project has been "successfully" accomplished according to the claim of the government/KEPCO. The completion of the project in Miryang possibly could mean (at least for some people) a "failure" of the Miryang movements since the main claim of the movement, which was preventing the transmission towers and lines, was not realized. More importantly, dependency on nuclear power energy also has not been decreased as the villagers have suggested. In other words, the issue of successful energy transition does not seem to be on the right track. 
Accordingly, a committeeperson, Gye-Sam Lee believes that the movement in Miryang could be seen as unsuccessful because it has requested too much sacrifice, however, on the other hand, claims that the movement cannot be considered as failure, either (Q7). The villagers indeed knew from the beginning of the battle that it would be a difficult fight to win against the powerful KEPCO, which is one of the biggest electric power companies that are legally protected by the government authority and laws (Q7). However, the important thing to notice is that the villagers have resisted, even after the unfavorable outcome of bringing to an end the transmission tower project, against the state violence that disabled the villagers to continue with their life. It is, in fact, significant to observe how the villagers practiced subjectivation and created the space where they were politically recognized.

"There is no progression without struggle" as Hegel famously said. In consequence, this constant resistance of the villagers could be a big pressure and excessively annoying for those who seek out for maintaining their power without any changes. Since they are forced to change, even if it is at a superficial level, the powerful authority in a way has pressure to hear and answer the questions of who caused what problems, but also what are the ways of living in a peaceful and just society. In other words, through the project applied in the villages of Miryang, the ecological matter of Miryang has clearly become 'politicized' as it "became an organizing theme for a successful movement, one that challenges state and professional authorities" (Robbins, 2004: 200).

In fact, this is the reason why the villagers and the committee cannot stop resisting, but more importantly, this is why the movement is extremely meaningful, as the committeeperson Mr. Lee emphasizes (Q5). In the end, this movement, represented by marginal communities like Miryang, strengthened their political representation, making their marginalized voices 
politically sound and relevant. The space of social cohesion seen in Miryang provided an opportunity to hear different unheard voices, "seeds of a new tomorrow" that ultimately can make society healthier, based on "equality and mutual respect" (Thiong'o, 1993: 24). If the voice from each and every person is not heard and included, there will be no "new tomorrows" since all the possible "seeds for tomorrow" would become rotten:

The wealth of a common global culture will then be expressed in the particularities of our different languages and cultures very much like a universal garden of many-colored flowers. The 'flowerness' of the different flowers is expressed in their very diversity. But there is cross-fertilization between them. And what is more they all contain themselves the seeds of a new tomorrow

(Thiong'o, 1993: 24)

As Thiong'o (1993: 29) furthermore points out, "local knowledge is not an island unto itself; it is part of the main, part of the sea". Therefore, the space created by the villagers who recognized their political power and agencies could be absolutely a positive contribution to the sustainable development discussion that needs to include those valuable ideas and arguments coming from the people's struggles. In fact, as the Miryang movement also gives emphasis to the vision of environmental justice is to develop "a holistic, community-based, participatory and integrative paradigm for achieving healthy and sustainable communities for all peoples" (Lee, 2005: 187).

Mainstream sustainable development discussion notably highlights the importance of including different groups and individuals even though there seems no specific guidance provided since sustainable development is more of a discourse that could be swayed by power. Thus, as the movement in Miryang demonstrates, claiming a political identity and recognizing 
an element of agency is an essential process and way to resist against the powerful hegemonic discourse. From a space of solidarity created through the villagers in Miryang, the marginalized social group challenged the social norm, questioning the justification of the national project and bringing in new values, under the slogan of "Let us live just the way we are based on the land as community". Accordingly, such values are not negotiable to the modernity based development discourse, but also it will designate which way the discussion of sustainable development must be taken.

\subsection{Conclusion}

In this last chapter, the resistance in Miryang has been examined through the environmental justice perspective due to find the possible ways of reaching a peaceful and sustainable future by completing the sustainable development discussion. For that, the environmental injustice perspectives of the case in Miryang was examined into four different justice measures, including distributional, procedural, and participatory, recognition, and capabilities. In other words, the Miryang case could be seen from the perspective of environmental justice as the Miryang movement contains strong characteristics of the environmental justice movement.

In conclusion, the long struggle of the Miryang villagers indeed brought unique discussions and perspectives by questioning the current capital-based development model, which has been reproduced in the sustainable development discourse. And, the villagers who became the fully awaken individuals based on the created political space raise their voice to be heard. Furthermore, these valuable messages provided by the villagers could be possible contributions to pave the road to sustainability, thus challenging the mainstream discourse of sustainable development. 


\section{GENERAL CONCLUSIONS}

\section{Conclusion}

The aim of this dissertation is to explore how the environmental justice approach could effectively pave the way for environmental sustainability, which is unquestionably related to social and economic sustainability. By following the six main chapters, this dissertation has shown how the environmental justice perspective helps not only to deconstruct the mainstream sustainable development discourse but also to reconstruct the discussion of sustainability.

Therefore, the first chapter analyzed how mainstream sustainable development has emerged and developed in world politics. Furthermore, the chapter discussed what the critiques of mainstream sustainable development are since the current mainstream sustainable development has been enormously affected by the discourse of modernization, which, ironically, is the main cause of the ecological crisis and environmental conflicts. In fact, the discourse of modernization is the core reason why the discussion of sustainable development has emerged. Thus, the chapter presented a critical view on the sustainable development discussion.

As various researchers and intellectuals previously examined, development as a modernization process has worsened the ecological crisis since the development process focused on economic growth based on the ideology of enlightenment that worships the rationality that separates nature as a single entity, which could be controlled by intelligent and rational humans. Accordingly, even though the importance of healthy nature and environmental sustainability was recognized in world politics starting with the 1987 WCED, up until now, 
unfortunately, the situation of environmental sustainability has not become any better while increasing the social-environmental conflicts.

However, despite all the disappointing results of sustainable development discussion, continuing to discuss the topic of sustainability is invaluable, and in order to do so, observing the mainstream sustainable development discourse from a critical perspective is of necessity. In fact, there have been incessant researches criticizing the discussion of mainstream sustainable development that continuously causes inequality and injustice due to greenneoliberalism, which focuses on gaining more profit while 'solving' ecological issues by applying scientific technology. For that matter, it is only fair to criticize the discourse of sustainable development which is colonized by the powerful discourse produced by rich countries of the Global North.

With this in mind, the research further explored ways to challenge the mainstream sustainable development that reproduces the destructive system by applying an environmental justice approach.

Following that, in the second chapter, the environmental justice perspective was proposed as an alternative approach to question and confront the mainstream sustainable development discussion. This is because the term environmental justice comes from real struggles of the minority population who perpetually have experienced environmental inequality and injustice. For that matter, through the environmental justice movements, the issue of distribution is definitely highlighted, but furthermore, the issues of procedural/participatory justice, recognition justice, and capabilities justice are emphasized since all these different types of justice are intertwined. As environmental justice movements 
have actually revealed in order to recognize unequal distribution, the powerless marginalized group must be recognized in the process first. The reason why the minority communities are disadvantaged is because of their invisibility in the decision-making process, thus their values and their way of life are simply disregarded.

The environmental justice movement contains fundamental values that could be a crucial input to challenge the discourse of sustainable development that excludes the voice of the powerless marginalized. Through the lens of environmental justice, the environmental crisis is examined from a multivalent perspective; which is distinctive from the classic environmental movement that analyzes environmental issues apolitically while simply underlining protection of nature. For the classic environmentalist, nature is something that needs to be protected under human control instead of viewing nature as the living place where we have to coexist peacefully together with other living-beings. In other words, through the environmental justice perspective, such an arrogant view of controlling nature is confronted based on this inclusive value of one for all and all for one. Additionally, as the environmental justice movement basically occurred due to the survival of the marginalized whose livelihoods are at risk, the movement imperatively includes the voice of the marginalized. By struggling against the powerful hegemony which hinders political opportunities for the marginal groups to be seen and heard, the movement helps to create a space that gives a voice to the voiceless.

The topic of sustainability is indeed essential and timely to be discussed, especially within a peace studies perspective as ecological well-being is a precondition to peace. Thus, in Chapter Three, the relationship between peace and sustainability has been observed, but also the chapter justified why it is important to include the environmental justice perspective as an alternative way to promote peace and sustainability. 
Since economic hegemonic power has hugely influenced the peace talk, the concept of liberal peace has been widespread in world politics by overly highlighting the role of economic power. Thus, the main sustainable development, which supposedly proposed to spread peace and sustainability, constantly causes inequality and injustice. For this issue, I proposed to apply an environmental justice perspective, which helps to enhance environmental sustainability and sustainable peace.

Within the presented frame of the theoretical base, the case of South Korea, a country that struggled to adopt the sustainable development discussion, has been examined. More specifically, the research presented the case of the Miryang movement to reveal the reality of sustainable development practice applied in South Korea, but more importantly, to highlight the valuable messages provided from the villagers through the struggle since these values could be a positive input to reconstruct the discussion of sustainable development.

Following that, in Chapter Four, situating South Korea in a debate of sustainable development, which visibly presented the irony of sustainable development discussion, was investigated. In order to understand the complexity of the Miryang conflict, not only the way South Korea has economically developed but also how sustainable development discussion has adapted was examined. By going through the specific historical context of South Korea, the main characteristics of the development process in South Korea were provided. South Korea has developed its economy as a means to secure the nation by the existing threat of North Korea. Thus, the country has been obsessed with economic growth even if it costs the people's livelihoods and the well-being of nature. Following that, the human-right violation has been righteously justified while environmental degradation was rather encouraged since there was a strong belief that economic growth eventually cures the environmental issues. 
After the 'successful' economic growth, however, the environmental issues have worsened due to different forms of pollution. Meanwhile, the pressure of being sustainably developed has increased as the sustainability issues became the most important matter of world politics. Therefore, South Korea, which was treading a fine line between sustainability and development, came up with a 'perfect solution', Green Growth policy, after long procrastination for practicing sustainable development.

Green Growth policy became a polemic concept among the academics due to the poor definition to be included as a flow of sustainable development. In addition, the consequences of the policy, specifically in the energy policy, were also disconcerting as the Green Growth energy policy depends on nuclear energy resources rather than "indisputable" green energy resources although clean energy technology is not the solution for the current socialenvironmental crisis. Furthermore, as the Green Growth policy was a political catchphrase, with the transition of political power, the impacts of Green Growth has radically decreased while the Korean Sustainable Development Goals has been implemented to take over the scene. Consequently, the Green Growth policy basically repeated the old economic development discourse with putting some green color outside instead of sincerely challenging the system that causes the entire crisis that the world is facing. Continuing the discussion of sustainable development is essential, but in order to succeed, the lessons from the failure of the past mistakes must be learned.

Therefore, Chapter Five focused on describing the conflict in Miryang, which is an outcome of South Korea's development process. The conflict in Miryang, which has lasted since 2005 , needs to be described in detail for the readers to have a clearer and wider picture 
to understand the complexity of the way South Korea has been evolved under the discussion of sustainability.

For that, the general process and the characteristics of the conflict were first presented, which could be divided into seven different phases. During the time of long conflict, the villagers experienced the violation of property rights, destruction of community, human rights violation, and the violation of health rights. Therefore, the roots of this never-ending conflict in Miryang have been analyzed from different scholars and activists, but the very root of the project in Miryang is directly connected to the nation's energy policy, which is the basic requirement for the development policy of the nation.

The Miryang conflict clearly demonstrated that applying the old development strategy, which justifies human violation and nature exhaustion to economic growth, is outdated. Moreover, in the process of resistance, the villagers in Miryang critically queried about the energy crisis. In the end, the conflict in Miryang showed how the "truth" about the energy crisis was constructed to benefit the elite groups of the society while normalizing the violence especially applied to the marginalized of the society.

Furthermore, the villagers in Miryang made a very clear point by underlying the danger of the project in Miryang not only for their benefit but for the well-being of all. Accordingly, the villagers in Miryang questioned if the use of nuclear energy could be future energy to really reach sustainable development goals. In fact, the Miryang conflict showed how the sustainable development policy is unsustainable. Thus, as the Green Growth energy policy indicated, 'wrongly' designed and applied policy could worsen the marginalized communities that were already suffering from the conventional economic development policy. In other words, the 
Miryang case proved how sustainable development discourse reproduces the modernization discourse that inevitably excludes the voice of the marginalized but further to exploit their livelihoods.

In the last chapter, therefore, the movement carried by the villagers in Miryang was observed from the environmental justice perspective. Based on the theoretical base of environmental justice developed in the context of South Korea, the environmental injustice aspect of the Miryang conflict can be seen clearly. But, meanwhile, the Miryang movement provides the perspectives (or messages) of environmental justice, which can be a useful input to further re-develop the sustainable development discourse. Through the movement, the villagers challenged the discourse of sustainable development, but furthermore, they shifted the discussion of sustainable development toward a more sustainable and peaceful future.

By including the voice of the villagers, the hegemonic approach to sustainability discussion can be challenged while leaving no one behind as the SDGs have been eagerly devoted for. As long as the proposed solution does not take into account the victim's voice to represent their interests, the same kind of conflicts will certainly be repeated as the history of mainstream sustainable development has proven. Thus, including the messages of the villagers in Miryang within the discussion of sustainable development could be a significant step.

The villagers in Miryang highlighted the energy transition, which is a key to successful sustainable development policy, to a more just energy policy. The villagers in Miryang doubted using nuclear energy, but also created a space to reflect on how to use scientific technology wisely. Technology is a useful tool to support positive changes but it cannot be a solution. In other words, without structural change, scientific technology is only becoming a bane. For that 
matter, the villagers of Miryang challenged the hegemonic power by creating the political space where they can be heard and seen. Then, what is further highlighted through the created space is the value of peaceful coexistence within nature as a community member that is built on a foundation of solidarity and interconnectedness.

\section{Findings}

In conclusion, the findings have demonstrated that even after the appearance of the sustainable development discussion, the environmental crisis has worsened and environmental conflicts have intensified. In a way, it indicates the failure of sustainable development. Since mainstream sustainable development discourse has principally focused on reviving the economy based on scientific technology, various policies and practices of sustainable development continuously cause environmental degradation while exploiting the livelihoods of the people, especially the powerless and marginalized. As a response, the environmental justice movement has followed worldwide, including the one in Miryang, South Korea.

The dissertation demonstrated how important and necessary it is to include different knowledge(s) of people who especially struggle due to their peaceful coexistence within nature to the sustainable development discussion. In fact, environmental sustainability is closely interconnected and interdependent to peace, thus it is more than necessary to challenge the mainstream approach to sustainable development, which re-produces modernization discourse, in order to transform the discourse toward a more just and peaceful future.

The Miryang environmental justice movement in South Korea, particularly, demonstrated that the powerless groups of the society; elderly farmers in South Korea could play an important role by bringing a new perspective to challenge the hegemonic approach to 
sustainable development that constantly produces injustice and inequality. Consequently, the valuable messages emphasized by the villagers in Miryang could be the positive input to the sustainable development discourse. In order to reach environmental sustainability and peace, therefore, it is vital to bring the values and perspective of the marginalized whose existence is dependent on nature, and include their voice within the discussion of sustainable development.

The struggle in Miryang was an exceptional case that significantly influenced Korean society. Accordingly, even though the movement in Miryang could not successfully stop the construction of Shin-Gori nuclear reactor number 5 and 6 due to the public decision made in 2017, I believe that the emphasized values through the movement can be helpful input within the discussion of sustainable development. The movement itself is meaningful to be observed since it can be considered as a significant step for the positive changes for the sustainable future. Furthermore, it may (hopefully) inspire additional scholarly studies, but it is also relevant to policymakers.

\section{Future Research Area}

Following this research and as future line research, it is of necessity to continue following the Miryang case and observing the impacts of the movement as the movement of the villagers continuously goes on, but also as South Korea intends to transform the conventional growth paradigm toward a more sustainable and just development, which supposedly promotes the culture of peace. Besides, it is significant following different environmental justice movement cases since there are more and more environmental conflicts that often (even) cause physical violence and harm, and the environmental justice approach advocates a more inclusive form of sustainable development. Therefore, observing more of the 
successful movement cases will help us to learn the practical tactics and real-world strategies to reach sustainable development. Furthermore, through successful environmental justice movements, the mainstream approach to sustainable development has more opportunities to be challenged to be reconstructed. 


\section{Bibliography}

Adhikari, S. (2019, June 7). MDGs Vs SDGs: 17 Differences. Public Health Note https://www.publichealthnotes.com/mdgs-vs-sdgs-17-differences/

Agyeman, J. \& Evans, B. (1995). Sustainability and democracy: Community participation in local agenda 21. Local Government Policy Making, 22 (2), 35-40

Agyeman, J., Bullard, R. D. \& Evans, B. (2003). Introduction: Joined-up Thinking: Bringing Together Sustainability, Environmental Justice and Equity. In J. Agyeman., R. D. Bullard \& B. Evans (Eds), Just Sustainabilities: Development in an Unequal World (pp. 1-16). Earthscan Publication Ltd.

Agyeman, J. \& Evans, B. (2004). 'Just Sustainability': the emerging discourse of environmental justice in Britain. The Geographical Journal, 170 (2), 155-164

Ah, S. R. (2007, February 17) Brief History of Korean Economy [In Korean: 간략하게 보는 한국 경제사]. Bemil 유용원의 군사세계

http://bemil.chosun.com/nbrd/bbs/view.html?b_bbs_id=10038\&num=14353

Ahn, G. H. (1988). Environmental Problems and Newspaper Editorial [In Korean: 환경문제와 신문사설]. Newspaper and Broadcast, 54-62.

Ahn, S. K. (2010). A Critical Analysis on Green Growth Theory: From the Perspective of the Environmental Law [In Korean: 녹색성장론에 대한 비판적 연구: 환경법적 관점에서]. Han Yang Law Review, 31: 13-33

Alvares, C. (2010). Science. In W. Sachs (Eds), The Development Dictionary: A Guide to Knowledge as Power ( $2^{\text {nd }}$ ed., pp. 243-259). Zed Books.

Amin, S. (2006, March 1). The Millennium Development Goals: A Critique from the South. Monthly Review https://monthlyreview.org/2006/03/01/the-millennium-development-goals-a-critique-fromthe-south/

Amster, R. (2014). Peace Ecology. Routledge.

An, S. C. (2014). Alternative Approaches to the Disputes over the Constructions of High-Voltage Power-Lines: From the Perspective of Environmental Compassion [In Korean: 고압송전선로건설 분쟁에 대한 대안적 접근: 환경 공감의 시각을 중심으로]. Dispute Resolution Studies Review, 12(2), $31-56$.

Aronson, D. (1996). Overview of Systems Thinking. The Thinking Page, Retrieved June 23, 2018, from 
http://www.thinking.net/Systems_Thinking/OverviewSTarticle.pdf

Atack, I. (2009). Peace Studies and Social Change: The Role of Ethics and Human Agency. Policy \& Practice: A Development Education Review, 9 (Autumn), 39-51.

Austin, R. \& Schill, M. (1991). Black, Brown, Poor, and Poisoned: Minority Grassroots Environmentalism and the Quest for Eco-Justice. The Kansas Journal of Law and Public Policy, 1(1), 69-82.

Banerjee, S. B. (2003). Who Sustain Whose Development? Sustainable Development and the Reinvention of Nature. Sage Publication, 24(1), 143-180.

Barash, D. P. \& Webel, C. P. (2009). Peace and Conflict Studies ( ${ }^{\text {rd }}$ ed.). Sage.

Barnett, J. (2007). Environmental Security and Peace. Journal of Human Security, 3(1) 4-16.

Barry, J. (1999). Rethinking Green Politics. Sage Publications.

Bate, T. (1975) Gramsci and the Theory of Hegemony. Journal of the History of Ideas, 36(2), 351-366.

Bauman, Z. (2007). Consuming Life. Polity Press.

Beder, S. (1994). Sustainable Development. Scribe Publications.

Brenton, T. (1994). The Greening of Machiavelli: The Evolution of International Environmental Politics. Earthscan.

Beretta, I. (2012). Some Highlights on the Concept of Environmental Justice and Its Use. e-cadernos CES, 17, 136-162. https://doi.org/10.4000/eces.1135

Bernstein, S. (2002). Liberal Environmentalism and Global Environmental Governance. Global Environmental Politics, 2(3), 1 - 16.

Blowers, A. (2003). Inequality and Community and the Challenge to Modernization: Evidence from the Nuclear Oases. In J. Agyeman., R. D. Bullard \& B. Evans (Eds), Just Sustainabilities: Development in an Unequal World (pp. 38-63). Earthscan Publication Ltd.

Boer, J. T., Pastor, Jr, M., Sadd, J. L. \& Snyder, L. D. (1997). Is there environmental racism? The demographics of hazardous waste in Los Angeles County. Social Science Quarterly, 78(4), 793-810.

Bonaiuti, M. (2012). Degrowth: Tools for a Complex Analysis of the Multidimensional Crisis. 
Capitalism Nature Socialism, 23(1), 30-50. DOI:10.1080/10455752.2011.648838

Boo, K.J., Ryu, J.C., Kim, H.C. \& Park, J.M. (2013). 2012 Modularization of Korea's Development Experience: Energy Policies. MOTIE (Ministry of Trade, Industry \& Energy).

http://www.kdi.re.kr/kdi_eng/publications/publication_view.jsp?pub_no=13343

Boyce, J. K., Klemer, A. R., Templet, P. H. \& Willis, C. E. (1999). Power Distribution, the Environment, and Public Health: A State-Level Analysis. Ecological Economics, 29(1), 127-40.

Brajer, V. \& Hall, J. V. (1992). Recent evidence on the distribution of air pollution effects. Contemporary Policy Issues, 10(2), 63-71.

Brand, P. C. \& Thomas, M.J. (2005). Urban environmentalism: global change and the mediation of local conflict, Routledge.

Benjamin, F. J. \& Chavis, R. (1993). Forward. In Robert D. B (Eds.), Confronting Environmental Racism: Voices from the Grassroots (pp.3-6). South End Press.

Bexter, P. \& Jack, S. (2008). Qualitative Caste Study: Methodology: Study Design and Implementation for Novice Researchers. The Qualitative Report, 13(4), 544-559.

Bretting, J. \& Prindeville, D. (1998). Environmental Justice and the Role of Indigenous Women Organizing Their Communities. In David Camacho (Eds.), Environmental Injustices, Political Struggles: Race, Class, and the Environment (pp.141-164). Duke University Press.

Brighouse, H. (2004). Justice. Polity.

Bryant, B. (1995). Pollution Prevention and Participatory Research as Methodology for Environmental Justice. Virginia Environmental Law Journal. 14(4), 589-611.

Bryant, R. (1998). Power, Knowledge, and Political Ecology in the Third World: a Review. Progress in Physical Geography: Earth and Environment, 22(1), 79-94.

Buckingham, S. \& Kulcur, R. (2009). Gendered Geographies of Environmental Injustice. Antipode 41(4), 659-683. https://doi.org/10.1111/j.1467-8330.2009.00693.x

Bufacchi, V. (2005). Two Concepts of Violence. Political Studies Review, 3, 193-204.

Bullard, R.D. (1990). Dumping in Dixie: Race, Class, and Environmental Quality, Westview Press.

Bullard, R.D. (1993). Race and Environmental Justice in the United States. Yale Journal of International Law, 12, 319-334. 
Bullard, R. D. (1994a). Grassroots Flowering: The Environmental Justice Movement Comes of Age. Amicus, 16 (Spring), 32-37.

Bullard, R. D. (Eds.). (1994b). People of Color Environmental Groups 1994-95 Directory. Environmental Justice Resource Center.

Bullard, R. D. (2000). Environmental justice in the 21 century. People of color environmental group. Directory, 1-21.

Bullard, R. D. \& Johnson, G.S. (2000). Environmental Justice: Grassroots Activism and Its Impact on Public Policy Decision Making. Journal of Social Issues, 56(3), 555-578.

Bullard, R. D. \& Wright, B. H. (2003). Environmental justice for all. In S. Plous \& S. Plous (Eds.), Understanding prejudice and discrimination (pp. 448-462). McGraw-Hill.

Bullard, R. D., Paul M, Robin S, \& Beverly W. (2007). Toxic Wastes and Race at Twenty, 19972007. United Church of Christ.

Burch, W. (1971). The Peregrine Falcon and the Urban Poor. Some Sociological Interrelations, Ohio State University.

Business Dictionary (n.d.). Chaebol. Retrieved May 31, 2018 from http://www.businessdictionary.com/definition/chaebol.html

Capra, F. (1997). The Web of Life. Schrodinger Lecture, Dublin, September 9th 1997

Capra, F. (1982). The Turning Point: Science, Society, and the Rising Culture, Simon and Schuster.

Carbon Tax Center (CTC). (n.d.). What's a carbon tax? Retrieved October 8, 2017 from https://www.carbontax.org/whats-a-carbon-tax/

Carrington, D. (2016 August, 29). The Anthropocene Epoch: Scientists Declare Dawn of HumanInfluenced Age. The Guardian. https://www.theguardian.com/environment/2016/aug/29/declareanthropocene-epoch-experts-urge-geological-congress-human-impact-earth

Castro, C..J. (2004). Sustainable Development: Mainstream and Critical Perspectives. Organization \& Environment, 17(2), 195-225.

Chang, H. J. (2002). Kicking Away the Ladder: Development Strategy in Historical Perspective. Anthem Press. 
Cheung, H. (2020 January, 23). What does Trump actually believe on climate change? BBC News. https://www.bbc.com/news/world-us-canada-51213003

Cho, S. B. (2012). A Research on Solutions and Cause relate to the Conflict of Constructions for Power Transmission Facilities: A Case Study on the pass area of Milyang-city in South Korea [In Korean: 송전선로 건설갈등의 장기화원인과 해결방안에 관한 연구]. Investigation of Public society, 2(2), 128-168.

Cho, M. Y. \& Chung, J. (2013, September 9). South Korea nuclear issues, tower protests raise blackout risks. Reuters. Retrieved June 23, 2018 from http:/www.reuters.com/article/2013/09/09/us-nuclearkorea-power-idUSBRE9880AR20130909

Cho, M. R. (2000). Special: Environmental Justice, Environmental Policy, Environmental Movement 1 - Re-examination on Environmental Justice: From Discourse to Practices. [In Korean: 특집/환경정의, 환경정책, 환경운동1-환경정의론의 재조명: 담론에서 실천으로]. Environment \& Life, 12, 28-47.

Cho, M. R. (2013) Environment Justice in the Developmental State: In Search for a Korean Theory of Environmental Justice. [In Korean: 개발국가로의 환경정의 한국적 환경정의론 모색]. Environmental Law Research, 35(3), 69-111.

Choe, S. H. (2013, October 29). As Power Line Grows, So Does Fight Between Ancient and Modern Korea. The New York Times. http://www.nytimes.com/2013/10/30/world/asia/koreans-say-power$\underline{\text { line-plan-threatens-tradition.html? } \mathrm{r}=0}$

Choi, B. D. (1998a). Ecology and Environmental Justice. Journal of the Korean Geographical Society, 33(4). 499-523.

Choi, B. D. (1998b). Ecology as a New Paradigm and Environmental Justice. Journal of the Korean Geographical Society, 33(S) 709-719.

Choi, B. D. (2001). Deep Ecology and Environmental Justice as Equality in a Living-Beings and SelfRealization. [In Korean: 심층생태학과 생물평등 및 자아실현으로써의 환경정의], Space and Society, $16,36-68$.

Choi, B. D. (2005). Liberal Environmentalism and Environmental Justice. Journal of the Korean Geographical Society, 40(6), 671-693.

Choi, B. D. (2010). Critical Ecology and Environmental Justice. Hanul Academy.

Chomsky, N. (1999). Profit over People: Neoliberalism and Global Order. Turnaround Press.

Chomsky, N. (2006). Deterring Democracy. Vintage Books. 
Clark, J. (2008). "Dialectical Political Ecology”. [online] Academia.edu. Available at: http://www.academia.edu/2937823/_Dialectical_Political_Ecology

Conference, Meetings and Events (n/d). Millennium Summit (6-8 September 2000). https://www.un.org/en/events/pastevents/millennium_summit.shtml

Connelly, S. (2007). Mapping Sustainable Development as a Contested Concept. The International Journal of Justice and Sustainability, 12 (3), 259-278.

Costanza, R. \& Daly, H. E. (1992). Natural Capital and Sustainable Development. Conservation Biology, $6(1), 37-46$.

De Soysa, I. (2002). Ecoviolence: Shirinking Pie, or Honey Pot? Global Environmental Politics. 2(4), $1-36$.

De Rivera, J. (Eds.). (2009). Handbook on Building Cultures of Peace. Springer.

Di Chiro, G. (1995). Nature as Community: The Convergence of Environment and Social Justice. W.W. Norton \& Company.

Dijk, T. (1995). Power and the News Media. In D. Paletz (Eds.), Political Communication and Action. (pp. 9-36). Hampton Press.

Dobson, A. (1998). Justice and the Environment: Conceptions of Environmental Sustainability and Dimensions of Social Justice. Oxford University Press.

Doyle, T. (1998). Sustainable development and Agenda 21: The Secular Bible of Global free markets and pluralist democracy. Third World Quarterly, 19(4), 771-786.

Drexhage, J. \& Murphy, D. (2010). 'Sustainable Development: From Brundtland to Rio 2012', in United Nations Headquarters, $1^{\text {st }}$ Meeting by the High Level Panel on Global Sustainability. United Nations.

Dryzek, J. (1997). The Politics of the Earth: Environmental Discourses. Oxford University Press.

Du Bose, J., Frost, J. D., Chamaeau, J. A. \& Vanegas, J. A. (1995). Sustainable development and technology. In Elms D \& Wilkinsin D (Eds.), The Environmentally Educated Engineer, Center for Advanced Engineering.

Du Pisani, J. A. (2006). Sustainable Development - Historical Roots of the Concept. Environmental Science, 3(2), 83-96. 
Duffield, J. S. (2014). South Korea's National Energy Plan Six Years On. Asian Politics \& Policy 6(3), 433-454.

Duffield, M. R. (2001). Global Governance and the New Wars: The Merging of Development and Security. Zed Books.

Dunlap, A. (2017). The Town is Surrounded:' From Climate Concerns to Life under Wind Turbines in La Ventosa. Mexico Human Geography, 10(2), 16-36.

Dunlap, A. (2018, May 10). End the "Green" Delusions: Industrial-scale Renewable Energy is Fossil Fuel+, computer software. VERSO. https://www.versobooks.com/blogs/3797-end-the-greendelusions-industrial-scale-renewable-energy-is-fossil-fuel

Dussel, E. (2000). Europe, Modernity, and Eurocentrism. Nepantla, 1(3), 465-478.

Dutta, K. (2020). Violence Triangle of Johan Galtung in Context of Conflict Theory. AIHR. https://www.aihrhre.org/understanding-violence-triangle-johan-galtung-conflict-theory/

Economic and Social Council. (2018). Committee for Development Policy. United Nations, Supplement No.13, 1-33.

Elliott, J. A. (2006). An Introduction to Sustainable Development ( $3^{\text {rd }}$ ed.). Routledge.

Eom, E. H. (2012). Spatialities of Environmental (In)justice and Politics of Scales through the electricity transmission tower conflicts in Miryang, Korea [In Korean: 환경(부)정의의 공간성과 스케일의 정치학: 밀양 송전탑 갈등을 사례로]. Space and Society, 22(4), 51-91.

Escobar, A. (1995). Introduction: Development and the Anthropology of Modernity. In A, Escobar (Eds.), Encountering Development: The Making and Unmaking of the Third World (pp. 3-20). Princeton University Press.

Escobar, A. (1996). Constructing Nature. In R. Peet \& M. Watts (Eds.), Liberation Ecologies: Environment, development, social movements (pp.46-68). Routledge.

Escobar, A. (2006). Difference and Conflict in the Struggle Over Natural Resources: A political ecology framework. Development, 49(3), 6-13.

Esteva, G. (2010). Development. In W, Sachs (Eds.), The Development Dictionary: A Guide to Knowledge as Power (2 ${ }^{\text {nd }}$ ed. pp.1-23). Zed Books.

Faber, D.R. \& McCarthy, D. (2003). Neo-liberalism, Globalization and Struggle for Ecological 
Democracy: Linking Sustainability and Environmental Justice. In J, Ageyman., R. D. Bullard. \& B Evans (Eds.), Just Sustainabilities. Development in an Unequal World. Earthscan.

Farley, H.M. \& Smith, Z.A. (2013). Sustainability: If it's everything, is it nothing? Taylor and Francis.

Fehling, M., Nelson, B. D. \& Venkatapuram, S. (2013). Limitations of the Millennium Development Goals: a literature review. Global Public Health, 8(10), 1109-1122.

Forastelli, F. (2013). Peace Profile: Vicent Martínez Guzmán. Peace Review: A Journal of Social Justice, 25(3), 439-446.

Foster, J. B. (2001, October 1). Ecology against capitalism. Monthly Review, 53(5).

https://monthlyreview.org/2001/10/01/ecology-against-capitalism/

Foucault, M. \& Gordon, C. (1980). Power/knowledge. Pantheon Books.

Foucault, M., Rainbow, P. \& Faubion, J. (1997). The essential works of Michel Foucault, 1954-1984, New Press.

Fouquet. R. (2016). Path dependence in energy systems and economic development, Natural energy. Nature Energy. https://doi.org/10.1038/nenergy.2016.98

Fraser, N. (2001). Recognition without Ethics? Theory, Culture, and Society, 18, 21-42.

Freeman III, A.M. (1972). Distribution of environmental quality. In A.V. Kneese \& B. T. Bower (Eds.), Environmental Quality Analysis: Theory and Methods in the Social Sciences (pp. 243-287). The Johns Hopkins Press.

Friedman, M. (1951). Neo-Liberalism and Its Prospects. Farmand, 89-93

https://miltonfriedman.hoover.org/friedman_images/Collections/2016c21/Farmand 02_17_1951.pdf

Galtung, J. (1964). An Editorial. Journal of Peace Research, 1(1), 1-4.

Galtung, J. (1967). Theories of Peace: A Synthetic Approach to Peace Thinking. International Peace Research Institute.

Galtung, J. (1969). Violence, Peace and Peace Research, Journal of Peace Research, 6(3), 167-191.

Galtung, J. (1990). Cultural Violence. Journal of Peace Research, 27(3), 291-305.

Galtung, J. (2013). Violence: Direct, Structural and Cultural. In H. G. Brauch (Eds.), Johan Galtung: 
Pioneer of Peace Research (pp. 35-58). Springer.

GAO (U.S. Government Accountability Office). (1983). Siting of Hazardous Waste Landfills and Their Correlation With Racial and Economic Status of Surrounding Communities. 1-25. https://www.gao.gov/products/RCED-83-168

Gare, A. (1995). Postmodernism and the Environmental Crisis, Routledge.

Gibbs, D.C., Longhurst, J. \& Braithwaite, C. (1998). 'Struggling with sustainability': weak and strong interpretations of sustainable development within local authority policy. Environment and Planning A, $30,1351-1365$.

Gladwin, T. N., Kennelly, J. J. \& Krause, T. (1995). Shifting Paradigms for Sustainable Development: Implications for Management Theory and Research. Academy of Management Review, 20(4), 874-907.

Go, E. J. (2019, October 3). Spider-Web like Transmission Lines 'The Rate of Burying Rate' One Extreme to Another Extreme. Seoul $90 \%$ vs Gang-Won 1\% [In Korean: 거미줄 전선'지중화율 '극과 극': 서울 90\% vs 강원 1\%].. Yonhap News Agency. https://www.yna.co.kr/view/AKR20191002180600003

Godbout, J. \& Cailé, A. (1998). The World of the Gift (D. Winkler, Trans). McGill-Queen's University Press.

Goldin I. \& Winters L. A. (1995). The Economics of Sustainable Development. University of Cambridge Press.

Gomes, A. (2012). Alter-Native 'Development': Indigenous forms of social ecology. Third World Quarterly, 33(6), 1059-1073.

Gomes, A. (2007). MODERNITY AND MALAYSIA: Settling the Menraq Forest Nomad. Routledge.

Green Action. (n.d.). Environmental Justice \& Environmental Racism.

http://greenaction.org/?page id=420

Green Growth Committee. (2009). Green Growth, National Strategy. [In Korean: 녹색성장

국가전략], Green Growth Korea.

file:///C:/Users/\%ED\%99\%8D\%EC\%9D\%80\%EC\%95\%84/Downloads/12578211754341\%20(1).PDF

Grewal, B. S. (2003). Johan Galtung: Positive and Negative Peace.

http://www.activeforpeace.org/no/fred/Positive_Negative_Peace.pdf 
Grosfoguel, R. (2008). Transmodernity, border thinking, and global coloniality: Decolonizing, political economy and postcolonial studies. Eurozine, 1-23.

Grossman, G. M. \& Krueger, A. B. (1991). Environmental impacts of a North American Free Trade Agreement, National Bureau of Economic Research Working Paper 3914. NBER.

Gu, J. S. (2012). A Study on the improvement of Environmental Inequality in Public Law [In Korean: 환경불평등의 개선에 관한 공법적 검토: 발전시설의 설치. 운영에 따른 환경 불평등을 중심으로]. Investigation of Public Law, 13(4): 295-322.

Gramling, C. (2020, March 4). Australia's wildfires have now been linked to climate change, ScienceNews. https://www.sciencenews.org/article/australia-wildfires-climate-change

Gwak, J. H. (2017, April 25). Lee Sang-Don "Yeongyang Wind Energy, Mountain Version of Four River Project". [In Korean: 영양 풍력발전단지, 산에 하는 4대강 사업" 주민 대책위와 기자 간담회..."산사태 위험 높아 주민 피해], Pressian.

http://www.pressian.com/news/article.html?no=156828

Ha, S. G. (2014). Measures of Rational Adjustment for Public Conflicts: Focusing on the Issue of the Transmission Tower in Miryang. [In Korean: 공공 갈등의 합리적 관리를 위한 방법 연구: 밀양 송전탑 건설의 갈등사례를 중심으로]. The Journal of Social Science, 21(2), 79-103.

Han, J. K. (2016). Reforming Electricity Bills Planned by Green Party: Industrial and Household Bills. [In Korean: 녹색당의 전기요금제 개편방향의 구상 (산업용과 가정용 요금을 중심으로)]. http://www.kgreens.org/wp-content/uploads/2016/08/JK_HAN-160817.pdf

Han, M. H. (1999). Environmental Justice and Reality. Environment \& Life, 130-141.

Haque, M. M. (1991). Sustainable development and environment: a challenge to technology choice decision-making. Project Appraisal, 6(3), 149-157.

Harvey, D. (1993). The nature of environment: the dialectics of social and environmental change. In R. Miliband \& L. Panitch (Eds), Real problems, false solutions (pp. 1-51). Merlin Press.

Hart, S. L. (1997). Beyond greening: Strategies for a sustainable world. Harvard Business Review, January/February, 6-76.

Hawkins, A. (1993). Contested Ground: International Environmentalism and Global Climate Change. In R.D. Lipschutz \& K.Conca (Eds), The State and Social Power in Global Environmental Politics. Columbia University Press. 
Hens, L. \& Nath, B. (2003). Environment, Development and Sustainability: A Multidisciplinary approach to the Theory and Practice of Sustainable Development. In The Johannesburg Conference (March), Springer, 5(1), 7-39.

Hermanns, H. (2015). Green Growth-Ecological Modernization Korean-Style? 21st century Political Science Review, 25(2), 263-286.

Hewitt, T. (2000). Half a century of development. In T. Allen \& A. Thomas (Eds.), Poverty and Development into the Twenty-First century (pp. 289-308). Oxford University Press.

Hird, J. A. (1993). Environmental policy and equity: The case of Superfund. Journal of Policy Analysis and Management, 12(2), 323-343.

Hobbs, M. (2008). On Discourse and Representation: Reflections on Michel Foucault's Contribution to the Study of the Mass Media. Annual Conference of the Australian Sociological Association University of Melbourne, Australia, 02nd to 05th December 2008. Melbourne: Published by TASA

Holifield, R., Porter, M. \& Walker, G. (Eds.). (2010). Spaces of Environmental Justice. WileyBlackwell.

Holmberg, J. \& Sandbrook, R. (1992). Sustainable development: what is to be done? In J. Holmberg (Eds.), Policies for a Small Planet (pp. 19-38). Earthscan.

Homer-Dixon, T. (1994). Environmental Scarcities and Violence Conflict: Evidence from Cases. International Security, 19(1), 5-40.

hooks, B. (2010). Teaching critical thinking: practical wisdom. Routledge.

Hopwood, B., Mellor, M., \& O'Brien, G. (2005). Sustainable Development: Mapping Different Approaches. Sustainable Development, 13, 38-52.

Hwang, J. H. (2002). Basis of Philosophical Comparison for Environmental Ethics. Pan-Korean Philosophy, 27, 291-312.

IAIA (International Association for Impact Assessment). (1999). Principles of Environmental Impact Assessment Best Practice. Institute of Environmental Assessment.

IISD. (n.d.). What is Sustainable Development? Retrieved 2018, July 4 from https://www.iisd.org/topic/sustainable-development

Illich, I. (1982). Peace vs. Development. (January, 1982): 53-60. https://democracyjournalarchive.files.wordpress.com/2015/06/illach_peace-vs-development- 
democracy-2-1_-jan-1981.pdf

INVEST KOREA. (2018). New \& Renewable Energy. Retrieved 2018, May 9 from http://www.investkorea.org/en/world/newenergy.do

ITHRVMR (Investigation Team of Human Rights Violation over the Miryang Transmission Tower). (2013). Human Violation Report on Miryang 765kV Transmission Tower Case. Investigation Team of Human Rights Violation over the Miryang Transmission Tower.

Jacobs, M. (1999). Sustainable development as a contested concept. In A. Dobson (Eds.), Fairness and Futurity. Oxford University Press.

Jacobsen, J.O., Hengartner, N.W. \& Louis, T.A. (2005). Inequity measures for evaluations of environmental justice: a case study of close proximity to highways in New York City. Environment and Planning A, 37: 21-43.

Jänicke, M. \& Weidner, H. (1997). National Environmental Policies: a Comparative Study of CapacityBuilding, Springer.

Jeon, J. K. (2009). The Harmonization of Sustainable Development Law and Green Growth Law in Korea. [In Korean: 지속가능발전과 녹색성장]. Seogang Law, 11(2), 25-43.

Jerrett, M., Burnett, R.T., Kanaroglou, P., Eyles, J., Finkelstein, N., Giovis, C. \& Brook, J.R. (2001). A GIS - environmental justice analysis of particulate air pollution in Hamilton, Canada. Environment and Planning A, 33: 955-973.

Ji, S. H. \& Jang, I. J. (2013). Comparing Electricity Bills of Korea and Main OECD Countries. [In Korean: 한국과 $\mathrm{OECD}$ 주요 국가간 전기요금 수준 비교분석]. CEO Report, 13(25).

Jin, S. H. (2007). Cognition and Reality in Environmental Sustainability of Korea. [In Korean: 한국의 환경지속성에 관한 인식과 실제]. Korean Poliy Sciences Review, 11(1), 179-208.

Johnson, T. (1993). Native Intelligence. Amicus Journal, 14(4), 11-13.

Jorgensen, M. \& Philips, L. (2002). Discourse Analysis as Theory and Method. Sage Publications.

Jungang daily. (1987, January 12). Obtaining a loan to pay farm household debts' [In Korean: 농가부채 빚 갚기 위해 빚낸다]. Jung Ang Ilbo.

http://article.joins.com/news/article/article.asp?total_id=2082018\&ctg=10

KEPCO-a (Korean Electric Power Corporation). (n.d.). Major Electricity Billing System. Retrieved 2018, June 1 from http://cyber.kepco.co.kr/ckepco/front/jsp/CY/H/C/CYHCHP00201.jsp 
KEPCO-b (Korean Electric Power Corporation). (n.d.). Information about Foreign Countries Electricity Charge Fee [In Korean: 외국 전기요금제도 정보]. Retrieved from 2020, April 28 from http://cyber.kepco.co.kr/ckepco/front/jsp/CY/H/C/CYHCHP00303.jsp

KEPCO. (2014). Sustainability Management Report [In Korean: 지속가능경 영 보고서]. Download at https://www.kps.co.kr/open_kps/openkps_01_04_2014.do

KFEM (Korean Federation for Environment Movement). (2013, October 22). Survey on Miryang Transmission Tower. Ecoseoul. Retrieved 2019, Aug 9 from http://www.ecoseoul.or.kr/xe/?mid=solar_material\&page=7\&order_type=asc\&listStyle=gallery \&doc ument srl $=1891990$

Kiezebrink, V., Wilde-Ramsing, J. \& Kate, G. T. (2018). Human Rights in Wind Turbine Supply Chains: Towards a Truly Sustainable Energy Transition. ActionAid, 1-31. https://www.somo.nl/wpcontent/uploads/2018/01/Final-ActionAid_Report-Human-Rights-in-Wind-Turbine-Supply-

Chains.pdf

Kim, B. W. (2019, October 4). Transmission line undergoing rate, regional gap extreme. Today Energy. http://www.todayenergy.kr/news/articleView.html?idxno=218096\&lang=en

Kim, D. R. \& Seo, E. R. (2015, January 14). Saemaeul Movement helped to overcome starvation? Nonsense. [In Korean: 새마을운동 덕분에 굶주림 면했다? 턱없는 소리], Pressian. Retrieved 2018, June 1 http://www.pressian.com/news/article.html?no=123180

Kim, E. J., Kim, J. S., Jang, M. S., Yi, Y. B. \& Hong, J. H. (2014). Investigation on Legal System related on Sustainable Development and Green Growth etc. [In Korean: 지속가능 발전과 녹색성장 등 관련 법체계 연구] Korea Legislation Research Institut.

file:///C:/Users/\%ED\%99\%8D\%EC\%9D\%80\%EC\%95\%84/Downloads/\%EC\%97\%B0\%EA\%B5\%A C\%EC\%9A\%A9\%EC\%97\%AD\%20\%EB\%B3\%B4\%EA\%B3\%A0\%ЕC\%84\%9C(\%EC\%B5\%9C\% EC\%A2\%85).pdf

Kim, H. G. (1994). Development Process and Environmental Problem: The Experience of Modern Korea. [In Korean: 경제발전과정과 환경문제: 현대한국의 경험]. Journal of Environment, 32,190201

Kim, H. S. (2014a). Human Exploration on Dispute Resolution: Reinterpretation of Chang-tzu and Its Application to the Conflict of Power-line Towers in Miryang. [In Korean: 갈등관리의 인문학적 성찰: 장자(莊子)의 재해석과 밀양 송전탑 사례에의 적용]. Korean Local Development Journal, 26(3), 130.

Kim, J. H. (2013). VIP Report for Sustainable Development [In Korean: 지속가능 성장을 위한 VIP 레포트: 국내 전력수급의 구조적 문제점 및 개선방안]. Hyundai Economic Research Institute, 
Kim, J. H., Kim, J. I., Kim, W. D., Kim, Y. W., Lee, H. J., Lee, S. J., Lee, Y. S., Ryu, B. R. \& Yu, T. K. (2017). Results of Participatory Surveys for Public Deliberation on Shin-Gori Nuclear Reactors No. 5 \& 6. The Public Deliberation Committee on Shin-Gori Nuclear Reactors No. 5 \& 6, 1-182.

Kim, W. C. (2016). Analyzing Miryang Transmission Tower Through the Procedure Justice. [In Korean: 절차적 정의의 관점으로 밀양 송전탑 분석- 형식적인 참여와 강요된 합의]. The Korean Association for Environmental Sociology, 189-209.

Kim, W. C. \& Yun, S. J. (2018). Stakeholders change and community collapse caused by KEPCO's conflict management strategy on Miryang $765 \mathrm{kV}$ transmission tower construction. [In Korean: 한전의 밀양 $765 \mathrm{kV}$ 송전탑 건설 갈등 관리전략으로 인한 이해관계자 변화와 공동체 붕괴]. ECO 22(1), 171-208.

Kim, Y. (2015). Gender Analysis on Miryang Struggle Against 765kV Transmission Tower. [In Korean: 밀양 $765 \mathrm{kV}$ 송전탑건설반대운동에 대한 젠더 분석: 젠더 점핑의 과정과 원인을 중심으로]. Journal of Korean Women's Studies 31(2), 1-53.

Kim, Y. \& Seol, M. W. (2015). Biographical Context of Participation in Social Movement: A biographyreconstructive analysis on experiences in Miryang struggle against $765 \mathrm{kV}$ transmission tower. [In Korean: 밀양 $765 \mathrm{kV}$ 송전탑건설반대운동에 참여한 여성주민들의 구술생애사 분석을 중심으로]. The Korean Journal of Archival Studies, 44, 101-151.

Kim, Y. M. (2014b, June 14). KEPCO-Miryang Villagers, 'Transmission Tower War. Yonhap news. http://www.yonhapnews.co.kr/bulletin/2014/06/11/0200000000AKR20140611069600052.HTML

Kim, Y. H. (2017a). Oral Memory and Narrative Representation: Focusing on the oral narratives of participants in the movement against the installation of transmission tower $(765 \mathrm{kV})$ in Miryang [In Korean: 구술 기억과 서사적 표상 - 밀양 $765 \mathrm{kV}$ 송전탑 건설 반대 운동 참여자들의 구술 서사를 중심으로]. Language Facts and Perspectives, 42(1), 5-34.

Kim, Y. H. (2017b, August 8). Re-delat Shin-Gori No.4 until Next year September or October. [In Korean: 신고리 4호기 준공, 내년 9월로 10개월 재연기]. Yonhap news. http://www.yonhapnews.co.kr/bulletin/2017/08/08/0200000000AKR20170808120800003.HTML

Koo, J. H. (2018, Feb 13). The Reason Why the Villagers in Miryang Cannot Open the Holiday Gift from the President. [In Korean: 밀양송전탑 주민이'문재인 대통령 명절 선물 개봉 못하는 이유], Voice of People. http://www.vop.co.kr/A00001255649.html

Krauss, C. (1994). Women of Color on the Front Line. In R. Bullard (Eds.), Unequal Protection: 
Environmental Justice and Communities of Color. CA: Sierra Club Books.

Kwon, H. S. (1997). Environmental Policy, the Theory and Practice: Environmental Conflicts in Korea, Environmental Movement, and Environmental Justice. [In Korean: 특집 2: 환경정책, 그 이론과 실천- 한국의 환경갈등, 환경운동 그리고 환경정의]. Environment \& Life 12, 44-55.

Kwon, H. S. (2002). Environmental Justice Movement in Korea. Korea Society and Public Administraction, 13(2), 151-166.

Lafferty, W. M. \& Meadowcroft, J. (2000a). Introduction. In W. M. Lafferty \& J. Meadowcroft (Eds.), Implementing sustainable development: Strategies and initiatives in high consumption societies. Oxford University Press.

Lafferty, W.M., \& Meadowcroft, J. (2000b). Concluding perspectives. In W. M. Lafferty \& J. Meadowcroft (Eds.), Implementing Sustainable Development: Strategies and Initiatives in High Consumption Societies (pp. 422-459). Oxford University Press.

Lakoff, G. (2010). Why it Matters How We Frame the Environment. Environmental Communication, $4(1), 70-81$.

Langhelle, O. (2000). Why ecological modernization and sustainable development should not be conflated. Journal of Environmental Policy and Planning, 2(4), 303-322.

Laurent, E. (2011). Issues in Environmental Justice within the European Union. Ecological Economics, $70,1846-1853$.

Lavelle, M. \& Coyle, M. (1992). (Eds). The racial divide in environmental law: Unequal protection (Special Supplement). National Law Journal.

Lears, T, (1985). The Concept of Cultural Hegemony: Problems and Possibilities. The American Historical Review, 90(3), 567-593. https://doi.org/10.1086/ahr/90.3.567

Lederach, J. P. (2003). The Little Book of Conflict Transformation. Good Books..

Lederach, J. P. (2005). The Moral Imagination: The Art and Soul of Building Peace. Oxford University Press.

Lee, B. A. (2018, September 27). Rethinking the Miryang Villagers at the corner of $3^{\text {rd }}$ Energy General Plan [In Korean: 3차 에너지기본계획 앞두고 다시 밀양주민들을 떠올리는 이유]. Energy and Climate Policy Institute.

http://ecpi.or.kr/epbrd/bbs/board.php?bo table=bbs16\&wr id=110788\&page= 
Lee, C. (2005). Environmental Justice. In H. Frumkin (Eds), Environmental Health from Global to Local (pp. 170-196). Jossey-Bass.

Lee, D. M. (2017a. July 17). Travel Map of Miryang. MEGO JIGO Retrieved 2020 April 28 from http://megojigo.com/bbs/board.php?bo table=openmap\&wr id=46

Lee, H. S. (2010). Problems to Realize Green Growth in Land Use Law. [In Korean: 녹색성장법에 따른 국토이용법제의 과제]. Korean Public Land Law Association, 49, 111-130.

Lee, H. S. (2013a). Review alternative and Policy Proposal on Shingori Bukgyeongnam 765kV Transmission Tower. [In Korean: 신고리 북경남 $765 \mathrm{kV}$ 송전탑 대안 검토와 정책 제언: 노후 원전 폐기와 신규 원전건설 중단을 중심으로 살펴본 밀양 송전탑 대안 연구], Energy Justice Action,

http://energyjustice.kr/zbxe/index.php?mid=energydata\&category=20661\&ckattempt=1\&document s $\mathrm{rl}=450794$

Lee, H. Y. \& Yun, S. J. (2013). An Analysis of News Coverage on Conflicts concerning Transmission Line Construction in Miryang - From a Perspective of Environmental Justice. [In Korean: 밀 양 고압 송전선로 건설 갈등에 대한 일간지 보도 분석- 환경정의 관점에서]. Economy and Society, 98, 4076.

Lee, J. W. \& Lee, Y. S. (2018). ‘2018 Statistics on Elderly Population’ [In Korean: 2018 고령자 통 계], Statistics Korea, 1-78. file:///C:/Users/HC1252DL-

2/Downloads/2018\%20\%C2\%B0\%C3\%AD $\%$ C2\%B7\%C3\%89\%C3\%80\%C3\%9A $\% 20 \% \mathrm{C} 3 \% 85 \% \mathrm{C}$ $3 \% \mathrm{AB} \% \mathrm{C} 2 \% \mathrm{~B} 0 \% \mathrm{C} 3 \% \mathrm{~A} 8 . \mathrm{pdf}$

Lee, K. I. (2017b, March 29). Gyeongbuk Baekdu Mountain Range...”Environmental Destruction”vs “Alternative Energy” [In Korean: 경북 백두대간 풍력발전소 줄이어... “환경파괴”vs

"대체에너지”]. Yonhap news.

http://www.yonhapnews.co.kr/bulletin/2017/03/27/0200000000AKR20170327152200053.HTML

Lee, K. M. (2017c, June 28). Push for reactors halt causes stir. The Korean Times.

http://www.koreatimes.co.kr/www/nation/2017/08/371_232114.html

Lee, S. G. (2007, March 21). Implementing Power Supply Development Plan. [In Korean: 전원개발사업실시계획],

http://www.motie.go.kr/motie/ms/nt/gosi/bbs/bbsView.do?bbs_seq_n=18838\&bbs_cd_n=5

Lee, S. H. (1997). For Practical Environmental Justice. [In Korean: 특집 1: 환경정책, 그 이론과 실천: 실천적 환경정의를 위하여], Environment \& Life, 32-43. 
Lee, S. H. (2000). Environmental Justice, Environmental Policy 5: Case of Wicheon Industrial Complex in Daegu. [In Korean: 특집/환경정의, 환경정책, 환경운동 5: 환경정의의 관점에서 본 대구 위천 공단의 문제]. Environment \& Life, (12), 84-95

Lee, S. H., Lee, J. P. \& Lee, B. A. (2014). A Study on Miryang Transmission Tower Conflict with Multiscalar Perspective. Space and Society, 252-286.

Lee, S. J. (2013b, May 24). Miryang Transmission Tower Construction, Because of exporting nuclear energy to UAE? Must Pay Penalty When Shin-Gori No.3 does not operate before 2015. Hangyure. http://www.hani.co.kr/arti/economy/economy general/588974.html

Lee, S. S. (2013c). Business and Human Rights Approach to the Disputes over the Construction of $765 \mathrm{kV}$ Power Cable Passing Milyang City and its Implications [In Korean: 밀양 송전선 분쟁에 대한 기업인권적 접근]. A Collection of Jurisprudence, 18(2): 119-158.

Lee, S. S. (2016). Political consciousness of the general public and living as "anti-communist citizen" in South Korea 1970s. [In Korean: 1970 년대 한국 대중의 정치의식과 ‘반공국민'으로 살아가기: 개인일기 4 종을 통해 본 1970 년대 대중의 정치의식]. Ethnic Culture Studies, 71, 41-88.

Lee, U. Y. (1990). Modern Korea's Structure and the Change: The Study of Park's Ruling Idea. [In Korean: 현대한국의 구조와 변동: 박정희의 통치이념에 대한 연구]. Yonsei Sociology, 11:343-382.

Lee, Y. H. (2011). The Green Growth Theory and Developing Countries in the Asia-Pacific Political Economic Causes and Theoretical Problems. The Korean Journal of International Studies, 51(4), 3560 .

Leggett, J. A. \& Carter, N. T. (2012). The United Nations Conference on Sustainable Development. Congressional Research Service. https://fas.org/sgp/crs/row/R42573.pdf

Liberty Korea Party. (2019, March 12). The Resolution on Insisting to Drop Nuclear-Phase Policy. [In Korean: 문재인 정부 탈원전 정책 폐기 촉구 결의문]. Retrieved 2019, April 24 from http://www.libertykoreaparty.kr/web/policy/briefing/policyBriefing/readPolicyBriefingView2.do?bbsI $\underline{\mathrm{d}=\mathrm{PBR} 000000001448496}$

Lippert, I. (2004). An Introduction to the Criticism on sustainable Development, Brandenburg University of Technology.

Low, N. P. (2000). Global Ethics and the Environment, Routledge

Lucena, C. \& Gummer, J. (2012, June 12). Rio 20+ Earth summit: Why Rio failed in the past and how it can succeed this time. The Guardian. https://www.theguardian.com/environment/2012/jun/12/rio20- 
agenda-politicians-john-gummer

Luhmann, N. (1989). Ecological Communication. University of Chicago Press

Luke, T. (1995). Sustainable development as a power/knowledge system: the problem of governmentality. In F. Fischer \& M. Black (Eds.), Greening Environmental Policy: The Politics of a Sustainable Future (pp. 21-32). Paul Chapman.

Macnaghten, P. \& Urry. J (1998). Contested natures, Sage.

Maddison, A. (2001). The World Economy: A Millennial Perspective, OECD.

Margai, F. L. (2001). Health risks and environmental inequity: a geographical analysis of accidental releases of hazardous materials. The Professional Geographer, 53(3): 422-434.

Martínez-Alier, J. (2002). The Environmentalism of the Poor: A Study of Ecological Conflicts And Valuation, Edward Elgar, Cheltenham \& Northampton.

Martinez-Alier, J., Temper, L., Del Bene, D. \& Scheidel, A. (2016). Is there a global environmental justice movement? The Journal of Peasant Studies, 43(3), 731-755. https://doi.org/10.1080/03066150.2016.1141198

Martínez-Guzmán, V. (2008). Peacemaking Philosophy, Barcelona, Universitat Oberta de Catalunya, [not officially published]

Martínez-Solimán, M. (2017, July 20). Sustainable development and sustaining peace: Two sides of the same coin. UNDP. https://www.undp.org/content/undp/en/home/blog/2017/7/20/Sustainabledevelopment-and-sustaining-peace-Two-sides-of-the-same-coin.html

Matsuda, H. \& Ohara, K. H. (2008). Hegemony and the Elaboration of the Process of Subalternity. In R. Howson \& K. Smith, (Eds.), Hegemony Studies in Consensus and Coercion (1 ${ }^{\text {st }}$ ed. pp.51-62). Routledge.

Mawhinney, M. (2002). Sustainable Development: Understanding the Green Debates, Blackwell, Science.

McArthur, J. \& Rasmussen, K. (2017). How successful were the Millennium Development Goals? BROOKINGS. https://www.brookings.edu/blog/future-development/2017/01/11/how-successfulwere-the-millennium-development-goals/

Mccarthy, J. (2004). Privatizing Conditions of Production: Trade Agreements as Neoliberal Environmental Governance. Geoforum, 35(1), 327-341. 
Meadow D. H. \& Club of Rome. (1972). The Limits to growth: A report for the Club of Rome's project on the predicament of mankind. Universe Books.

Mebratu, D. (1998). Sustainability and Sustainable Development: Historical and Conceptual Review. Elsevier, 18, 493-520.

Mebratu, M. (2012). Degrowth: Tools for a Complex Analysis of the Multidimensional Crisis. Capitalism Nature Socialism, 23(1), 30-50.

Mennis, J. L. \& Jordan, L. (2005). The distribution of environmental equity: exploring the spatial nonstationarity in multivariate models of air toxic releases. Annals of the Association of American Geographers, 95(2), 249-268.

Mies, M. \& Shiva V. (1993). Ecofeminism, Spinifex Press.

Milman, O. (2018, December 20). Interview: Robert Bullard: 'Environmental justice isn't just slang, it's real. The Guardian. https://www.theguardian.com/commentisfree/2018/dec/20/robert-bullardinterview-environmental-justice-civil-rights-movement

Min, J. H., Jang, W., Han, S. H., Kim, D. \& Kwak, Y. D. (2018). How conflict occurs and what causes conflict: Conflict analysis framework for public infrastructure project. Journal of Management in Engineering, 34(4). https://doi.org/10.1061/(ASCE)ME.1943-5479.0000625

Ministry of Environment Republic of Korea. (1995). 1995 Environmental Statistics Yearbook. file:///C:/Users/\%ED $\% 99 \% 8 \mathrm{D} \% \mathrm{EC} \% 9 \mathrm{D} \% 80 \% \mathrm{EC} \% 95 \% 84 /$ Downloads $/ 1995 \% \mathrm{ED} \% 99 \% 98 \% \mathrm{EA} \%$ B2\%BD $\%$ ED $\% 86 \%$ B5\%EA $\%$ B3\%84\%EC $\% 97 \%$ B0\%EA $\%$ B0\%90.pdf

Ministry of Trade, Industry and Energy. (2000, January 14). The fifth Long-Term Demand Supply Program. [In Korean: 제 5 차 장기 전력계획 수급], Retrieved 2018, April 30 from http://www.motie.go.kr/motiee/presse/press2/bbs/bbsView.do?bbs seq n $=1841 \& b b s$ cd n $=81$

Miryang City. (n.d.). Current State of Women in Miryang [In Korean: 밀양시 여성현 황] Retrieved 2019 April 23 from http://miryang.go.kr/sub/04 05 02.php

Miryang Culture \& Tour. (2015). Special Product. Retrieved 2018 December 10 from http://tour.miryang.go.kr/sub/05 $03 \quad 03 . p h p$

Miryang Statement Project. (2014). Living Miryang [In Korean: 밀양을 살다]. 오월의 봄.

Mitcham, C. (1995). The Concept of Sustainable Development: its Origins and Ambivalence. Technology In Society, 17(3), 311-326. 
Mohai, P. \& Bryant, B. (1992). Race, poverty, and the environment. EPA Journal, 18(1): 6-8.

Mol, A. \& Spaargaren, G. (1993). Environment, modernity and the risk-society: the apocalyptic horizon of environmental reform. International Sociology, 8(4), 431-459.

Mol, A., Spaargaren, G. \& Sonnenfeld, D. (2009). Ecological modernization: Three decades of policy, practice, and theoretical reflection. The Ecological Modernization Reader. Environmental reform in theory and practice, 3-14.

Mol, P. J., Sonnenfeld, D. A. \& Spaargaren, G. (Eds.). (2009). The Ecological Modernization Reader: Environmental Reform in Theory and Practice, Routledge.

Moon, J. W. (2016). 'Cultural Village' and 'Miryang Transmission Tower Grannies'. [In Korean: '감천문화마을'과 '밀양송전탑할매'의 담론적 실천을 중심으로]. Wonkwang Journal of Humanities, 17(1), 209-238.

Moore, J. W. (2019). The Capitalocene and Planetary Justice. Maize, 6, 49-54.

Munene, M. (2009). "Generic peace" and "The peace": a discourse. Journal of Language, Technology \& Entrepreneurship in Africa, 1 (2), 218-228.

Muñoz, F. A. (2001). La Paz Imperfecta. Universidad de Granada.

Napton, M. L. \& Day, F. A. (1992). Polluted neighborhoods in Texas: Who lives there? Environment and Behavior, 24(4), 508-526.

National Energy Committee. (2008). The 1st National Energy Basic Plan: 2008-2030. [In Korean: 제1차 국가에너지 기본계획: 2008-2030].

www.aurum.re.kr/Legal/PlanFileDownLoad.aspx?num=163

National Key Indicator. (2018). Electric Consumption per Person.

http://www.index.go.kr/potal/main/EachDtlPageDetail.do?idx_cd=4102

Ngwira, P. M. (2015). Sustainable Development Goals (SDGs) A Critique, Linkedin.

https://www.linkedin.com/pulse/sustainable-development-goals-sdgs-critique-percy-mabvuto-ngwira/

Nixon, R. (2011). Slow Violence and the Environmentalism of the Poor. Harvard University Press.

Norberg, J. (2003). An Unequal Distribution - of Capitalism. CATO Institute. https://www.cato.org/publications/commentary/unequal-distribution-capitalism 
NPP (National Priorities Project), (n.d.). Military Spending in the United States. Retrieved from May 1, 2020 from https://www.nationalpriorities.org/campaigns/military-spending-united-states/

O'Riordan, T. (2000). The sustainability debate. In T. O'Riordan (Eds.), Environmental Science for Environmental Management (2nd edition, 29-62), Pearson Education.

OECD. (2015). OECD Multilingual Summaries In It Together: Why Less Inequality Benefits All (Summary in English). OECDpublishing. https://doi.org/10.1787/bc9f5d0b-en

Okereke, C. (2008). Global Justice and Neoliberal Environmental Governance Ethics, sustainable development and international co-operation, Routledge.

Olsson, L., Hourcade, J. C. \& Kohler, J. (2014). Sustainable Development in a Globalized World. Journal of Environment and Development, 23(1), 3-14.

Omar, S. M. (2012). Rethinking Development from a Postcolonial Perspective. Journal of Conflictology, $3(1), 42-49$.

Omar, S. M. (2014). Methodology and Techniques of Research Lecture [Power Point slides]. Retrieved from University Jaume I

Orsato, R. J. \& Clegg, S. R. (2005). Radical Reformism: Towards Critical Ecological Modernization. Sustainable Development, 13, 253-267.

Palmer, B. (2016, May 18). The History of Environmental Justice in Five Minutes. NRDC. https://www.nrdc.org/stories/history-environmental-justice-five-minutes

Park, I. H. (2011). The Ethics of Truths and Bare Life: Badiou and Beckett. [In Korean: 진리의 윤리학과 벌거벗은 생명: 바디우와 베케트]. JMBARD, 24(2), 57-78.

Park, J. M. (2006). The Concepts of Environmental Justice: Its Limitations and Alternative Conceptualization. [In Korean: 환경정의 개념의 한계와 대안적 개념화] $E C O, 10(2), 75-114$.

Paul, B. D. (2008). A History of the Concept of Sustainable Development: Literature Review. Economic Science Series, 17(2), 581-585.

Pearce, D. \& Warford, J. J. (1993). World without end: Economics, environment, and sustainable development. Oxford University Press..

Peet, R. \& Hartwick, E. (2009). Theories of Development: Contentions, Arguments, Alternatives (2nd ed). The Guilford Press. 
Peña, Devon (ed.) (1999). 'Nos Encercaron: A Theoretical Exegesis on the Politics of Place in the Intermountain West', Paper given at the Conference on New West, Environment, Culture, and Community Program, Northern Arizona University, Flagstaff, AZ, 1999 (June).

Pepper, D. (1998). Sustainable development and ecological modernization: A radical homocentric perspective. Wiley Online Library, 6(1), 1-7.

Perlin, S. A., Seltzer, R. W., Creason, J. \& Sexton, K. (1995). Distribution of industrial air emissions by income and race in the United States: An approach using the toxic release inventory. Environmental Science and Technology, 29(1), 69-80.

Peters, E. D. (2003, December 23). Latin America's Failed Macroeconomic dictatorships. Project Syndicat. https://www.project-syndicate.org/commentary/latin-america-s-failed-macroeconomicdictatorships?barrier=accesspaylog

Pettinger, T. (2017, September 11). Environmental Kuznets Curve. Economics Help. https://www.economicshelp.org/blog/14337/environment/environmental-kuznets-curve/

PNU (Pusan National University) Locality Achieves. (2015). Remember Miryang: Brief History of the Struggles in Miryang. [In Korean: 밀양을 기억해 주세요: 밀양 송전탑 반대투쟁 약사]. http://mta.localityarchives.org/exhibits/show/-------10----------/10years

Pogge, T. W. \& Sengupta, M. (2016). Assessing the sustainable development goals from a human rights perspective. Journal of International and Comparative Social Policy, 32(2), 83-97.

Polanyi, K. (2001). The Great Transformation: The Political and Economic Origins of Our Time (2 $2^{\text {nd }}$ ed.). Beacon Press.

Pollock, P. H., III. \& Vittas, M. E. (1995). Who bears the burdens of environmental pollution? Race, ethnicity, and environmental equity in Florida. Social Science Quarterly, 76(2), 294-310.

Principles of Environmental Justice. (1991). https://www.ejnet.org/ej/principles.pdf

Prizzia, R. (2007). Sustainable Development in an International Perspective. In K.V. Thai, D. Rham \& J. D. Coggburn. (Eds.), Handbook of Globalization and the Environment (19-42). CRC Press.

ProCon.org. (2019). History of Climate change Debate. https://climatechange.procon.org/history-ofclimate-change-debate/

Pulido, L. (1996). A critical review of the methodology of environmental racism research. Antipode, 28 (2), 142-159. 
Pyo, D. W. (2015). Conflict of Miryang Transmission Towers and Comprehending the Compensation Law [In Korean: 밀양 송전탑 갈등과 「송주법」이해]. The Law of Land Compensation, 15, 103-127.

Rahnema, M. \& Bawtree, V. (1997). The Post- Development Reader, Zed Books.

Rapport, A. (1992). Peace: An Idea Whose Time Has Come. The University of Michigan Press.

Ravaioli, C. \& Paul, E. (1995). Economists and the environment: What the top economists say about the environment (R. Bates, Trans.). Zed Books.

Rawls, J. (1971). A Theory of Justice. Oxford University Press.

Rawls, J. (1993). Political Liberalism. Columbia University Press.

Redclift, M. (2005). Sustainable Development (1987-2005): An Oxymoron Comes of Age. Sustainable Development, 13, 212-227.

Reinsborough, P. \& Canning, D. (2010). RE:Imagining Change, PM Press.

Rist, G. (2008). History of Development: From Western Origins to Global Faith (3 ${ }^{\text {rd }}$ ed.), (P. Camiller, Trans.). Zed Books.

Robbins, P. (2012). Political ecology: A critical introduction (2 ${ }^{\text {nd }}$ ed.). Blackwell Pub.

Rodeheaver, D. \& Cutrer, J. G. (1995). Environmental Equity and the Case of West Dallas. In S. R. Ingman (Eds.), An aging population, an aging planet, and a sustainable future. Center for Texas Studies.

Rossi, M. S., Halina, S. B. \& Leo, W.B. (2000). Leaders in sustainable development: How agents of change define the agenda. Business Strategy and the Environment, 9, 273-286.

Rostow, W. W. (1978). The World Economy. History \& Prospect. University of Texas Press.

Saad-Filho, A. \& Johnston, D. (Eds.). (2005). Neoliberalism: A Critical Reader. Pluto Press.

Sachs, J. D. (2005). Investing in Development: A Practical Plan to Achieve the Millennium Development Goals. United Nations Development Programme. file:///C:/Users/\%ED\%99\%8D\%EC\%9D\%80\%EC\%95\%84/Downloads/Investing_in_development_a practical_plan to achie.pdf

Sachs, W. (Eds.). (2010). The Development Dictionary: A Guide to Knowledge as Power (2 $2^{\text {nd }}$ ed.). Zed Books. 
Salomon, G. (2009). Peace Education: Its Nature, Nurture and the Challenges It Faces. In J. De Rivera (Eds.), Handbook on Building Cultures of Peace (107-121). Springer Science+Business Media LLC.

Sancton, T. A. (1989, January 2). Planet Of The Year: What on EARTH Are We Doing? TIME. http://content.time.com/time/subscriber/article/0,33009,956627-1,00.html

Sandbu, M. (2015, September 15). Critics question success of UN's Millennium Development Goals. Financial Times. https://www.ft.com/content/51d1c0aa-5085-11e5-8642-453585f2cfcd

Sbert, J. M. (2010). Progress. In W. Sachs. (Eds.), The Development Dictionary: A Guide to Knowledge as Power ( $2^{\text {nd }}$ ed.). Zed Books.

Scheidel, A., Del Bene, D., Liu, J., Navas, G., Mingorria, S., Demaria, F., Avila, S., Roy, B., Ertor, I., Temper, L. \& Martinez-Alier, J. (2020). Environmental conflicts and defenders: A global overview. Global Environmental Change 63,1-12.

Schlosberg, D. (2007). Defining Environmental Justice: Theories, Movements, and Nature. Oxford University Press.

Schroeder, R., Martin, K., Wilson, B. \& Sen, D. (2008). Third World Environmental Justice. An International Journal 21(7), 547-555. https://doi.org/10.1080/08941920802100721

SDGs Knowledge Platform. (n/d). World Summit on Sustainable Development (WSSD), Johannesburg Summit. https://sustainabledevelopment.un.org/milesstones/wssd Retrieved 2017 April 23.

Seidl, D. (2004). Luhmann's Theory of Autopoietic Social Systems. Munich Business Research Paper, 20042.

Sen, A. (1985). Well-Being, Agency and Freedom: The Dewey Lectures 1984. The Journal of Philosophy, 82(4), 169-221.

Senge, P. M. (1990). The Fifth Discipline: The Art and Practice of the Learning Organization, Doubledat/Currency.

Shifferd, K. D. (2011). From War to Peace: A Guide to the Next Hundred Years. McFarland \& Company.

Shiva, V. (2010, November 7). Time to End War Against the Earth. Common Dreams. https://www.commondreams.org/views/2010/11/07/time-end-war-against-earth\#

Shrader-Frechette, K. (2002). Environmental Justice: Creating Equality, Reclaiming Democracy. Oxford University Press. 
Sikor, T. (2013). Introduction. In T. Sikor. (Eds.), The Justice and Injustice of Ecosystem Service. Routledge.

Sim, H. G., Kim, C. S., Yang, G. Y. \& Kim, S. W. (2014). A Frame Analysis on the 765kV Transmission Line Construction: Focusing on the Cognition of the Residents in Gijang County and Miryang City. [In Korean: 고압송전선로 건설갈등의 프레임 분석: 기장군과 밀양시 주민인식조사를 중심으로]. Korean Administration Publish, 26(2), 214-264.

Sneddon, C., Howarth, R. B. \& Norgaard, R. B. (2006). Sustainable development in a post-Brundtland world. Ecological Economics, 57, 253-568.

Sohn, S. K. (2015, August 26). Wind Energy Generator Low Frequency Noise, Villagers Suffer. [In Korean: 풍력발전기 저주파 소음, 주민들 정신병 생길 지경], Nocut News. http://www.nocutnews.co.kr/news/4463889

Sohn, H. Y. (2019, November 5). 'Dream Technology' Superconductive cable. KEPCO, Commercialized for the first time in the world. [In Korean: "꿈의 기술' 초전도 케이블. 한전, 세계 최초 상용화]. Jungang Ilbo. https://news.joins.com/article/23624902

Spaargaren, G. (1997). The Ecological Modernization of Production and Consumption: Essays in Environmental Sociology. Landbouwuniversiteit Wageningen.

STATISTICS KOREA. (2018). Renewable energy supply statue report. [In Korean: 신재생 에너지 현황보고]. http://www.index.go.kr/potal/main/eachdtlpagedetail.do?Idx_cd=1171

Stern, D. I. (2004). The Rise and Fall of the Environmental Kuznets Curve. World Development, 32(8), 1419-1439.

Stop Wasting Food. (2017). About Stop Wasting Food. Retrieved 2017, October 8 from http://stopwastingfoodmovement.org/

Stromberg, J. (2013, January). What is the Anthropocene and Are We in It? Smithsonian Magazine. https://www.smithsonianmag.com/science-nature/what-is-the-anthropocene-and-are-we-in-it$\underline{164801414 /}$

Sustainable Development Committee. (2019). A Report on Korean-Sustainable Development Goals (KSDGs). [In Korean: 2019 국가 지속가능발전목표(K-SDGs) 수립보고서]. Ministry of Environment. 1572586046142 K-SDGs_report.pdf

Sustainable Development Goals. (n/d). About the Sustainable Development Goals. Retrieved 2017, July 4 from https://www.un.org/sustainabledevelopment/sustainable-development-goals/ 
Taylor, D. E. (1993). Environmentalism and the Politics of Inclusion. In D. R. Bullard (Eds.), Confronting Environmental Racism: Voices from the Grassroots (53-61). South End Press.

Taylor, D. E. (2000). The Rise of the Environmental Justice Paradigm: Injustice Framing and the Social Construction of Environmental Discourses. American Behavioral Scientist, 45, 508-580.

Tesh, S. \& Williams, B. (1996). Identity Politics, Disinterested Politics, and Environmental Justice. Polity, 18(3), 285-305.

Tetsuya, T. (2013). System of Sacrifice: Fukishima, Okinawa [In Korean: 희생의 시스템 후쿠시마 오키나와 (S. D. Han. Trans.). 돌베개. (Original Work Published 2012).

The Friends of the Earth International (FOE). (2012, June 18). Rio+20 summit under corporations' undue influence. Retrieved 2017, August 15 from http://www.foei.org/news/blogs/rio-20/rio20-summitunder-corporations-undue-influence-2

Thich Nhat Hanh. (2008). The World We Have: A Buddhist Approach to Peace and Ecology (13 ${ }^{\text {th }}$ Ed.). ReadHowYouWant.

Thiong'o. N. W. (1993). Moving the Center: The Struggle for Cultural Freedom. James Currey Ltd.

Toda, K. (1996). For Environmental Justice: Structure of Environmental Destruction and Elitism [In Korean: 환경정의를 위하여: 환경 파괴의 구조와 엘리트 주의] (W. S. Kim. Trans.). History of Creation and Critics.

Truman, H. S. (1999). Inaugural Address. In L. Copeland and others (Eds.), The World's great speeches, Courier Dover Publications.

Txetxyu, A. (2017, December 18). Comunicación, Conflictos y Cambio Social. [Seminar]. Seminario Permanente IUDESP, Universidad Jaume I, Castellon, Spain.

Tziarras, Z. (2012). Liberal Peace and Peace-Building: Another Critique. The GW Post Research Paper, $1-13$.

U.S. EPA (United States Environmental Protection Agency). (1998). Guidance for incorporating environmental justice in EPA's NEPA compliance analysis. United States Environmental Protection Agency.

https://www.epa.gov/sites/production/files/2015-04/documents/ej-guidance-nepa-complianceanalyses.pdf

UCC (United Church of Christ) (1987). TOXIC WASTES AND RACE In The United States A 
National Report on the Racial and Socio-Economic Characteristics of Communities with Hazardous Waste Sites. Commission for Racial Justice. https://www.nrc.gov/docs/ML1310/ML13109A339.pdf

Ullrich, O. (2010). Technology. In W. Sachs. (Eds.), The Development Dictionary: A Guide to Knowledge as Power ( $2^{\text {nd }}$ ed. 275-287). Zed Books.

UN (United Nations). (2015). Transforming our world: The 2030 agenda for sustainable development. https://sustainabledevelopment.un.org/content/documents/21252030\%20Agenda $\% 20$ for $\% 20$ Sustainab le $\% 20$ Development $\% 20 \mathrm{web} . p d f$

UNDP. (2015, September 28). Sustainable Development Booklet.

http://www.undp.org/content/undp/en/home/librarypage/corporate/sustainable-development-goalsbooklet.html

UNEP. (2009). Overview of the Republic of Korea's Green Growth National Vision (An Interim Report). The United Nations Environment Programme as part of its Green Economy Initiative. file:///C:/Users/\%ED $\% 99 \% 8 \mathrm{D} \% \mathrm{EC} \% 9 \mathrm{D} \% 80 \% \mathrm{EC} \% 95 \% 84 /$ Downloads/Korea-UNEP-REPORT.pdf

UNEP. (2011). Towards a Green Economy: Pathways to Sustainable Development and Poverty Eradication. https://sustainabledevelopment.un.org/content/documents/126GER synthesis en.pdf

UNESCAP. (2006). Green Growth at a Glance: The Way Forward for Asia and the Pacific. United Nations Publication.

UNESCAP. (2008). Greening Growth in Asia and the Pacific Follow-up to the World Summit on Sustainable Development: Taking action on the Regional Implementation Plan for Sustainable Development in Asia and the Pacific, 2006-2010. United Nations publication

UNESCAP. (2009). Eco-efficiency Indicators: Measuring Resource-use Efficiency and the Impact of Economic Activities on the Environment. United Nation Publication.

UNESCAP. (n.d.). The Ninth Policy Consultation of the Seoul Initiative Network on Green Growth. Http://www.unescap.org/events/ninth-policy-consultation-seoul-initiative-network-green-growth$\underline{\text { singg }}$

UN International Day of Peace. (n.d.). Building a "Culture of Peace".

https://internationaldayofpeace.org/culture-of-

peace/\#: : text=As $\% 20$ defined $\% 20$ by $\% 20$ the $\% 20$ United,founding $\% 20$ over $\% 2060 \% 20$ years $\% 20 \mathrm{ago} \%$ $\underline{2 \mathrm{C}}$

Union of Concerned Scientists (2020, May 11). Each Country's Share of $\mathrm{CO}^{2}$ Emissions. Retrieved 2020, Aug 9 from https://www.ucsusa.org/resources/each-countrys-share-co2-emissions 
Vaughan, A. (2016, January 7). Human impact has pushed Earth into the Anthropocene, scientists say. The Guardian. https://www.theguardian.com/environment/2016/jan/07/human-impact-has-pushedearth-into-the-anthropocene-scientists-say

Waage, J., Banerji, R., Campbell, O., Chirwa, E., Collender, G. \& Diertiens, V. (2010). The Millennium Development Goals: A Cross-Sectoral Analysis and Principles for Goal Setting After 2015. The Lancet, 376(9745), 991-1023.

Wackernagel, M. \& Silverstein, J. (2000). Big Things First: Focusing on the Scale Imperative with the Ecological Footprint. Ecological Economics, 32, 341-394.

Walker, G. P. \& Bulkeley, H. (2006). Geographies of environmental justice. Geoforum, 37, 655- 659.

Wallensteen, P. (2001). The Growing Peace Research Agenda. Kroc Institute Occasional Paper, \#21:OP:4, 1-28.

Warrick, C. (2015). History of the Environmental Justice Movement. 1-25.

DOI: $\underline{10.13140 / R G \cdot 2 \cdot 1.3317 .3208}$

WCED (World Commission on Environment and Development). (1987). Our Common Future, University Press.

Weale, A. (1992). The New Politics of Pollution. Manchester University Press.

White, L. (1967). The Historical Roots of Our Ecological Crisis. Science, 155(3767), 1203-1207.

Wilkinson, R. \& Pickett, K. (2009). The Sprit Level: Why More Equal Societies Almost Always Do Better, Allen Lane.

Woo, M. Y. \& Gang, J. G. (2013). A Study on the Conflict and Improvement Plan for Land Compensation in the Construction of High-Pressure Power Transmission System. [In Korean: 초고압 송전선로 건설에 따른 토지보상에 대한 갈등과 개선방안에 관한 연구]. Korean Real Estate Academy, 53(may 2013), 201-211.

World Bank. (1992). World development report 1992: Development and the environment, Oxford University Press.

World Nuclear Association. (2019, December). Nuclear Power in South Korea. Retrieved 2019, April 24 from http://www.world-nuclear.org/information-library/country-profiles/countries-o-s/southkorea.aspx 
Worster, D. (1993). The wealth of nature: environmental history and the ecological imagination, Oxford University Press.

Yandle, T. \& Burton, D. (1996). Reexamining environmental justice: A statistical analysis of historical hazardous waste landfill siting patterns in metropolitan texas. Social Science Quarterly, 77(3), 477-492.

Yi, I. H. (2008). An Analytical Review of Environmental Research: The Issues and Trend. Space \& Environment, 29, 32-67.

Yin, R. K. (2014). Case study research design and methods ( $5^{\text {th }}$ ed.). Sage.

Young, I. (1990). Justice and the Politics of Difference. Princeton University Press.

Yun, M. J. (2011). The Rethinking of Green Growth. [In Korean: 녹색성장 주의에 대한 재고찰]. Social Science Studies, 35(2), 65-92.

Yun, S. J. (2006). Looking at the Selection Process of Low and Medium Level Radioactive Waste Disposal Site from and Environmental Justice Perspective. [In Korean: 환경정의 관점에서 본 중·저준위 방사성 폐기물 처분장 입지선정과정]. $E C O, 10(1), 7-42$.

Yun, S. J. (2009). The Ideological Basis and the Reality of "Low Carbon Green Growth". [In Korean: ‘저탄소 녹색성장’의 이념적 기초와 실재]. ECO, 13(1), 219-266.

Yun, S. J. \& Won, G. Y. (2012). Social Acceptance of Lee Myung-bak's Green Growth-based Climate Change Policy Regime: An Evaluation Based on a Survey of Experts' Perceptions. [In Korean: 녹색성장에 기초한 이명박 정부 기후변화정책레짐에 대한 사회적 수용과 평가- 전문가 인식조사를 중심으로]. $E C O, 16(2), 7-50$.

Zafar, S. (2008). Negative Impacts of Incineration-based Waste-to-Energy Technology. file:///C:/Users/\%ED $\% 99 \% 8 \mathrm{D} \% \mathrm{EC} \% 9 \mathrm{D} \% 80 \% \mathrm{EC} \% 95 \% 84 /$ Downloads/NegativeAspectsofIncinerati on-basedWaste-to-EnergyTechnologies.pdf 


\section{APPENDIX}

A Short Conversation Conducted on May 23, 2018, with the representative of the committee, Lee, Gye-Sam (Original: In Korean).

Q.1. 투쟁하게 된 계기 또는 이유?

: 2012 년도 1 월 16 일에 이치우 어르신이 분신 자결하는 사건이 있었고 그 이전에 밀양에 시민단체 사람들이 돕기는 했지만 2005 년도 부터 시작된 투쟁이어서 그 이후에는 계속 지속적으로는 관여를 못하고 있었다가 (나: 그 이후는 언제죠? 이: 2007 년부터는 못 했었어요) 그러다 그 이후에는 밀양시에서 관장을 하면서 정부와 한전과 협상을 계속하고 중재역할들을 밀양시가 하고 있어서 그리고 거기에 관련된 단체들이 거기에 개입을 하고 있어서 저희같은 단체가 개입을 하는게 아니란 생각이 들어서 좀 손을 놓고 있다가 그러다가 충격적인 사고를 겪고 주민들도 저희에게 도움을 요청하시고 하셔서 대책위가 새로 결성되었죠 2012 년 2 월달에 그때부터 일을하고 있습니다.

(Q. 저희들이란 누구인가요? A: 여기 밀양에 원래 존재하고 있던 시민단체를 말하는 것이에요.)

Q.2. 송전탑을 지어졌는데도 계속 싸우고 있는 이유는 무엇일까요?

: 국가폭력에 대한 상처에 대해서 정부나 가해자인 한국전력 경찰에서 단 한차례도 책임을 인정하거나 사과나 주민들이 요구하는 여러가지 재산이나 건강피해 마을공동체 파괴 국가폭력에 대해서 진상을 조사하거나 하지 않아서 그걸 바라면서 지금까지 버텨온 것이죠. 이번 정부 들어서 그러한 흐름이 있기는 하지만 아무것도 된 것이 없다고 볼 수 있죠.

Q.3. 그것이 이유라면 해결책 또는 (이러한 삶이 유지가 되는게 힘이 들기 때문에) 분쟁이 해결될수 있는 합의점은 무엇이 있을까요?

: 저희들이 4 가지 요구를 계속 2014 년부터 내걸고 있는데, 하나는 국가폭력과 송전탑 사업에 대한 진상조사, 책임자 처벌, 사과가 첫번째구요. 두 번째는 재산이나 건강 피해 실태 조사를 해서 거기에 맞는 적절한 조취를 취할 것. 그리고 밀양 투쟁을 가능하게 했던 에너지 악법들을 다시 계정하라는 것. 그리고 고리 핵 발전단지의 노후원전 고리 2,3,4 호기를 수명을 연장하지 말고 설계수명이 종료가 되면 폐쇄하고 신고리 5.6 호기를 신규 건설하지 않으면 밀양 송전선로 자체가 필요가 없기 때문에 철거해라 라는 
것이었는데 그런데 신고리 5,6 호기가 작년에 그렇게 (공론화 과정) 되면서 철거에 대한 이야기가 좀 어렵게 된 건 사실이에요

Q.4. 공론화 과정을 거쳐서 짓기로 결정이 되었어고 그것이 번복이 될 가능성이 낮은데, 그로 인해 허탈감이 클 것 같고 그로 인해 주민들의 투쟁이 약화 될 거 같은데 그런것에 대한 논의는 이루어 졌나요?

: 하고 있죠. 하고 있기 언제까지 우리가 버틸 수 있을까 고민하고 있죠.

Q.5. 그러면 선생님이 생각하실 때 송전탑 투쟁이 주는 의미가 무엇일까? 그리고 왜 이 투쟁이 중요한가?

: 그렇죠. 에너지 분야는 지금까지 한전같은 사업자가 무소불위의 권한을 행사를 햇잖아요. 법 위에서도 압도적으로 위에 있고 주민들에게 동의를 받지 않아도 철탑을 세울수 있으니깐 지금 현재로서는. 그리고 그것을 무마하기 위해서 동원했던게 돈 아니면 공권력이잖아요. 뭐 이런 방식으로 주민들의 생존권을 수십년간 빼앗아 왔던건데 밀양 주민들이 나서지 않았다면 지금도 그대로일거라고 생각하고 큰 경종을 울렸다고 생각해요. 그렇지만 실질적으로 정부나 사업자인 한전이 제대로 개선을 하거나 밀양투쟁 같은 일이 다시 반복하지 않게 여러가지 법을 고치거나 하는 이런 조치가 사실 없었죠. 유일하게 송전법이나 보상법이 밀양투쟁 과정에서 생기기는 했지만 밀양 주민들이 반대했던 법이죠 왜냐면 돈을 매년씩 조금씩 주면서 무마하려고 했던 법이지 근본적으로 개선하려고 했던건 없엇죠. 물론 국가 에너지 기본계획 같은데서 송전선로 문제 때문에 에너지 시스템을 중앙집권형에서 지역분산형으로 바꿔야 한다는 원칙을 증명하긴 했지만 하부계획에서는 발전소를 여전히 크게 짓고 송전선로를 새로 깔고 이런 흐름이 둔화된 것은 사실이지만 그렇다고 변했다고 보는건 어려운 상황이죠. 그런 상황에서 밀양 투쟁이 계속 버티고 있다는 것은 어쨌든 저들에게 성가시고 힘든 존재로서 계속 또 버텨야 하는 당위성도 또 있는 것이고요.

Q.6. 투쟁 자체가 우리 삶에 던져 줄 수 있는 메세지?

: 전기에 대해서 다들 무시 했잖아요. 그냥 편하게 쓰면 된다고 생각했으니깐. 그런데 이 중요한 공공재이고 우리의 물질적 삶에 있어서 가장 근간이 되는게 에너지 이잖아요. 그런데 에너지인 전기가 어떻게 만들어 져서 어떻게 우리 삶에 어떻게 도달하게 된다는 것에 대해서 무지했던 것을 이 과정에 담겨져 있는 폭력적이 제도와 관행에 대해서 밀양 투쟁이 크개 밝혀 드러냈다는 생각을 해요. 에너지 민주화에 있어서 밀양 투쟁이 큰 시발점이라 생각을 해요. 
Q.7. 누구는 밀양 투쟁은 실패다 라고 말하는 사람이 있다. 선생님도 실패라고 생각하시는지 아니면 그렇지 않은지? (이: 왜 그렇게 생각하죠? 나: 이미 지어져 버려서 실패라던 사람들이 있더라)

: 이건 애초에 이기기 어려운 싸움이었죠. 13 년간 주민들이 할 수 있는 모든 것을 다 해왔고 지금도 하고 있는데 워 물리적인 힘의 차이로 해결하자면 비교할 수 없죠. 그 거대한 세계 최대 전력회사 하고 압도적인 법의 우위가 있고 그리고 박근혜 정부에서는 엄청난 공권력을 동원했고 이길수 없는 싸움이었죠 만약에 그걸 기준으로 한다면. 그렇지만 그래서 주민들의 투쟁이 더 소중하다고 생각하죠 어려운 줄 알면서도 지금도 버티고 있으니까요. 그리고 전국에 에너지에 관심있는 국민들이 밀양 주민에게 빚을 지고 있다고 생각해요. (나: 그러면 그런 의미에서 실패가 아닌 성공이라고 말 할 수 있을까요?) 그렇지만 성공했다고 하긴 어렵죠 너무 많은 희생이 있었으니깐 그 과정에서.

Q.8. 작년에 신고리 5,6 호기와 관련하여, 문재인 에너지 들어서서 재생 에너지라던지 지속가능발전 (물론 예전부터 논의되던 것이지만) 밀양 주민들이 어떻게 국가 에너지 정책에 영향을 주고 받을 수 있을까요?

: 밀양 주민들은 생존권을 지키기 위한 투쟁이었고 그것의 의미를 받아들여서 제도를 고치고 시스템을 바꾸는 것을 정부와 한전의 몫이죠 그런 의미에서 굉장이 불만스럽죠. 큰 틀에서 지속가능한 시스템 재생에너지로 가기 위해서는 모든 문제가 그러하지만 과거에 대한 청산 작업이 중요한 거잖아요. 그런데 굉장히 우리가 안타까운거는 그런게걸가능하게 했던 세력이 존재하는데 이들에 대해서 그 어떤 책임추궁이나 문제제기를 한 적이 없어요. 없고 그냥 그대로 그들을 온전한체 다른 시스템을 만들겠다는 건데 그리고 실제로 그것이 잘 안 이루어 지기도 하고요. 마치 일제 감정기를 거치고 나서 친일 청산을 제대로 못하고 토지개혁이나 여러가지 시스템을 고치지 못한채 남한은 현대사가 계속 이어졌잖아요 그 많은 파행을 겪은거나 비슷한 거 같아요. 그래서 저는 밀양같은 데를 제대로 정리하지 않고 가고 있는것에 대해서 굉장히 회의적이죠. 지속가능이나 혹은 에너지 전환에 대한 의지를 신뢰할 수 없는 그런거죠.

Q.9. 이 문제와 관련하여 사회에 던지고 싶은 말은 무엇인가요?

: 저는 문재인 대통령도 밀양 현장에 와 봤고 주민들의 이야기를 들어서 다 알고 있고 또 이런 공공갈등이 어떻게 생기는 지를 아마 모르지는 않을거라 생각해요. 하지만 중요한 것은 환부를 들어내고 수술을 하는 작업이 반드시 필요한건데 수술없이 그런 곪은 상처를 치요할 수 있다고 생각하는 것은 저는 틀렸다고 생각하고요. 또 한국은 이슈 자체가 다이나믹하고 많아서 어디서 부터 손을 대야 할 지 어려운게 참 많잖아요 
그렇지만 이것을 그냥 적당한 선에서 타협하고 봉합하고서는 그냥 예전의 주체들이 그대로 다시 이 새로운 시스템을 만들어 가는것 자체가 사실은 불가능한 잘못된 방향이 아닐까 하고 생각해요. 그리고 언론이든 시민사회든 다 마찬가지로 지금의 기존세력, 관료집단 그리고 자본, 을 감당하기에는 되게 벅차다는 생각이 드네요. 그래서 사실 밀양같은 곳을 다시 일어나지 않아야 하는데 다시 일어날 수 밖에 없는 구조고 이런 문제도 계속 해결하지 못하고 시간을 끌 수 밖에 없는 거 같고. 한편으로는 시간이 가기를 바라는 사람들이 그냥 우리가 자연소멸하기를 기다리고 있는건 아닌가 하는 생각이 들고 그러네요 마치 위안부 할머니들이 돌아가시기를 일본정부가 기다리는거 처럼.

Q.10. 선생님은 비슷한 일들이 많이 일어나실거라 보나요?

: 조심은 하껬지만 근본적인 구조가 바꿔지지 않아서 많이 바뀔 거 같지 않다고 생각해요. 
A Short Conversation Conducted on May 23, 2018, with the representative of the committee, Lee, Gye-Sam (Translated in English)

Q1. What is the motivation/reason behind the struggle?

A: The struggle began in 2005 and some local civic groups participated in the struggle until 2007 since the Miryang city government took a charge to mediate the conflict. However, after the tragic incident of Mr. Chi-Woo Lee in January 2012, the villagers asked for the help of the civic groups. Therefore, the committee has organized in February 2012 and since then we are working together.

(Q. Who are 'we'?) A: The civic groups existed before the conflict started.

Q2. What are the reasons for continuing the resistance after the transmission tower project has been completed?

A: The perpetrators, including the Government, KEPCO, and the police authority, never sincerely apologized but neither accepted the state violence that threatened the villager's property, health, and village community. Thus, the villagers have been endured by proposing the government officially investigate the state violence. In fact, the current government (President Moon's government) seems taking a different path, but nothing has changed yet.

Q3. If those are the reasons of resistance, what could be the possible solution to transform the conflict in Miryang?

A: In fact, we have demanded four claims since 2014. The first is to punish the person in charge and sincere apology after conducting the investigation about the Miryang transmission project and related state violence. The second is to provide a proper action according to the research on what actually had damaged. Then, we proposed to revise the unjust energy policy and related laws. Lastly, closing down old nuclear reactors (Gori \# 2,3,4,) instead of renewing its design lives, but also nullifying Shin-Gori no 5 and 6 reactors. Then, the transmission towers and lines are not necessarily to be built. However, after the public decision on Shin-Gori 5 and 6 last year, it is indeed difficult to bring the topic of removing the transmission towers.

Q4. Sadly, it seems that there is a bare possibility of changing the decision already made. What is the plan for now? How does the event affect the movement?

A: Yes, we are talking about how we should carry the movement, but also we are not sure how much longer we could endure.

Q5. How significant is the Miryang movement? And why is this movement important?

A: So far in the energy field KEPCO was able to control enormous power. In fact, all the violence committed by KEPCO has been legally protected, and the only way to 'solve' the conflict was either monetary compensation or overusing government authority. This (constant violence) is the only way how KEPCO has dealt with the situation for several decades. Thus, Miryang villagers greatly challenged KEPCO, and it is significant. Therefore, through the national energy principles, the necessity of changing the energy system has been recognized, but there are no substantial changes (e.g., revising law) yet in order to prevent KEPCO to repeat the same mistakes. It seems that there is a lack of will for the real changes as the only changes were revising transmission tower law and compensation law, which could not get supported by the Miryang villagers. Revising these two laws were obviously not the substantial changes that 
the villagers yearned for. However, our existence is annoying for them as they 'pretend' to change things but also acknowledge the problems caused by them, and this is the reason why we need to resist.

Q6. What are the messages that we could learn from the movement?

A: No one put any importance on using electricity. It was always there to be used for our convenience. In fact, the thing is that energy is the most important public goods to maintain the basis of our material lives. However, no one really paid attention to the process of producing the energy, which indeed requires constant violence and sacrifice of someone's lives. In this sense, the Miryang movement revealed the cruel reality that is sustained by the violent system. In fact, the Miryang movement played a significant role in energy democracy.

Q7. Since the Miryang Transmission Tower project has completed, some evaluated the Miryang movement as a failure. What do you think about it? Do you think this is also a failure? A: From the beginning, it was a battle that we could not win. The villagers had done everything that they could have done for 13 years, and they are still struggling. In fact, it is impossible to compare the physical force since KEPCO, one of the biggest electric power companies in the world is legally protected by government authority and laws. We obviously started a losing battle. However, this is why the movement is important and significant. We knew that this will be a difficult fight from the beginning, but we are still enduring. More importantly, many citizens who care about the energy issue think that they owed Miryang villagers.

(Q. So do you think the movement is successful then?)

A: But at the same time it is difficult to say that the movement is successful because it required too much sacrifice to continue the process.

Q8. There has been a long debate about renewable energy and sustainable development, but from the regime of President Moon, the discussion has been more intense. Do you think the movement in Miryang has influenced the nation's energy policy?

A: For the villagers in Miryang, it was a fight to protect their right to live healthy, but to change the system is the job of the government and KEPCO. In this sense, we are not satisfied at all. In order to transform our energy system, it is necessary to acknowledge the old system, which obviously failed to reach sustainable development. What I am saying is that this positive transformation is not possible without learning from the past's fault. But, sadly, so far no one questions who or which power caused the problem, thus the existed power group continues without being responsible for what they have done. It is clear that the change is slow or impossible as long as the power groups stay in the same position. How the government is dealing with the case of Miryang seems parallel to our modern history that could not stop but continued from the unjust history. In this sense, without fully reflecting and learning from the case of Miryang, I doubt the sincerity of the government that promises to transform the energy policy in a more sustainable way.

Q9. What are the messages that you want to share with society?

A: I bet that Mr. President Moon is aware of the details of the public conflicts, including the case of Miryang. So, in order to solve the problems, a big surgery is of necessity. I understand that the issues in South Korea are too dynamic so it seems confusing where to start. But, being difficult cannot justify anyone who was in charge of the unjust energy system to continue to 
work on the new system. I believe with such groups of people it is impossible to make any changes. It is indeed wrong. And, the media and civil societies seem overwhelmed by the existed power. The thing is that the Miryang case should not repeat anywhere but as long as we maintain the current system there will be continuous cases like Miryang. On the other hand, I think that maybe some people just want time passes by until the villagers in Miryang give up and disappear from the social discussion as if the Japanese government is waiting for the death of our grandmothers ("comfort women") who suffered under the sexual violation during the Japanese colonialization.

Q10. So do you believe that similar cases will be repeated in the future?

A: I think they will be more cautious, but no dramatic changes will happen without substantial changes. 